\title{
ANÁLISE DA VIABILIDADE ECONÔMICA DO PROJETO ESTRUTURAL DE EDIFÍCIOS DE MÚLTIPLOS ANDARES COM ESTRUTURA DE AÇO
}

Dissertação apresentada à Escola de Engenharia de São Carlos da Universidade de São Paulo para obtenção do título de mestre em Engenharia de Estruturas

Área de concentração: Engenharia de Estruturas

Orientador: Prof. Dr. José Jairo de Sáles

\section{Versão corrigida}

A versão original encontra-se na Escola de Engenharia de São Carlos

São Carlos 
AUTORIZO A REPRODUÇÃO E DIVULGAÇÃO TOTAL OU PARCIAL DESTE TRABALHO, POR QUALQUER MEIO CONVENCIONAL OU ELETRÔNICO, PARA FINS DE ESTUDO E PESQUISA, DESDE QUE CITADA A FONTE.

Ficha catalográfica preparada pela Seção de Atendimento ao Usuário do Serviço de Biblioteca - EESC/USP

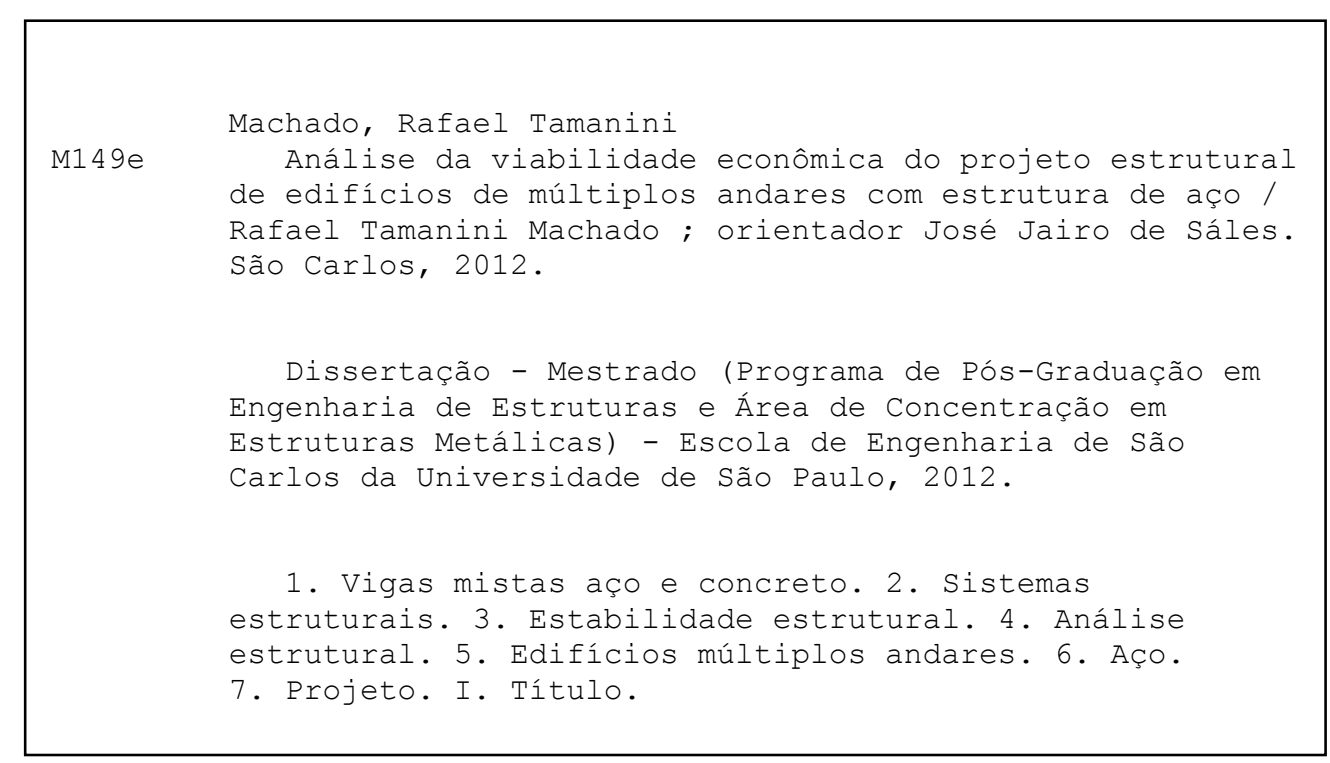




\section{FOLHA DE JULGAMENTO}

\section{Candidata: Engenheiro RAFAEL TAMANINI MACHADO.}

Título da dissertação: "Estudo do projeto de edifícios de múltiplos andares com estrutura de aço".

Data da defesa: 20/08/2012

\section{Comissão Julgadora:}

\section{Resultado:}

Prof. Dr. José Jairo de Sáles (Orientador)

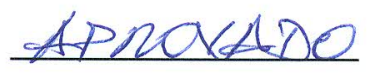

(Escola de Engenharia de São Carlos/EESC)

Prof. Dr. Jorge Munaiar Neto

(Escola de Engenharia de São Carlos/EESC)

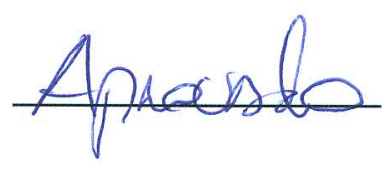

Prof. Dr. Renato Bertolino Junior

Adnovido

(Universidade Estadual Paulista “Júlio de Mesquita Filho"/UNESP - Ilha Solteira)

Coordenador do Programa de Pós-Graduação em Engenharia Civil (Engenharia de Estruturas):

Profa. Associada Ana Lucia Homce de Cresce El Debs

Presidente da Comissão de Pós-Graduação:

Prof. Titular Denis Vinicius Coury 



\section{AGRADECIMENTOS}

A Deus, pela serenidade e riquezas naturais, em especial, as da região serrana do Espírito Santo, lugar onde concluí esse trabalho.

Ao prof. Dr. José Jairo de Sáles, pela simpatia, liberdade na pesquisa, excelência de sua tese, origem dessa dissertação, e flexibilidade nos prazos.

À minha família, pelo apoio, amor e compreensão e, em especial, a minha mãe, por sempre acreditar que era possível.

Ao Rafael Eclache, pela paciência e apoio nos momentos mais complicados. Muito obrigado e sucesso em seu caminho.

Aos AMIGOS pelas palavras de incentivo, conselhos e apoio irrestrito.

Aos profs. do curso de Engenharia Civil da UFV, pela base profissional indispensável para a realização desse trabalho e, em especial, aos profs. Drs. Gustavo de Souza Veríssimo e José Luiz Rangel Paes por me conduzirem ao mestrado.

À equipe técnica e administrativa do SET, sempre atenciosos e prestativos.

Enfim, deixo minha gratidão a todos que participaram e contribuíram, direta ou indiretamente, ao longo dessa caminhada. 



\title{
RESUMO
}

\begin{abstract}
MACHADO, R.T. Análise da viabilidade econômica do projeto estrutural de edifícios de múltiplos andares com estrutura de aço. 2012. Dissertação (Mestrado) - Escola de Engenharia de São Carlos, Universidade de São Paulo, São Carlos, 2012.
\end{abstract}

O presente estudo traz uma revisão bibliográfica dos sistemas estruturais, da estabilidade e análise estrutural de edifícios de múltiplos andares com estrutura de aço e, ainda, do emprego de elementos mistos aço e concreto nesses sistemas, com ênfase às vigas mistas. É aplicável a duas áreas, a saber: acadêmica e prática. Na área acadêmica, contribui com informações que permitem iniciar linhas de pesquisas para diversos assuntos. Na área prática, através de exemplos, contribui com a análise da viabilidade do processo construtivo e estrutural. $E$ por meio de instruções mínimas, contribui para o desenvolvimento de projetos de estruturas metálicas. A referida pesquisa é embasada na ABNT NBR 8800:2008 e, quando indispensável, nas normas ANSI/AISC 360-10 e EN 1994-1-1:2004.

Palavras-chave: vigas mistas aço e concreto, sistemas estruturais, estabilidade, análise estrutural, edifícios múltiplos andares, aço, projeto 



\begin{abstract}
MACHADO, R.T. Analysis of the economic viability of the structural design of multi-story buildings with steel structures. 2012. Dissertação (Mestrado) - Escola de Engenharia de São Carlos, Universidade de São Paulo, São Carlos, 2012.
\end{abstract}

The concerned study brings a literature review of structural systems, stability and structural analysis of multistory buildings with steel structures and also the use of steel-concrete composite elements in those systems, with emphasis on composite beams. It applies to two subjects, namely: academic and practical. In academics, it contributes with informations that allows you to start several lines of research. In the practice, through examples, it contributes with the assessment of the viability of the construction and structural process. And using minimal instructions, it contributes to the development of steel structure projects. The related research is based on the ABNT NBR 8800:2008 and, when necessary, on ANSI/AISC 360-10 and EN 1994-11:2004.

Keywords: steel-concrete composite beams, structural systems, stability, structural analysis, multistory buildings, steel, project 



\section{LISTA DE SÍMBOLOS}

\section{Letras romanas minúsculas}

a espessura de concreto comprimido na laje ou, no caso de interação parcial, espessura considerada efetiva;

b largura unitária da laje; largura efetiva da laje de concreto;

$b_{f} \quad$ largura da mesa do perfil de aço;

d altura do perfil de aço; distância;

f fator de redução;

$\mathrm{f}_{\mathrm{ck}} \quad$ resistência característica do concreto à compressão;

$\mathrm{f}_{\mathrm{cd}}$ resistência de cálculo do concreto à compressão;

$\mathrm{f}_{\mathrm{ct.ef}}$ resistência média à tração efetiva do concreto no momento em que se formam as primeiras fissuras;

$\mathrm{f}_{\mathrm{ctm}}$ resistência médio de ruptura do concreto à tração simples (EN 1992-1$1: 2004)$;

$\mathrm{f}_{\mathrm{sd}} \quad$ resistência de cálculo ao escoamento do aço da armadura;

$\mathrm{f}_{\mathrm{u}} \quad$ resistência característica à ruptura por tração;

$\mathrm{f}_{\mathrm{ucs}}$ resistência característica à ruptura por tração do conector de cisalhamento;

$\mathrm{f}_{\mathrm{y}}$ resistência característica ao escoamento do perfil de aço;

$\mathrm{f}_{\mathrm{ycs}}$ resistência característica ao escoamento do conector de cisalhamento;

$\mathrm{f}_{\mathrm{yd}}$ resistência de cálculo ao escoamento do perfil de aço;

$\mathrm{f}_{\mathrm{yF}}$ resistência característica ao escoamento da fôrma de aço incorporada;

$\mathrm{f}_{\mathrm{yFd}}$ resistência de cálculo ao escoamento da fôrma de aço incorporada;

$\mathrm{f}_{\mathrm{ys}}$ resistência característica ao escoamento do aço da armadura; 
h distância entre as faces internas das mesas nos perfis soldados e esse valor menos dois raios de concordância nos perfis laminados; distância entre dois pavimentos consecutivos;

$\mathrm{h}_{\mathrm{F}} \quad$ espessura da pré-laje pré-moldada de concreto ou a altura das nervuras da fôrma de aço incorporada;

$h_{p} \quad$ dobro da altura da parte comprimida da alma;

$\mathrm{h}_{0} \quad$ distância do topo à base do edifício (EN 1993-1-1:2005);

k coeficiente; parâmetro;

q pressão dinâmica devido ao vento;

t espessura;

$t_{c} \quad$ altura da laje de;

$t_{f} \quad$ espessura da mesa superior do perfil de aço;

$t_{w} \quad$ espessura da alma do perfil de aço;

u deslocamento relativo entre dois pavimentos consecutivos;

$\mathrm{w}_{\mathrm{k}}$ abertura máxima característica das fissuras;

y coordenada; distância;

z nível do pavimento.

\section{Letras romanas maiúsculas}

A área;

$\mathrm{A}_{\mathrm{a}} \quad$ área do perfil de aço;

$\mathrm{A}_{\text {e.c }} \quad$ área equivalente de concreto;

$\mathrm{A}_{\mathrm{sl}} \quad$ área das barras da armadura longitudinal;

A sl.di armadura mínima de tração sob deformações impostas;

$\mathrm{C}_{\mathrm{ad}}$ força resistente de cálculo da região comprimida do perfil de aço; 
$\mathrm{C}_{\mathrm{b}}$ fator de correção da distribuição não uniforme dos momentos fletores;

$\mathrm{C}_{\mathrm{cd}}$ força resistente de cálculo da espessura de concreto comprimido;

CV força resultante da sobreposição das forças horizontais atuantes em uma das faces do edifício, a saber: força de arrasto e força componente do binário;

D valor característica das ações permanentes (ASCE/SEI 7-10)

E módulo de elasticidade longitudinal do aço;

$E_{a} \quad$ módulo de elasticidade longitudinal do aço (EN 1994-1-1:2004);

$\mathrm{E}_{\mathrm{a}} \mathrm{l}_{1}$ rigidez da seção transversal da viga mista assumindo que o concreto tracionado não fissura (EN 1994-1-1:2004);

$\mathrm{E}_{\mathrm{a}} \mathrm{I}_{2}$ rigidez da seção transversal da viga mista desconsiderando o concreto tracionado, porém incluindo a armadura (EN 1994-1-1:2004);

F força, valor de ação;

$F_{\text {e.a }}$ força de arrasto atuante sobre cada eixo;

$F_{\text {e.b }} \quad$ força de arrasto atuante sobre cada fila;

$\mathrm{F}_{\mathrm{hd}} \quad$ força de cisalhamento de cálculo entre o componente de aço e a laje;

$F_{\text {t.a }} \quad$ força componente do binário atuante sobre os eixos;

$F_{\text {t.b }} \quad$ força componente do binário atuante sobre as filas;

G ação permanente devido exclusivamente ao peso próprio;

H distância do topo da estrutura à base; força horizontal;

$\mathrm{H}_{\mathrm{i}} \quad$ desnível entre dois pavimentos consecutivos (ABNT NBR 6118:2003);

I momento de inércia;

L Valor característica das ações variáveis (ASCE/SEI 7-10); distância; vão;

$\mathrm{L}_{e} \quad$ trecho de flexão positiva na viga mista;

$L_{F} \quad$ vão teórico da fôrma na direção das nervuras; 
M momento fletor;

$\mathrm{M}_{\mathrm{f} . \mathrm{Rd}}$ momento fletor resistente plástico de uma seção constituída apenas pelas mesas da viga mista (EN 1994-1-1:2004)

$\mathrm{M}_{\mathrm{n}}^{-}$momento fletor solicitante negativo nominal sobre a laje;

N força normal; força gravitacional;

P ação; valor característico do pré-esforço (EN 1990:2002);

Q ação variável decorrente o uso ou ocupação;

$\mathrm{Q}_{\mathrm{Rd}} \quad$ força resistente de cálculo de um conector de cisalhamento;

$\mathrm{R} \quad$ rigidez lateral;

S espaçamento; fator;

$R_{m} \quad$ coeficiente de ajuste;

$\mathrm{T}_{\mathrm{ad}}$ força resistente de cálculo da região tracionada do perfil de aço;

$T_{d s}$ força resistente de cálculo de tração correspondente à área das barras da armadura;

V força cortante;

$\mathrm{V}_{\mathrm{k}} \quad$ velocidade característica do vento;

W ação variável devido ao vento; módulo resistente elástico;

$\mathrm{W}_{\mathrm{a}}$ valor característico da ação do vento (ASCE/SEI 7-10);

Z módulo resistente plástico;

\section{Letras gregas minúsculas}

$\alpha \quad$ parâmetro;

$\beta_{\mathrm{vm}} \quad$ coeficiente que garante a plastificação parcial das seções mistas com ligações semirrígidas;

$\delta \quad$ flecha; deslocamento; 
$\gamma \quad$ coeficiente de ponderação das ações ou das resistências;

$\lambda \quad$ índice de esbeltez; parâmetro de esbeltez;

$\lambda_{\mathrm{p}} \quad$ parâmetro de esbeltez limite relativo a seções compactas;

$\lambda_{\mathrm{r}} \quad$ parâmetro de esbeltez limite relativo a seções semicompactas;

$\sigma \quad$ tensão normal;

$\sigma_{\mathrm{cd}}$ tensão de cálculo de compressão;

$\sigma_{\text {ct.car }}$ tensão de tração no concreto calculado com a combinação característica;

$\sigma_{\mathrm{si}}$ tensão de tração no centro geométrico da armadura;

$\sigma_{\text {st }}$ máxima tensão de tração permitida na armadura imediatamente após a fissuração;

$\sigma_{\mathrm{td}} \quad$ tensão de cálculo de tração;

$\eta_{\mathrm{i}} \quad$ grau de interação na interface aço e concreto da viga;

$\chi_{\text {dist }}$ fator de redução para flambagem lateral distorcional da seção transversal;

$\psi$ fator de combinação ou de redução das ações variáveis;

\section{Letras gregas maiúsculas}

$\Sigma \quad$ somatório;

$\Delta \quad$ deslocamento relativo entre dois pavimentos;

$\Phi$ diâmetro da barra da armadura;

\section{Letras romanas minúsculas subscritas}
a seção de aço;
c concreto; compressão;
d de cálculo;
dist distorcional;
e elástico; equivalente;
ef propriedade efetiva; 
f mesa;

g ação permanente;

i face inferior da seção mista; número de ordem;

k característico; nominal;

n região de momento fletor negativo;

p região de momento fletor positivo;

pl plastificação;

s armadura; face superior da seção mista;

tr propriedades teóricas;

$\mathrm{x}$ relativo ao eixo $\mathrm{x}$;

y escoamento; relativo ao eixo y;

t $\quad$ torção; tração;

w alma;

\section{Letras romanas maiúsculas subscritas}

F fôrma de aço;

G ação permanente;

Q ação variável;

$\mathrm{Rd}$ resistente de cálculo;

Sd solicitante de cálculo;

\section{Letras gregas minúsculas subscritas}

$\alpha \quad$ relativo à seção homogeneizada por $\mathrm{E} / \mathrm{E}_{\mathrm{c}}$;

$2 \alpha$ relativo à seção homogeneizada por $2 \mathrm{E} / \mathrm{E}_{\mathrm{c}}$;

$3 \alpha$ relativo à seção homogeneizada por $3 \mathrm{E} / \mathrm{E}_{\mathrm{c}}$; 


\section{SUMÁRIO}

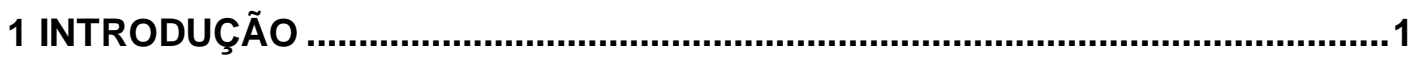

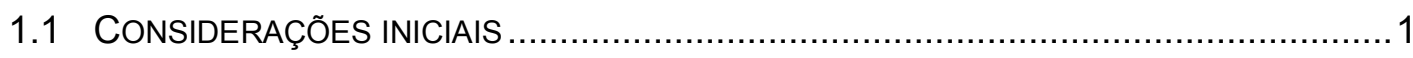

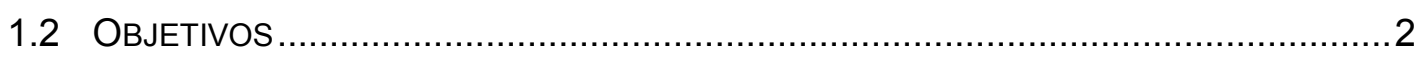

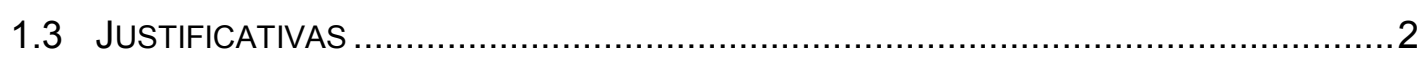

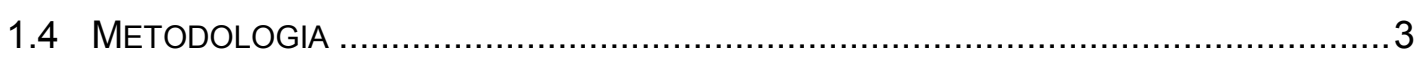

1.4.1 Edifício Modelo ............................................................................

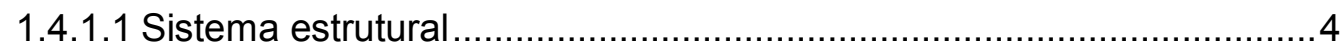

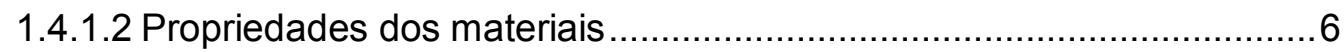

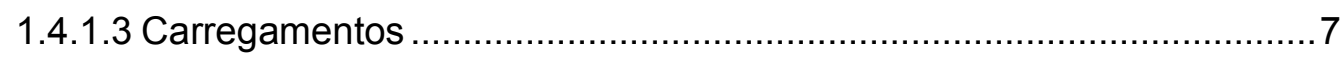

1.4.2 Distribuição da pesquisa ........................................................... 10

2 ASPECTOS GERAIS .................................................................................13

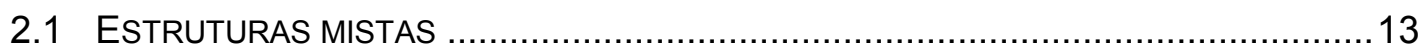

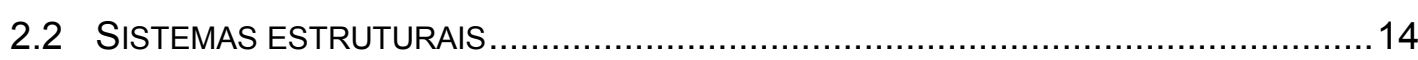

2.2.1 Subsistemas estruturais verticais................................................ 15

2.2.1.1 Estrutura com quadros rígidos .................................................... 18

2.2.1.2 Estrutura com quadros treliçados.................................................... 19

2.2.1.3 Estrutura com paredes de cisalhamento.........................................21

2.2.1.4 Estrutura com núcleos rígidos .........................................................23

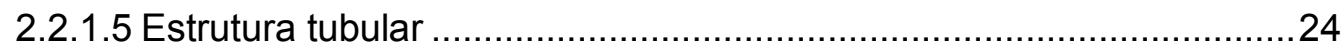

2.2.2 Subsistemas estruturais horizontais ...................................................22

2.2.2.1 Lajes mistas com fôrma de aço incorporada ao concreto ..................27

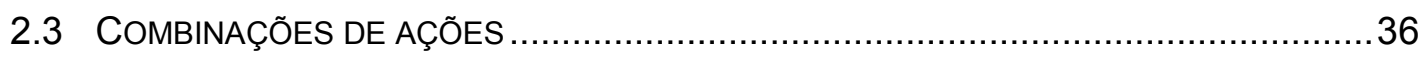

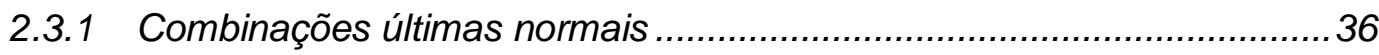

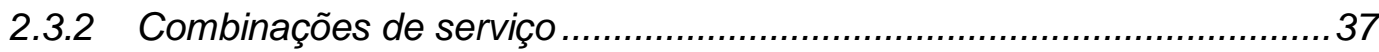

2.3.2.1 Combinação quase permanente de serviço .......................................37

2.3.2.2 Combinação frequente de serviço.................................................... 38

2.3.2.3 Combinação rara de serviço ......................................................... 38

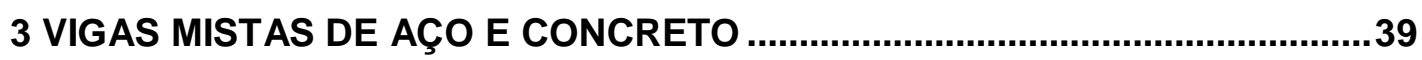

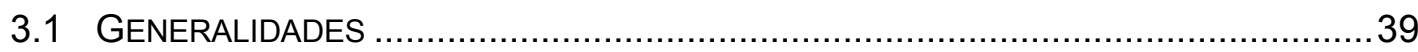

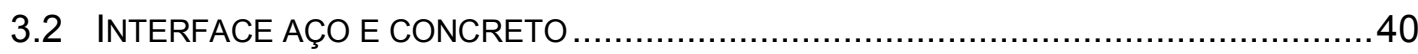

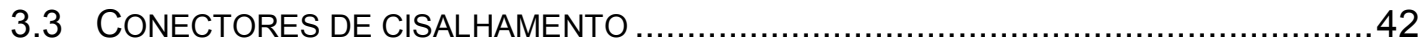

3.4 SISTEMAS BIAPOAIDOS, CONTÍNUOS E SEMICONTÍNUOS ..................................45 


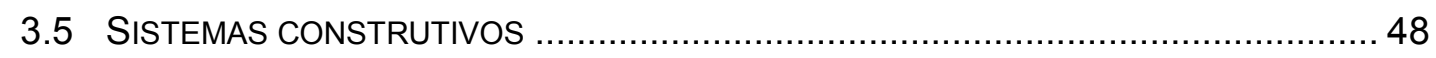

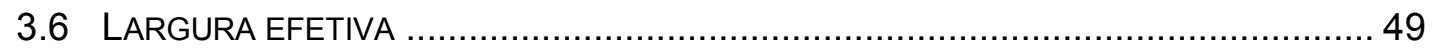

3.7 EFEITOS DE LONGA DURAÇÃO DO CONCRETO ............................................. 50

3.8 ANÁLISE ESTRUTURAL E DIMENSIONAMENTO .............................................. 51

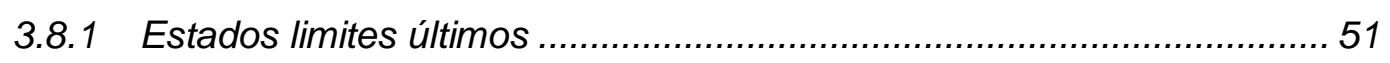

3.8.1.1 Análise estrutural dos esforços ................................................ 51

3.8.1.2 Resistência à flexão na região de momentos fletores positivos ......... 55

3.8.1.3 Resistência à flexão na região de momentos fletores negativos........ 64

3.8.1.4 Resistência ao cisalhamento vertical ............................................... 69

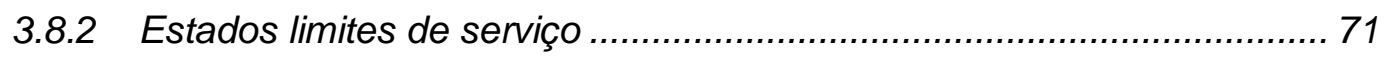

3.8.2.1 Controle dos deslocamentos excessivos ...................................... 72

3.8.2.2 Controle da fissuração no concreto ................................................ 76

3.8.3 Exemplo: pré-dimensionamento das vigas do edifício modelo 1........... 79

3.8.3.1 Avaliação do grau de interação, sistema estrutural e construtivo ...... 80

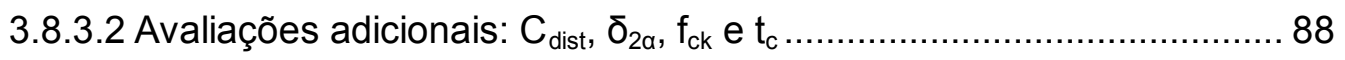

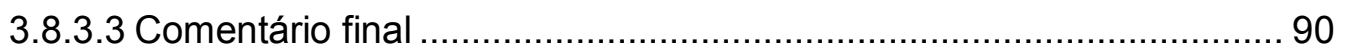

4 ESTABILIDADE E ANÁLISE ESTRUTURAL ................................................. 93

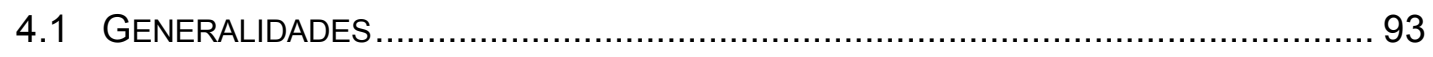

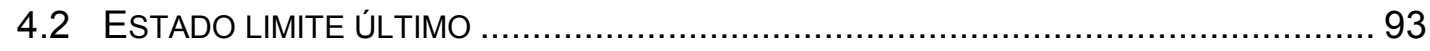

4.2.1 Classificação da estrutura quanto aos sistemas resistentes de ações

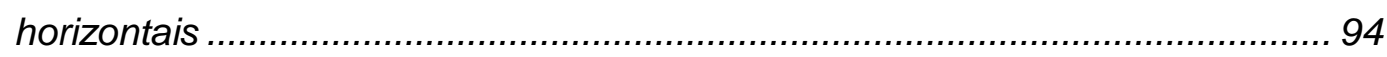

4.2.2 Classificação da estrutura quanto à sensibilidade a deslocamentos

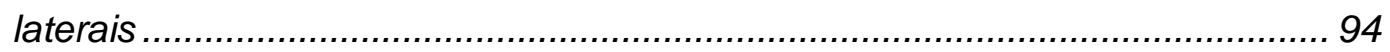

4.2.3 Efeitos que contribuem para a perda de estabilidade dos pórticos ........ 95

4.2.4 Solicitações de compressão e flexão combinadas ................................ 98

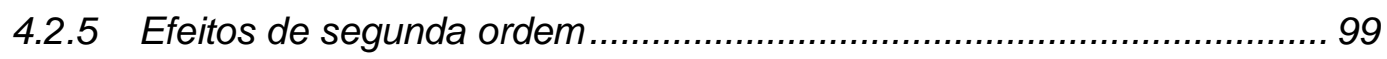

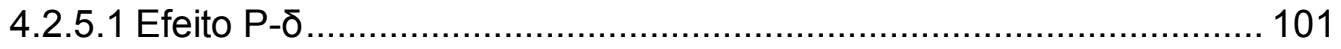

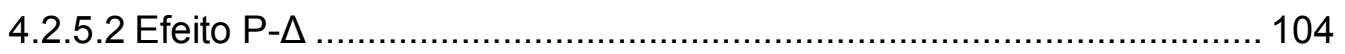

4.2.6 Método da análise direta................................................................ 106

4.2.7 Determinação dos esforços solicitantes.......................................... 107

4.2.7.1 Pequena deslocabilidade ........................................................... 107

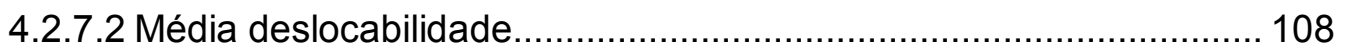

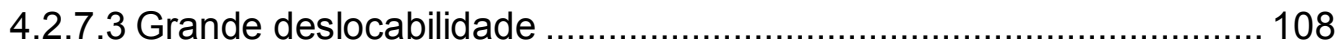

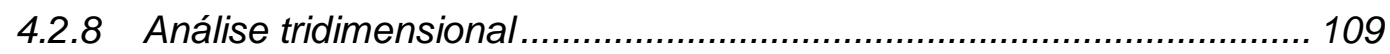

4.2.9 Exemplo: Verificação dos estados limites últimos de um edifício escritório com estrutura metálica e 20 pavimentos ...................................................... 111 


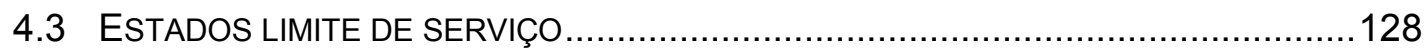

4.3.1 Deslocamentos laterais .............................................................. 129

4.3.2 Avaliação normativa dos deslocamentos laterais .............................131

4.3.3 Exemplo: verificação dos estados limites de serviço de um edifício escritório com estrutura metálica e 20 pavimentos ......................................... 133

4.3.3.1 Deslocamentos laterais ............................................................. 133

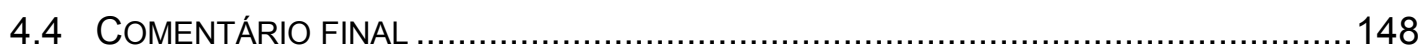

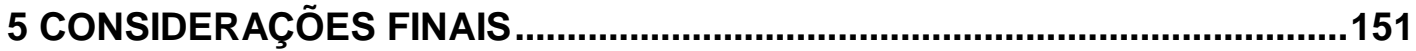

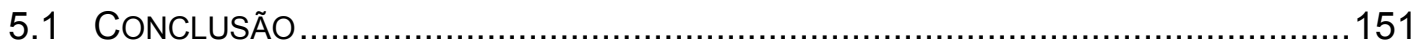

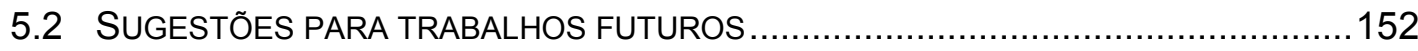

REFERÊNCIAS BIBLIOGRÁFICAS ..........................................................153

APÊNDICE A: CÁLCULO DAS AÇÕES HORIZONTAIS DEVIDO AO VENTO SEGUNDO AS PRESCRIÇÕES DA ABNT NBR 6123:1988 ................................159

APÊNDICE B: CÁLCULO DE UMA VIGA MISTA CONTÍNUA NÃO ESCORADA SEGUNDO AS PRESCRIÇÕES DA ABNT NBR 8800:2008 ...............................167

APÊNDICE C: CÁLCULO DE UM PILAR ISOLADO SOB SOLICITAÇÕES COMBINADAS SEGUNDO AS PRESCRIÇÕES DA ABNT NBR 8800:2008.........227 



\section{CAPÍTULO 1: INTRODUÇÃO}

\subsection{CONSIDERAÇÕES INICIAIS}

A primeira norma brasileira que abordava o projeto e a execução de estruturas mistas de edifícios compostos por perfis laminados e soldados à temperatura ambiente foi a NB-14 (1958). Essa norma fundamentava-se principalmente na norma alemã DIN 4114 (1952) que empregava o método de cálculo das tensões admissíveis. Com o passar do tempo, esse método apresentouse ultrapassado, levando, em certos casos, a estruturas inadequadas.

Na edição da ABNT NBR 8800:1986 houve um grande avanço no quesito da segurança estrutural, onde o método das tensões admissíveis foi substituído pelo método dos estados limites, trocando um método de cálculo com base determinística por um método com base probabilística. A ABNT NBR 8800:1986 inovava ainda com as prescrições para o projeto de vigas mistas de aço e concreto, que começava a ser cada vez mais aplicadas no Brasil.

Fakury (2007) ressalva que exceto o emprego das curvas múltiplas de flambagem proposto na Europa pelo ECCS (1976), e dos anexos relacionados a valores de deformações, vibrações em piso, efeito p-delta, flambagem de barras axialmente comprimidas por flexo-torção e a aberturas em almas de vigas, que seguiram a norma canadense CAN/CSA S16.1:1984, a ABNT NBR 8800:1986 fundamentou-se nas recomendações de uma versão preliminar da especificação americana AISC-LRFD-1986.

A necessidade de uma norma de projeto de estruturas de aço de edifícios em situação de incêndio no Brasil resultou na edição da ABNT NBR 14323:1999. Essa norma também inclui elementos estruturais mistos de aço e concreto, a saber, vigas mistas, pilares mistos e lajes mistas. No caso dos dois últimos, também foi apresentada as prescrições para o projeto à temperatura ambiente.

As principais mudanças apresentadas na ABNT NBR 8800:2008 em relação à ABNT NBR 8800:1986 se estendem ao conteúdo, análise e estabilidade estrutural e 
dimensionamento das barras isoladas, dos elementos estruturais mistos e de suas respectivas ligações.

\subsection{OBJETIVOS}

Esse trabalho pretende abranger o desempenho de vigas mistas de aço e concreto em sistemas estruturais de edifícios de andares múltiplos com estrutura de aço e, ainda, introduzir a abordagem dos sistemas de estabilização lateral e análise estrutural aplicáveis a essas edificações, apresentando uma análise crítica nos aspectos acadêmicos e práticos. Destina-se a estudantes e engenheiros calculistas de estruturas metálicas.

\subsection{JUSTIFICATIVAS}

Há uma grande expectativa de que a copa de 2014 possa mudar a cultura na construção civil e impulsionar a aplicação de sistemas industrializados em aço no país. Com base na China, De Azevedo (2010) afirma que o consumo per capita de produtos siderúrgicos reflete o nível de investimento e infraestrutura de um país. Em 1980 , esse consumo entre os chineses era de $34 \mathrm{~kg} / \mathrm{hab}$, volume quase dez vezes menor do que o atual.

Alva (2000) destaca a necessidade de pesquisas e trabalhos condizentes com a realidade brasileira que contribuam para a viabilidade técnica e econômica do sistema estrutural em aço, já consagrado em países desenvolvidos, mas que ainda não se desenvolveu amplamente na construção civil nacional. O Brasil, desde década de 80 , registra o consumo de produtos siderúrgicos na faixa de $100 \mathrm{~kg} / \mathrm{hab}$.

Souza (2009) apresenta o procedimento de análise de segunda ordem conforme as recomendações da ABNT NBR 8800:2008, destaca sua importância na verificação da estabilidade da estrutura e ainda compara com as recomendações trazidas pela norma americana e europeia de cálculo de estruturas metálicas. 0 autor também destaca a escassez de trabalhos voltados para a utilização em projetos e incorporação em códigos normativos. 
Portanto, esse trabalho vem contribuir à análise da viabilidade econômica e estrutural de edifícios de múltiplos andares com estrutura de aço em virtude da carência de trabalhos voltados a aplicação em projetos.

\subsection{METODOLOGIA}

Nesse item será apresentado o edifício modelo de estudo, o conteúdo e a forma de abordagem de cada capítulo desse trabalho.

\subsubsection{EDIFÍCIO MODELO}

Os capítulos discutidos ao longo desse trabalho terão como base 0 desenvolvimento do sistema de estabilização e do dimensionamento do Edifício Modelo 1, ilustrado abaixo, fundamentado no exemplo estudado por Sáles (1995). Trata-se de um edifício escritório de 20 pavimentos com 3,5 m de pé direito e $900 \mathrm{~m}^{2}$ de área construída por pavimento.

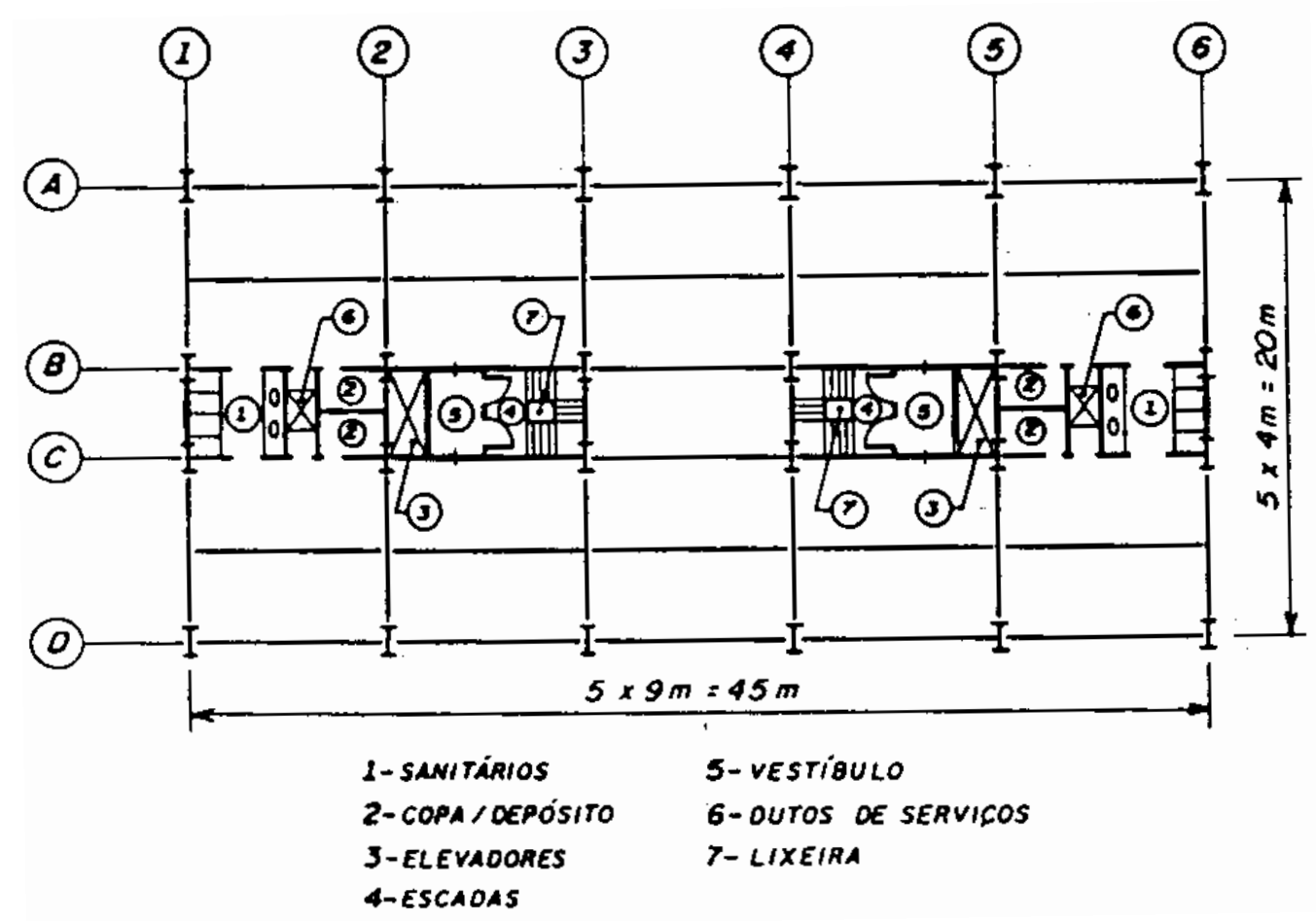

Figura 1.1 - Planta baixa do pavimento tipo do Edifício Modelo 1 (SÁLES, 1995) 
A escolha desse projeto arquitetônico se deve ao fato de suas características favorecerem a estrutura ser concebida em concreto armado, situação essa, bastante usual enfrentada em escritórios de estruturas metálicas.

\subsubsection{Sistema estrutural}

Os elementos do sistema estrutural desse modelo são compostos por lajes mistas (fôrma de aço incorporada ao concreto), viga mista (aço e concreto) e pilares isolados (aço). Os pilares são considerados engastados na fundação. O vigamento e as ligações vigas-pilares são demonstrados na Figura 1.2 e Figuras 1.3 e 1.4, respectivamente. Já as ligações das barras de contraventamento, não representadas, são flexíveis.

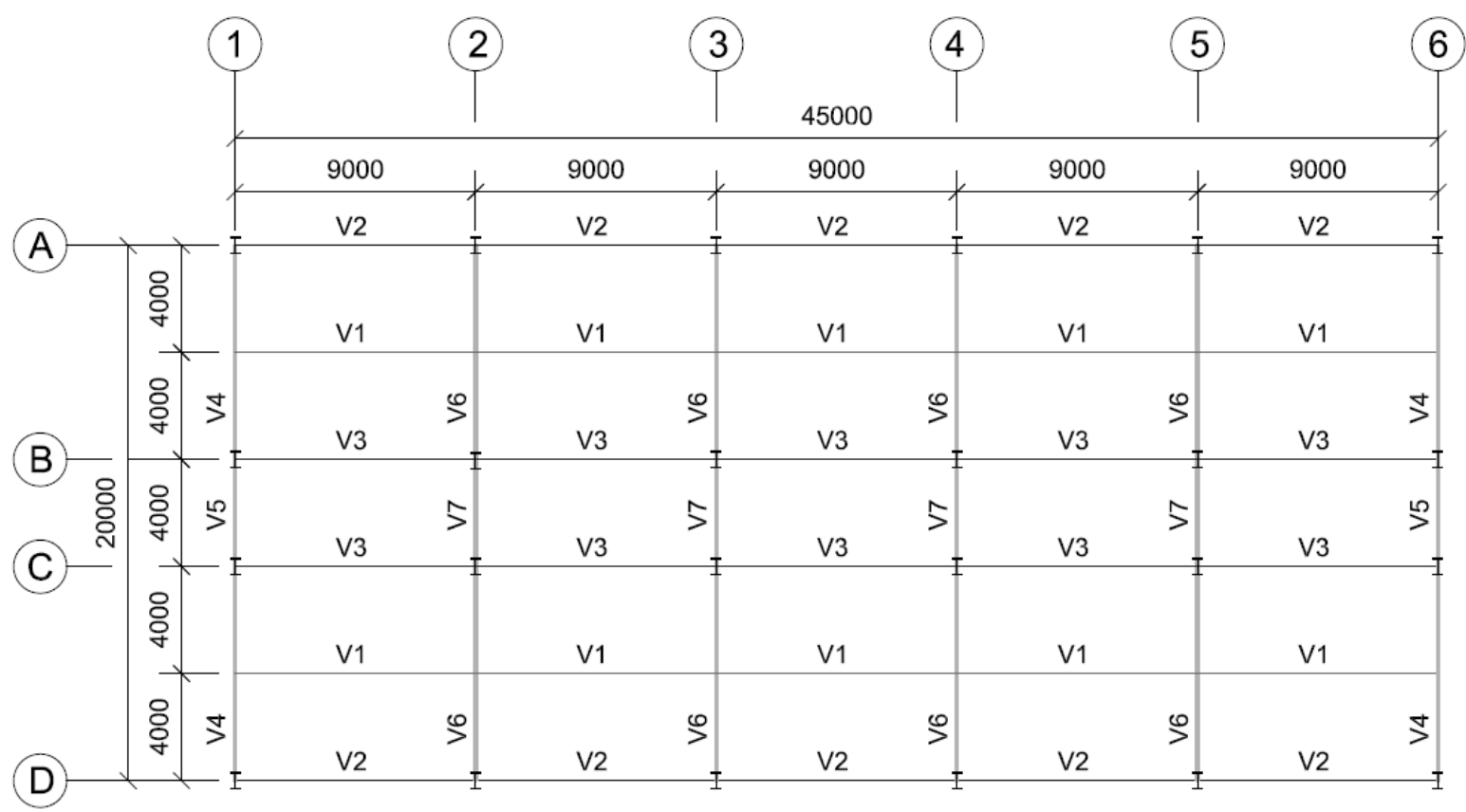

Figura 1.2 - Plano das vigas do pavimento tipo do Edifício Modelo 1 


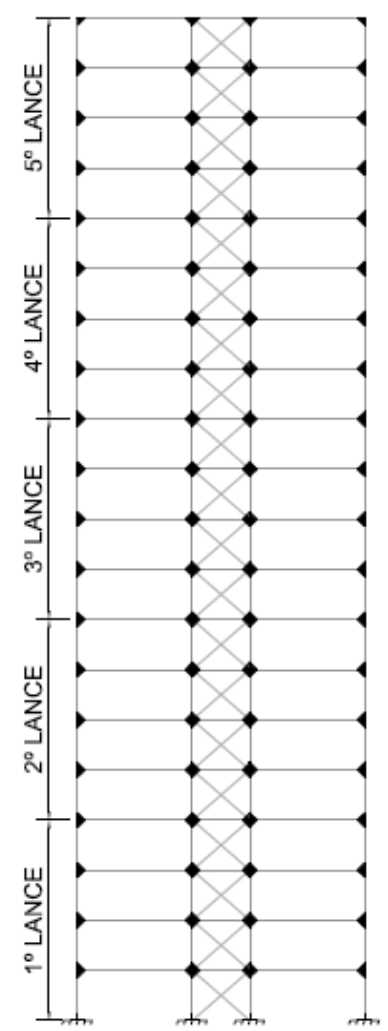

(a)

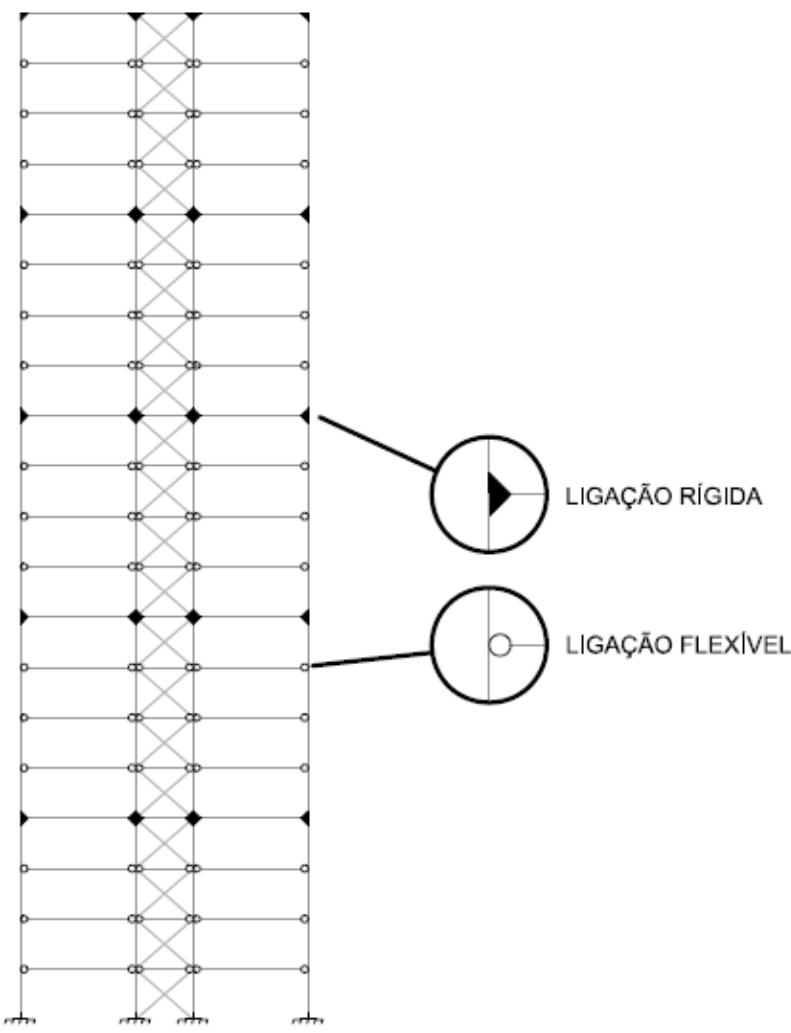

(b)

Figura 1.3 - Edifício Modelo 1 - Elevação dos eixos: (a) 1, 2, 5 e 6; (b) 3 e 4

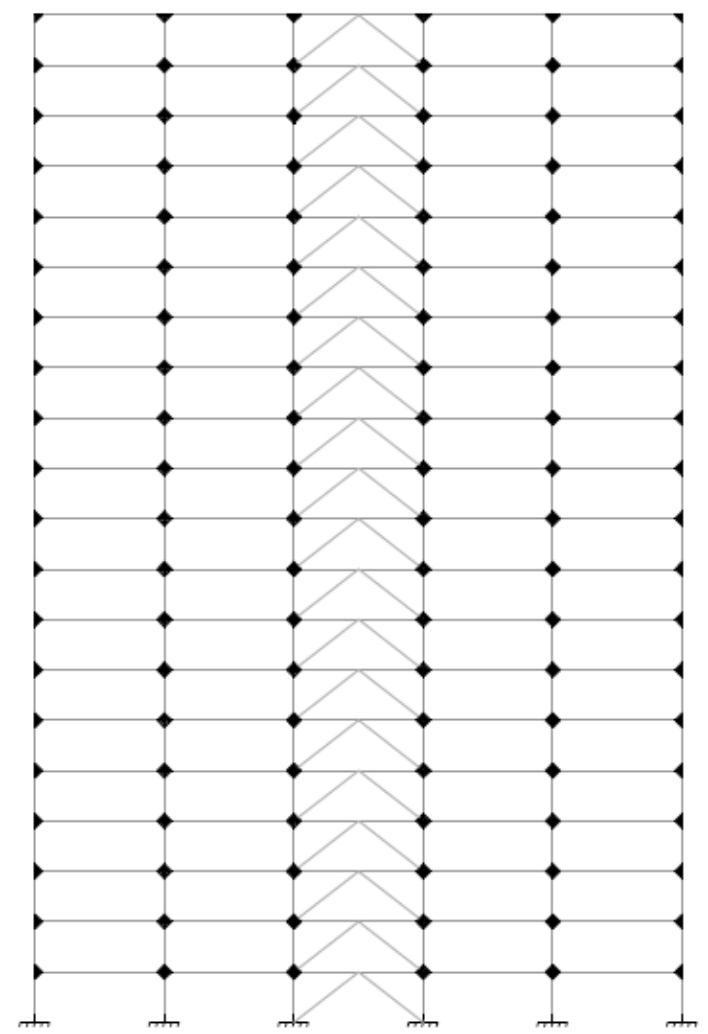

(a)

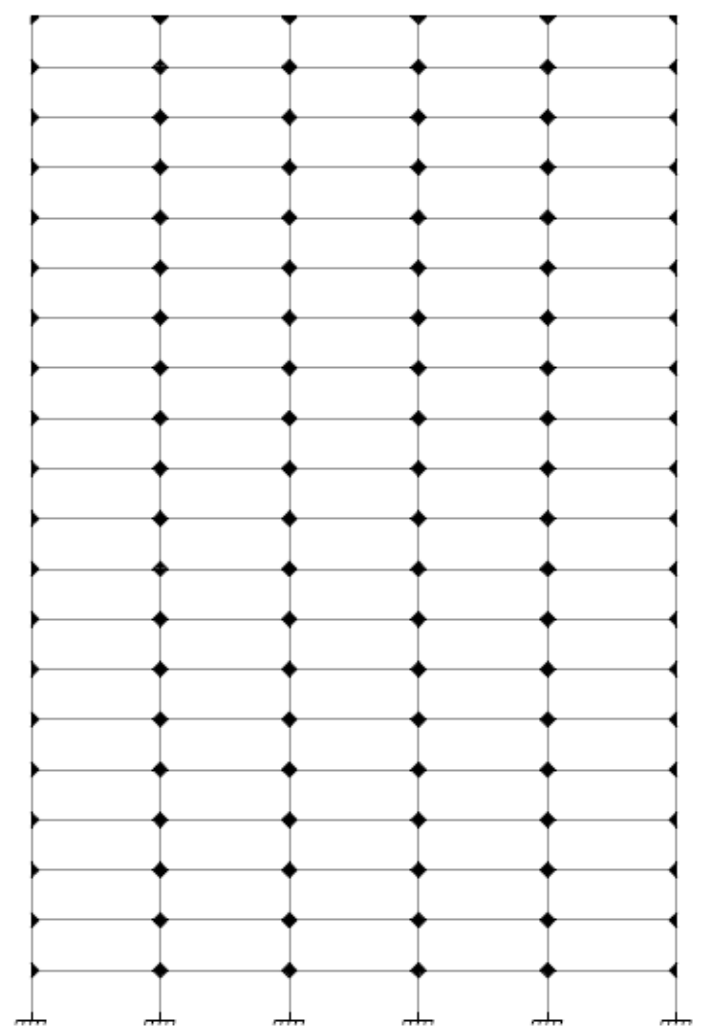

(b)

Figura 1.4 - Edifício Modelo 1 - Elevação das filas: (a) A e D; (b) B e C 


\subsubsection{Propriedades dos materiais}

A seguir são apresentadas as características dos materiais empregados nas lajes mistas, vigas mistas e pilares.

\subsection{Perfil de aço (ASTM A572 GRAU 50)}

Resistência característica ao escoamento

$$
f_{y}=34,5 \mathrm{kN} / \mathrm{cm}^{2}
$$

Resistência característica à ruptura por tração

$\mathrm{f}_{\mathrm{u}}=45 \mathrm{kN} / \mathrm{cm}^{2}$

Módulo de elasticidade longitudinal

$E=20000 \mathrm{kN} / \mathrm{cm}^{2}$

\subsection{Conector de cisalhamento pino com cabeça (aço de baixo carbono)}

Resistência característica ao escoamento $\quad \mathrm{f}_{\mathrm{ycs}}=35 \mathrm{kN} / \mathrm{cm}^{2}$

Resistência característica à ruptura por tração $\quad \mathrm{f}_{\mathrm{ucs}}=45 \mathrm{kN} / \mathrm{cm}^{2}$

Módulo de elasticidade longitudinal $\quad E=20000 \mathrm{kN} / \mathrm{cm}^{2}$

\subsection{Concreto (C20)}

Resistência característica à compressão

$\mathrm{f}_{\mathrm{ck}}=2 \mathrm{kN} / \mathrm{cm}^{2}$

Módulo de elasticidade secante

$E_{c}=2128,74 \mathrm{kN} / \mathrm{cm}^{2}$

\subsection{Fôrma incorporada (ASTM A653 - grau 40)}

Resistência característica ao escoamento

$\mathrm{f}_{\mathrm{yF}}=28 \mathrm{kN} / \mathrm{cm}^{2}$

Módulo de elasticidade longitudinal

$$
E=20000 \mathrm{kN} / \mathrm{cm}^{2}
$$


Resistência característica ao escoamento

Módulo de elasticidade longitudinal $f_{y s}=50 \mathrm{kN} / \mathrm{cm}^{2}$

$E=20000 \mathrm{kN} / \mathrm{cm}^{2}$

\subsubsection{Carregamentos}

Salvo o tipo de laje e fachada, os materiais empregados na estrutura e acabamento foram mantidos de Sáles (1995). Os valores dos carregamentos são baseados na ABNT NBR 6120:1980 e ABNT NBR 6123:1988.

Tabela 1.1 - Cargas sobre a edificação

\begin{tabular}{|c|c|c|}
\hline \multicolumn{3}{|c|}{ Carregamento permanente } \\
\hline Material & Pavimento tipo & Cobertura \\
\hline Viga de aço & $0,7 \mathrm{kN} / \mathrm{m}$ & $0,7 \mathrm{kN} / \mathrm{m}$ \\
\hline Laje (concreto) & $2,56 \mathrm{kN} / \mathrm{m}^{2}$ & $2,31 \mathrm{kN} / \mathrm{m}^{2}$ \\
\hline Argamassa de nivelamento ${ }^{(a)}$ & $0,57 \mathrm{kN} / \mathrm{m}^{2}$ & $0,75 \mathrm{kN} / \mathrm{m}^{2}$ \\
\hline Carpete & $0,05 \mathrm{kN} / \mathrm{m}^{2}$ & - \\
\hline Fôrros e serviços & $0,5 \mathrm{kN} / \mathrm{m}^{2}$ & $0,5 \mathrm{kN} / \mathrm{m}^{2}$ \\
\hline Fôrma incorporada & $0,15 \mathrm{kN} / \mathrm{m}^{2}$ & - \\
\hline Divisórias móveis & $1,0 \mathrm{kN} / \mathrm{m}^{2}$ & - \\
\hline Fachadas (módulos unitizados) & $1,23 \mathrm{kN} / \mathrm{m}$ & - \\
\hline \multicolumn{3}{|c|}{ Sobrecarga de utilização } \\
\hline Escritório e cobertura & \multicolumn{2}{|c|}{$2,0 \mathrm{kN} / \mathrm{m}^{2}$} \\
\hline
\end{tabular}

Na verificação do dimensionamento será realizada a redução da sobrecarga conforme a ABNT NBR 6120:1980 recomenda. 
Tabela 1.2 - Redução das cargas acidentais (ABNT NBR 6120:1980)

\begin{tabular}{|c|c|}
\hline Número de pisos acima do elemento ${ }^{\text {(a) }}$ & $\begin{array}{c}\text { Redução percentual das cargas } \\
\text { acidentais (\%) }\end{array}$ \\
\hline Até 3 & 0 \\
\hline 4 & 20 \\
\hline 5 & 40 \\
\hline 6 em diante & 60 \\
\hline${ }^{(a)}$ Para efeito de aplicação desses valores, a cobertura é considerada como piso. \\
\hline
\end{tabular}

A definição do carregamento lateral foi baseada no Método da Largura de Influência. As lajes são simuladas no SAP 2000 (COMPUTER AND STRUCTURES INC., 2009) por diafragmas (constraints type - diaphragm) supostos muito rígidos em seus planos e completamente flexíveis transversalmente aos mesmos. Esse comportamento das lajes responsabiliza-se em conduzir as ações horizontais aos respectivos sistemas resistentes, além de compatibilizar os deslocamentos ao nível de cada andar.

O procedimento de cálculo aplicado na definição das ações horizontais conforme a ABNT NBR 6123:1988 é exposto no APÊNDICE A. Os resultados dos cálculos, desenvolvidos no Mathcad (PARAMETRIC TECHNOLOGY CORPORATION, 2007), são apresentados nas Tabelas 1.3, 1.4 e 1.5. O Mathcad é uma planilha eletrônica com excelentes ferramentas de edição de texto, além de matemáticas. É um software bastante aplicável na engenharia no desenvolvimento de memoriais de cálculo. 
Tabela 1.3 - Valores dos vetores para os respectivos níveis $(\mathrm{z})$ dos andares: fator $\mathrm{S}_{2}$; velocidade característica do vento $\left(\mathrm{V}_{\mathrm{k}}\right)$; pressão dinâmica $(\mathrm{q})$; força de arrasto atuando em cada eixo $\left(F_{e . a}\right)$ e fila $\left(F_{e . b}\right)$

\begin{tabular}{|c|c|c|c|c|c|}
\hline$z(m)$ & $S_{2}$ & $V_{k}(\mathrm{~m} / \mathrm{s})$ & $q\left(k N / m^{2}\right)$ & $F_{\text {e.a }}(\mathrm{kN})$ & $F_{\text {e.b }}(\mathrm{kN})$ \\
\hline 3,5 & 0,69 & 27,70 & 0,47 & 13,58 & 7,00 \\
\hline 7 & 0,76 & 30,42 & 0,57 & 16,38 & 8,44 \\
\hline 10,5 & 0,80 & 32,13 & 0,63 & 18,27 & 9,41 \\
\hline 14 & 0,84 & 33,40 & 0,68 & 19,75 & 10,17 \\
\hline 17,5 & 0,86 & 34,42 & 0,73 & 20,98 & 10,81 \\
\hline 21 & 0,88 & 35,28 & 0,76 & 22,03 & 11,35 \\
\hline 24,5 & 0,90 & 36,02 & 0,80 & 22,97 & 11,83 \\
\hline 28 & 0,92 & 36,68 & 0,82 & 23,81 & 12,27 \\
\hline 31,5 & 0,93 & 37,27 & 0,85 & 24,58 & 12,66 \\
\hline 35 & 0,95 & 37,80 & 0,88 & 25,29 & 13,03 \\
\hline 38,5 & 0,96 & 38,29 & 0,90 & 25,95 & 13,37 \\
\hline 42 & 0,97 & 38,74 & 0,92 & 26,57 & 13,69 \\
\hline 45,5 & 0,98 & 39,16 & 0,94 & 27,15 & 13,99 \\
\hline 49 & 0,99 & 39,56 & 0,96 & 27,70 & 14,27 \\
\hline 52,5 & 1,00 & 39,93 & 0,98 & 28,22 & 14,54 \\
\hline 56 & 1,01 & 40,28 & 0,99 & 28,72 & 14,79 \\
\hline 59,5 & 1,02 & 40,61 & 1,01 & 29,19 & 15,04 \\
\hline 63 & 1,02 & 40,92 & 1,03 & 29,64 & 15,27 \\
\hline 66,5 & 1,03 & 41,22 & 1,04 & 30,08 & 15,50 \\
\hline 70 & 1,04 & 41,51 & 1,06 & 30,50 & 15,71 \\
\hline & & & & & \\
\hline
\end{tabular}

Tabela 1.4 - Forças componentes dos binários sobre cada eixo $\left(F_{\text {t.a }}\right)$ e fila $\left(F_{t . b}\right)$

\begin{tabular}{|c|c|c|c|c|c|c|c|c|c|c|}
\hline$z(m)$ & $F_{\text {t.a. } 1}(\mathrm{kN})$ & $F_{\text {t.a.2 }}(\mathrm{kN})$ & $F_{\text {t.a. } 3}(\mathrm{kN})$ & $F_{\text {t.a. }}(\mathrm{kN})$ & $F_{\text {t.a. }}(\mathrm{kN})$ & $F_{\text {t.a.6 }}(\mathrm{kN})$ & $F_{\text {t.b.A }}(\mathrm{kN})$ & $F_{\text {t.b. }}(\mathrm{kN})$ & $F_{\text {t.b.c }}(\mathrm{kN})$ & $F_{\text {t.b. }}(\mathrm{kN})$ \\
\hline 3,5 & 8,73 & 5,24 & 1,75 & $-1,75$ & $-5,24$ & $-8,73$ & 4,04 & 0,81 & $-0,81$ & $-4,04$ \\
\hline 7 & 10,53 & 6,32 & 2,11 & $-2,11$ & $-6,32$ & $-10,53$ & 4,87 & 0,97 & $-0,97$ & $-4,87$ \\
\hline 10,5 & 11,75 & 7,05 & 2,35 & $-2,35$ & $-7,05$ & $-11,75$ & 5,43 & 1,09 & $-1,09$ & $-5,43$ \\
\hline 14 & 12,70 & 7,62 & 2,54 & $-2,54$ & $-7,62$ & $-12,70$ & 5,87 & 1,17 & $-1,17$ & $-5,87$ \\
\hline 17,5 & 13,48 & 8,09 & 2,70 & $-2,70$ & $-8,09$ & $-13,48$ & 6,23 & 1,25 & $-1,25$ & $-6,23$ \\
\hline 21 & 14,17 & 8,50 & 2,83 & $-2,83$ & $-8,50$ & $-14,17$ & 6,55 & 1,31 & $-1,31$ & $-6,55$ \\
\hline 24,5 & 14,77 & 8,86 & 2,95 & $-2,95$ & $-8,86$ & $-14,77$ & 6,83 & 1,37 & $-1,37$ & $-6,83$ \\
\hline 28 & 15,31 & 9,19 & 3,06 & $-3,06$ & $-9,19$ & $-15,31$ & 7,08 & 1,42 & $-1,42$ & $-7,08$ \\
\hline 31,5 & 15,80 & 9,48 & 3,16 & $-3,16$ & $-9,48$ & $-15,80$ & 7,31 & 1,46 & $-1,46$ & $-7,31$ \\
\hline 35 & 16,26 & 9,76 & 3,25 & $-3,25$ & $-9,76$ & $-16,26$ & 7,52 & 1,50 & $-1,50$ & $-7,52$ \\
\hline 38,5 & 16,68 & 10,01 & 3,34 & $-3,34$ & $-10,01$ & $-16,68$ & 7,71 & 1,54 & $-1,54$ & $-7,71$ \\
\hline 42 & 17,08 & 10,25 & 3,42 & $-3,42$ & $-10,25$ & $-17,08$ & 7,90 & 1,58 & $-1,58$ & $-7,90$ \\
\hline 45,5 & 17,45 & 10,47 & 3,49 & $-3,49$ & $-10,47$ & $-17,45$ & 8,07 & 1,61 & $-1,61$ & $-8,07$ \\
\hline 49 & 17,81 & 10,68 & 3,56 & $-3,56$ & $-10,68$ & $-17,81$ & 8,23 & 1,65 & $-1,65$ & $-8,23$ \\
\hline 52,5 & 18,14 & 10,88 & 3,63 & $-3,63$ & $-10,88$ & $-18,14$ & 8,39 & 1,68 & $-1,68$ & $-8,39$ \\
\hline 56 & 18,46 & 11,08 & 3,69 & $-3,69$ & $-11,08$ & $-18,46$ & 8,53 & 1,71 & $-1,71$ & $-8,53$ \\
\hline 59,5 & 18,76 & 11,26 & 3,75 & $-3,75$ & $-11,26$ & $-18,76$ & 8,68 & 1,74 & $-1,74$ & $-8,68$ \\
\hline 63 & 19,06 & 11,43 & 3,81 & $-3,81$ & $-11,43$ & $-19,06$ & 8,81 & 1,76 & $-1,76$ & $-8,81$ \\
\hline 66,5 & 19,34 & 11,60 & 3,87 & $-3,87$ & $-11,60$ & $-19,34$ & 8,94 & 1,79 & $-1,79$ & $-8,94$ \\
\hline 70 & 19,61 & 11,76 & 3,92 & $-3,92$ & $-11,76$ & $-19,61$ & 9,06 & 1,81 & $-1,81$ & $-9,06$ \\
\hline
\end{tabular}


Tabela 1.5 - Sobreposição das forças horizontais atuantes na edificação devidas ao vento (CV): resultante incidindo sobre cada eixo e fila

\begin{tabular}{|c|c|c|c|c|c|c|c|c|c|c|}
\hline$z(m)$ & $\mathrm{CV}_{1}(\mathrm{kN})$ & $\mathrm{CV}_{2}(\mathrm{kN})$ & $\mathrm{CV}_{3}(\mathrm{kN})$ & $\mathrm{CV}_{4}(\mathrm{kN})$ & $\mathrm{CV}_{5}(\mathrm{kN})$ & $\mathrm{CV}_{6}(\mathrm{kN})$ & $\mathrm{CV}_{\mathrm{A}}(\mathrm{kN})$ & $\mathrm{CV}_{\mathrm{B}}(\mathrm{kN})$ & $\mathrm{CV}_{\mathrm{C}}(\mathrm{kN})$ & $C V_{D}(k N)$ \\
\hline 3,5 & 22,32 & 18,82 & 15,33 & 11,84 & 8,34 & 4,85 & 11,03 & 7,80 & 6,19 & 2,96 \\
\hline 7 & 26,91 & 22,70 & 18,48 & 14,27 & 10,06 & 5,85 & 13,31 & 9,41 & 7,46 & 3,57 \\
\hline 10,5 & 30,02 & 25,32 & 20,62 & 15,92 & 11,23 & 6,53 & 14,84 & 10,50 & 8,33 & 3,98 \\
\hline 14 & 32,45 & 27,37 & 22,29 & 17,21 & 12,13 & 7,05 & 16,04 & 11,35 & 9,00 & 4,30 \\
\hline 17,5 & 34,46 & 29,07 & 23,67 & 18,28 & 12,89 & 7,49 & 17,04 & 12,05 & 9,56 & 4,57 \\
\hline 21 & 36,20 & 30,53 & 24,87 & 19,20 & 13,54 & 7,87 & 17,90 & 12,66 & 10,04 & 4,80 \\
\hline 24,5 & 37,74 & 31,83 & 25,92 & 20,02 & 14,11 & 8,20 & 18,66 & 13,20 & 10,47 & 5,01 \\
\hline 28 & 39,12 & 33,00 & 26,88 & 20,75 & 14,63 & 8,51 & 19,35 & 13,68 & 10,85 & 5,19 \\
\hline 31,5 & 40,39 & 34,07 & 27,74 & 21,42 & 15,10 & 8,78 & 19,97 & 14,13 & 11,20 & 5,36 \\
\hline 35 & 41,55 & 35,05 & 28,55 & 22,04 & 15,54 & 9,03 & 20,55 & 14,53 & 11,53 & 5,51 \\
\hline 38,5 & 42,64 & 35,96 & 29,29 & 22,62 & 15,94 & 9,27 & 21,08 & 14,91 & 11,83 & 5,66 \\
\hline 42 & 43,65 & 36,82 & 29,99 & 23,15 & 16,32 & 9,49 & 21,58 & 15,27 & 12,11 & 5,79 \\
\hline 45,5 & 44,60 & 37,62 & 30,64 & 23,66 & 16,68 & 9,70 & 22,06 & 15,60 & 12,37 & 5,92 \\
\hline 49 & 45,51 & 38,38 & 31,26 & 24,14 & 17,01 & 9,89 & 22,50 & 15,92 & 12,62 & 6,04 \\
\hline 52,5 & 46,36 & 39,10 & 31,85 & 24,59 & 17,33 & 10,08 & 22,92 & 16,21 & 12,86 & 6,15 \\
\hline 56 & 47,18 & 39,79 & 32,41 & 25,02 & 17,64 & 10,26 & 23,33 & 16,50 & 13,09 & 6,26 \\
\hline 59,5 & 47,95 & 40,45 & 32,94 & 25,44 & 17,93 & 10,42 & 23,71 & 16,77 & 13,30 & 6,36 \\
\hline 63 & 48,70 & 41,08 & 33,45 & 25,83 & 18,21 & 10,59 & 24,08 & 17,03 & 13,51 & 6,46 \\
\hline 66,5 & 49,42 & 41,68 & 33,95 & 26,21 & 18,48 & 10,74 & 24,44 & 17,28 & 13,71 & 6,56 \\
\hline 70 & 50,11 & 42,26 & 34,42 & 26,58 & 18,74 & 10,89 & 24,78 & 17,52 & 13,90 & 6,65 \\
\hline
\end{tabular}

\subsubsection{DISTRIBUIÇÃO DA PESQUISA}

O capítulo 2 desse trabalho desenvolverá uma breve introdução aos sistemas estruturais verticais e horizontais usualmente aplicados em edifícios múltiplos andares com estrutura de aço, assim como, ao conceito dos elementos estruturais mistos de aço e concreto cada vez mais presentes nessas construções e enfatizará as lajes com fôrma de aço incorporada ao concreto. Também estão presentes nesse capítulo as combinações de ações aplicáveis aos edifícios comerciais.

Baseado em análises elásticas planas realizadas no Ftool (PUC-Rio, 2008), o capítulo 3 abordará o desempenho de vigas mistas de aço e concreto frente aos estados limites recomendados pela ABNT NBR 8800:2008 variando o grau de interação entre os materiais, sistema construtivo, sistema estrutural, entre outras considerações, como o efeito de longa duração do concreto. Além disso, trará as definições básicas necessárias para o entendimento do mecanismo dessas estruturas. 
No final desse capítulo serão comentadas as avaliações realizadas dentro das possibilidades estruturais e construtivas do modelo analisado de forma a esclarecer as decisões tomadas no vigamento da edificação.

A partir das características do Edifício Modelo 1, no capítulo 4 será desenvolvido mais 3 modelos (Figuras 4.9 a 4.11) para o estudo dos sistemas resistentes a carregamentos laterais dos eixos 1 a 6 (Figura 1.3). Simploriamente, a configuração das filas A a D (Figura 1.2) será mantida para os demais modelos.

O capítulo apresentará as recomendações trazidas pela ABNT NBR 8800:2008 quanto à estabilidade e análise estrutural de edifícios de andares múltiplos de aço. Com base na análise tridimensional elástica realizada pelo SAP 2000 (COMPUTER AND STRUCTURES INC., 2009), será avaliada a influência da rigidez lateral da estrutura no cálculo do efeito de segunda ordem global baseado no método de amplificação dos esforços proposto pela norma brasileira.

Nesse capítulo também será realizada a análise dos deslocamentos laterais da edificação enfatizando a torção global da estrutura provocada pela ação excêntrica do vento conforme recomendado pela ABNT NBR 6123:1988.

Ainda são apresentados comentários no final do capítulo 4 que envolve as etapas de pré-dimensionamento e dimensionamento dos elementos estruturais constituintes da edificação, assim como, sobre os critérios utilizados na definição do sistema estrutural vertical empregado.

No capítulo 5 serão destacadas as principais ideias referentes ao desempenho estrutural das vigas mistas de aço e concreto e ainda sobre a estabilização lateral e análise estrutural com base no edifício de múltiplo andar estudado ao longo desse trabalho.

Por fim, de forma a consolidar os conceitos trazidos nesse trabalho, os apêndices exemplificarão o memorial de cálculo relativo ao levantamento das ações horizontais e à verificação do dimensionamento de uma viga mista de aço e concreto e de um pilar isolado de aço, todos referentes ao modelo estudado e desenvolvidas no Mathcad (PARAMETRIC TECHNOLOGY CORPORATION, 2007). 



\section{CAPÍTULO 2: ASPECTOS GERAIS}

\subsection{ESTRUTURAS MISTAS}

As estruturas mistas de aço e concreto são originadas das associações entre perfis de aço e o concreto estrutural de forma que os materiais trabalhem conjuntamente para resistir aos esforços solicitantes. Essas estruturas trazem novas aplicações tanto para o aço quanto para o concreto com a exploração das melhores características de cada material e consequentemente, vantagens importantes para a construção civil.

Em relação ao aço estrutural, ocorre uma redução do seu consumo, com a substituição de parte do aço necessário para resistir às ações, pelo concreto, que tem menor custo e, além disso, contribui para a redução das instabilidades locais dos elementos do perfil de aço. Por outro lado, no concreto estrutural verifica-se a possibilidade de se dispensar fôrmas e escoramentos, reduzindo custos com material e mão-de-obra, e o aumento da precisão dimensional dos elementos.

A crescente utilização de estruturas mistas é atribuída a diversos fatores, entre os quais, a necessidade cada vez maior de grandes áreas livres por pavimento e da redução das dimensões da seção transversal dos elementos constituintes.

Outro aspecto importante é a rapidez e facilidade de execução dessas estruturas, atendendo aos prazos de entrega da edificação sem grandes acréscimos no custo final do empreendimento, e ainda, cabe destacar que seu emprego nas construções demanda de uma pequena área de ocupação no canteiro de obras atendendo a limitações impostas pela vizinhança.

Atualmente, a utilização dos elementos mistos de aço e concreto ganharam novo impulso no Brasil com a publicação, em julho de 2008, da nova versão da ABNT NBR 8800:2008, que aborda em seus anexos, recomendações de projeto para vigas, pilares, lajes e ligações mistas.

Antes, a ABNT NBR 8800:1986 abordava apenas o dimensionamento de vigas mistas e o dimensionamento de pilares mistos e lajes mistas em temperatura 
ambiente foram incluídos num dos anexos da ABNT NBR 14323:1999 que aborda o dimensionamento de estruturas de aço em situação de incêndio.

\subsection{SISTEMAS ESTRUTURAIS}

Desde o início das estruturas de aço, os projetistas chegaram à conclusão de que quanto mais modulados e racionalizados fossem os projetos, menor seria seu custo final, tanto pela economia de escala na fabricação de seus componentes, como na seriação de estocagem, manuseio e montagem destes componentes, resultando em uma redução do prazo de execução total da obra (SÁLES, 1995).

Essas vantagens, que a pré-fabricação proporciona, podem acarretar a falsa visão de que as estruturas de aço são mais econômicas do que qualquer outra opção de material estrutural.

A seguir são citadas algumas características da obra que podem influenciar na escolha do sistema estrutural: tipo de fundação; tempo de construção; tipo de ocupação; disponibilidade e custo dos materiais; recursos da construtora; local da obra e acessos; possibilidade de adaptações; compatibilidade com sistemas complementares; manutenção e reparos; vãos livres; espaço livre para a estrutura; espaço livre para utilidades; altura da edificação; proteção contra a corrosão; proteção contra fogo; estética; desperdício materiais/mão-de-obra; segurança do trabalhador; custos financeiros; adequação ambiental; qualidade e durabilidade; desempenho; e incômodo de áreas próximas (IBS/CBCA, 2008).

É necessário então hierarquizar as características identificadas, definindo um peso para cada uma delas, de acordo com a sua importância para o empreendimento e, em seguida, estabelecer notas aos sistemas estruturais para cada uma das características analisadas. Ao final calculam-se as médias aritméticas ponderadas para cada sistema e os maiores resultados devem indicar os sistemas mais adequados para a obra.

A estrutura de aço tem muitas características que são favoráveis para alguns tipos particulares de edificações, tais como: facilidade de emprego em construções com grandes vãos e altura ocupando menor espaço estrutural e liberando áreas para a ocupação útil; melhor aproveitamento do terreno e solo de baixa capacidade 
suporte; menor necessidade de canteiro; liberação de muitos andares simultaneamente; modulação com melhor desempenho na fabricação e montagem; precisão favorecendo a utilização de outros componentes industrializados de vedação e fachadas; montagem sob condições atmosféricas adversas; e facilidade na necessidade de ampliações, adaptações e desmontagem futuras.

O consumo de aço normalmente é expresso pela razão entre o peso total da estrutura metálica e a área dos pisos. Dentre os fatores que contribuem para a diminuição desse consumo pode ser destacados: o sistema estrutural a empregar; arranjos e tipos dos contraventamentos, núcleos, paredes e demais elementos de enrijecimento da estrutura; arranjo, tipo e espaçamento da seção dos pilares; arranjo das vigas; e elementos de fechamento.

O sistema estrutural de um edifício constitui uma unidade tridimensional cujo comportamento é de extrema complexidade. A compreensão desse comportamento pode ser facilitada decompondo o todo em suas partes constituintes. Essa decomposição pode ser de forma natural, uma vez que há separação física que torna alguns subsistemas independentes dos demais, e por representação teórica baseado nos fundamentos da Teoria das Estruturas, que ajusta um determinado subsistema a um modelo teórico existente (CORREAA, 1991).

Dessa forma, o sistema estrutural pode ser decomposto em subsistemas estruturais, em geral planos, que por sua vez se decompõem em subsistemas mais simples, em muitos casos elementos lineares.

\subsubsection{SUBSISTEMAS ESTRUTURAIS VERTICAIS}

De modo geral, a estrutura do edifício de andares múltiplos adquire configurações típicas conhecidas em função da maneira como são resistidos os esforços horizontais, podendo apresentar-se com quadros rígidos, quadros treliçados, paredes de cisalhamento, núcleo de concreto e estrutura tubular (IBS/CBCA, 2004).

O subsistema vertical é economicamente viável até o instante em que sua resistência destinada às ações horizontais não ultrapassa sua resistência destinada a conter as ações verticais. A Figura 2.1 apresenta, generalizadamente, os limites 
em que determinados sistemas estruturais apresentam-se eficientes em projetos de edifícios de múltiplos andares com estrutura de aço.

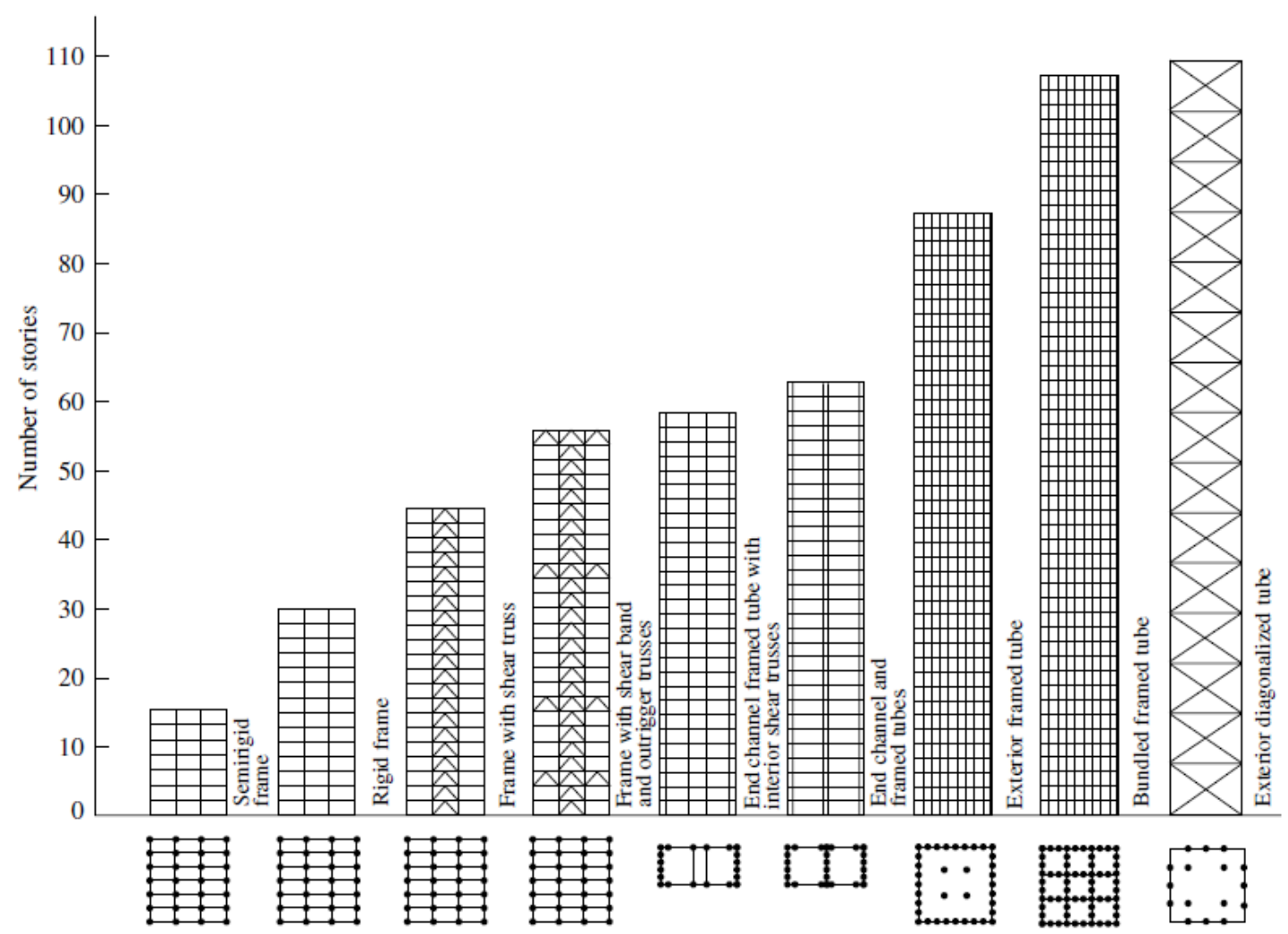

Figura 2.1 - Catalogação de edifícios múltiplo andares em aço em relação aos sistemas estruturais (CHEN; LUI, 2005)

Os sistemas estruturais de estabilização lateral apresentam dois modos de deformação devido à deflexão provocada pelas ações laterais, a saber, flexão e cortante. No primeiro, os sistemas estabilizantes comportam-se como vigas em balanço (Figuras 2.2a e 2.3a), apresentando alongamento dos pilares barlavento e encurtamento dos situadas a sotavento.

Já no modo cortante, os sistemas com quadros semirrígidos e rígidos, representados na Figura 2.1 por semirigid frame ou rigid frame respectivamente, reagem às ações laterais através da flexão das vigas e pilares (Figura 2.2b) e, por outro lado, os sistemas com quadros treliçados, exposto na mesma ilustração por frame with shear truss, frame with shear truss and outrigger trusses e exterior diagonalized tube, reagem às ações laterais através do encurtamento $\mathrm{e}$ alongamento das diagonais (Figura 2.3b). 
(a)

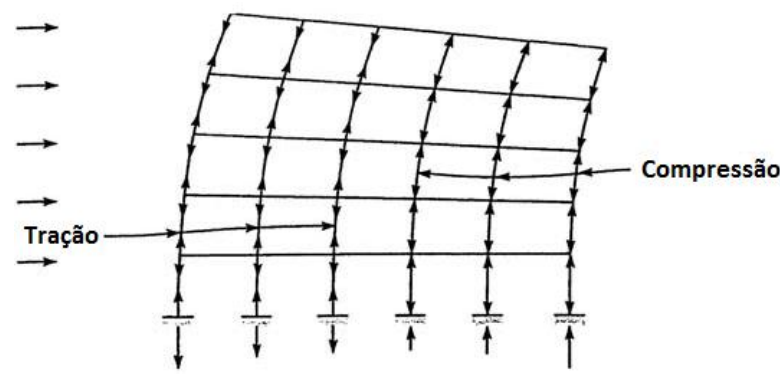

$+$

(b)
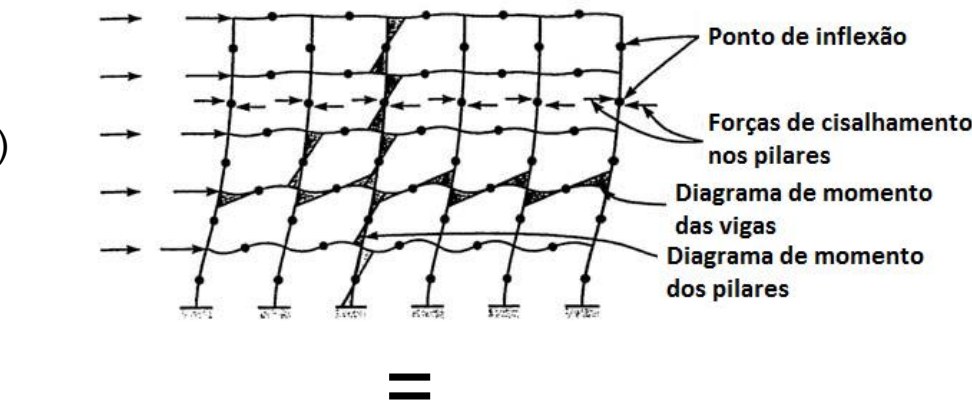

(c)

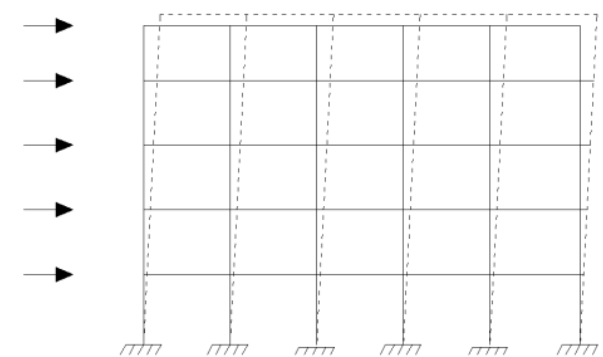

Figura 2.2 - Modos de deformação de um quadro com nós rígidos sob ações laterais: (a) modo flexionante; (b) modo cortante; (c) combinação dos efeitos

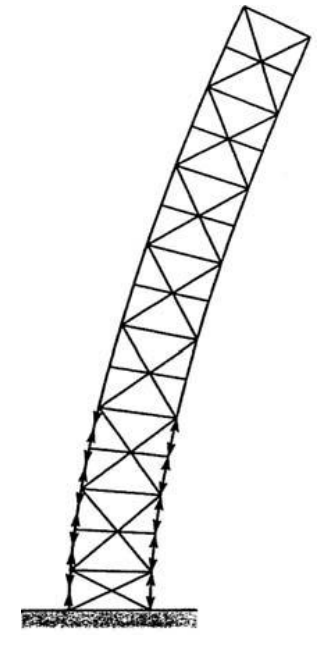

(a)

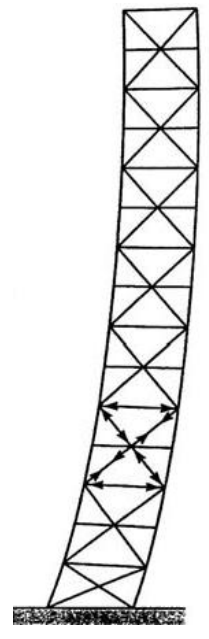

(b)

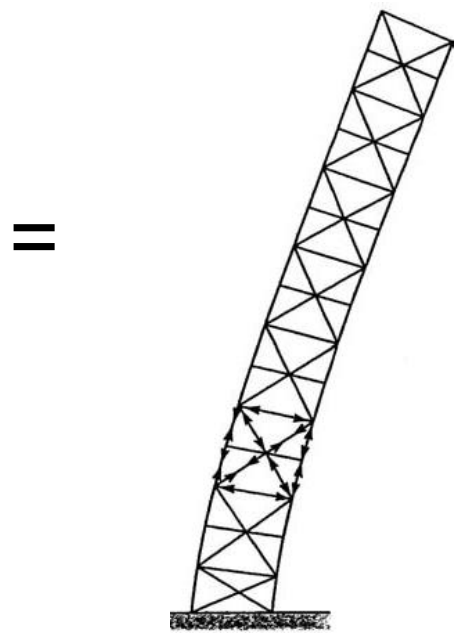

(c)

Figura 2.3 - Modos de deformação de um quadro treliçado sob ações laterais: (a) modo flexionante; (b) modo cortante; (c) combinação dos efeitos 
A contribuição de cada modo de deformação é diferente entre esses sistemas. Nos pórticos com nós rígidos $20 \%$ da deflexão lateral ocorre no modo à flexão enquanto que o modo cortante corresponde ao restante, sendo $65 \%$ resultante da flexão das vigas e 15\% referente à flexão dos pilares (RIBEIRO, 1990).

No caso dos pórticos treliçados, assim como os núcleos rígidos, a maior contribuição nos deslocamentos laterais são provenientes do modo à flexão. Chen e Lui (2005) acrescentam aos sistemas com modo de flexão predominante as estruturas tubulares aporticadas (framed tubes) e treliçadas (diagonal tubes) também apresentadas na Figura 2.1.

As características dos principais sistemas estabilizantes dos edifícios com andares múltiplos são abordadas na sequência.

\subsubsection{Estrutura com quadros rígidos}

Em edifícios com no máximo quatro andares, o subsistema estrutural mais empregado é o com quadros rígidos (Figura 2.4), cuja estabilidade é assegurada pela capacidade de transmissão de momentos das ligações vigas-pilares. Sua presença em edifícios se justifica pela dificuldade de se criar núcleos rígidos decorrentes da ausência de elevadores, salvo os casos onde é possível a criação desses núcleos em caixas de escadas ou em ambientes de circulação vertical.

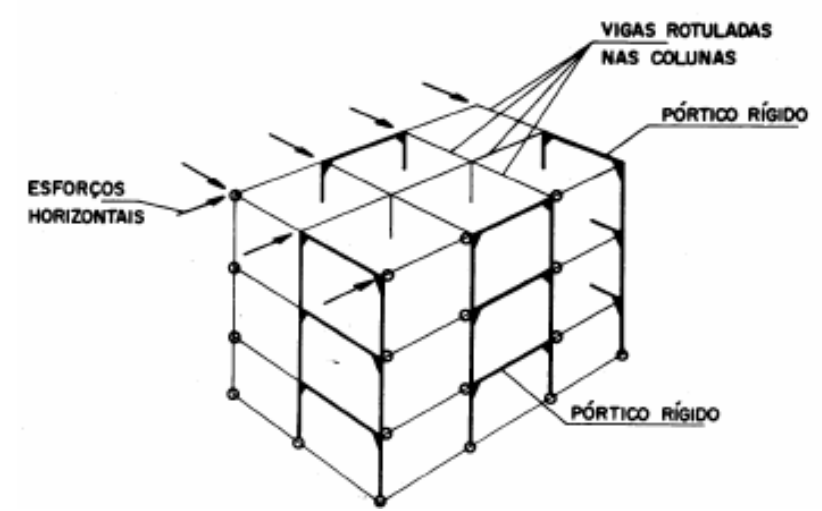

Figura 2.4 - Estrutura com quadros rígidos (IBS/CBCA, 2004)

Essas estruturas formadas por quadros rígidos dispostos nas duas direções, constituindo um pórtico tridimensional, podem ser econômicas para edifícios até 20 ou 30 pavimentos. Entretanto, com a necessidade de elevadores e caixas de 
escadas a solução com núcleo resistente, apresentada adiante, pode ser mais adequada.

A principal vantagem desse subsistema é deixar livres para a utilização todos os vãos entre pilares, sem os inconvenientes das treliças ou paredes dos demais subsistemas (IBS/CBCA, 2004).

Entre as desvantagens do pórtico rígido, pode-se destacar que as ligações vigas-pilares são de execução mais elaborada e os pilares são significativamente mais pesados porque, além da compressão, são submetidos também à flexão. Frequentemente, os deslocamentos horizontais são fatores preponderantes no dimensionamento, ocasionando menor aproveitamento da resistência do aço.

A combinação dessa série de fatores resulta em um subsistema menos econômico em relação aos outros.

\subsubsection{Estrutura com quadros treliçados}

O contraventado vertical geralmente, em "X" (Figura 2.5) ou "K" (Figura 1.4a), ao longo de toda altura do edifício pode ser a solução mais indicada para edifícios de até aproximadamente 40 pavimentos. A partir dessa altura o material empregado nas diagonais passa a ter considerável influência no custo da obra para torna-los suficientemente rígido e resistente (MD/SDI, 1989).

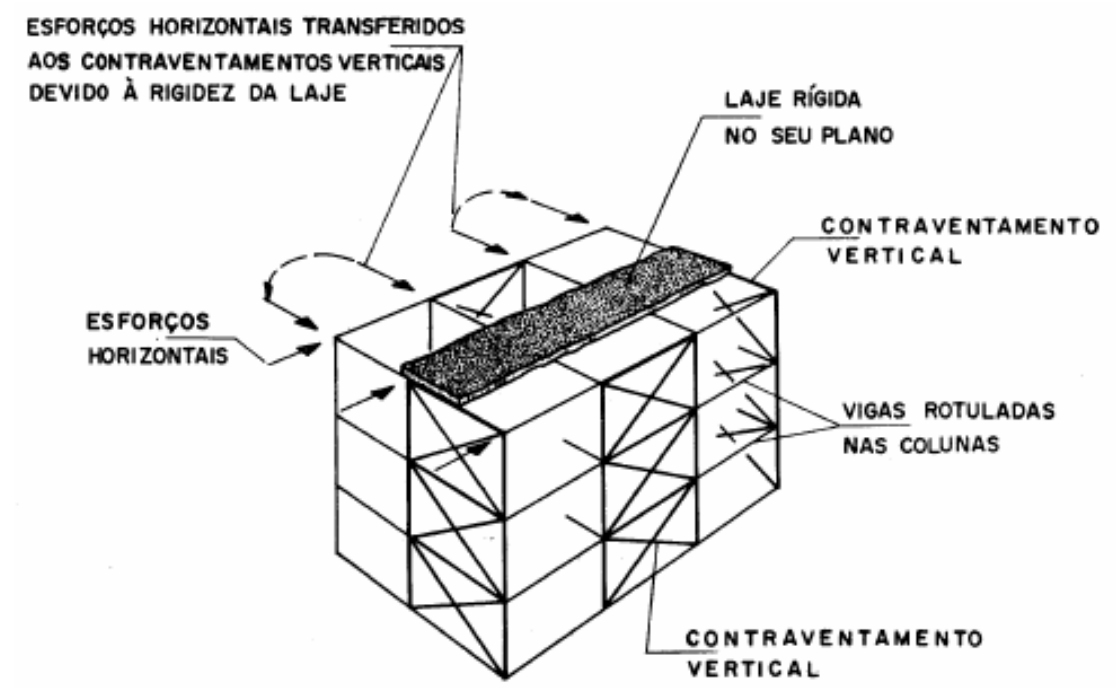

Figura 2.5 - Estrutura com quadros treliçados (IBS/CBCA, 2004) 
Adicionando treliças horizontais (outrigger trusses - Figura 2.6) rigidamente ligadas ao contraventamento vertical é possível mobilizar os pilares externos, por meio de ligações flexíveis, de forma a contribuírem na resistência às ações laterais. $\mathrm{Na}$ ilustração abaixo se observa que quando a treliça vertical tende a fletir sob ações horizontais, o outrigger trabalha, transmitindo esforços de tração e compressão aos pilares externos a barlavento e sotavento, respectivamente.

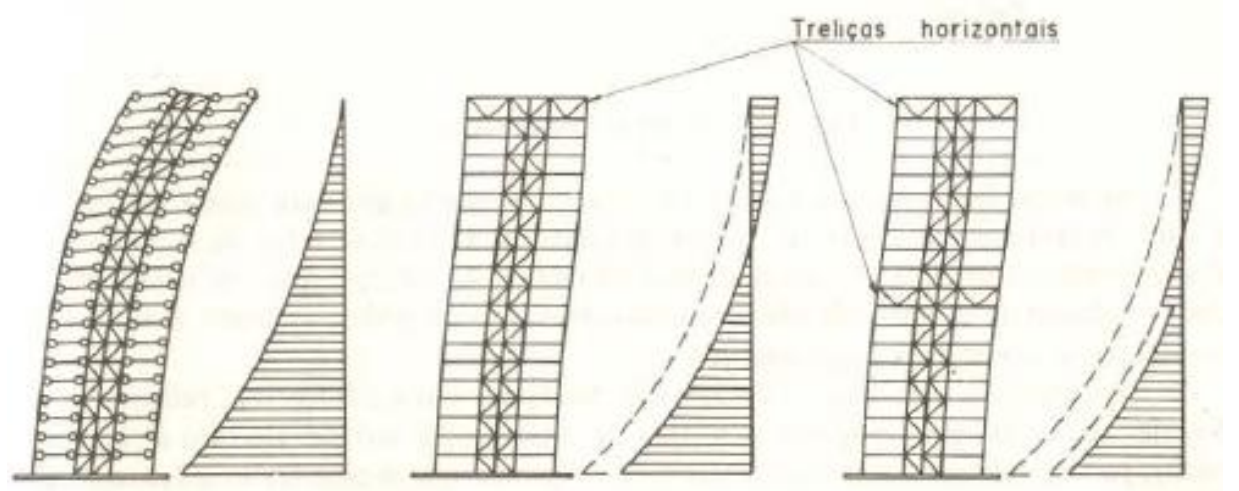

Figura 2.6 - Influência das treliças horizontais no diagrama de momento fletor (MD/SDI, 1989)

Dessa forma consegue-se reduzir o momento fletor $\mathrm{e}$, consequentemente melhorar a eficiência do sistema, possibilitando o dimensionamento de estruturas econômicas com até 60 pavimentos, além de acarretar economia também na fundação.

Os resultados de estudos da quantidade e posição das treliças horizontais convergem para a colocação de duas treliças, uma nas proximidades do topo e outra a meia altura (SÁLES, 1995). Precisamente, a localização do ponto ótimo na altura do edifício para o enésimo outrigger é dada por (TARANATH, 2005): 1/(n+1), $2 /(n+1), \ldots, n /(n+1)$.

A introdução de esforços axiais aos pilares externos ligados ao outrigger pode resultar no aumento da bitola do pilar a sotavento, anteriormente submetido apenas a cargas gravitacionais. Empregando um cintamento composto por treliças horizontais (belt tusses) aplicados na fachada e ao mesmo nível do outrigger (Figura 2.7), consegue-se distribuir esse esforço adicional aos demais pilares situados na fachada. 


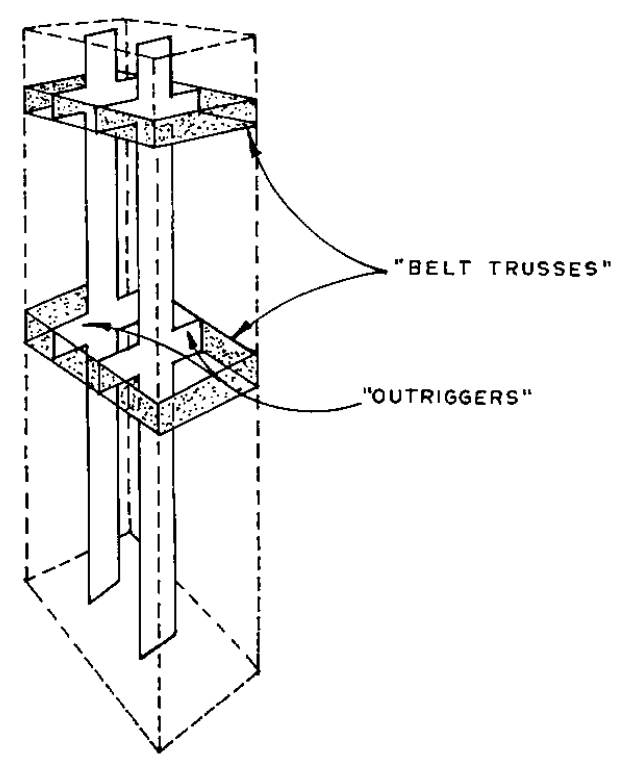

Figura 2.7 - Edifício alto com outriggers e belt tusses (RIBEIRO, 1990)

As vantagens dos subsistemas estruturais constituídos de quadros treliçados são decorrentes da fácil execução das ligações flexíveis, dos baixos deslocamentos horizontais consequentes da alta rigidez lateral da estrutura e, por último, dos pilares serem dimensionados apenas para o efeito das forças normais, resultando, assim, em um edifício mais leve, portanto mais econômico.

A interferência provocada pelos vãos treliçados internamente com a circulação dentro do edifício e externamente com a colocação de esquadrias nas fachadas englobam as principais desvantagens desse subsistema.

\subsubsection{Estrutura com paredes de cisalhamento}

Consiste em um subsistema formado por paredes de concreto armado ou alvenaria estrutural construídas nos vãos entre vigas e pilares. A estabilidade horizontal é garantida pela ação de contraventamento por cisalhamento entre as paredes, por ação em balanço das paredes e núcleos de contraventamento e pela ação de diafragma das lajes de pisos, conforme a ilustração simplificada na Figura 2.8 (IBS/CBCA, 2004). 


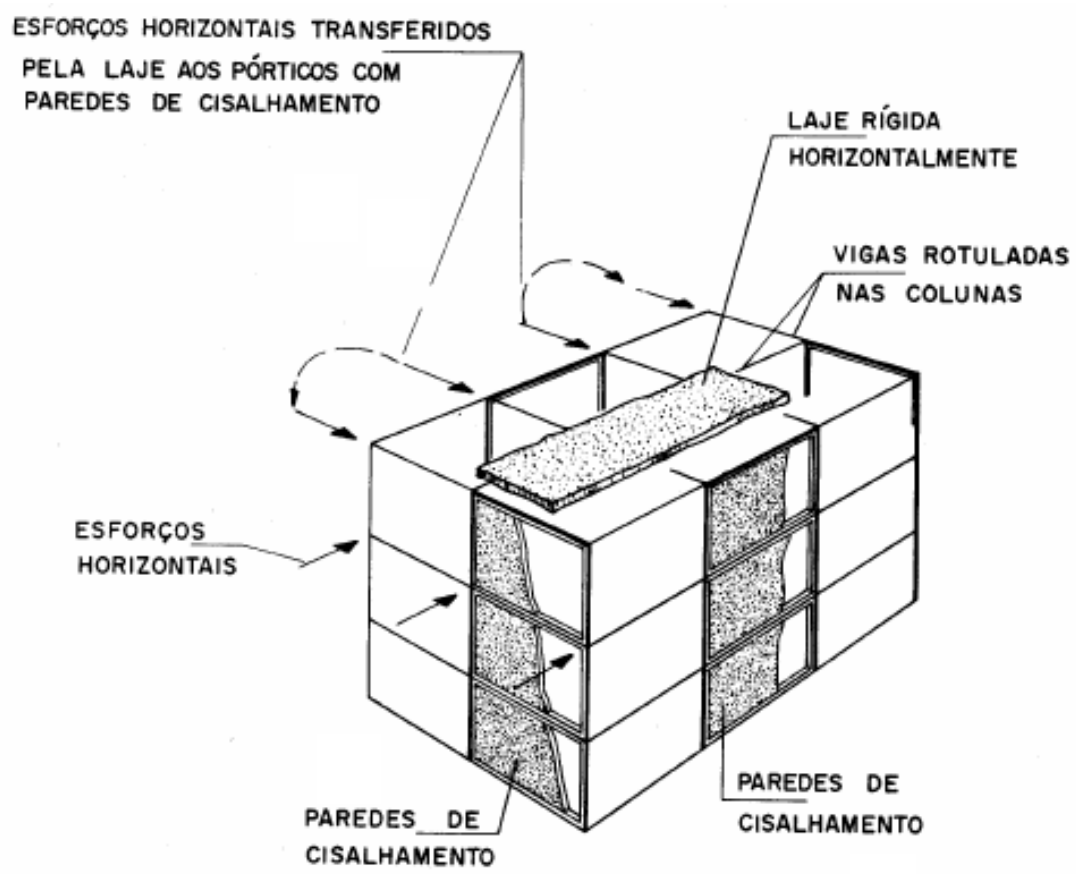

Figura 2.8 - Estrutura com paredes de cisalhamento composto por painéis (IBS/CBCA, 2004)

Alternativamente, uma parede armada, ilustrado na Figura 2.9, pode substituir uma linha inteira de pilares no edifício, de tal forma que, além do enrijecimento horizontal por ela promovido, também absorva as cargas verticais dos pilares.

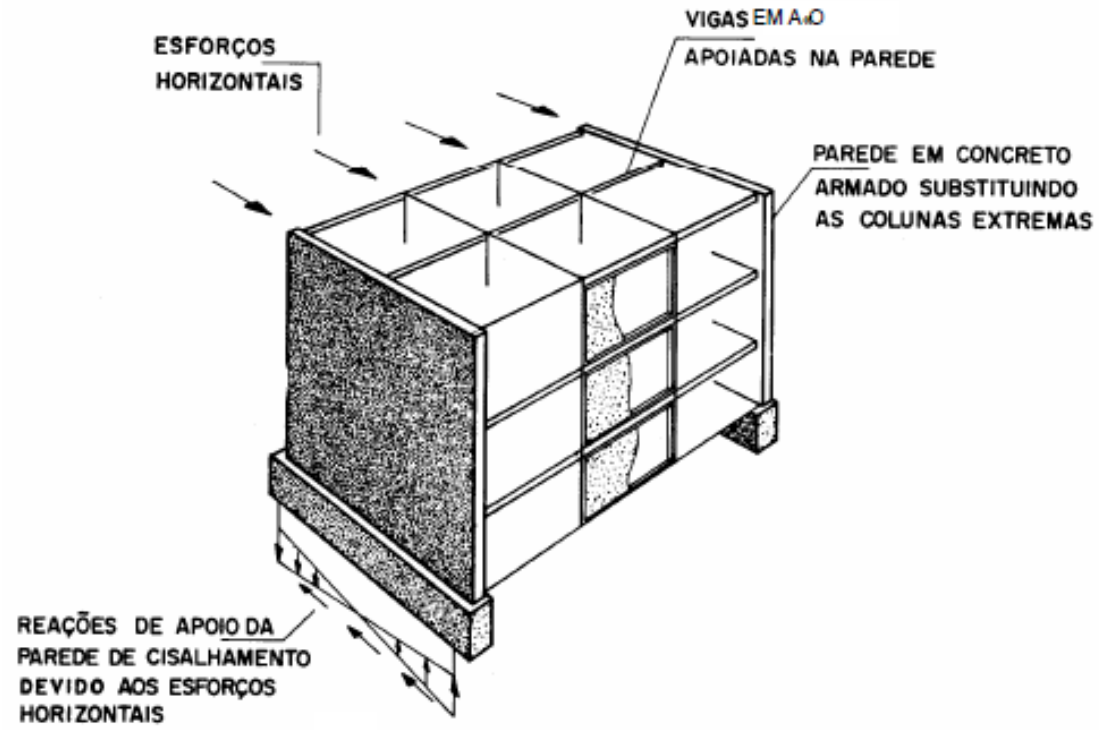

Figura 2.9 - Estrutura com paredes de cisalhamento composto por paredes armadas (IBS/CBCA, 2004)

Esse subsistema também conduz a uma estrutura final leve, com as vigas rotuladas nos pilares. 
As suas principais desvantagens são relacionadas às paredes de cisalhamento que acarretam na perda de flexibilidade na circulação interna e de recursos arquitetônicos nas fachadas. Além disso, há a necessidade destas paredes serem construídas numa rapidez compatível com a montagem da estrutura, ou a utilização de contraventamentos de montagem.

\subsubsection{Estrutura com núcleos rígidos}

Os núcleos rígidos (Figura 2.10) nas estruturas são responsáveis pela absorção de todas as ações horizontais. Os deslocamentos apresentam uma variação aproximadamente linear, confirmando que essa estrutura é mais deformável à flexão que ao cortante, ou seja, possui um comportamento mais próximo de uma viga engastada do que de um pórtico.

Quando localizado afastado do centro de gravidade do edifício, além dos esforços horizontais e verticais, o núcleo tem que absorver esforços de torção. Essas estruturas podem ser compostas por núcleo metálico aporticado, núcleo metálico treliçado, núcleo de concreto e núcleo misto aço e concreto.

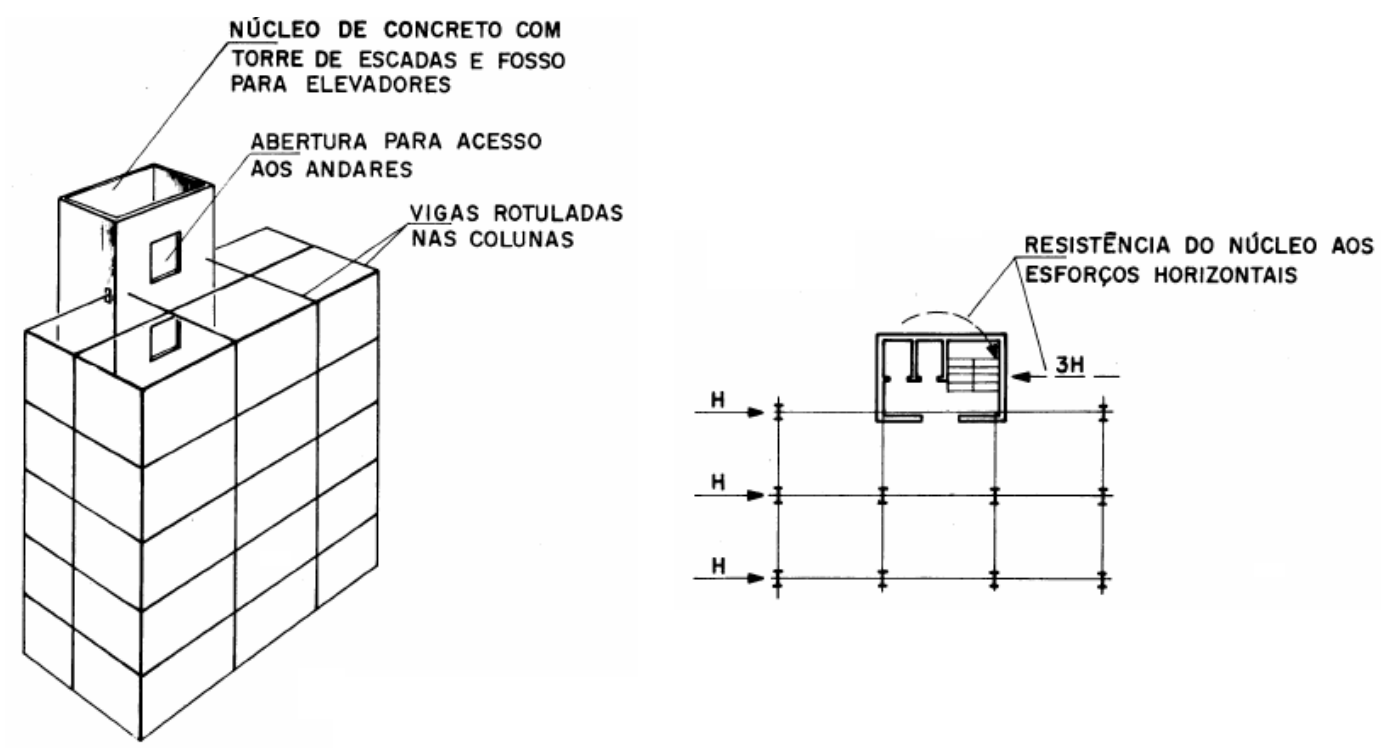

Figura 2.10 - Estrutura com núcleo de concreto armado (IBS/CBCA, 2004)

Edifícios com núcleo metálico aporticado normalmente originam estruturas com maior rigidez à flexão nos pilares e vigas dos quadros constituintes do núcleo e pilares e vigas leves nos pórticos dispostos em sua periferia. 
Outra maneira de buscar a eficiência do subsistema, proporcionando um consumo menor de aço, consiste em treliçar os pórticos constituintes do núcleo, transformando estes quadros em treliças verticais contínuas, do térreo a cobertura. Com a adição das diagonais de contraventamento há uma redução no peso dos pilares juntos ao núcleo seguida do aumento do peso da estrutura com as diagonais.

Subsistemas com núcleo de concreto armado evidentemente apresentam menor consumo de aço em relação aos anteriores, entretanto o consumo de concreto estrutural é bem maior e, além disso, esta solução onera as fundações, por causa do alto peso próprio do concreto das paredes que formam o núcleo estrutural.

Vale ressaltar nesse caso, a necessidade de se utilizar processos de construção que permitem execução rápida, para acompanhar a montagem da estrutura metálica, exigindo bastante atenção no cronograma da obra. Também cabe destacar, que embora prudentemente executado, o núcleo de concreto dificilmente atinge a precisão de fabricação das estruturas de aço, fato que exige cuidado especial nas ligações aço e concreto.

Os núcleos mistos geralmente são formados pelo quadro e a parede de concreto armado, assim obtém-se uma estrutura mais rígida que o subsistema simplesmente aporticado. Esse subsistema colabora com o cronograma da obra evitando os problemas do subsistema anterior. A estrutura de aço incorporada no núcleo é responsável pela estabilidade global da obra e pelas ações que ocorrem durante a construção.

Em geral, os edifícios com núcleos rígidos permitem a possibilidade de se empregar apenas ligações flexíveis. Dessa forma, elementos estruturais mistos, principalmente as vigas mistas, são bastante eficientes quando empregados a esses sistemas, uma vez que o concreto trabalha apenas a compressão.

\subsubsection{Estrutura tubular}

As estruturas tubulares é o resultado da evolução estrutural dos edifícios de grande altura, apresentando-se como uma solução estrutural bastante eficiente. Isso fica evidenciada pelo consumo de aço por metro cúbico de construção, chegando a 
ser comparado com o de prédios com a metade de sua altura, construídos segundo outros subsistemas estruturais (MD/SDI, 1989).

O principio básico dos prédios tubulares é a distribuição dos pilares e vigas principais ao longo das fachadas, funcionando como se fossem as paredes de um tubo oco em balanço, engastado no terreno. Estas paredes são constituídas por pilares em toda periferia, com pequeno espaçamento entre si, dispostos com o eixo de maior inércia no sentido do quadro, ligados por vigas de piso com elevada altura.

O edifício pode ser projetado de modo que todos os carregamentos horizontais sejam suportados pelas paredes externas do tubo e ainda de forma que o arranjo dos pilares e das vigas confere à estrutura uma rigidez à torção. Entre os subsistemas estruturais tubulares se destacam o tubo aporticado, tubo treliçado e tubo treliçado com pilares na Figura 2.11.

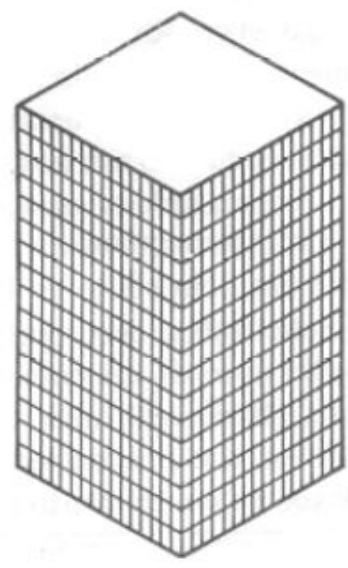

(a)

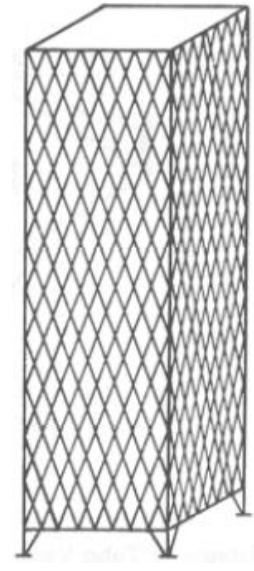

(b)

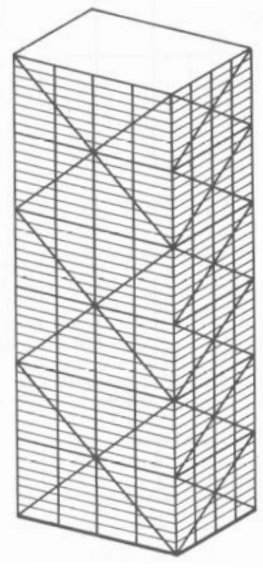

(c)

Figura 2.11 - Estrutura tubular: (a) tubo aporticado; (b) tubo treliçado; (c) tubo treliçado com pilares (MD/SDI,1989)

\subsubsection{SUBSISTEMAS ESTRUTURAIS HORIZONTAIS}

Esses subsistemas, composto de laje, vigamento e eventuais contraventamentos, trabalham predominantemente à flexão, devendo transmitir as ações gravitacionais até as vigas principais, aos pilares, ao núcleo ou as paredes de cisalhamento. Além disso, deve formar planos horizontais rígidos que distribuem as ações laterais entre os diversos subsistemas verticais resistentes, comportando-se como um diafragma. 
Denominam-se vigas principais aquelas que fazem parte do enrijecimento vertical do edifício e de secundárias as que se destinam apenas a suportar as ações verticais provenientes do piso. As vigas principais variam em função principalmente dos aspectos arquitetônicos e estruturais. Geralmente o vigamento do piso, quando dentro da compatibilidade dos vão econômico das lajes, torna-se mais econômico à medida que o percurso da carga até o pilar diminui.

Os dutos de utilidades possuem grande influência na distância entre os pisos. Para evitar o aumento da cota do piso, os dutos devem correr no mesmo plano das vigas principais interceptando-as e conduzindo a algumas alternativas, conforme a Figura 2.12.

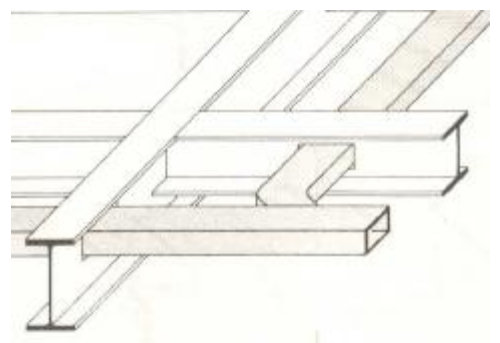

(a)

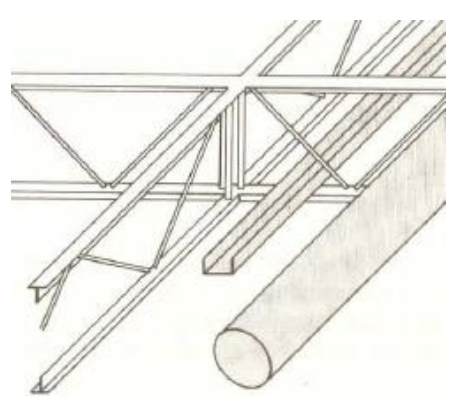

(b)

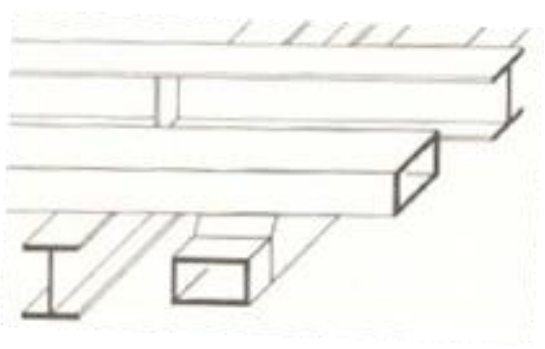

(c)

Figura 2.12 - Passagem de dutos nos subsistemas horizontais usuais: (a) abertura nas almas; (b) treliças de altura constante; (c) viga sobre viga (MD/SDI, 1989)

A laje com fôrmas de aço incorporada, caracterizando uma estrutura de lajes mistas, fornece vantagens sobre as pré-moldadas e fabricadas in loco, pois além da fôrma contribuir como armadura positiva, dispensa, em alguns casos, o escoramento e funciona como diafragma horizontal antes da concretagem. A Figura 2.13 mostra uma aplicação do sistema de lajes mistas em edifícios. 


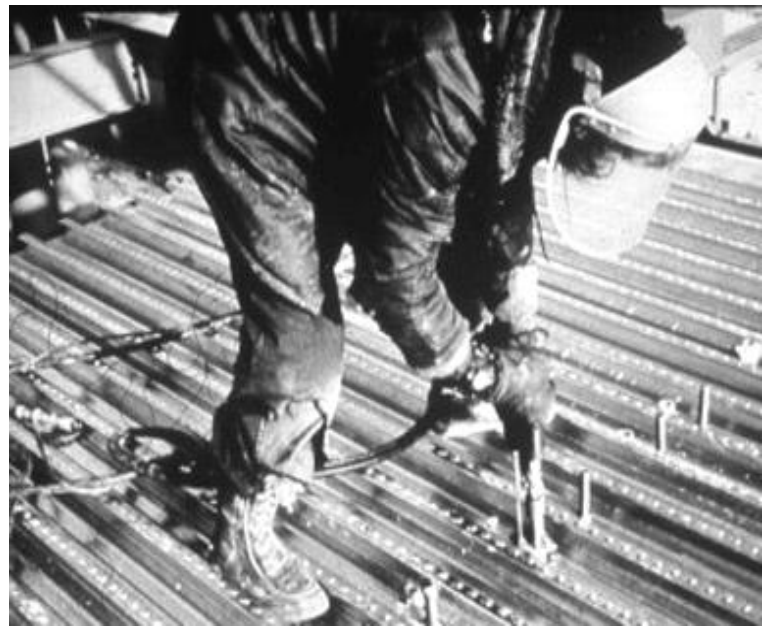

(a)

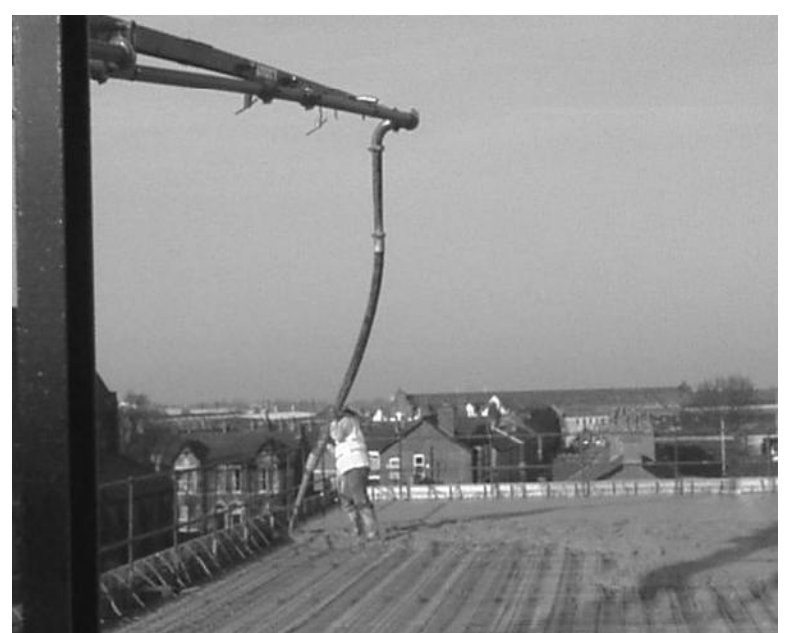

(b)

Figura 2.13 - Aplicação de laje mista: (a) conector de cisalhamento stud bolt; (b) concretagem

Outro fator relevante é a incorporação da resistência à compressão das lajes na resistência à flexão das vigas de aço, apresentando resultados estruturais e econômicos bastantes satisfatórios, o que justifica a viga mista ser aplicado em quase totalidade das construções atuais. Entretanto, essa solução estrutural pode conduzir a pisos bastante flexíveis que, dependendo da natureza de ocupação, podem apresentar vibrações acima do nível recomendado. Essas estruturas serão abordadas com maior precisão no capítulo 3.

\subsubsection{Lajes mistas com fôrma de aço incorporada ao concreto}

\subsection{Generalidades}

O emprego das lajes com fôrma de aço incorporada é uma alternativa atraente visto que permite a racionalização do processo construtivo e, por isso, são empregadas com sucesso em edificações industriais e urbanas, pontes, viadutos e obras diversas. Dentre as vantagens advindas do uso dessas fôrmas destacam-se as seguintes (MANUAL [...], 2007):

- Usualmente, dispensa o escoramento tornando o canteiro de obras mais organizado excluindo o tempo gasto com montagem e desmontagem dos escoramentos e desforma; 
- Durante a montagem transforma-se em plataforma de trabalho nos andares superiores e em proteção aos operários em serviço nos andares inferiores;

- São leves, de fácil manuseio e instalação;

- Permite fácil execução das diversas instalações e a fixação de forros suspensos;

- Elimina o emprego da madeira, que compõe uma parcela significativa do custo total de uma estrutura de concreto;

- Funciona como diafragma horizontal, travando as vigas perpendiculares a direção das nervuras da laje e acrescentando mais segurança ao trabalho durante a construção do edifício;

- Substitui a armadura de tração na laje na região de momento fletor positivo, resultando em economia de tempo, material e mão de obra.

O somatório dessas características acarreta em uma notável economia na construção, reduzindo prazos, desperdícios de materiais, custo com mão de obra e ainda incrementa a qualidade do produto final.

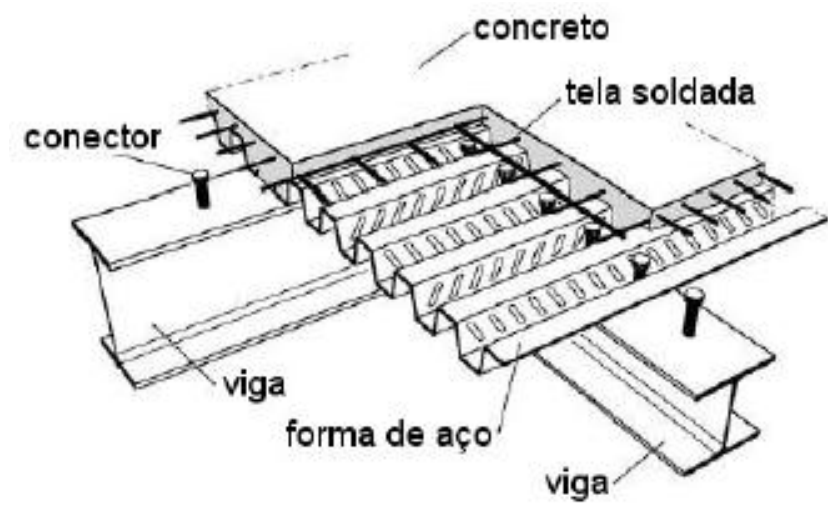

Figura 2.14 - Laje com fôrma de aço incorporada

As principais desvantagens da laje mista são: o emprego de forros suspensos, por razões estéticas e o aumento da quantidade de vigas secundárias, caso trabalhe com o sistema não escorado ou fôrmas de pequena altura, devido à limitação dos vãos antes da cura.

O dimensionamento das lajes mistas engloba a análise do sistema tanto na fase de construção, que seria a verificação da fôrma trabalhando isoladamente sob a 
ação do peso próprio do concreto fresco e a sobrecarga de construção, quanto na fase mista, após a resistência do concreto atingir a $0,75 f_{c k}$, quando a laje entra em serviço.

Vale ressaltar que, dentre os possíveis modos de ruína do sistema de laje mista, o estado limite último por cisalhamento longitudinal é o atingido com maior frequência (QUEIROZ; PIMENTA; DA MATA, 2001).

\subsubsection{Dimensionamento da laje antes da cura do concreto}

Segundo a ABNT NBR 8800:2008, deve ser utilizada análise elástica na determinação dos esforços solicitantes não apenas para os estados limites de utilização, mas também para os estados limites últimos. No cálculo das fôrmas contínuas, mesmo com a ocorrência de flambagem local nas partes comprimidas da seção, os esforços podem ser determinados sem consideração da variação da rigidez.

A consideração da rigidez uniforme é uma hipótese simplificadora a favor da segurança. Alternativamente, o cálculo pode ser feito por aproximações sucessivas, admitindo-se para cada incremento de carga, os valores de rigidez das seções efetivas. Apesar de bastante trabalhoso, em Johnson e Anderson (2004), constatase que este processo leva a uma redistribuição dos momentos sobre os apoios em torno de $5 \%$ a $15 \%$.

\subsection{Estados limites últimos}

A verificação da fôrma de aço na fase inicial deve ser realizada com base na ABNT NBR 14762:2010. O efeito das mossas deve ser considerado adequadamente nas resistências de cálculo.

\subsection{Estados limites de serviço}

Nesta fase, o estado limite de utilização a ser verificado, de acordo com a ABNT NBR 8800:2008, é o deslocamento máximo da fôrma sob seu peso próprio e o peso do concreto fresco, excluindo-se a sobrecarga de utilização. 


\subsection{Dimensionamento da laje após a cura do concreto}

A área da seção transversal da fôrma, necessária para a fase de construção, de acordo com Johnson (2004), é frequentemente mais do que suficiente para suprir a necessidade de armadura inferior da laje mista. Esse fato justifica o usual emprego das lajes biapoiadas.

\subsection{Estados limites últimos}

Os estados limites últimos a serem verificados são consolidados nos seguintes modos de colapso, ilustrado na Figura 2.15 a seguir (ABNT NBR 8800:2008):

- Seção crítica l: resistência ao momento fletor. Apresenta-se crítico quando o vão de cisalhamento é suficientemente grande.

- Seção crítica II: resistência ao cisalhamento longitudinal. Usualmente o estado limite das lajes mistas.

- Seção crítica III: resistência ao cisalhamento vertical. É crítico apenas em situações especiais, tais como, em lajes espessas de vão pequeno, submetidas a cargas elevadas.

- Perímetro crítico (Figura 2.15b): resistência à punção. Pode ser o estado limite critico se o perímetro da área carregada e a espessura da laje forem baixos e se a carga for suficientemente elevada. 


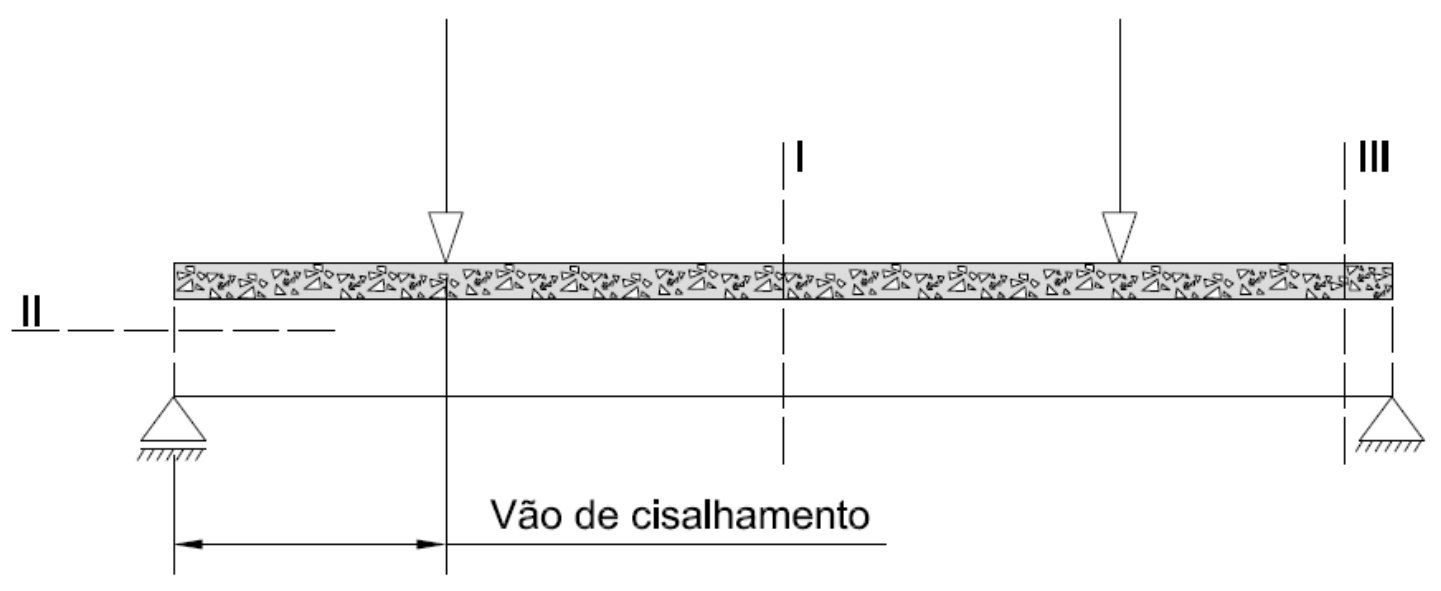

(a)
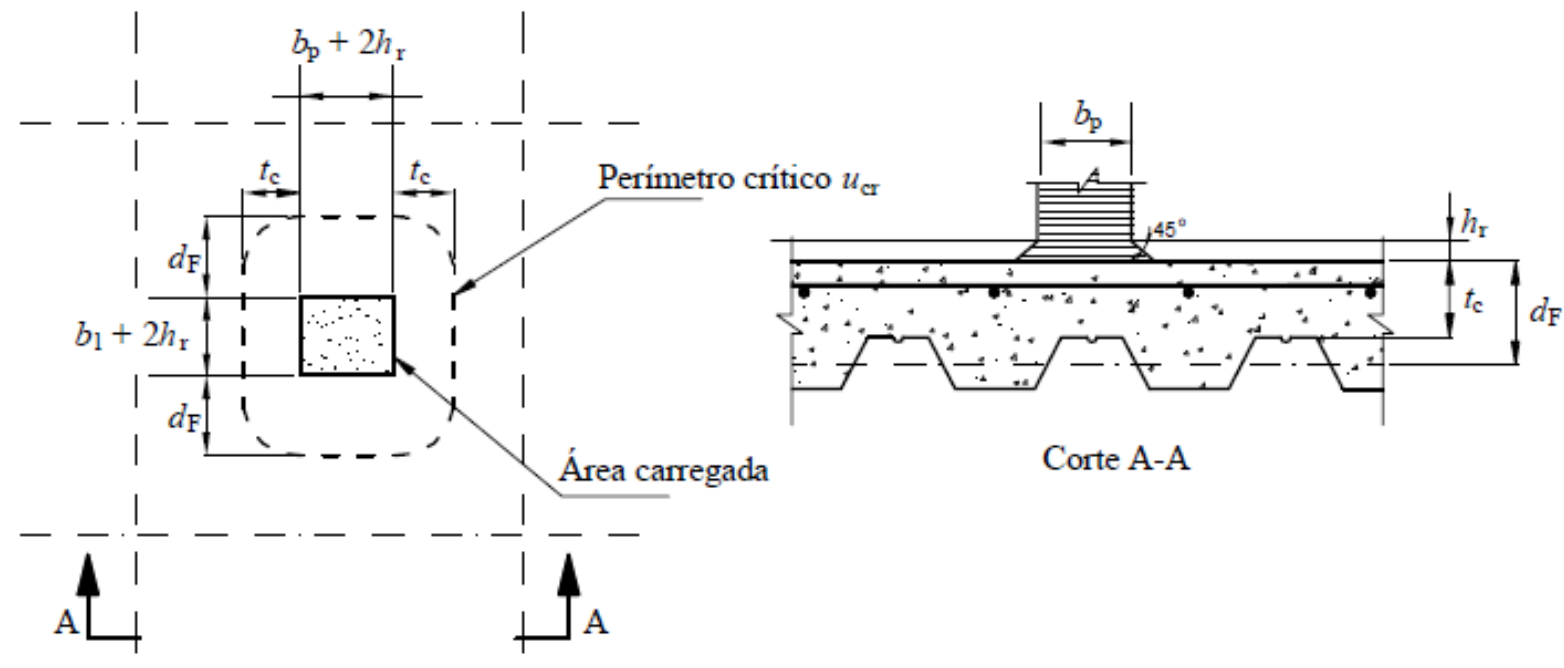

Corte A-A

(b)

Figura 2.15 - Estados limites últimos das lajes mistas: (a) seções críticas; (b) perímetro crítico para punção (ABNT NBR 8800:2008)

\subsection{Estados limites de serviço}

Nessa fase, conforme a ABNT NBR 8800:2008, dois estados limites de serviço devem ser verificados, a saber: estado limite de controle das fissuras e deslocamento vertical excessivo.

Nas lajes calculadas como simplesmente apoiadas, devem ser adicionadas armaduras nas duas direções, sobre toda extensão da superfície, para combater os efeitos de retração e temperatura. Apesar de essas lajes serem consideradas simplesmente apoiadas, o concreto é um material contínuo, precisando da adição de 
armadura para controlar as fissuras nos locais onde possa haver essa tendência, como, por exemplo, sobre os apoios, nas ligações de vigas secundárias com vigas principais e em relação a pilares.

Nas regiões de momento negativo de lajes contínuas o estado limite de fissuração deve ser verificado de acordo com a ABNT NBR 6118:2003, devendo ser atendido os estados limites de deformação, fissuração ou de descompressão e formação de fissuras (armadura ativa).

Para melhorar o desempenho e a dutilidade à flexão, assim como controlar a fissuração, é necessário atender valores mínimos de armadura passiva. E ainda, uma armadura máxima é especificada para se respeitar o campo de validade dos ensaios que originaram as prescrições do funcionamento do conjunto aço e concreto.

\subsection{Exemplo: Dimensionamento das lajes mistas de aço e concreto do Edifício Modelo 1}

O dimensionamento das lajes não é simples, depende de parâmetros obtidos experimentalmente, cuja inclusão na norma tem o importante papel de difusão do uso e de servir de base de indicação nos ensaios. A prática usual consiste em os próprios fabricantes encomendarem os ensaios e, apresentarem tabelas de uso prático específica para o produto.

Com a finalidade de trabalhar no capítulo 3 com o pré-dimensionamento das vigas mistas considerando a espessura do concreto e especificação da laje incorporada de acordo com as recomendações da ABNT NBR 8800:2008, as lajes mistas com fôrma de aço incorporada ao concreto foram dimensionadas para os estados limites últimos e de serviço verificados antes e após a cura do concreto segundo as tabelas do fabricante (Tabela 2.1) disponível em Metform (2011) e Manual [...] (2007). 
Tabela 2.1 - Cargas e vão máximos (METFORM, 2011)

\begin{tabular}{|c|c|c|c|c|c|c|c|c|c|c|c|c|}
\hline \multirow{3}{*}{$\begin{array}{c}\text { Altura } \\
\text { total da } \\
\text { laje } \\
(\mathrm{mm})\end{array}$} & \multirow{3}{*}{$\begin{array}{c}\text { Espessura } \\
\text { Steel Deck } \\
(\mathrm{mm})\end{array}$} & \multicolumn{4}{|c|}{ Vãos máximos sem escoramento } & \multirow{3}{*}{$\begin{array}{c}\text { Peso } \\
\text { próprio } \\
\left(\mathrm{kN} / \mathrm{m}^{2}\right)\end{array}$} & \multirow{3}{*}{$\begin{array}{c}\text { Momento de } \\
\text { inércia da } \\
\text { laje mista } \\
\left(10^{6} \mathrm{~mm}^{4} / \mathrm{m}\right)\end{array}$} & \multicolumn{5}{|c|}{ Vãos das lajes mistas com steel deck MF-75 (mm) } \\
\hline & & \multirow{2}{*}{$\begin{array}{c}\text { Simples } \\
(\mathrm{mm})\end{array}$} & \multirow{2}{*}{$\begin{array}{r}\text { Duplo } \\
\text { (mm) }\end{array}$} & \multirow{2}{*}{$\begin{array}{l}\text { Triplo } \\
(\mathrm{mm})\end{array}$} & \multirow{2}{*}{$\begin{array}{c}\text { Balanço } \\
(\mathrm{mm})\end{array}$} & & & $\cdots$ & 3.500 & 3.750 & 4.000 & $\ldots$ \\
\hline & & & & & & & & \multicolumn{5}{|c|}{ Carga sobreposta máxima $\left(\mathrm{kN} / \mathrm{m}^{2}\right)$} \\
\hline$\ldots$ & & & & & & & & $\ldots$ & & $\ldots$ & $\cdots$ & $\ldots$ \\
\hline \multirow{3}{*}{140} & 0,80 & 2.200 & 3.100 & 3.200 & 1.150 & 2,50 & 13,17 & $\ldots$ & 2,63 & 1,98 & 1,44 & $\ldots$ \\
\hline & 0,95 & 2.850 & 3.500 & 3.600 & 1.350 & 2,52 & 13,99 & $\ldots$ & 3,62 & 2,85 & 2,23 & $\ldots$ \\
\hline & 1,25 & 3.500 & 4.150 & 4.250 & 1.600 & 2,55 & 15,68 & $\ldots$ & 5,59 & 4,61 & 3,81 & $\ldots$ \\
\hline \multirow{3}{*}{150} & 0,80 & 2.000 & 3.000 & 3.100 & 1.100 & 2,74 & 16,06 & $\ldots$ & 2,90 & 2,18 & 1,59 & $\ldots$ \\
\hline & 0,95 & 2.650 & 3.400 & 3.500 & 1.300 & 2,75 & 17,04 & $\ldots$ & 3,98 & 3,14 & 2,45 & $\ldots$ \\
\hline & 1,25 & 3.400 & 4.000 & 4.100 & 1.550 & 2,79 & 19,05 & $\ldots$ & 6,15 & 5,07 & 4,19 & $\ldots$ \\
\hline$\ldots$ & $\ldots$ & $\ldots$ & $\ldots$ & $\ldots$ & $\ldots$ & $\ldots$ & $\ldots$ & $\ldots$ & $\ldots$ & $\ldots$ & $\ldots$ & $\ldots$ \\
\hline
\end{tabular}

Para a avaliação das ações que devem solicitar essa estrutura, tornam-se necessárias algumas suposições dos materiais de acabamento e serviços. Muitas dessas variáveis são definidas no projeto de arquitetura ou de serviços, porém, não fogem muito dos adotados nos subitens sequentes, retirados da ABNT NBR 6120:1980.

\subsection{Lajes do pavimento tipo}

Os valores das cargas máximas admissíveis à flexão na Tabela 2.1 consideram as lajes mistas isostáticas após a cura do concreto. Esses valores foram comparados com a soma de todas das cargas sobrepostas atuantes nessa fase, exceto o peso próprio das lajes (Tabela 2.2). Vale destacar, que os valores dessas ações, dispostas a seguir, não são majorados, pois essa consideração já foi realizada na tabela.

Tabela 2.2 Cargas atuantes no piso do pavimento tipo após a cura do concreto excluindo o peso próprio da laje mista de aço e concreto

\begin{tabular}{|c|c|}
\hline \multicolumn{2}{|c|}{ Carregamento permanente } \\
\hline Material & Pavimento tipo \\
\hline Argamassa de nivelamento & $0,57 \mathrm{kN} / \mathrm{m}^{2}$ \\
\hline Carpete & $0,05 \mathrm{kN} / \mathrm{m}^{2}$ \\
\hline Fôrros e serviços & $0,5 \mathrm{kN} / \mathrm{m}^{2}$ \\
\hline Divisórias móveis & $1,0 \mathrm{kN} / \mathrm{m}^{2}$ \\
\hline \multicolumn{2}{|c|}{ Sobrecarga de utilização } \\
\hline Escritório & $2,0 \mathrm{kN} / \mathrm{m}^{2}$ \\
\hline
\end{tabular}


Assim, o valor da carga sobreposta total para comparação na Tabela 2.1 é de $4,12 \mathrm{kN} / \mathrm{m}^{2}$. Esse valor induz o projetista a adotar a fôrma com nervuras de $75 \mathrm{~mm}$ de altura, 1,25 $\mathrm{mm}$ de espessura e altura total de $150 \mathrm{~mm}$, porém, na mesma tabela, o vão máximo sem escoramento para dimensiona-la como biapoiada é de $3400 \mathrm{~mm}$. Isso nos obrigaria utilizar escoramentos, o que inviabiliza, principalmente, o custo e o espaço disponível na obra.

Para vencer os $4000 \mathrm{~mm}$ que o projeto necessita, estudou-se a possibilidade de adotar lajes mistas contínuas. Segundo o Manual [...] (2007), é permitido o uso de um vão simplesmente apoiado equivalente para determinação da resistência. $O$ comprimento desse vão pode ser tomado igual a 0,8 e 0,9 vezes o vão real para os vãos internos e externos, respectivamente.

Como todas as lajes do piso desse projeto, simplificadamente, possuem o mesmo carregamento uniformemente distribuído sobre a superfície, o vão extremo demonstra-se crítico. A fôrma incorporada com altura total de $140 \mathrm{~mm}$, conforme a Tabela 2.1, é uma solução que atende o vão de 3600 mm sem adição de armadura positiva.

A capacidade de carga à flexão da seção armada nas regiões com continuidade estrutural foi verificada segundo a Tabela 2.3 disponível também em MANUAL [...] (2007) e elaborada conforme a ABNT NBR 6118:2003. Na formulação dessa tabela foram considerados telas soldadas em aço CA-60 ( $\left.f_{\mathrm{ys}}=600 \mathrm{MPa}\right)$ posicionadas a $20 \mathrm{~mm}$ do topo da superfície de concreto da laje. A indicação "X" da tabela corresponde à armadura em tela soldada.

Tabela 2.3 - Seções armadas: resistência ao momento fletor negativo (MANUAL, 2007)

\begin{tabular}{|c|c|c|c|c|c|c|c|c|c|}
\hline \multirow{2}{*}{$\begin{array}{c}\text { Altura total } \\
\text { da laje }\end{array}$} & \multicolumn{10}{c|}{ Armaduras em telas soldadas } \\
\cline { 2 - 11 }$(\mathbf{m m})$ & & $\mathbf{X ~ 7 5}$ & $\mathbf{X} \mathbf{9 2}$ & $\mathbf{X} \mathbf{1 1 3}$ & $\mathbf{X} \mathbf{1 3 8}$ & $\mathbf{X ~ 1 5 9}$ & $\mathbf{X ~ 1 9 6}$ & $\mathbf{X ~ 2 4 6}$ & $\mathbf{X ~ 2 8 3}$ \\
\hline $\mathbf{1 3 0}$ & $\mathbf{M}_{\mathbf{n}}{ }^{-}(\mathrm{kN} \cdot \mathrm{m} / \mathrm{m})$ & - & 3,64 & 4,43 & 5,35 & 6,11 & 7,42 & 9,12 & 10,32 \\
\hline $\mathbf{1 4 0}$ & $\mathbf{M}_{\mathbf{n}}{ }^{-}(\mathrm{kN} \cdot \mathrm{m} / \mathrm{m})$ & - & - & 4,85 & 5,87 & 6,71 & 8,15 & 10,03 & 11,37 \\
\hline $\mathbf{1 5 0}$ & $\mathbf{M}_{\mathbf{n}}{ }^{-}(\mathrm{kN} \cdot \mathrm{m} / \mathrm{m})$ & - & - & 5,27 & 6,38 & 7,30 & 8,88 & 10,95 & 12,43 \\
\hline $\mathbf{1 6 0}$ & $\mathbf{M}_{\mathbf{n}}{ }^{-}(\mathrm{kN} \cdot \mathrm{m} / \mathrm{m})$ & - & - & - & 6,90 & 7,89 & 9,61 & 11,87 & 13,48 \\
\hline $\mathbf{1 7 0}$ & $\mathbf{M}_{\mathbf{n}}{ }^{-}(\mathrm{kN} \cdot \mathrm{m} / \mathrm{m})$ & - & - & - & - & 8,48 & 10,34 & 12,78 & 14,54 \\
\hline $\mathbf{1 8 0}$ & $\mathbf{M}_{\mathbf{n}}{ }^{-}(\mathrm{kN} \cdot \mathrm{m} / \mathrm{m})$ & - & - & - & - & 9,08 & 11,07 & 13,70 & 15,59 \\
\hline $\mathbf{1 9 0}$ & $\mathbf{M}_{\mathbf{n}}{ }^{-}(\mathrm{kN} \cdot \mathrm{m} / \mathrm{m})$ & - & - & - & - & - & 11,80 & 14,62 & 16,65 \\
\hline $\mathbf{2 0 0}$ & $\mathbf{M}_{\mathbf{n}}{ }^{-}(\mathrm{kN} \cdot \mathrm{m} / \mathrm{m})$ & - & - & - & - & - & 12,53 & 15,53 & 17,70 \\
\hline
\end{tabular}


Na manipulação dessa tabela permite-se, simplificadamente, que o momento fletor negativo nominal $\left(\mathrm{M}_{\mathrm{n}}{ }^{-}\right)$seja tomado como a metade do momento fletor positivo no mesmo vão, porém biapoiado. Assim, o momento fletor nominal solicitante de $6,83 \mathrm{kNm} / \mathrm{m}$ para a laje com altura total de $140 \mathrm{~mm}$ é atendido com a tela soldada $X$ 196. Para definição do tipo de tela a ser usada basta verificar a área mínima de aço necessária no sentido paralelo às nervuras (ABNT NBR 6118:2003):

$\mathrm{A}_{\mathrm{S} . \min }=0,15 \% \mathrm{~b} \mathrm{~d}_{\mathrm{F}}$

$A_{\text {S.min }}=0,15 \% \times 1000 \times 102,5=153,75 \mathrm{~mm}^{2} / \mathrm{m}$

Sendo b a largura unitária da laje, tomada igual a $1000 \mathrm{~mm}$ e $\mathrm{d}_{\mathrm{F}}$ a distância da face superior da laje de concreto ao centro geométrico (centroide) da seção efetiva da fôrma.

Portanto, deverá ser adotada a tela M-196 (196 mm²/m de área de aço no sentido paralelo as nervuras e $98 \mathrm{~mm}^{2} / \mathrm{m}$ no sentido perpendicular), conforme a especificação do catálogo de telas soldadas (IBTS, 2011). Vale destacar que a taxa de armadura negativa adotada na viga mista representa a folga de armadura necessária no dimensionamento das lajes para momento negativo.

Analisando a fase construtiva da laje em questão, de acordo com a Tabela 2.1, o máximo vão duplo admissível é de $4150 \mathrm{~mm}$. Logo, o vão de $4000 \mathrm{~mm}$ suporta satisfatoriamente as cargas de construção da estrutura, sem que se faça necessário o uso de escoramentos.

Sendo assim, a laje mista adotada no pavimento tipo possui altura total de $140 \mathrm{~mm}$ e fôrma incorporada com 1,25 mm de espessura e $75 \mathrm{~mm}$ na altura das nervuras.

É importante salientar que as tabelas empregadas no dimensionamento das lajes, assim como no projeto, consideram o concreto estrutural com resistência à compressão $\left(f_{\mathrm{ck}}\right)$ igual a $2 \mathrm{kN} / \mathrm{cm}^{2}$. 


\subsection{Lajes da cobertura}

Devido a menor intensidade das ações que solicitam a cobertura, demonstradas abaixo, é possível dimensionar as lajes com menor resistência e consequentemente menor peso. A sequência do cálculo dessas lajes obedece à mesma tomada para as lajes do pavimento tipo.

Tabela 2.4 Cargas atuantes no piso da cobertura após a cura do concreto excluindo o peso próprio da laje mista de aço e concreto

\begin{tabular}{|c|c|}
\hline \multicolumn{2}{|c|}{ Carregamento permanente } \\
\hline Material & Pavimento tipo \\
\hline Impermeabilização & $0,75 \mathrm{kN} / \mathrm{m}^{2}$ \\
\hline Fôrros e serviços & $0,5 \mathrm{kN} / \mathrm{m}^{2}$ \\
\hline \multicolumn{2}{|c|}{ Sobrecarga de utilização } \\
\hline Cobertura & $2,0 \mathrm{kN} / \mathrm{m}^{2}$ \\
\hline
\end{tabular}

Para atender as ações acima, foi dimensionada uma laje mista simplesmente apoiada com altura total de $130 \mathrm{~mm}$ e fôrma incorporada com $1,25 \mathrm{~mm}$ de espessura e $75 \mathrm{~mm}$ na altura das nervuras. $\mathrm{Na}$ fase construtiva essa fôrma incorporada para vãos duplos atende um vão de $4300 \mathrm{~mm}$ e na fase final essa laje suporta uma carga sobreposta nominal de $3,42 \mathrm{kN} / \mathrm{m}^{2}$.

\subsection{COMBINAÇÕES DE AÇÕES}

A ABNT NBR 8800:2008 considera dois estados limites a serem verificados, estados limites últimos e estados limites de serviço. Os estados limites últimos estão relacionados com a segurança da estrutura sujeita às combinações mais desfavoráveis de ações previstas em toda a vida útil, durante a construção ou quando atuar uma ação especial ou excepcional. Já os estados limites de serviço referem-se ao desempenho da estrutura sob condições normais de utilização.

\subsubsection{COMBINAÇÕES ÚLTIMAS NORMAIS}

Exemplificando, as combinações últimas normais possíveis em um edifício de andares múltiplos submetido a basicamente três ações combinadas, a ação 
permanente devido o peso próprio $(G)$, as ações variáveis devido à ocupação $(Q)$ e o vento $(W)$, podem ser expressas da seguinte forma:

$C 1: 1,4 G+1,5 Q+1,4 \cdot 0,6 W$

$\mathrm{C} 2: 1,4 \mathrm{G}+1,4 \mathrm{~W}+1,5 \cdot 0,7 \mathrm{Q}$

Observa-se que as ações permanentes diretas desfavoráveis à segurança, simplificadamente, foram agrupadas, com coeficiente de ponderação igual a 1,4, válido quando as ações variáveis decorrentes do uso e ocupação forem inferiores a $5 \mathrm{kN} / \mathrm{m}^{2}$.

Nos casos em que as ações permanentes são favoráveis à segurança uma terceira combinação deve ser verificada:

C3: $1,0 \mathrm{G}+1,4 \mathrm{~W}$

Já no caso da ação variável devido ao vento favorável à segurança, verificase:

C4: $1,4 \mathrm{G}+1,5 \mathrm{Q}$

\subsubsection{COMBINAÇÕES DE SERVIÇO}

Para verificação dos estados limites de serviço, as combinações de serviço constatadas no dimensionamento dos edifícios de andares múltiplos são apresentadas na sequência.

\subsubsection{Combinação quase permanente de serviço}

Aplicadas para avaliar os efeitos de longa duração e para a aparência da estrutura. No caso de edifícios, resume-se a seguinte equação:

C5: $1 \mathrm{G}+0,4 \mathrm{Q}$ 


\subsubsection{Combinação frequente de serviço}

Utilizadas a estados limites reversíveis, ou seja, que não proporcionam danos permanentes à estrutura ou outros componentes do edifício, incluindo limites relacionados ao conforto do usuário e ao funcionamento de equipamentos, tais como vibrações excessivas, empoçamento em coberturas e abertura de fissuras. No caso desse trabalho, são avaliadas as seguintes expressões:

C6: $1 G+0,3 W+0,4 Q$

C7: $1 \mathrm{G}+0,3 \mathrm{~W}$

C8: $1 \mathrm{G}+0,6 \mathrm{Q}$

\subsubsection{Combinação rara de serviço}

Referentes aos estados limites irreversíveis, isto é, que trazem danos permanentes à estrutura ou outros componentes da edificação e para limites relacionados ao funcionamento adequado da estrutura, tais como danos a divisórias e fechamentos. Da mesma maneira que os demais casos chegam-se as seguintes expressões:

C9: $1 G+1 Q+0,3 W$

C10: $1 G+1 W+0,6 Q$

C11: $1 G+1 W$

$C 12: 1 G+1 Q$ 


\section{CAPÍTULO 3: VIGAS MISTAS DE AÇO E CONCRETO}

\subsection{GENERALIDADES}

As vigas mistas são constituídas pela associação de uma viga de aço com uma laje de concreto, ligadas por meio de conectores de cisalhamento soldados à mesa superior do perfil, de forma que trabalhem em conjunto para resistir à flexão.

Nos edifícios, o perfil I é o mais empregado nessas estruturas e são usualmente associados à laje de concreto conforme a Figura 3.1. Frequentemente, as lajes de concreto são moldadas in loco, com face inferior plana ou com fôrma de aço incorporada, ou ainda, podem ser formadas de elementos pré-moldados.

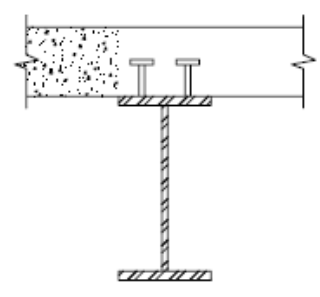

(a)

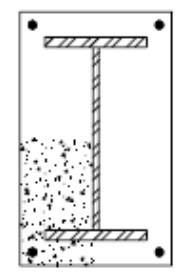

(c)

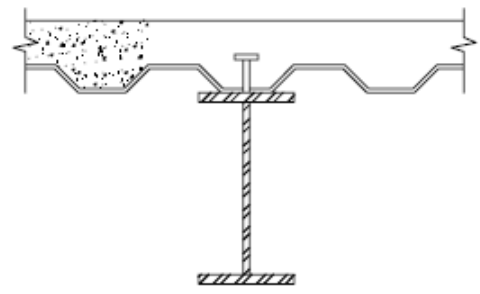

(b)

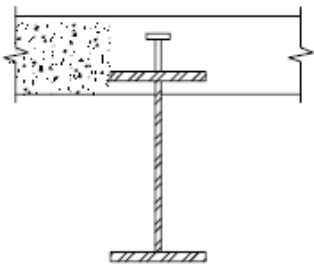

(d)

Figura 3.1- Tipos usuais de seções de viga mista: (a) laje com face interior plana; (b) laje com fôrma de aço incorporada; (c) viga de aço totalmente embutida no concreto; (d) vigas de aço parcialmente embutida no concreto (MALITE, 1990)

A ABNT NBR 8800:2008 aborda vigas mistas formadas por um componente de aço simétrico em relação ao plano de flexão, que pode ser um perfil I, caixão, tubular retangular ou uma treliça, com uma laje de concreto armado com ou sem forma de aço incorporada, posicionada acima de sua face superior. 
Uma das vantagens da utilização de vigas mistas em subsistemas de pisos é o acréscimo de resistência e de rigidez. Sistemas bem dimensionados, pela associação dos elementos de aço e de concreto, possibilita a redução da altura dos elementos estruturais, implicando em reduções de peso da ordem de 20 a 40\%. A principal desvantagem reside na necessidade de inserir conectores de cisalhamento na interface aço e concreto (QUEIROZ; PIMENTA; DA MATA, 2001).

\subsection{INTERFACE AÇO E CONCRETO}

A aderência natural entre os dois materiais, aço e concreto, e as forças de atrito presentes, normalmente, não são considerados nos cálculos (Figura 3.2a), embora possam atingir valores bastante elevados. O rompimento dessa aderência ocorre para valores de carga que variam em função de diversos fatores tais como: relação água e cimento, retração do concreto, tensões devido à variação de temperatura, falhas locais de contato, entre outras (QUEIROZ; PIMENTA; DA MATA, 2001).

Outro fator relevante que torna impraticável a contribuição da aderência nos cálculos de sistemas mistos é o rompimento pré-maturo da adesão química em ensaios dinâmicos ou com ciclos de carregamento e descarregamento. Assim, é necessário o emprego de conectores de cisalhamento para transmitir a força de cisalhamento na interface entre os dois materiais. Nesse caso, duas situações são estudadas: a interação completa e a interação parcial.

Quando o número de conectores for suficiente para absorver a totalidade do cisalhamento longitudinal na interface aço e concreto tem-se interação completa. Neste caso, o escorregamento longitudinal e o afastamento vertical relativo são desprezados. Dessa forma, segundo a distribuição de deformações, verifica-se a existência de uma única linha neutra, conforme apresentado na Figura 3.2b.

É possível utilizar um número menor de conectores, sem reduções significativas no momento resistente da seção mista, caracterizando uma interação parcial. Suas particularidades são o momento fletor resistente e rigidez a flexão da seção composta determinada pelo corte dos conectores e a existência de duas 
linhas neutras (Figura 3.2c) decorrentes ao escorregamento relativo na interface aço e concreto.

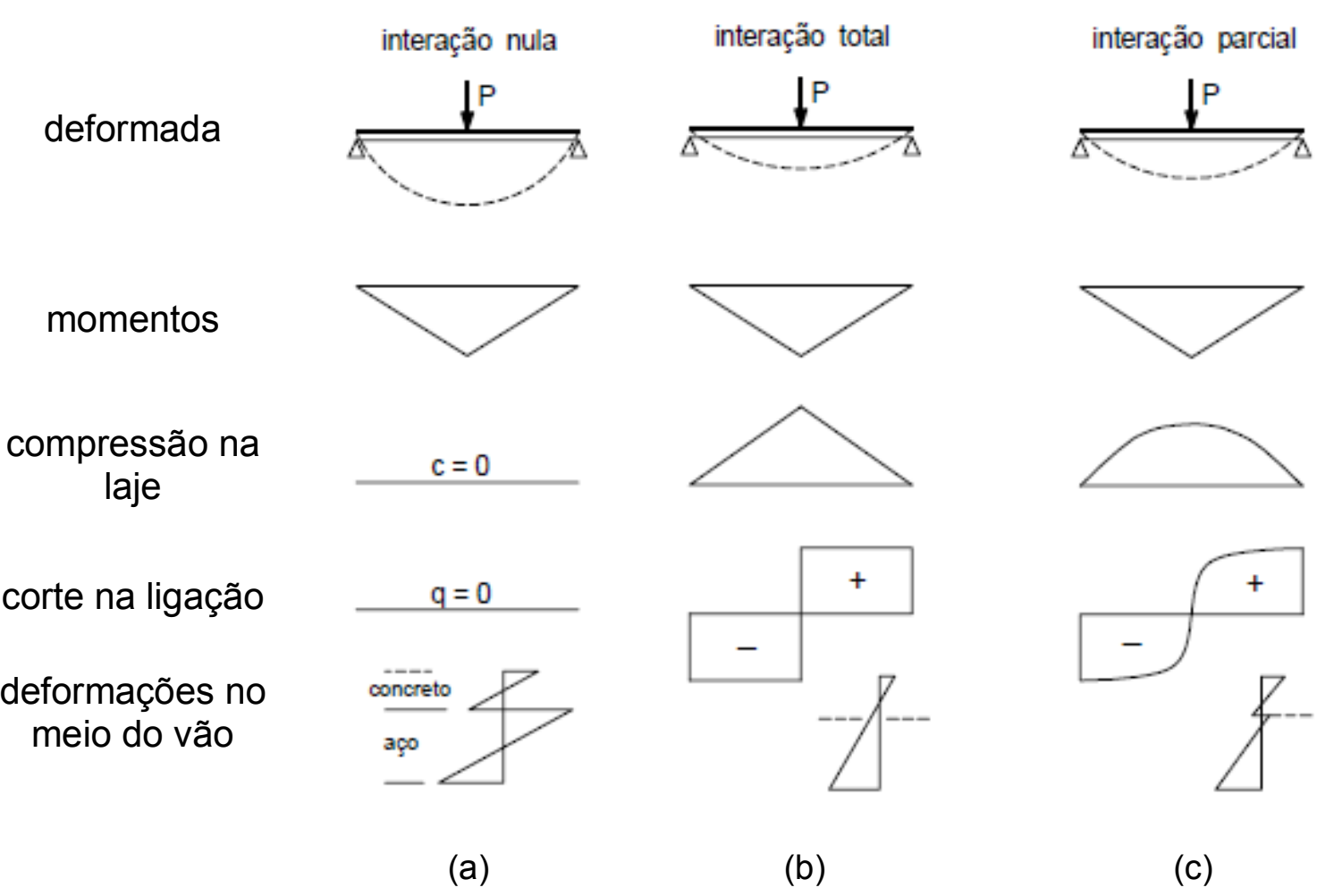

Figura 3.2 - Interação aço e concreto: (a) interação nula; (b) interação total; (c) interação parcial (ALVA, 2000)

O grau de interação aço e concreto é calculado pela seguinte relação:

$\eta_{\mathrm{i}}=\sum \mathrm{Q}_{\mathrm{Rd}} / \mathrm{F}_{\mathrm{hd}}$

Na expressão 3.1:

$\sum \mathrm{Q}_{\mathrm{Rd}}$ somatório das resistências de cálculo individuais dos conectores;

$\mathrm{F}_{\text {hd }}$ força de cisalhamento de cálculo entre o componente de aço e a laje, tomada pelo menor valor entre a força resistente de cálculo do concreto da laje e do perfil de aço. 
No caso das vigas mistas de alma cheia com perfil de mesas iguais, a ABNT NBR 8800:2008 recomenda que o grau de interação $\left(\eta_{i}\right)$ não seja inferior a:

$$
\begin{array}{ll}
\eta_{\mathrm{i}}=1-\frac{\mathrm{E}}{578 \mathrm{f}_{\mathrm{y}}}\left(0,75-0,03 \mathrm{~L}_{\mathrm{e}}\right) \geq 0,40 & \text { para } \mathrm{L}_{\mathrm{e}} \leq 25 \mathrm{~m} \\
\eta_{\mathrm{i}}=1 \text { (interação completa) } & \text { para } \mathrm{L}_{\mathrm{e}}>25 \mathrm{~m}
\end{array}
$$

Onde $\mathrm{L}_{\mathrm{e}}$ é o trecho de flexão positivo dado pela distância entre dois pontos de momento fletores nulos.

Dentre as causas que levam a maioria das vigas mistas de piso serem calculadas utilizando interação parcial entre os materiais componentes, pode-se destacar:

- a redução da resistência à flexão devido à interação parcial é menor do que a redução do número de conectores, ou seja, uma redução de $50 \%$ no número de conectores, por exemplo, reduz a resistência por volta de $20 \%$;

- sistemas construtivos não escorados, a bitola de aço necessária para resistir às cargas antes da cura do concreto, normalmente, não precisa da interação completa para resistir o carregamento como seção mista, exceto em casos de sobrecarga muito elevada.

Vale salientar, que o custo unitário $(\mathrm{R} \$ / \mathrm{kg})$ do conector instalado é superior ao do perfil, devendo o número de conectores, respeitar essa relação na busca de uma estrutura economicamente eficiente. Segundo Queiroz, Pimenta e Da Mata (2001), graus de interação da ordem de $70 \%$ a $90 \%$ são bastante interessantes do ponto de vista econômico.

\subsection{CONECTORES DE CISALHAMENTO}

Os conectores são classificados em flexíveis e rígidos. O conceito de rigidez, nesse caso, está relacionado pela capacidade de restrição ao escorregamento da ligação entre a viga de aço e laje de concreto. A Figura 3.3 apresenta os tipos de conectores flexíveis e rígidos mais utilizados. Dentre os flexíveis, os pinos com 
cabeça são os mais usuais. Isso se deve a facilidade de seu emprego nas vigas, através do processo de soldagem semiautomático.

CONECTORES FLEXIVEIS

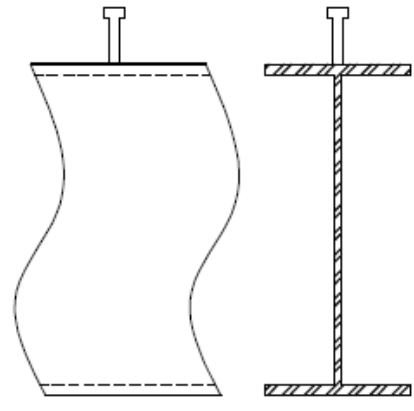

(a)

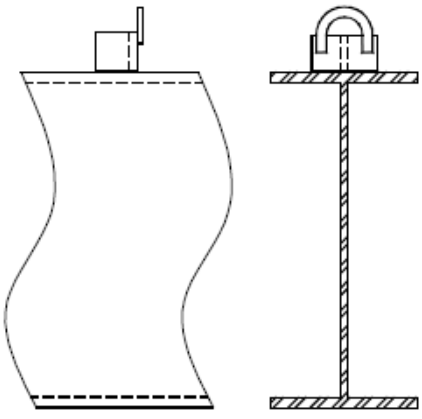

(d)

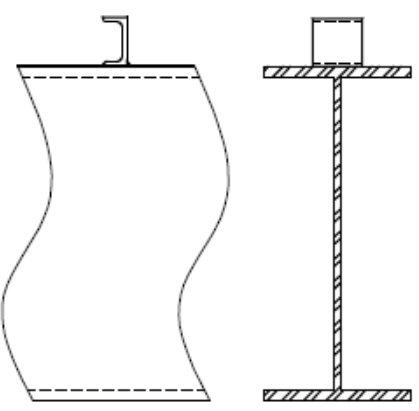

(b)

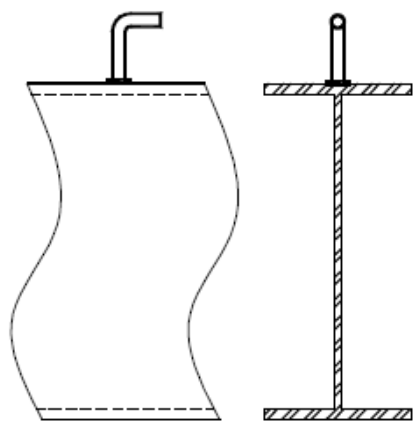

(c)

\section{CONECTORES RÍGIDOS}

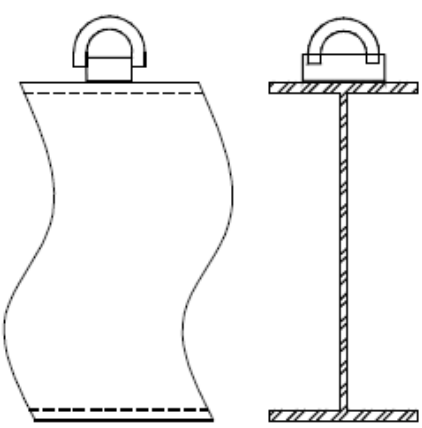

(e)

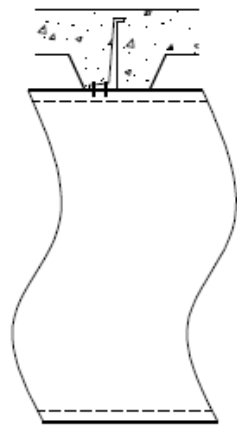

(f)

Figura 3.3 - Tipos usuais de conectores: (a) pino com cabeça; (b) perfil U laminado; (c) pino com gancho; (d) perfil "T" com gancho (preponderante em pontes); (e) barra chata com gancho (preponderante em pontes); (f) HVB da "Hilti" (fabricante) (FABRIZZI, 2007)

O aspecto estrutural mais importante dos conectores de cisalhamento é a relação existente entre a força de cisalhamento $(F)$ transmitida pelo conector e o escorregamento relativo (s) na interface aço e concreto, determinando seu comportamento dúctil. O diagrama típico de $\mathrm{F}$ x s (Figura 3.5) é obtido através do ensaio denominado push test (Figura 3.4), cujos procedimentos são trazidos pela EN 1994-1-1:2004. 

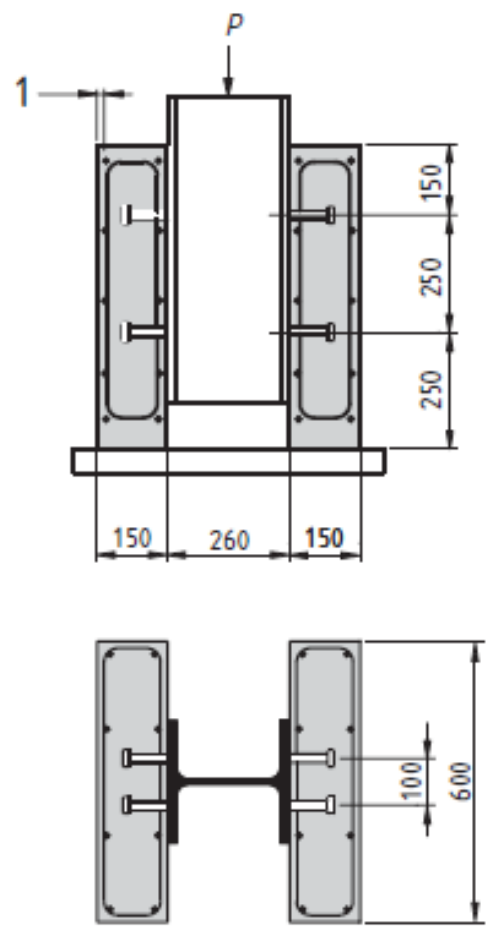

NUMERAÇÃO

1 Recobrimento $15 \mathrm{~mm}$

2 Assentamento em argamassa

3 Recuo opcional

4

Armadura:

$\Phi 10 \mathrm{~mm}, 45 \leq \mathrm{f}_{\mathrm{ys}} \leq 50 \mathrm{kN} / \mathrm{cm}^{2}$

Perfil de aço:

HE 260 ou $254 \times 254 \times 89$ kgf UC

Figura 3.4 - Padrão push test (EN 1994-1-1:2004)

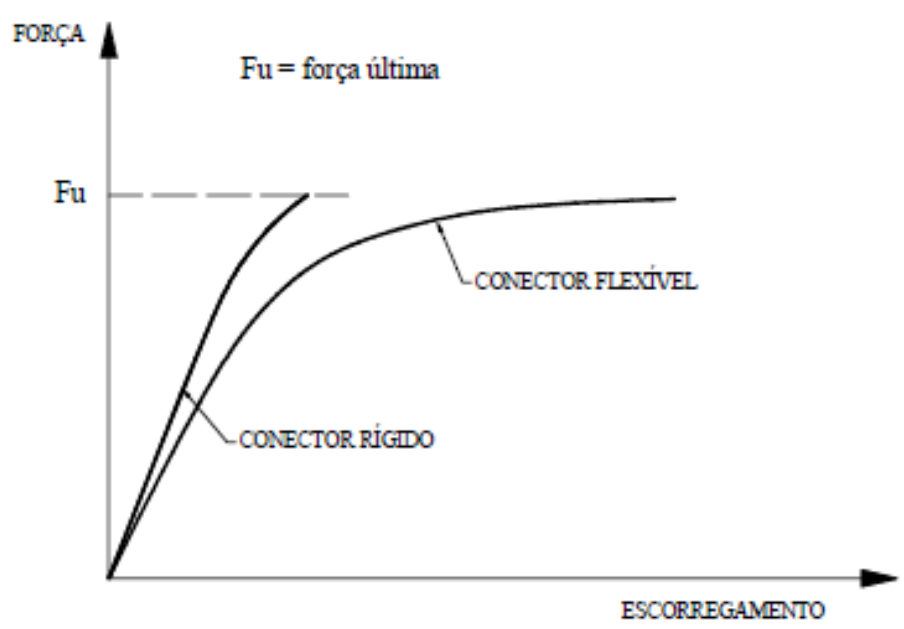

Figura 3.5 - Curva F x s para conectores de cisalhamento (ALVA, 2000)

$\mathrm{Na}$ prática, exceto nas regiões de carga concentrada, os conetores dúcteis podem ser uniformemente distribuídos na viga, e no caso de interação parcial, é permitido adotar a teoria plástica no cálculo da resistência da seção mista. A ABNT NBR 8800:2008 e a EN 1994-1-1:2004 não prescrevem a utilização de conectores 
rígidos por serem raramente aplicados em edifícios. Esses, usualmente aplicados em projetos de pontes, são abordados pelo BS 5400-5:1979.

Um fator determinante na ruptura da ligação da viga com a laje (Figura 3.6) é a resistência à compressão do concreto que influencia tanto o modo de colapso quanto a capacidade nominal do conector. A ruptura pode ocorrer por esmagamento da laje, em concretos de baixa resistência à compressão, enquanto que em concretos de alta resistência, predomina a ruptura por cisalhamento dos conectores.

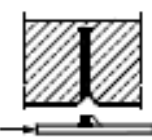

(a)

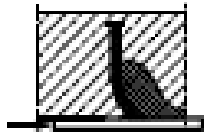

(b)

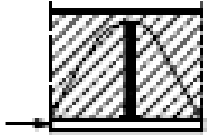

(c)

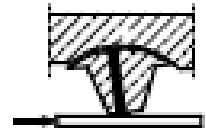

(d)

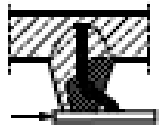

(e)

Figura 3.6 - Possíveis modos de colapso obtidos dos ensaios tipo push-out: (a) ruptura por cisalhamento do conector junto à solda; (b) esmagamento do concreto ao redor do conector; (c) arrancamento do concreto (forma de cone); (d) ruptura por cisalhamento da nervura de concreto; (e) fissuração do concreto da nervura devido à formação de rótulas plásticas (deformações excessivas do conector)

Além das forças de cisalhamento longitudinais, os conectores são submetidos a forças verticais que tendem separar os dois elementos componentes do sistema misto. Estas forças são muito menores do que aquelas, sendo a resistência dos pinos com cabeça, de praxe, não verificadas por possuírem dispositivos que garantem suficiente resistência às mesmas (JOHNSON; ANDERSON, 2004).

Para outros tipos de conectores, a EN 1994-1-1:2004 recomenda essa verificação para uma força correspondente a um décimo da resistência ao cisalhamento.

\subsection{SISTEMAS BIAPOAIDOS, CONTÍNUOS E SEMICONTÍNUOS}

As vigas mistas de alma cheia, as quais o componente de aço é um perfil I, podem ser dividas em biapoiadas, contínuas ou semicontínuas. As biapoiadas possuem as ligações vigas-pilares rotuladas. Os sistemas contínuos são formados por ligações de resistência total que são capazes de desenvolver a capacidade de resistência da viga. Já os sistemas semicontínuos, as ligações são de resistência parcial e suportam desenvolver apenas uma parcela da capacidade da viga. 
Usuais, as vigas mistas biapoiadas, apresentam exclusivamente momentos fletores positivos que contribuem para maior eficiência das estruturas mistas. Dentre as vantagens das vigas biapoiadas pode-se destacar (JOHNSON, 2004):

- normalmente, pequena parte da alma fica submetida à compressão e como a mesa comprimida é travada pela laje, a resistência da viga não é limitada pela flambagem do perfil de aço global ou local;

- a alma é sujeita a estados de tensão menos severos, possibilitando a execução de furos para passagem de dutos;

- os esforços de flexão e cortantes são estaticamente determinados e não são influenciados pela fissuração, retração ou deformação lenta do concreto;

- não há interação entre os comportamentos dos vão adjacentes;

- a transmissão de momentos para os pilares é baixa ou quase nula;

- a fibra extrema superior da laje de concreto é comprimida, exceto nos apoios devido à tendência de continuidade;

- apresenta análise estrutural mais simples e dimensionamento rápido.

As vigas mistas contínuas e semicontínuas, nas regiões de momento negativo, apresentam singularidades opostas às vigas biapoiadas, tais como, mesa de concreto tracionada e perfil de aço comprimido. A resistência do concreto a tração é desprezada devendo ser considerado apenas a armadura devidamente ancorada na laje.

Ainda nessa região, a laje de concreto apresentará fissuras, podendo atingir o estado limite de serviço. Já o perfil de aço, submetido à compressão, irá sofrer efeitos de instabilidade. A Figura 3.7 apresenta simplificadamente o comportamento dessas vigas nas regiões de momento positivo e negativo. 


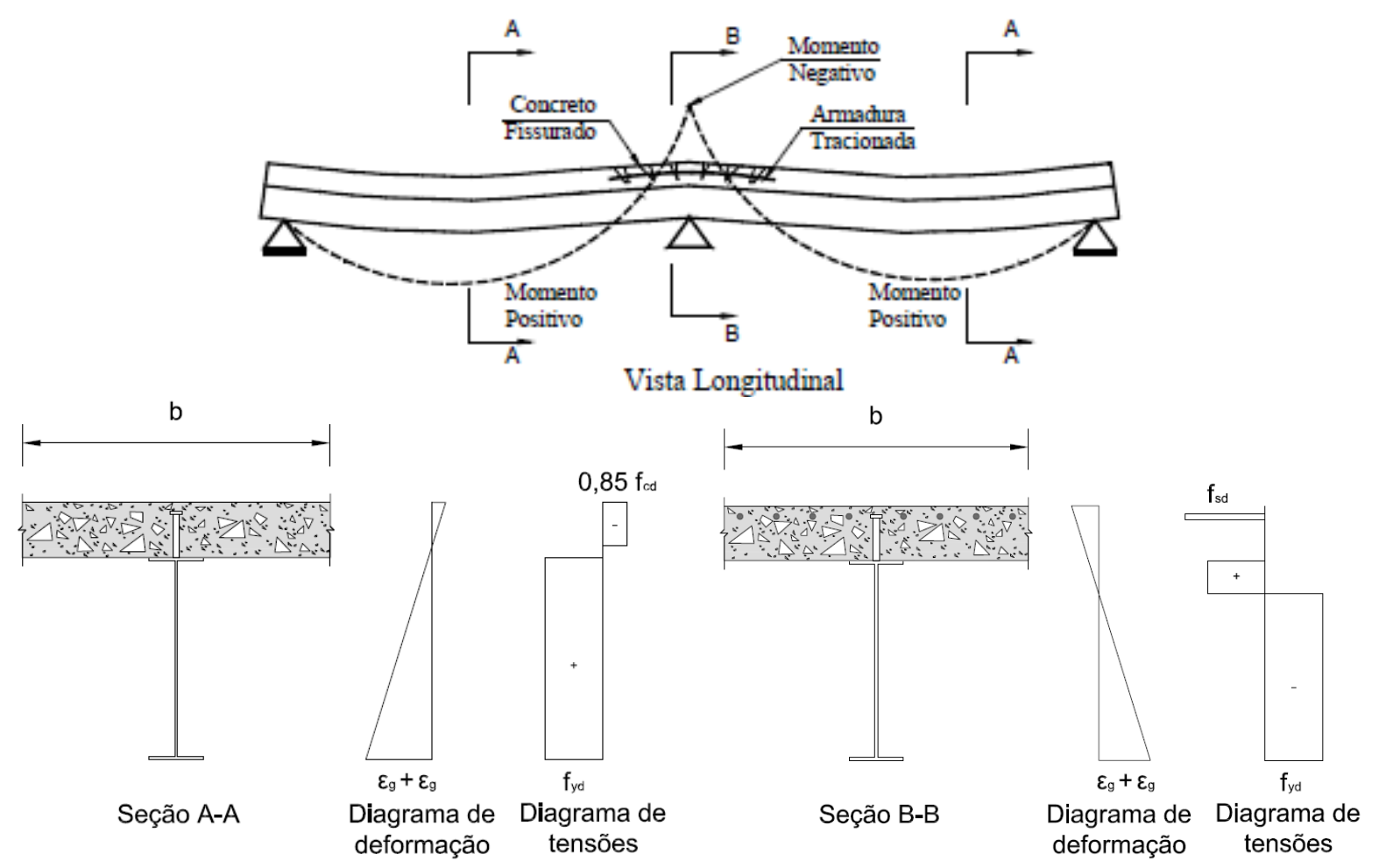

Figura 3.7 - Comportamento das vigas mistas contínuas nas regiões de momento positivo e negativo (FABRIZZI, 2007)

Generalizando, as vantagens das vigas contínuas e semicontínuas sobre as vigas biapoiadas, englobam (JOHNSON, 2004):

- maior relação vão/altura, redução de peso e consequentemente custos em sistemas bem dimensionados;

- maior controle de fissuração da superfície do concreto junto aos apoios;

- ganho de rigidez global da estrutura;

- frequência natural mais elevada e, consequentemente, baixa susceptibilidade a vibrações causadas pelo movimento de pessoas;

- resultam em estruturas mais robustas resistentes a efeitos de incêndio e explosão.

Comparando os sistemas contínuos e semicontínuos, pode-se ainda destacar que as vigas semicontínuas possuem melhor aproveitamento das seções mistas, tanto nas regiões de momento positivo quanto nas regiões de momento negativo e que suas ligações tem menor custo. 
Por outro lado, a continuidade desses sistemas requer o emprego de ligações mais complexas e onerosas e a análise estrutural torna-se mais trabalhosa, por se tratar de sistemas estaticamente indeterminados e com rigidez e resistência à flexão variável ao longo do comprimento de uma seção uniforme de aço devido à fissuração do concreto, mudanças da largura efetiva e variação na armadura longitudinal no concreto.

A determinação dos esforços e deslocamentos dessas vigas não é precisa. Além da variação ao longo do tempo causada pela fluência e retração do concreto, existem os efeitos da fissuração do concreto. Estes efeitos são influenciados pela sequência construtiva da laje, método construtivo das vigas e pelos efeitos da temperatura, retração e deslizamento longitudinal.

Vale ressaltar que a utilização de vigas mistas biapoiadas, semicontínuas ou contínuas dependerá da geometria do edifício, método de execução, sistema estrutural adotado, disponibilidade de materiais e serviços.

\subsection{SISTEMAS CONSTRUTIVOS}

As vigas mistas podem ser construídas com ou sem escoramento. Segundo a ABNT NBR 8800:2008, nas construções escoradas (Figura 3.8-b), o elemento estrutural deve entrar em serviço somente após o concreto atingir $75 \%$ da resistência característica à compressão, quando todas as ações, peso próprio (g) e sobrecargas (q), são suportados pela seção mista.

Escorada

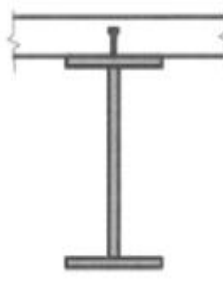

(a)

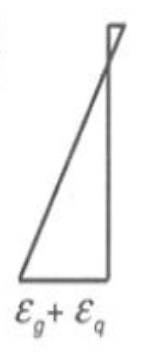

(b)

Não escorada

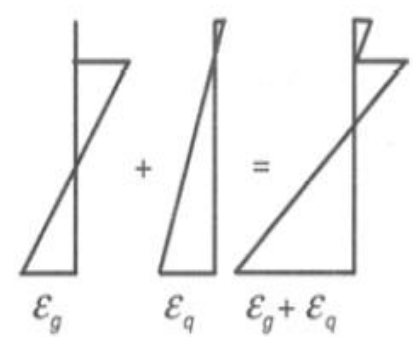

(c)

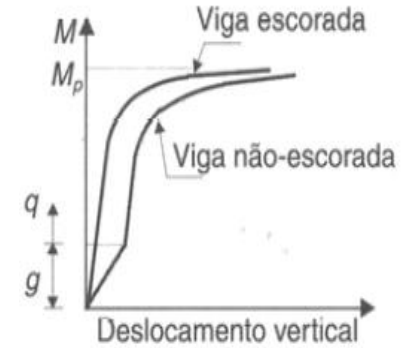

(d)

Figura 3.8 - Comportamento de vigas construídas com e sem escoramento: (a) viga mista; (b) diagrama de deformação na seção da viga escorada; (c) diagramas de deformação na seção da viga não escorada; (d) respostas das vigas em termos de deslocamentos verticais para ação de cargas crescentes (PFEIL, 2009) 
Nas construções não escoradas, a seção de aço deve ser dimensionada para as cargas de construção resultante do peso do concreto fresco (g) e sobrecarga construtiva. Após o endurecimento do concreto, a seção mista é finalmente submetida à aplicação das sobrecargas (q) e demais ações permanentes resultando no diagrama de deformações composto mostrado na Figura 3.8-c.

Nas construções escoradas os deslocamentos verticais devido à carga $\mathrm{g}$ (Figura 3.8-d) são inferiores aos das vigas não escoradas, uma vez que, naquelas todo carregamento $(g+q)$ é resistido pela seção mista. Entretanto, as tensões de plastificação desenvolvidas nas vigas mistas são as mesmas nos dois casos construtivos e, consequentemente, a seção composta atinge o mesmo momento fletor resistente.

Cabe destacar, que nas seções transversais de classe 1 ou 2 (seção compacta) em questão, toda carga de projeto atuante pode ser assumida resistida pela seção composta independente do sistema construtivo. Isso ocorre porque o comportamento inelástico que precede a ruptura à flexão da seção permite a redistribuição interna das tensões (JOHNSON, 2004).

Em decorrência do sistema construtivo, as viga não escoradas podem apresentar deslocamentos excessivos durante a construção ou em serviço. Por outro lado, eliminam os custos com escoramento e restrições do espaço disponível na obra.

\subsection{LARGURA EFETIVA}

O cálculo da máxima tensão de flexão em vigas é baseado na teoria elementar da flexão que supõe as tensões axiais não variam ao longo da mesa de uma viga. No entanto, à medida que nos afastamos do eixo da viga, ocorre a difusão das tensões axiais (efeito shear lag) o que torna necessário a substituição da largura real das mesas por uma largura reduzida, denominada largura efetiva (Figura 3.9), de forma que a referida teoria forneça o valor correto. 


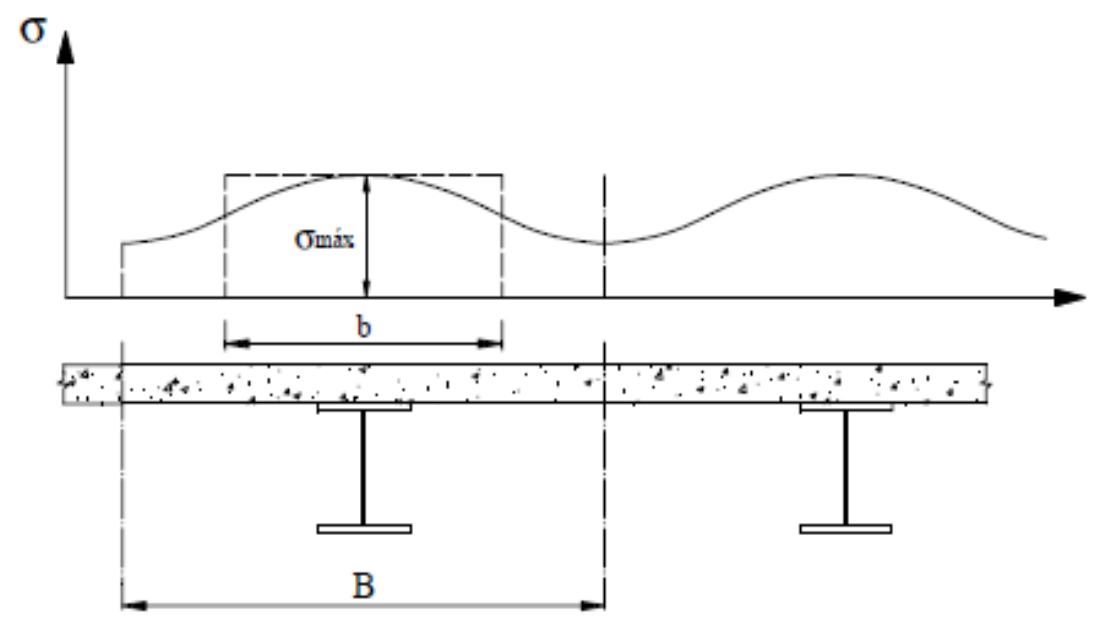

Figura 3.9 - Distribuição das tensões longitudinais (efeito Shear Lag) (ALVA, 2000)

O cálculo exato da largura efetiva é baseado na teoria da elasticidade e é muito trabalhoso, visto que depende de diversos fatores, tais como, condições de apoio; tipo do carregamento e, consequentemente, da distribuição de momentos; armadura longitudinal da laje de concreto; e relação espessura da laje e altura da viga.

Além desses fatores, a resolução das equações que regem o fenômeno inviabiliza seu cálculo em nível de projeto. Por esse motivo, o efeito shear lag é levado em consideração pela ABNT NBR 8800:2008 através de recomendações práticas conservadoras.

\subsection{EFEITOS DE LONGA DURAÇÃO DO CONCRETO}

O concreto das lajes, em decorrência das condições de cura e exposição, apresenta uma retração volumétrica após seu endurecimento, podendo exceder 0,03\% do seu comprimento em ambientes de edifícios quando não são restringidas. Nas vigas mistas o encurtamento do concreto é impedido pela seção metálica, resultando no perfil metálico esforço de flexo-compressão e na laje tração ambos desprezados no projeto (JOHNSON, 2004).

A fluência é usualmente relacionada com a redução do módulo de elasticidade do concreto em função do tempo. O concreto sob compressão resultante do momento fletor oriundo do carregamento sofre efeito de fluência deformando-se lentamente. 
As tensões pertinentes à retração desenvolvem-se lentamente, e são amenizadas pela fluência do concreto, porém a importância desses efeitos nos deslocamentos não deve ser desprezada, pois podem levar a um aumento significativo.

\subsection{ANÁLISE ESTRUTURAL E DIMENSIONAMENTO}

Esse item apresenta o procedimento de análise e dimensionamento das vigas mistas de alma cheia segundo as prescrições da ABNT NBR 8800:2008. As verificações do cisalhamento longitudinal, dos limites de vibração e do sistema semicontínuo não serão abordadas nessa pesquisa.

No APÊNDICE B é apresentado o cálculo de uma viga mista de alma cheia, contínua, não escorada, interação parcial e seção mista compacta. Trata-se de uma planilha eletrônica desenvolvida no Mathcad (PARAMETRIC TECHNOLOGY CORPORATION, 2007). O dimensionamento segue as recomendações da ABNT NBR 8800:2008 para a verificação dos estados limites últimos e de serviço.

\subsubsection{ESTADOS LIMITES ÚLTIMOS}

O cálculo de vigas mistas envolve a avaliação do seu desempenho segundo os seguintes estados limites últimos:

- resistência à flexão da seção mista e, no caso do sistema construtivo ser não escorado, da seção de aço durante a construção;

- resistência ao cisalhamento vertical;

- resistência ao cisalhamento longitudinal.

\subsubsection{Análise estrutural dos esforços}

$\mathrm{Na}$ determinação dos esforços solicitantes de cálculo pode-se utilizar a análise global plástica segundo o diagrama tensão-deformação rígido-plástica (análise rígido-plástica) ou a analise global elástica baseada no diagrama de tensãodeformação elástico-linear (análise elástica). Alternativamente, para as vigas mistas, 
a ABNT NBR 8800:2008 recomenda a análise elástica com redistribuição de momentos com base na EN 1994-1-1:2004.

A fissuração do concreto nas zonas tracionadas da seção transversal tem uma influência direta na análise elástica das estruturas mistas. Nas vigas mistas a rigidez a flexão de uma seção completamente fissuradas pode ser menor do que um quarto da rigidez da mesma seção não fissurada. Portanto, a variação da rigidez ao longo do comprimento de uma seção uniforme leva a incertezas na distribuição dos momentos e consequentemente na quantidade de fissuras (JOHNSON, 2004).

Por essas razões, e também por motivos econômicos, o cálculo é baseado na previsão da resistência última através de ensaios em vez de analises baseadas na teoria elástica. Assim, métodos foram desenvolvidos a partir do comportamento de modelos simplificados. A EN 1994-1-1:2004 traz um procedimento geral e um procedimento simplificado para considerar a perda de rigidez nas regiões de momento negativo.

O procedimento geral consiste, inicialmente, em determinar a envoltória de forças internas e os momentos para a combinação característica, dada pela formulação a seguir (EN 1990:2002), utilizando o modelo de análise não fissurado, ou seja, com a rigidez da seção não fissurada $\left(\mathrm{E}_{\mathrm{a}} \mathrm{I}_{1}\right)$.

$\sum_{j \geq 1} G_{k, j}+" P "+" Q_{k, 1} "+\sum_{i>1} \psi_{0, i} \cdot Q_{k, i}$

Da equação 3.4 , seguem:

G valor característico das ações permanentes;

Q valor característico das ações variáveis;

P valor característico do pré-esforço;

$\Psi_{0} \quad$ fator de combinação de uma ação variável (0,7 para sobrecarga de escritório).

Se nas regiões em que o concreto é tracionado, a tensão atuante na fibra extrema for maior que duas vezes a tensão média de ruptura do concreto à tração $\left(f_{c t m}\right)$, calculado pela equação 3.5 (EN 1992-1-1:2004), a rigidez precisa ser 
calculada desprezando o concreto tracionado e considerando a armadura $\left(\mathrm{E}_{\mathrm{a}} \mathrm{I}_{2}\right)$. Essa é a definição do modelo de análise fissurado.

$\mathrm{f}_{\mathrm{ctm}}=0,3 \mathrm{f}_{\mathrm{ck}}^{2 / 3}$

Simplificadamente, nas vigas mistas contínuas com relação dos vãos adjacentes, vão menor sobre vão maior, na região dos apoios superior a 0,6, considera-se a rigidez à flexão $\mathrm{E}_{\mathrm{a}} \mathrm{I}_{2}$ ao longo de $15 \%$ do vão para cada lado do apoio, e a rigidez não fissurada $E_{a} l_{1}$, nas demais regiões conforme ilustrado na Figura 3.10.
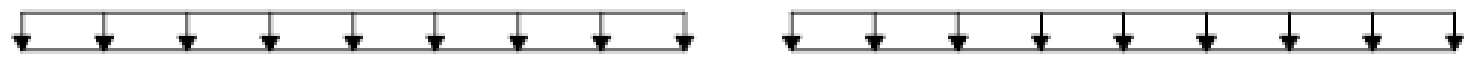

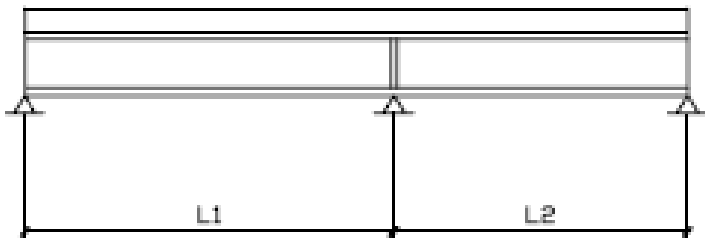

Rigidez à flexão

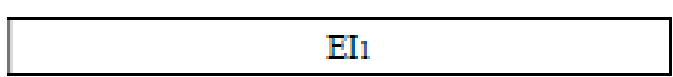

a) Seção "não-fissurada"

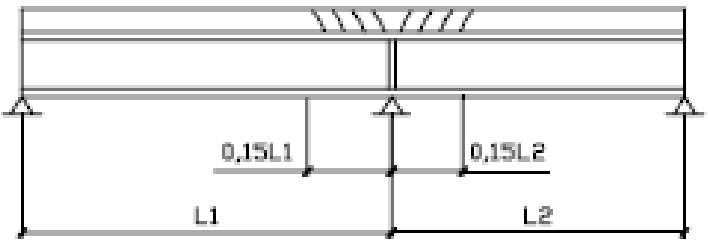

Rigidez à flexão

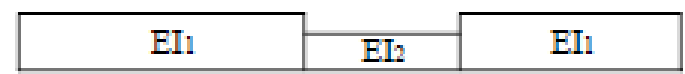

b) Seção "fissurada"

Figura 3.10 - Distribuição da rigidez a flexão adotada na análise elástica (ALVA, 2000)

Para levar em conta, de forma aproximada, os efeitos da fissuração do concreto, do comportamento inelástico dos materiais e da flambagem local dos elementos de aço, os momentos negativos obtidos após o processamento da análise elástica, podem ser redistribuídos, mantendo-se, porém, o equilíbrio entre as ações aplicadas e os esforços internos.

A redistribuição dos momentos sobre o apoio está limitada às percentagens dadas na Tabela 3.1. 
Tabela 3.1 - Limite de redistribuição dos momentos negativos, porcentagem de redução do momento fletor inicial (EN 1994-1-1:2004)

\begin{tabular}{|c|c|c|c|c|}
\hline $\begin{array}{c}\text { Classe da seção na região } \\
\text { de momento negativo }\end{array}$ & 1 & 2 & 3 & 4 \\
\hline $\begin{array}{c}\text { Modelo de análise } \\
\text { não-fissurado }\end{array}$ & 40 & 30 & 20 & 10 \\
\hline $\begin{array}{c}\text { Modelo de análise } \\
\text { fissurado }\end{array}$ & 25 & 15 & 10 & 0 \\
\hline
\end{tabular}

De acordo com a Tabela 3.1, a redistribuição dos momentos é realizada para quatro classes, a saber:

- classe 1: seções capazes de formar uma rótula plástica com capacidade de rotação necessária para uma análise plástica sem a redução da sua resistência;

- classe 2: seções capazes de atingir a resistência plástica à flexão, porém com a capacidade de rotação limitada pela flambagem local;

- classe 3: seções em que a tensão na fibra extrema comprimida, calculada com base numa distribuição elástica de tensões, pode atingir a resistência de escoamento, porém a flambagem local pode impedir o desenvolvimento da resistência plástica à flexão;

- classe 4: seções em que a flambagem local ocorre antes que a tensão de escoamento seja atingida em pelo menos um dos elementos dos perfis de aço.

Essa classificação obedece aos limites máximos das relações largura e espessura dos elementos prescritos pela EN 1993:2005.

Em uma adaptação à classificação adotada pela ABNT NBR 8800:2008 podese afirmar para as solicitações à flexão que as seções compactas englobam os elementos das classes 1 e 2 , enquanto que a seções semicompactas e esbeltas englobam as seções das classes 3 e 4 , respectivamente. 
Já a análise elástica dos esforços e deslocamentos recomendada pelo ANSI/AISC 360-10 considera a perda de rigidez nas regiões de momento negativo através de uma rigidez constante calculada pela média ponderada dos momentos de inércias correspondentes às regiões de flexão positiva $\left(\mathrm{I}_{\text {pos }}\right)$ e negativa $\left(\mathrm{I}_{\text {neg }}\right)$, tomada da seguinte forma:

$\mathrm{I}_{\mathrm{t}}=\mathrm{aI}$ pos $+\mathrm{bI}_{\text {neg }}$

Para as vigas contínuas sujeitas apenas a ações gravitacionais, o valor de a é tomado por 0,6 e o valor de b é tomado por 0,4. Nos casos em que as vigas mistas compõem o sistema estabilizante lateral, os valores de a e b nos cálculos relativos ao vento devem ser iguais a 0,5 .

\subsubsection{Resistência à flexão na região de momentos fletores positivos}

A ABNT NBR 8800:2008 aborda a resistência à flexão na região de momento positivo de vigas mistas com alma cheia cujo parâmetro de esbeltez é inferior a $3,76 \sqrt{E / f_{y}}$ (seções compactas) ou entre esse limite e 5,70 $\sqrt{E / f_{y}}$ (seções semicompactas). Seções que as almas flambam ainda no regime elástico não são aplicáveis às vigas mistas.

A norma fornece a resistência à flexão para sistemas contínuos, semicontínuos e biapoiados. No caso das vigas com ligações parciais, a resistência é multiplicada pelo coeficiente $\beta_{\mathrm{vm}}$ tomado igual a $0,85,0,90$ e 0,95 conforme a capacidade de rotação necessária para a ligação. Nos demais casos $\beta_{\mathrm{vm}}=1,0$.

O grau de interação entre os materiais também deve ser considerado nesse cálculo.

A Figura 3.11 apresenta a distribuição das tensões nas seções mistas compactas conforme a interação aço e concreto empregado de forma a ilustrar a formulação apresentada nesse item. Valem destacar as duas linhas neutras plásticas decorrentes da interação parcial aço e concreto na seção. 


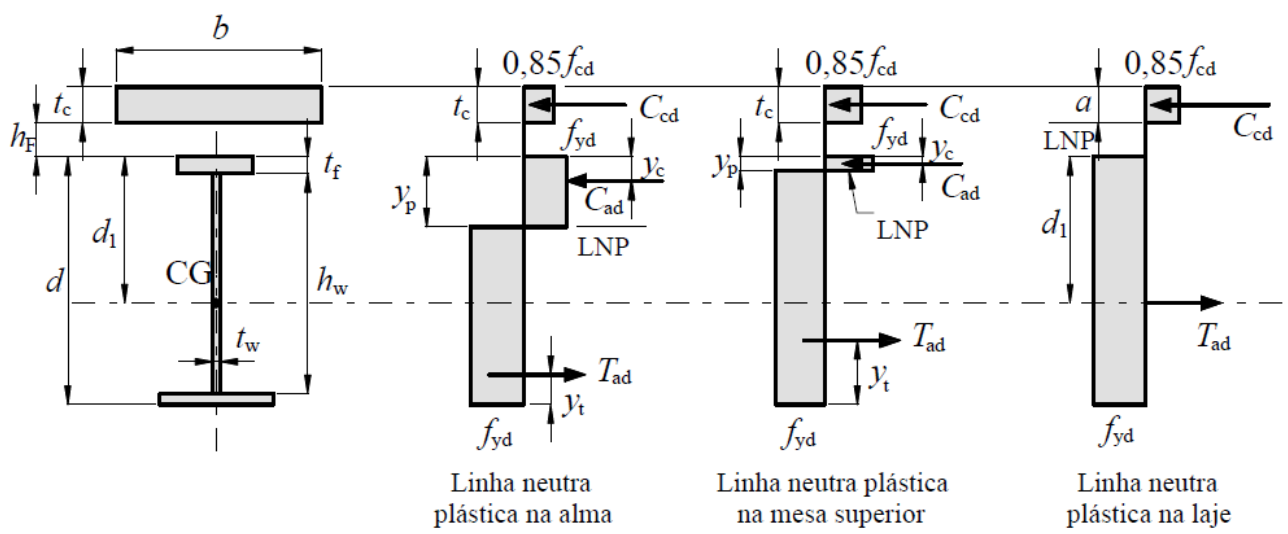

(a)

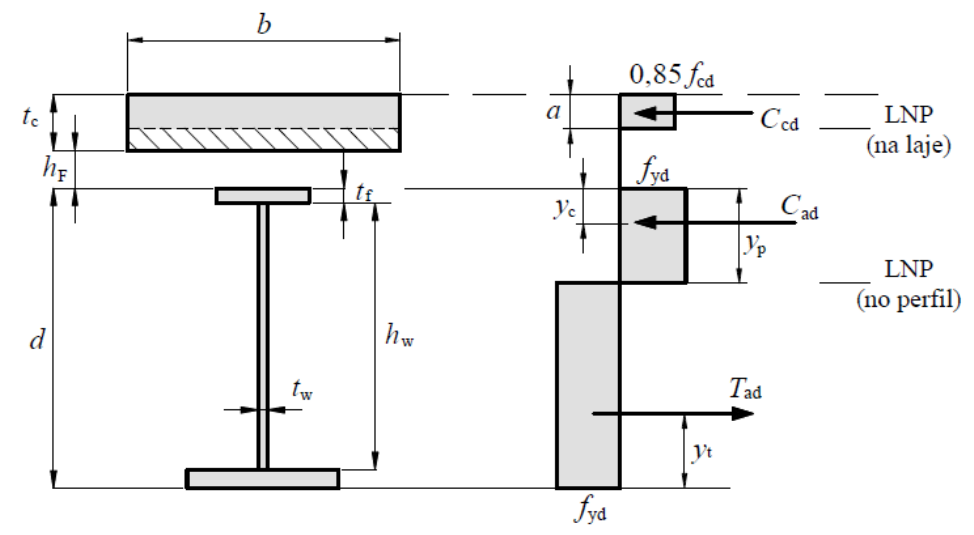

(b)

Figura 3.11 - Distribuição de tensões em vigas mistas de alma cheia compacta sob momento positivo: (a) interação completa; (b) interação parcial (ABNT NBR 8800:2008)

Neste capítulo, a maioria das fórmulas é apresentada em termos das resistências de cálculo dos materiais baseadas na Tabela 3.2, dada por:

- Aço dos perfis:

$$
\mathrm{f}_{\mathrm{yd}}=\frac{\mathrm{f}_{\mathrm{y}}}{\gamma_{\mathrm{a} 1}}
$$

- Aço da fôrma de aço incorporada: $\mathrm{f}_{\mathrm{yFd}}=\frac{\mathrm{f}_{\mathrm{yF}}}{\gamma_{\mathrm{a} 1}}$

- Aço das barras da armadura:

$$
\mathrm{f}_{\mathrm{sd}}=\frac{\mathrm{f}_{\mathrm{ys}}}{\gamma_{\mathrm{s}}}
$$

- Concreto:

$$
\mathrm{f}_{\mathrm{cd}}=\frac{\mathrm{f}_{\mathrm{ck}}}{\gamma_{\mathrm{s}}}
$$


Tabela 3.2 - Valores dos coeficientes de ponderação das resistências das combinações normais (ABNT NBR 8800:2008)

\begin{tabular}{|c|c|c|c|c|c|}
\hline Material & $\begin{array}{c}\text { Escoamento, } \\
\text { flambagem e } \\
\text { instabilidade do } \\
\text { aço estrutural }\end{array}$ & Conectores & $\begin{array}{c}\text { Fôrma de aço } \\
\text { incorporada }\end{array}$ & Aço da armadura & Concreto \\
\hline Simbologia & $\gamma_{\mathrm{a} 1}$ & $\gamma_{\mathrm{a} 1}$ & $\gamma_{\mathrm{a} 1}$ & $\gamma_{\mathrm{s}}$ & $\gamma_{\mathrm{c}}$ \\
\hline $\begin{array}{c}\text { Combinação } \\
\text { normal }\end{array}$ & 1,10 & 1,10 & 1,10 & 1,15 & 1,40 \\
\hline
\end{tabular}

\subsection{Construção escorada}

\subsection{Viga mista de alma cheia com $h / t_{w} \leq 3,76 \sqrt{E / f_{y}}$}

- Interação completa e linha neutra plástica na laje

Comportamento das forças resistentes:

$\sum Q_{R d} \geq A_{a} f_{y d}$ e $0,85 f_{c d} b_{p} t_{c} \geq A_{a} f_{y d}$

Satisfeitas essas condições:

$\mathrm{C}_{\mathrm{cd}}=0,85 \mathrm{f}_{\mathrm{cd}} \mathrm{b}_{\mathrm{p}} \mathrm{a}$

$\mathrm{T}_{\mathrm{ad}}=\mathrm{A}_{\mathrm{a}} \mathrm{f}_{\mathrm{yd}}$

$\mathrm{a}=\frac{\mathrm{T}_{\mathrm{ad}}}{0,85 \mathrm{f}_{\mathrm{cd}} \mathrm{b}_{\mathrm{p}}}$

$\mathrm{M}_{\mathrm{Rd} . \mathrm{p}}=\beta_{\mathrm{vm}} \mathrm{T}_{\mathrm{ad}}\left(\mathrm{d}_{1}+\mathrm{h}_{\mathrm{F}}+\mathrm{t}_{\mathrm{c}}-\frac{\mathrm{a}}{2}\right)$

- Interação completa e linha neutra plástica no perfil

Comportamento das forças resistentes:

$\sum Q_{R d} \geq 0,85 f_{c d} b_{p} t_{c}$ e $A_{a} f_{y d} \geq 0,85 f_{c d} b_{p} t_{c}$ 
Satisfeitas as condições:

$\mathrm{C}_{\mathrm{cd}}=0,85 \mathrm{f}_{\mathrm{cd}} \mathrm{b}_{\mathrm{p}} \mathrm{t}_{\mathrm{c}}$

$\mathrm{C}_{\mathrm{ad}}=\frac{1}{2}\left(\mathrm{~A}_{\mathrm{a}} \mathrm{f}_{\mathrm{yd}}-\mathrm{C}_{\mathrm{cd}}\right)$

$\mathrm{T}_{\mathrm{ad}}=\mathrm{C}_{\mathrm{cd}}+\mathrm{C}_{\mathrm{ad}}$

A posição da linha neutra plástica medida a partir do topo pode ser determinada da seguinte forma:

Para a linha neutra na mesa superior, ou seja, $C_{a d} \leq A_{a f} f_{y d}$ :

$\mathrm{y}_{\mathrm{p}}=\frac{\mathrm{C}_{\mathrm{ad}}}{\mathrm{A}_{\mathrm{af}} \mathrm{f}_{\mathrm{yd}}} \mathrm{t}_{\mathrm{f}}$

Para a linha neutra na alma, ou seja, $\mathrm{C}_{\mathrm{ad}}>\mathrm{A}_{\mathrm{af}} \mathrm{f}_{\mathrm{yd}}$ :

$y_{p}=t_{f}+h_{w}\left(\frac{C_{a d}-A_{a f} f_{y d}}{A_{a w} f_{y d}}\right)$

Dessa forma, o momento fletor resistente de cálculo é dado por:

$M_{\text {Rd.p }}=\beta_{v m}\left[C_{a d}\left(d-y_{t}-y_{c}\right)+C_{c d}\left(\frac{t_{c}}{2}+h_{F}+d-y_{t}\right)\right]$

- Interação parcial

Comportamento das forças resistentes:

$\sum \mathrm{Q}_{\mathrm{Rd}}<\mathrm{A}_{\mathrm{a}} \mathrm{f}_{\mathrm{yd}}$ e $\sum \mathrm{Q}_{\mathrm{Rd}}<0,85 \mathrm{f}_{\mathrm{cd}} \mathrm{b}_{\mathrm{p}} \mathrm{t}_{\mathrm{c}}$

Atendida essas condições e o grau de interação mínimo da viga mista (equações 3.2 e 3.3), tem-se $C_{c d}=\sum Q_{R d}$. As expressões 3.12, 3.13 e 3.14 em conjunto com a nova definição de $C_{c d}$ são válidas na determinação de $C_{a d}, T_{a d}$ e $y_{p}$. 
O momento fletor resistente de cálculo é dado por:

$$
\mathrm{M}_{\text {Rd.p }}=\beta_{\mathrm{vm}}\left[\mathrm{C}_{\mathrm{ad}}\left(\mathrm{d}-\mathrm{y}_{\mathrm{t}}-\mathrm{y}_{\mathrm{c}}\right)+\mathrm{C}_{\mathrm{cd}}\left(\mathrm{t}_{\mathrm{c}}-\frac{\mathrm{a}}{2}+\mathrm{h}_{\mathrm{F}}+\mathrm{d}-\mathrm{y}_{\mathrm{t}}\right)\right]
$$

Com na expressão 3.17:

$$
\mathrm{a}=\frac{\mathrm{C}_{\mathrm{cd}}}{0,85 \mathrm{f}_{\mathrm{cd}} \mathrm{b}_{\mathrm{p}}}
$$

Nas expressões dadas em 3.8.1.2.1.1:

a espessura de concreto comprimido na laje ou, no caso de interação parcial, espessura considerada efetiva;

$A_{a} \quad$ área do perfil de aço;

$\mathrm{A}_{\mathrm{af}} \quad$ área da mesa superior do perfil de aço;

$\mathrm{A}_{\mathrm{aw}}$ área da alma do perfil de aço, dada por $\mathrm{h}_{\mathrm{w}} \mathrm{t}_{\mathrm{w}}$;

$b_{p} \quad$ largura efetiva da laje de concreto na região de flexão positiva (tracionando as fibras inferiores);

$\mathrm{C}_{\mathrm{ad}}$ força resistente de cálculo da região comprimida do perfil de aço;

$\mathrm{C}_{\mathrm{cd}} \quad$ força resistente de cálculo da espessura de concreto comprimido;

$\Sigma Q_{R d}$ somatório das forças resistentes de cálculo individuais $Q_{R d}$ dos conectores de cisalhamento situados entre a seção de momento positivo máximo e a seção de momento nulo;

d altura do perfil de aço;

$d_{1} \quad$ distância do centroide do perfil de aço até a face superior desse perfil;

h distância entre as faces internas das mesas nos perfis soldados e esse valor menos dois raios de concordância nos perfis laminados;

$h_{w}$ distância entre as faces internas do perfil de aço; 
$\mathrm{h}_{\mathrm{F}} \quad$ espessura da pré-laje pré-moldada de concreto ou a altura das nervuras da fôrma de aço incorporada (tomar $h_{F}=0$ na ausência desses sistemas);

$y_{c} \quad$ distância do centroide da parte comprimida do perfil de aço até a face superior desse perfil;

$y_{p}$ distância da linha neutra da seção mista plastificada até a face superior do perfil de aço;

$y_{t}$ distância do centroide da parte tracionada do perfil de aço até a face inferior desse perfil;

$t_{c} \quad$ altura da laje de concreto (nos casos de lajes com pré-laje de concreto prémoldada ou com fôrma de aço incorporada é tomado a espessura acima da pré-laje ou nervura, respectivamente);

$t_{f} \quad$ espessura da mesa superior do perfil de aço

$t_{w} \quad$ espessura da alma do perfil de aço;

$\mathrm{T}_{\mathrm{ad}}$ força resistente de cálculo da região tracionada do perfil de aço;

\subsection{Viga mista de alma cheia com $3,76 \sqrt{E / f_{y}}<h / t_{w} \leq 5,70 \sqrt{E / f_{y}}$}

Para os perfis de seção mista semicompacta, a tensão de tração de cálculo na face inferior do perfil de aço não pode ultrapassar $f_{y d}$ e a tensão de compressão de cálculo na face superior da laje de concreto não pode ultrapassar $f_{c d}$.

- Interação completa

No caso de interação completa, as tensões correspondentes ao $M_{\text {sd.p são }}$ obtidas das propriedades teóricas da seção homogeneizada, isto é, dividindo a largura efetiva da laje de concreto por $\alpha_{\mathrm{E}}=\mathrm{E} / \mathrm{E}_{\mathrm{c}}$, onde $\mathrm{E}_{\mathrm{c}}$ é o módulo de elasticidade secante do concreto.

Assim como no dimensionamento plástico, no processo elástico o concreto tracionado é desprezado. Dessa forma, dois casos são possíveis, a saber: linha neutra no concreto e linha neutra no perfil de aço (Figura 3.12). 

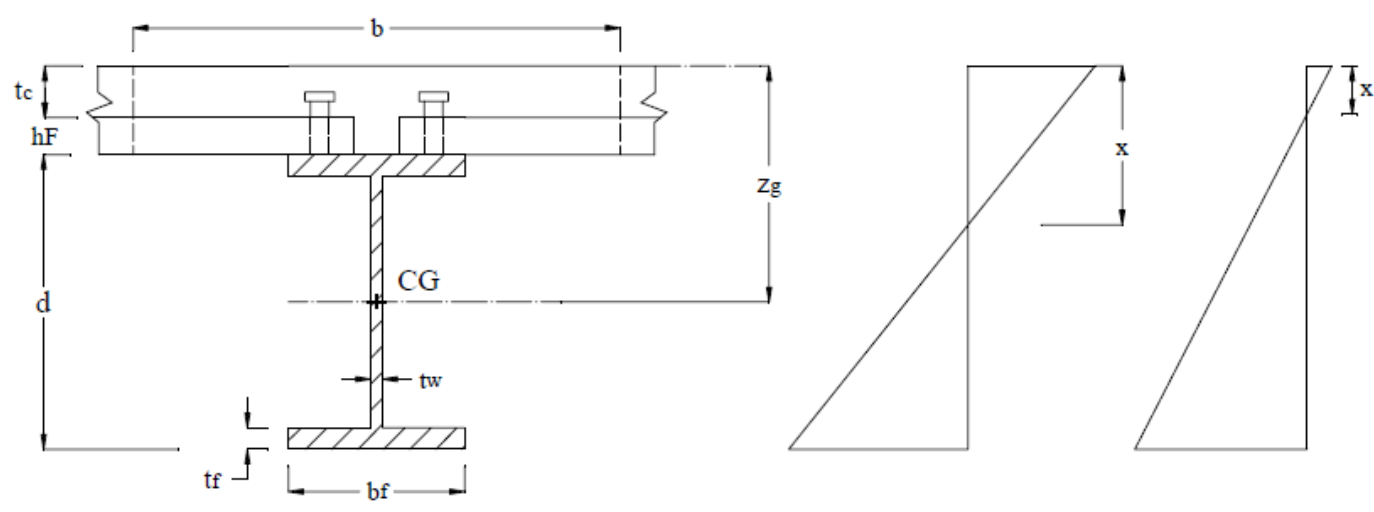
a) Seção da viga mista
b) L.N. na viga de aço
c) L.N. na laje

Figura 3.12 - Deformações nas vigas mistas sob momento positivo: análise elástica e interação completa (ALVA, 2000)

\section{Linha neutra elástica na laje de concreto}

A posição da linha neutra segundo a face superior $\left(\mathrm{y}_{\mathrm{p} . \mathrm{s}}\right)$, calculada desprezando o concreto entre as nervuras, e o momento de inércia teórico da seção homogeneizada $\left(I_{\text {tr.p.x }}\right)$ podem ser determinados pelas seguintes expressões:

$$
\begin{aligned}
& y_{p . s}=\frac{A_{a} \alpha_{E}}{b_{p}}\left(\sqrt{1+\frac{2 b_{p} y_{a}^{\prime}}{A_{a} \alpha_{E}}}-1\right) \\
& I_{\text {tr.p.x }}=I_{a x}+I_{\text {e.c.x }}+A_{a} y_{a}^{\prime 2}+A_{\text {e.c }} y_{\text {e.c }}^{\prime 2}-\left(A_{\text {e.c }}+A_{a}\right) y_{p . s}^{2}
\end{aligned}
$$

Nas expressões 3.19 e 3.20 , seguem:

$\mathrm{A}_{\mathrm{a}} \quad$ área do perfil de aço;

$A_{e . c} \quad$ área equivalente de concreto $\left(A_{e . c}=y_{p . s} b_{p} / \alpha_{E}\right) ;$

$b_{p} \quad$ largura efetiva da laje de concreto na região de flexão positiva (tracionando as fibras inferiores);

$\mathrm{I}_{\mathrm{ax}}$ momento de inércia do perfil de aço em relação ao eixo que passa pelo centroide da seção desse perfil;

$\mathrm{I}_{\text {e.c.x }}$ momento de inércia da área equivalente de concreto em relação ao eixo que passa pelo centroide dessa área; 
$\mathrm{y}^{\prime}{ }_{\mathrm{a}} \quad$ posição do centroide do perfil de aço segundo a face superior da laje;

$\mathrm{y}_{\text {e.c }}^{\prime}$ posição do centroide da área equivalente de concreto segundo a face superior da laje.

Para que $\mathrm{y}_{\mathrm{p} . \mathrm{s}}$ seja menor que $\mathrm{t}_{\mathrm{c}}$ e a expressão 3.19 seja válida, a seguinte condição deve ser atendida:

$$
\mathrm{A}_{\mathrm{a}}\left(\mathrm{y}_{\mathrm{p} . \mathrm{s}}-\mathrm{t}_{\mathrm{c}}\right)<\frac{1}{2} \mathrm{~b}_{\mathrm{p}} \frac{\mathrm{t}_{\mathrm{c}}^{2}}{\alpha_{\mathrm{E}}}
$$

Os módulos de resistência elásticos da seção mista segundo a face superior da laje $\left(W_{\text {tr.p.x.s }}\right)$ e inferior do perfil $\left(W_{\text {tr.p.x.i }}\right)$ são calculados por:

$\mathrm{W}_{\text {tr.p.x.s }}=\frac{\mathrm{I}_{\text {tr.p.x }}}{\mathrm{y}_{\mathrm{p} . \mathrm{s}}}$

$\mathrm{W}_{\text {tr.p.x.i }}=\frac{\mathrm{I}_{\text {tr.p.x }}}{\mathrm{y}_{\text {p.i }}}$

Onde: $y_{p . i}=d+h_{F}+t_{f}-y_{p . s}$

$>$ Linha neutra elástica no perfil de aço

Quando a condição 3.21 não é satisfeita, o cálculo da posição da linha neutra e do momento de inércia teórico da seção homogeneizada pode ser determinado pelas seguintes expressões:

$$
\begin{aligned}
& y_{p . s}=\frac{A_{a} y_{a}^{\prime}+A_{e . c} y_{e . c}^{\prime}}{A_{a}+A_{e . c}} \\
& I_{\text {tr.p.x }}=I_{a x}+I_{e . c . x}+A_{a} y_{a}^{\prime 2}+A_{e . c} y_{\text {e.c }}^{\prime 2}-\left(A_{e . c}+A_{a}\right) y_{p . s}^{2}
\end{aligned}
$$

O módulo de resistência elástico superior e o inferior da seção mista são calculados de acordo com as expressões 3.22 e 3.23 . 
As tensões de cálculo de compressão na face superior de concreto $\left(\sigma_{\mathrm{cd}}\right)$ e tração na mesa inferior do perfil de aço $\left(\sigma_{\mathrm{td}}\right)$ são dadas por:

$$
\begin{aligned}
\sigma_{\mathrm{cd}} & =\frac{\mathrm{M}_{\text {Sd.p }}}{\alpha_{\mathrm{E}} \mathrm{W}_{\text {tr.p.x.s }}} \\
\sigma_{\mathrm{td}} & =\frac{\mathrm{M}_{\text {Sd.p }}}{\mathrm{W}_{\text {tr.p.x.i }}}
\end{aligned}
$$

Em função dos recursos de programação do Mathcad (PARAMETRIC TECHNOLOGY CORPORATION, 2007), no APÊNDICE B as expressões de cálculo de $y_{\text {p.s }}, 3.19$ e 3.24 , são substituídas por um ciclo que se fecha quando a condição (while) $\mathrm{t}_{\mathrm{cc}}>\mathrm{y}_{\mathrm{p} . \mathrm{s}}$ não for mais satisfeita. Garantindo, dessa forma, que as propriedades da seção homogeneizada sejam calculadas com o concreto tracionado desprezado.

$$
t_{c c}=\mid \begin{aligned}
& t_{c c} \leftarrow t_{c} \\
& \text { while } t_{c c}>y_{p . s} \\
& \begin{array}{l}
t_{c c} \leftarrow y_{p . s} \\
A_{e . c} \leftarrow b \cdot \frac{t_{C C}}{\alpha_{E}} \\
y_{\text {laje }} \leftarrow \frac{t_{c c}}{2} \\
y_{p . s} \leftarrow \frac{A_{\text {e.c }} \cdot y_{\text {laje }}^{\prime}+A_{a \cdot} \cdot y_{\text {perfil }}^{\prime}}{A_{\text {e.c }}+A_{a}}
\end{array}
\end{aligned}
$$

Figura 3.13 - Cálculo do concreto comprimido $\left(t_{c c}\right)$ na seção homogeneizada

- Interação parcial

Já no caso de interação parcial, atendidas as condições das expressões 3.2 e 3.3, as tensões são calculadas pelas equações 3.26 e 3.27 alterando apenas o valor de $W_{\text {tr.p.x.i }}$ para:

$$
\mathrm{W}_{\text {ef.p.x.i }}=\mathrm{W}_{\mathrm{a}}+\sqrt{\frac{\sum \mathrm{Q}_{\mathrm{Rd}}}{\mathrm{F}_{\mathrm{hd}}}}\left[\mathrm{W}_{\text {tr.p.x.i }}-\mathrm{W}_{\mathrm{a}}\right]
$$

Onde $\mathrm{W}_{\mathrm{a}}$ é o módulo de resistência elástico inferior do perfil de aço. 


\subsection{Construção não escorada}

Como viga mista, as mesmas verificações dadas em 3.8.1.2.1 devem ser atendidas para todas as solicitações de cálculo atuantes na estrutura, isso inclui as ações permanentes atuantes antes da cura do concreto, conforme item 3.5. Além disso, devem ser atendidas duas exigências:

- o componente de aço isolado deve ter resistência de cálculo adequada para suportar todas as ações de cálculo aplicadas antes do concreto atingir uma resistência igual a $0,75 \mathrm{f}_{\mathrm{ck}}$.

- nas vigas mistas semicompactas, deve-se ter na mesa inferior da seção mais solicitada:

$\frac{M_{\text {Ga.Sd }}}{W_{a}}+\frac{M_{L . S d}}{W_{\text {ef.p.x.i }}} \leq f_{\text {yd }}$

Na equação 3.33 , tem-se:

$M_{G a . S d}$ e $M_{L . S d} \quad$ momentos fletores solicitantes de cálculo devidos às ações atuantes antes e depois do concreto atingir $0,75 \mathrm{f}_{\mathrm{ck}}$, respectivamente.

$\mathrm{W}_{\mathrm{a}}$ e $\mathrm{W}_{\mathrm{ef}} \quad$ calculados de acordo com o item 3.8.1.2.1.2

\subsubsection{Resistência à flexão na região de momentos fletores negativos}

Uma das inovações da ABNT NBR 8800:2008 foi considerar a contribuição da armadura longitudinal, presente na largura efetiva da laje de concreto, na resistência à flexão das regiões de momento negativo das vigas mistas de alma cheia.

Nesse caso é necessário que o número de conectores de cisalhamento seja suficiente para absorver os esforços horizontais entre o perfil de aço e o concreto, ou seja:

$\sum Q_{R d} \geq T_{d s}$ 
$\mathrm{Na}$ equação $3.30 \mathrm{~T}_{\mathrm{ds}}$ é a força resistente de tração de cálculo correspondente à área das barras da armadura longitudinal $\left(\mathrm{A}_{\mathrm{sl}}\right)$ presente na largura efetiva da laje de concreto dada por:

$\mathrm{T}_{\mathrm{ds}}=\mathrm{A}_{\mathrm{sl}} \mathrm{f}_{\mathrm{sd}}$

Além disso, a seção mista deve ser compacta de forma a atender as seguintes prescrições:

- $b_{f} / 2 t_{f}$ inferior a $0,38 \sqrt{E / f_{y}}$ para impedir a flambagem local da mesa;

- $\mathrm{h}_{\mathrm{p}} / \mathrm{t}_{\mathrm{w}}$ inferior a $3.76 \sqrt{\mathrm{E} / \mathrm{f}_{\mathrm{y}}}$ para impedir a flambagem local da alma.

Sendo:

$b_{\mathrm{f}} \quad$ largura da mesa do perfil de aço (mesa inferior);

$t_{\mathrm{f}} \quad$ espessura da mesa do perfil de aço (mesa inferior);

$\mathrm{h}_{\mathrm{p}} \quad$ dobro da altura da parte comprimida da alma (subtraída de duas vezes o raio de concordância entre a mesa e a alma nos perfis laminados), com a posição da linha neutra plástica calculada para a seção mista sujeita a flexão negativa;

$t_{w} \quad$ espessura da alma do perfil de aço.

O momento fletor resistente de cálculo nas seções mistas compactas cujas tensões são ilustradas na Figura 3.14 é igual a:

$M_{\text {Rd.n }}=T_{d s} d_{3}+A_{a t} f_{y d} d_{4}+A_{a c} f_{y d} d_{5}$

Na equação 3.32 seguem as seguintes definições:

$\mathrm{A}_{\mathrm{at}}$ área tracionada na seção do perfil de aço;

$\mathrm{A}_{\mathrm{ac}}$ área comprimida da seção do perfil de aço;

$\mathrm{d}_{3} \quad$ distância do centro geométrico da armadura longitudinal à LNP;

$\mathrm{d}_{4} \quad$ distância da força de tração, situada no centro geométrico da área tracionada da seção do perfil de aço, à LNP; 
$d_{5}$ distância da força de compressão, situada no centro geométrico da área comprimida da seção do perfil de aço, à LNP.

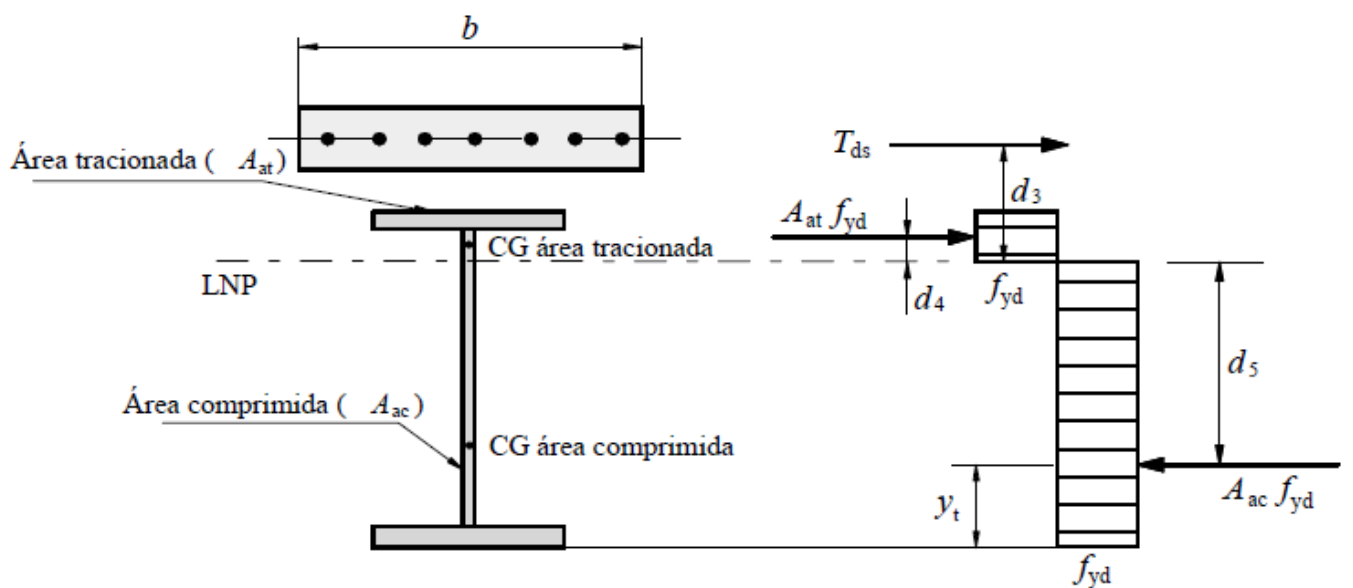

Figura 3.14 - Distribuição das tensões em vigas mistas de alma cheia compacta sob momento negativo (ABNT NBR 8800:2008)

$\mathrm{Na}$ região de momento negativo, deve ser verificada a instabilidade por distorção que se caracteriza pela perda de planicidade da alma e o deslocamento lateral da mesa inferior. Isso ocorre porque a laje de concreto não consegue evitar os deslocamentos laterais em toda seção do perfil. Nesse caso, diferentemente do comportamento da instabilidade lateral com torção, a forma da seção transversal não é mantida conforme ilustração a seguir.

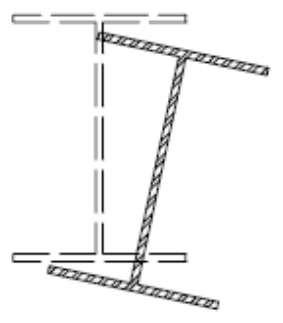

(a)

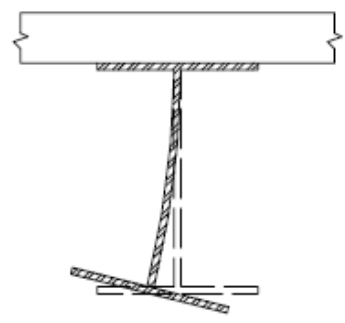

(b)

$$
\begin{array}{ll}
== & \text { nos apoios } \\
\underline{\underline{m}} & \text { na metade do vão }
\end{array}
$$

Figura 3.15 - Modo de instabilidade lateral nas vigas com perfil isolado e com seção mista:

(a) flambagem lateral com torção; (b) flambagem lateral distorcional (ALVA, 2000)

A ABNT NBR 8800:2008 assegura a não ocorrência de flambagem lateral com distorção da seção transversal das vigas contínuas pela seguinte expressão:

$\mathrm{M}_{\text {Sd.n }} \leq \mathrm{M}_{\text {dist.Rd.n }}$ 
Onde, na expressão 3.33:

MSd.n momento fletor solicitante de cálculo na região de flexão negativa;

Mdist.Rd.n momento fletor resistente de cálculo na região de flexão negativa, para o estado limite de flambagem lateral com distorção da seção transversal, calculado pela equação 3.34 .

$\mathrm{M}_{\text {dist.Rd.n }}=\chi_{\text {dist }} \mathrm{M}_{\mathrm{Rd} . \mathrm{n}}$

Na equação 3.34, temos:

M $\quad$ momento fletor resistente de cálculo da seção;

X fist fator de redução para flambagem lateral com distorção da seção transversal, obtido da curva de resistência à compressão (expressões 3.35 e 3.36) em função do parâmetro de esbeltez $\left(\lambda_{\text {dist }}\right)$ dado simplificadamente, para os perfis de aço com dois eixos de simetria pela equação 3.37 .

$\lambda_{\text {dist }} \leq 1,5: \quad \chi=0,658^{\lambda_{\text {dist }}^{2}}$

$\lambda_{\text {dist }}>1,5: \quad \chi=\frac{0,877}{\lambda_{\text {dist }}^{2}}$

$\lambda_{\text {dist }}=5,0\left(1+\frac{t_{w} h_{o}}{4 b_{f} t_{f}}\right)\left[\left(\frac{f_{y}}{E C_{\text {dist }}}\right)^{2}\left(\frac{h_{o}}{t_{w}}\right)^{3}\left(\frac{t_{f}}{b_{f}}\right)\right]^{0,25}$

Sendo na equação 3.37 :

$b_{f} \quad$ largura da mesa do perfil de aço;

$\mathrm{f}_{\mathrm{y}}$ resistência característica do perfil de aço;

$h_{\circ} \quad$ distância entre os centroides das mesas do perfil de aço;

$t_{f} \quad$ espessura da mesa do perfil de aço;

$t_{w} \quad$ espessura da alma do perfil de aço; 
$\mathrm{C}_{\text {dist }}$ coeficiente que depende da distribuição dos momentos fletores no comprimento $L$ entre apoios verticais com ambas as mesas do perfil de aço obrigatoriamente contidas lateralmente nesses apoios. As Tabelas 3.3 e 3.4 apresentam o valor de $\mathrm{C}_{\text {dist }}$ para casos específicos de carregamento sobre as vigas contínuas.

Tabela 3.3 - Coeficiente $\mathrm{C}_{\text {dist }}$ para vigas contínuas com carregamento no comprimento $\mathrm{L}$ (ABNT NBR 8800:2008)

\begin{tabular}{|c|c|c|c|c|c|c|c|c|c|c|}
\hline \multirow{2}{*}{$\begin{array}{l}\text { Condiçöes de } \\
\text { carregamento } \\
\text { e apoio }\end{array}$} & \multirow{2}{*}{$\begin{array}{l}\text { Diagrama de } \\
\text { momento fletor }{ }^{a}\end{array}$} & \multicolumn{9}{|c|}{$\psi$} \\
\hline & & 0,50 & 0,75 & 1,00 & 1,25 & 1,50 & 1,75 & 2,00 & 2,25 & 2,50 \\
\hline (4) & & 41,5 & 30,2 & 24,5 & 21,1 & 19,0 & 17,5 & 16,5 & 15,7 & 15,2 \\
\hline \multirow{3}{*}{ 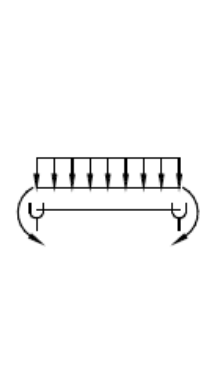 } & ${ }^{4 M_{0}}$ & 33,9 & 22,7 & 17,3 & 14,1 & 13,0 & 12,0 & 11,4 & 10,9 & 10,6 \\
\hline & $\psi M_{0}[$ & 28,2 & 18,0 & 13,7 & 11,7 & 10,6 & 10,0 & 9,5 & 9,1 & 8,9 \\
\hline & $\psi_{1}^{M M_{0}}$ & 21,9 & 13,9 & 11,0 & 9,6 & 8,8 & 8,3 & 8,0 & 7,8 & 7,6 \\
\hline$\stackrel{1}{\longrightarrow}$ & & 28,4 & 21,8 & 18,6 & 16,7 & 15,6 & 14,8 & 14,2 & 13,8 & 13,5 \\
\hline$\left(\begin{array}{l}1 \\
\left(\begin{array}{l}4 \\
4\end{array}\right)\end{array}\right.$ & $\psi M_{0} \triangle \stackrel{M_{0}}{1} \Delta^{\psi M_{0}}$ & 12,7 & 9,89 & 8,6 & 8,0 & 7,7 & 7,4 & 7,2 & 7,1 & 7,0 \\
\hline
\end{tabular}

Tabela 3.4 - Coeficiente $C_{\text {dist }}$ para vigas contínuas e semicontínuas sem carregamento no comprimento L (ABNT NBR 8800:2008)

\begin{tabular}{|c|c|c|c|c|c|c|}
\hline \multirow{2}{*}{$\begin{array}{l}\text { Condiçōes de } \\
\text { carregamento e apoio }\end{array}$} & \multirow{2}{*}{$\begin{array}{l}\text { Diagrama de } \\
\text { momento fletor }\end{array}$} & \multicolumn{5}{|c|}{$\psi$} \\
\hline & & 0,00 & 0,25 & 0,50 & 0,75 & 1,00 \\
\hline$\left(\begin{array}{ll}Y & Y\end{array}\right)$ & $M{ }_{\text {aceitável }}{ }^{M}$ & 11,1 & 9,5 & 8,2 & 7,1 & 6,2 \\
\hline$\left(\begin{array}{ll}Y & Y\end{array}\right)$ & aceitavel & 11,1 & 12,8 & 14,6 & 16,3 & 18,1 \\
\hline
\end{tabular}


Independente do carregamento e resistência das ligações, a flambagem lateral distorcional pode ser contabilizada conservadoramente pela equação 3.38 aplicado aos casos de vigas de aço isoladas com uma das mesas livre para deslocar lateralmente e a outra com travamento lateral contínuo.

$C_{b}=3,0-\frac{2}{3} \frac{M_{1}}{M_{0}}-\frac{8}{3} \frac{M_{2}}{M_{0}+M_{1}}$

$\mathrm{M}_{0} \quad$ maior momento fletor solicitante de cálculo que comprime a mesa livre nas extremidades do comprimento destravado tomado com sinal negativo;

$\mathrm{M}_{1}$ momento fletor solicitante de cálculo na outra extremidade do comprimento destravado. Se esse momento comprimir a mesa livre, deve ser tomado com sinal negativo nos segundo e terceiro termos da equação. Se tracionar a mesa livre, deve ser tomado com sinal positivo no segundo termo da equação e igual a zero no terceiro termo;

$M_{2}$ momento fletor solicitante de cálculo na seção central do comprimento destravado, com sinal positivo se tracionar a mesa livre e sinal negativo se tracionar a mesa com contenção lateral contínua.

Nas vigas mistas semicontínuas, considerações adicionais devem ser realizadas sobre a resistência das ligações e, se for o caso, sobre a análise rígidoplástica.

\subsubsection{Resistência ao cisalhamento vertical}

A força cortante resistente de cálculo de vigas mistas de alma cheia, $V_{R d}$, de acordo com a ABNT NBR 8800:2008, é determinada considerando apenas os estados limites últimos de escoamento e flambagem por cisalhamento da alma do perfil de aço, com segue:

$-\mathrm{V}_{\mathrm{Rd}}=\frac{\mathrm{V}_{\mathrm{pl}}}{\gamma_{\mathrm{a} 1}}$, para: $\lambda \leq \lambda_{\mathrm{p}}$

$-\mathrm{V}_{\mathrm{Rd}}=\frac{\lambda_{\mathrm{p}}}{\lambda} \frac{\mathrm{V}_{\mathrm{pl}}}{\gamma_{\mathrm{a} 1}}$, para: $\lambda_{\mathrm{p}}<\lambda \leq \lambda_{\mathrm{r}}$ 
- $\mathrm{V}_{\mathrm{Rd}}=1,24\left(\frac{\lambda_{\mathrm{p}}}{\lambda}\right)^{2} \frac{\mathrm{V}_{\mathrm{pl}}}{\gamma_{\mathrm{a} 1}}$, para: $\lambda>\lambda_{\mathrm{r}}$

Nas expressões 3.39, 3.40 e 3.41, temos:

$\lambda \quad$ esbeltez da alma tomado por $\mathrm{h} / t_{w}$;

$\lambda_{\mathrm{p}} \quad$ parâmetro de esbeltez limite para seções compactas, igual a $\quad 1,10 \sqrt{\frac{\mathrm{k}_{\mathrm{v}} \mathrm{E}}{\mathrm{f}_{\mathrm{y}}}}$;

$\lambda_{\mathrm{r}} \quad$ parâmetro de esbeltez limite para seções semicompactas, igual a $1,37 \sqrt{\frac{\mathrm{k}_{\mathrm{v}} \mathrm{E}}{\mathrm{f}_{\mathrm{y}}}}$;

$\mathrm{k}_{\mathrm{V}}=\left\{\begin{array}{l}5,0 \text { para almas sem enrijecedores, para } \frac{\mathrm{a}}{\mathrm{h}}>3 \text { ou para } \frac{\mathrm{a}}{\mathrm{h}}>\left[\frac{260}{\left(\mathrm{~h} / \mathrm{t}_{\mathrm{w}}\right)}\right]^{2} \\ 5+\frac{5}{(\mathrm{a} / \mathrm{h})^{2}}, \text { para os demais casos }\end{array}\right.$

a distância entre as linhas de centro de dois enrijecedores transversais adjacentes;

h altura da alma, tomada igual à distância entre as faces internas das mesas nos perfis soldados e igual a esse valor menos os raios de concordância entre a mesa e a alma nos perfis laminados;

$\mathrm{t}_{\mathrm{w}} \quad$ espessura da alma;

$\mathrm{V}_{\mathrm{pl}}$ força cortante correspondente á plastificação da alma por cisalhamento, tomado por $0,6 A_{w} f_{y}$, onde:

$\mathrm{A}_{\mathrm{w}}$ área efetiva de cisalhamento, igual a $\mathrm{dt}_{\mathrm{w}}$, sendo: $\mathrm{d}$ a altura total $\mathrm{da}$ seção transversal e $t_{w}$ a espessura da alma. 
Quando a força cortante solicitante de cálculo, $V_{S d}$, é maior que a metade da resistência de cálculo, $V_{\mathrm{Rd}}$, seus efeitos devem ser considerados no cálculo do momento resistente das vigas mistas, atendendo, no caso das seções pertencerem às classes 1 e 2, ao seguinte critério (EN 1994:2004):

$\mathrm{M}_{\mathrm{Sd}} \leq \mathrm{M}_{\mathrm{f} . \mathrm{Rd}}+\left(\mathrm{M}_{\mathrm{Rd}}-\mathrm{M}_{\mathrm{f} . \mathrm{Rd}}\right)\left(1-\left(\frac{2 \mathrm{~V}_{\mathrm{Sd}}}{\mathrm{V}_{\mathrm{Rd}}}-1\right)^{2}\right)$

Na equação 3.42, tem-se:

$\mathrm{M}_{\mathrm{Sd}} \quad$ momento solicitante de cálculo na viga mista;

$\mathrm{M}_{\mathrm{Rd}}$ momento resistente plástico de cálculo da viga mista determinado em 3.8.1.2 e 3.8.1.3.

$\mathrm{M}_{\mathrm{f} \text { Rd }}$ momento resistente plástico de cálculo de uma seção constituída apenas pelas mesas da viga mista, tomando a largura efetiva igual ao valor definido em 3.8.1.2 e 3.8.1.3;

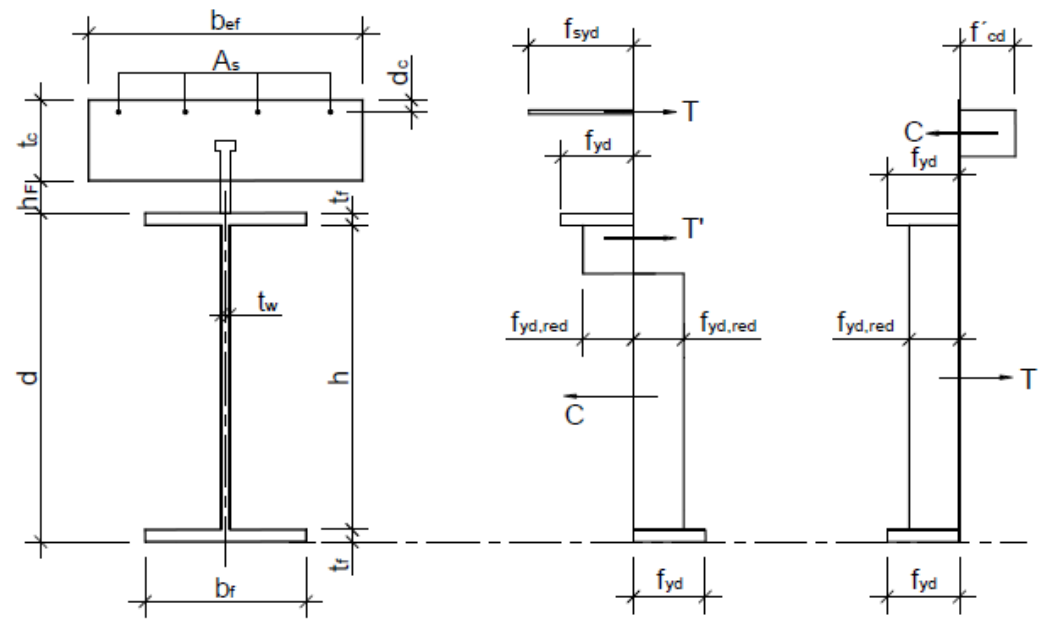

Figura 3.16 - Distribuição plástica das tensões modificadas pelo efeito do cisalhamento vertical (EN 1994-1-1:2004)

\subsubsection{ESTADOS LIMITES DE SERVIÇO}

Os deslocamentos excessivos usualmente governam o dimensionamento de vigas mistas simplesmente apoiadas com sistema não escorado. Já no caso de carregamento dinâmico sobre o piso, por exemplo, piso de salão de dança, deve-se atentar aos limites de vibração. A largura das fissuras que surgem nos apoios devido 
à tendência de continuidade do concreto ou às regiões de momento negativo, caso das vigas contínuas ou semicontínuas, também integra os limites de serviço a serem verificados.

\subsubsection{Controle dos deslocamentos excessivos}

\subsection{Análise estrutural para obtenção dos deslocamentos}

A determinação dos deslocamentos em vigas mistas contínuas é usualmente realizada por análise elástica a partir da combinação rara das ações e, de modo geral, deve considerar o sistema construtivo, os efeitos de shear lag, a fluência e retração do concreto, a fissuração do concreto, o escoamento do aço estrutural e o escorregamento longitudinal nos casos de interação parcial entre o aço e o concreto.

Nas vigas não escoradas avaliam-se os deslocamentos na estrutura por meio da sobreposição dos efeitos das ações aplicadas antes e após a cura do concreto sobre o perfil isolado e a seção mista, respectivamente.

O efeito de shear lag é calculado nas regiões de momentos positivos e negativos. As propriedades geométricas da seção mista, aço e concreto, são tomadas através da homogeneização teórica de seus componentes. Essas são definidas pela divisão entre a largura efetiva de concreto e a razão modular $\left(\alpha_{E}\right)$ dos respectivos materiais. Na região tracionada, a largura efetiva apenas limita a distribuição da armadura longitudinal, uma vez que o concreto presente é desprezado.

Os efeitos de deformação lenta são admitidos através da redução do módulo de elasticidade do concreto na homogeneização teórica da seção transversal. A ABNT NBR 8800:2008 permite, simplificadamente, considerar os efeitos de longa duração reduzindo o módulo de elasticidade do concreto à terceira parte. A partir disso são definidos os deslocamentos oriundos das ações permanentes e dos valores quase permanentes das ações variáveis.

A EN 1994-1-1:2004 apresenta um procedimento alternativo para consideração dos efeitos de deformação lenta baseado na utilização de apenas um 
valor, o dobro da razão modular. É aplicável para qualquer tipo de ações usuais de edifício, exceto para estruturas destinadas a ações elevadas, como depósitos.

Ainda de acordo com a norma europeia, o efeito da fissura do concreto nas regiões de momentos negativos pode ser considerado mediante uma análise elástica admitindo a seção do concreto fissurada sem redistribuição dos momentos, conforme 3.8.1.1, ou de uma análise elástica simplificada.

O método simplificado é aplicado em vigas com seções críticas nas classes 1,2 e 3 a partir do modelo não fissurado. Consiste em multiplicar pelo coeficiente de redução $\mathrm{f}_{1}$, os momentos fletores sobre os apoios que provocarem tensões superiores a $1,5 \mathrm{f}_{\mathrm{ctm}}$, e corrigir os momentos fletores positivos dos vãos adjacentes.

Nas situações em que as cargas por unidade de comprimento são iguais em todos os vãos e as diferenças dos comprimentos de todos vãos são inferiores a $25 \%$ calcula-se $\mathrm{f}_{1}$ pela seguinte forma:

$f_{1}=\left[\frac{E_{a} I_{1}}{E_{a} I_{2}}\right]^{-0,35} \geq 0,6$

Sendo que $\mathrm{E}_{\mathrm{a}} \mathrm{I}_{1}$ e $\mathrm{E}_{\mathrm{a}} \mathrm{I}_{2}$ as rigidezes de flexão da seção mista homogeneizada assumindo o concreto não fissurado e fissurado, respectivamente. Nos demais casos assume-se conservadoramente $\mathrm{f}_{1}=0,6$.

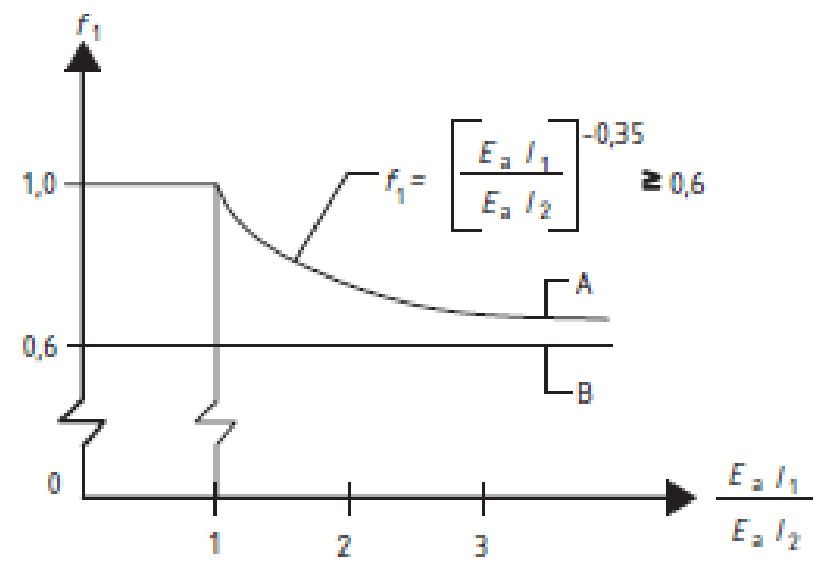

Figura 3.17 Fator de redução do momentos fletores sobre os apoios internos (EN 1994-1-1:2004)

Nas vigas mistas não escoradas, pode-se considerar, caso exista, a influência da plastificação local da seção de aço sobre os apoios. Consiste em multiplicar os 
momentos fletores sobre os apoios por um coeficiente de redução adicional (Figura 3.18) dado por $\mathrm{f}_{2}=0,5$ ou $\mathrm{f}_{2}=0,7$ quando a tensão de escoamento é atingida antes ou depois da cura do concreto da laje, respectivamente.

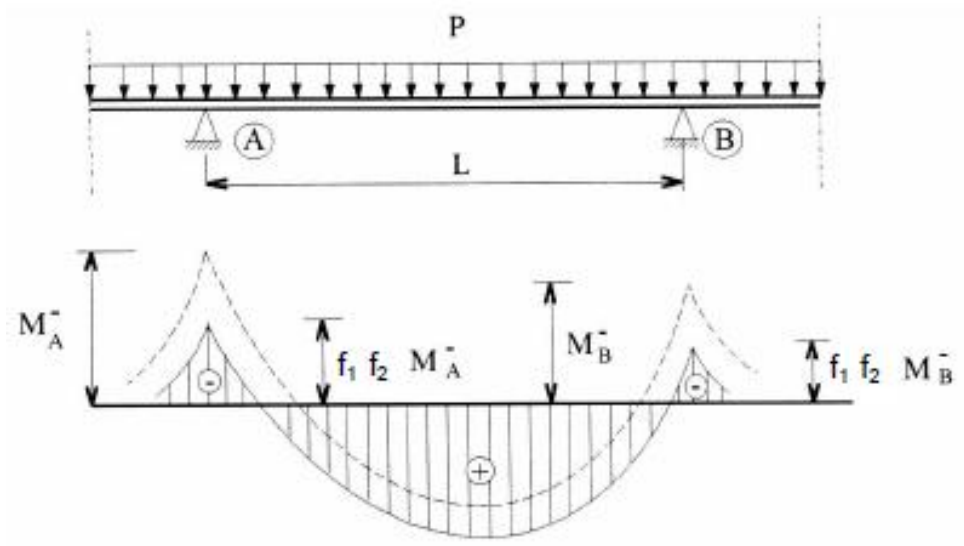

Figura 3.18 - Efeito da fissura do concreto e do escoamento do aço estrutural na avaliação dos deslocamentos em uma viga mista contínua

Os deslocamentos em vigas mistas contínuas são calculados em função dos momentos fletores reduzidos conforme a Figura 3.18. Trata-se de uma excelente alternativa para os casos em que a razão entre o vão menor sobre o maior seja inferior a 0,6 (vigas transversais desse projeto) e nas vigas que o perfil de aço atinge o escoamento sobre os apoios, frequente entre as vigas não escoradas.

O processo construtivo das ligações mistas consideradas nesse trabalho possibilita aproximar o comportamento estrutural das vigas mistas contínuas antes da cura ao de uma viga biapoiada. Dessa forma, o escoamento da seção de aço não ocorre, normalmente, sobre os apoios e sim na metade do vão. Portanto, as tensões nessa seção devem ser verificadas para a validação da analise elástica.

A validação da análise elástica dos deslocamentos deve ser verificada comprovando que a máxima tensão não atinja a resistência ao escoamento do aço do perfil, nem do aço da armadura no caso das vigas contínuas e semicontínuas. As tensões são baseadas nas propriedades elásticas da seção, considerando, apropriadamente, o comportamento antes e após a cura do concreto. No caso de interação parcial, na região de momento positivo, pode-se utilizar as propriedades efetivas da seção, conforme equação 3.28 . 
Nas vigas mistas com interação parcial, a ABNT NBR 8800:2008 contabiliza o escorregamento longitudinal, decorrente do grau de interação entre o perfil e a laje de concreto, pelo momento de inércia efetivo da seção mista, dado por:

$\mathrm{I}_{\mathrm{ef}}=\mathrm{I}_{\mathrm{a}}+\sqrt{\frac{\sum \mathrm{Q}_{\mathrm{Rd}}}{\mathrm{F}_{\mathrm{hd}}}}\left(\mathrm{I}_{\mathrm{tr}}-\mathrm{I}_{\mathrm{a}}\right)$

Onde: $I_{a}$ e $I_{t r}$ são os momentos de inércia do perfil de aço e da seção mista teoricamente homogeneizada, respectivamente.

Nas vigas mistas semicontínuas, além dessas considerações, a rigidez das ligações deve ser levada em conta na análise elástica.

\subsection{Limite dos deslocamentos excessivos}

Uma vez realizada a análise dos deslocamentos, deve-se verifica-los frente aos valores máximos de deslocamentos recomendados pela ABNT NBR 8800:2008. No caso das vigas de piso, o valor máximo é representado pela relação L/350, sendo $L$ o vão teórico entre apoios ou o dobro do comprimento teórico do balanço.

Em alguns casos podem-se adotar limites mais rigorosos, de forma a considerar, por exemplo, a finalidade da edificação, as características dos materiais de acabamento, o funcionamento adequado dos equipamentos, medidas econômicas e a percepção ao desconforto.

Os deslocamentos a serem verificados nas vigas mistas são ilustrados na Figura 3.19, onde: $\delta_{0}$ é a contraflecha; $\delta_{1}$ é o deslocamento decorrente das ações permanentes, sem o efeito de longa duração; $\delta_{2}$ é o deslocamento decorrente do efeito de longa duração das ações permanentes; $\delta_{3}$ deslocamento decorrente das ações variáveis, considerando, se houver, os efeitos de longa duração devido aos valores quase permanentes dessas ações; $\delta_{\max }$ é o deslocamento máximo atingido pela viga incluindo a contraflecha; e $\delta_{\text {tot }}$ é a soma $\delta_{1}, \delta_{2}$ e $\delta_{3}$. 


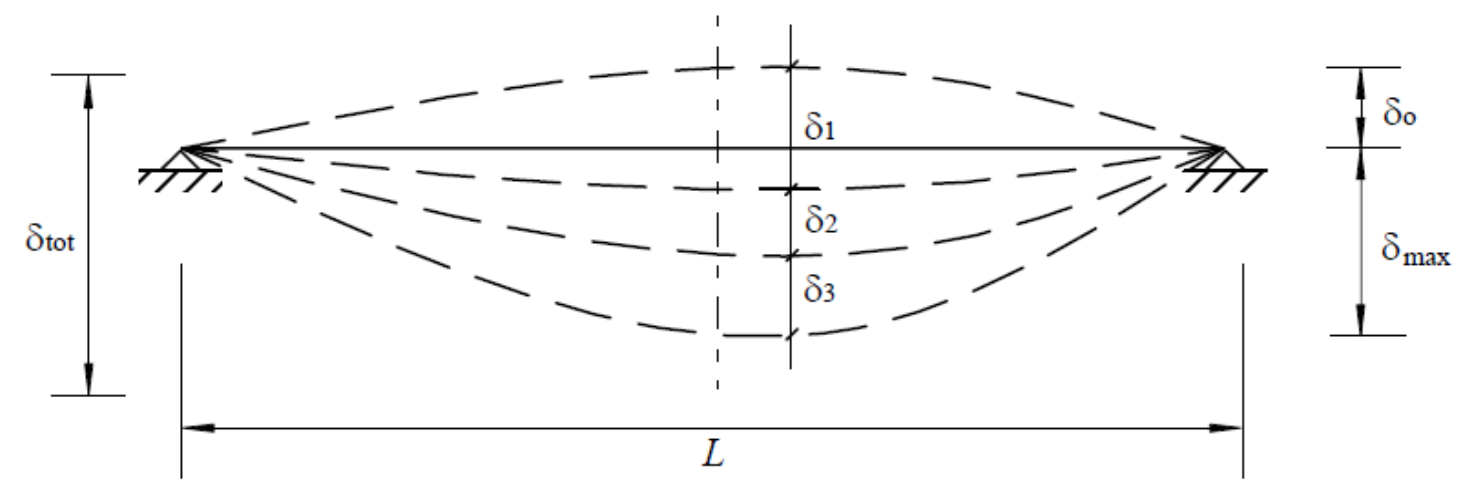

Figura 3.19 - Deslocamentos verticais a serem considerados (ABNT NBR 8800:2008)

Pode-se adotar uma contraflecha na viga com valor limite igual à flecha proveniente das ações permanentes $\left(\delta_{1}\right)$.

Usualmente, apenas a fração dos deslocamentos devido às ações variáveis $\left(\delta_{3}\right)$, somada à fração dos deslocamentos devido aos efeitos de longa duração das ações permanentes $\left(\delta_{2}\right)$, é responsável por acarretar danos aos elementos não estruturais. Entretanto, é comum somar também os deslocamentos da parte das ações permanentes atuantes após a construção do elemento não estrutural em questão.

Nesse trabalho, uma vez que não é realizada uma análise específica para avaliação da aparência da estrutura, a saber, uma análise elástica para a combinação quase permanente das ações, o deslocamento limite excessivo é, conservadoramente, comparado ao deslocamento máximo atingido pela estrutura $\left(\delta_{\max }\right)$.

\subsubsection{Controle da fissuração no concreto}

As fissuras devem ser verificadas de forma a garantir, além da aparência aceitável, o funcionamento adequado e a durabilidade da estrutura. O surgimento das fendas é praticamente inevitável nas regiões de momento negativo ou com tendência de continuidade, por exemplo, junto aos apoios de vigas biapoiadas.

A partir de uma adaptação da ABNT NBR 6118:2003 e da EN 1992-1-1:2004, a ABNT NBR 8800:2008 traz o cálculo da armadura mínima longitudinal de tração sob deformações impostas e dos limites estimados de abertura das fissuras (ver 
ABNT NBR 8800:2008) ou do diâmetro e do espaçamento máximo das barras da armadura.

\subsection{Armadura mínima de tração sob deformações impostas}

O cálculo da armadura mínima longitudinal de tração para controle das fissuras, procedentes dos esforços gerados pela restrição das deformações impostas nas regiões de momento negativo (por exemplo, retração) ou da tendência de continuidade das vigas, é aplicável nas situações que requerem esse controle (por exemplo, edifícios comerciais) e dado por:

$\mathrm{A}_{\text {sl.di }}=\frac{\mathrm{kk}_{\mathrm{c}} \mathrm{k}_{\mathrm{s}} \mathrm{f}_{\mathrm{ct.ef}} \mathrm{A}_{\mathrm{ct}}}{\sigma_{\mathrm{st}}}$

$\mathrm{A}_{\mathrm{ct}} \quad$ área efetiva da laje de concreto (produto da largura efetiva pela espessura);

k coeficiente de correção que considera os mecanismos de geração de tensões de tração, podendo ser tomado igual a 0,8;

$\mathrm{k}_{\mathrm{c}} \quad$ coeficiente que considera o auto equilíbrio e a distribuição das tensões na laje de concreto imediatamente antes da fissuração, podendo ser tomado, conservadoramente, igual a 1,0 (ver forma mais precisa na ABNT NBR 8800:2008);

$\mathrm{k}_{\mathrm{s}} \quad$ coeficiente que considera o efeito da redução da força normal na laje de concreto devido à fissuração inicial e ao deslizamento local da ligação entre a laje e o perfil de aço, podendo ser tomado igual a 0,9;

$\mathrm{f}_{\text {ct.ef }}$ resistência média à tração efetiva do concreto no momento em que se formam as primeiras fissuras, dependente das condições ambientais, natureza das fôrmas e do cimento empregado. No caso de incerteza na idade de ocorrência da fissuração, recomenda-se o valor mínimo de $3 \mathrm{MPa}$; 
$\sigma_{\text {st }}$ máxima tensão de tração permitida na armadura imediatamente após a fissuração. Seu valor, em megapascal, não pode exceder:

$\sigma_{\mathrm{st}}=810 \mathrm{w}_{\mathrm{k}}^{0,5} \sqrt{\frac{\mathrm{f}_{\mathrm{ck}}^{2 / 3}}{\phi}} \leq \mathrm{f}_{\mathrm{ys}}$

Onde na expressão 3.46 :

$\mathrm{f}_{\mathrm{ck}}$ resistência característica do concreto à compressão, expressa em megapascal (MPa);

$\mathrm{f}_{\mathrm{ys}}$ resistência característica do aço ao escoamento, expressa em megapascal (MPa);

$\mathrm{w}_{\mathrm{k}}$ é a abertura máxima característica das fissuras (Tabela 3.5), em função da agressividade ambiental, expressa em milímetros ( $\mathrm{mm})$;

$\Phi$ diâmetro das barras da armadura adotado inferior a $20 \mathrm{~mm}$, em milímetros.

Tabela 3.5 - Valores limites da abertura máxima característica das fissuras $\left(\mathrm{w}_{\mathrm{k}}\right)$

\begin{tabular}{|c|c|c|}
\hline Agressividade ambiental $^{\text {a }}$ & Ambiente & $\begin{array}{c}\boldsymbol{w}_{\mathrm{k}} \\
\mathbf{m m}\end{array}$ \\
\hline I (fraca) & Rural ou submersa & 0,4 \\
\hline II (moderada) & Urbano & 0,3 \\
\hline III (forte) & Marinho e industrial & 0,3 \\
\hline IV (muito forte) & $\begin{array}{c}\text { Industrial químico agressivo e } \\
\text { respingos de maré }\end{array}$ & 0,2 \\
\hline $\begin{array}{c}\text { a Pode-se admitir uma agressividade ambiental um nível mais brando em ambiente interno } \\
\text { seco ou se o concreto for revestido com argamassa e pintura. }\end{array}$ \\
\hline
\end{tabular}

\subsection{Armadura mínima de tração sob ações impostas}

Quando a área da armadura necessária para proporcionar a resistência à flexão aos estados limites últimos for superior à armadura mínima exigida em 3.8.2.2.1, o controle da abertura das fissuras deve ser realizado. Uma alternativa para essa verificação é respeitar o diâmetro máximo $\left(\phi_{\max }\right)$ e o espaçamento 
máximo $\left(\mathrm{S}_{\max }\right)$ apresentados na Tabela 3.6 em função da tensão de tração do centro geométrico da armadura considerada $\left(\sigma_{\mathrm{si}}\right)$.

Tabela 3.6 - Diâmetro e espaçamento máximo das barras da armadura em função da tensão de tração (ABNT NBR 8800:2008)

\begin{tabular}{|c|c|c|}
\hline $\begin{array}{c}\text { Tensão } \sigma_{\text {si }} \\
\mathrm{MPa}\end{array}$ & $\begin{array}{c}\phi_{\max } \\
\mathrm{mm}\end{array}$ & $\begin{array}{c}\boldsymbol{s}_{\max } \\
\mathrm{mm}\end{array}$ \\
\hline 280 & 16 & 150 \\
\hline 320 & 12,5 & 100 \\
\hline 360 & 10 & 50 \\
\hline 400 & 8 & - \\
\hline
\end{tabular}

A tensão $\sigma_{\mathrm{si}}$ é calculada usando a combinação frequente de serviço em uma análise elástica que considera seção do concreto fissurada, conforme 3.8.1.1, sem redistribuição dos momentos. No caso do sistema construtivo da viga ser não escorado, devem ser consideradas apenas as ações atuantes após a cura do concreto.

\subsubsection{EXEMPLO: PRÉ-DIMENSIONAMENTO DAS VIGAS DO EDIFÍCIO MODELO 1}

A determinação dos esforços e deslocamentos no pré-dimensionamento das vigas mistas do Edifício Modelo 1 (Figura 1.2) foi realizada no Ftool (PUC-Rio, 2008). Esse software é restrito à análise linear no plano e, portanto, além de ser eficiente para essa etapa, possui a interface do usuário simples.

Devido à simetria do sistema dos pisos, as vigas cujos vãos localizam-se entre os eixos 1-2 e 2-3 possuem o mesmo comportamento estrutural das vigas opostas simétricas, ou seja, localizadas nos eixos 5-6 e 4-5, respectivamente. Dessa forma, simplificadamente, as vigas correspondentes a estes eixos não serão apresentadas diretamente.

A avaliação das vigas nesse exemplo é baseada nas ações sobre pavimento tipo (ver 1.4.1.3), portanto de acordo com o exemplo avaliado no item 2.2.2.1.4 na seção mista dessas vigas é empregado forma de aço incorporada com nervuras de $75 \mathrm{~mm}$ de altura e $65 \mathrm{~mm}$ de concreto. 


\subsubsection{Avaliação do grau de interação, sistema estrutural e construtivo}

Inicialmente, estuda-se a possibilidade de todas as vigas serem escoradas e, com exceção da viga secundária V1, contínuas. Nas vigas contínuas transversais, a relação entre os vãos adjacentes $\left(L_{V 6} / L_{V 7}=2\right)$ é maior que 1,5 , assim, conforme a ABNT NBR 8800:2008, a análise rígido-plástica não é aplicável. Alternativamente, a análise elástica com redistribuição dos momentos (EN 1994-1-1:2004) foi empregada na determinação dos esforços resultantes da combinação C4 (expressão 2.5).

A partir da análise das vigas mistas contínuas com o concreto não fissurado e os momentos fletores negativos reduzidos em 30\%, verifica-se que a menor tensão de tração no concreto ( $\sigma_{\text {ct.car }}$ ) para a combinação característica (expressão 3.4) ocorre com o valor de $18,4 \mathrm{kN} / \mathrm{cm}^{2}$ (Tabela 3.7) na viga V4. Esse valor é maior do que $2 \mathrm{f}_{\mathrm{ctm}}\left(0,44 \mathrm{kN} / \mathrm{cm}^{2}\right)$, portanto, a análise dos esforços deve considerar a fissuração do concreto e uma redução de $15 \%$ nos momentos fletores negativos.

Tabela 3.7 - Tensões de tração no concreto calculada pelos modelos de análise não fissurados com $30 \%$ de redução dos momentos fletores negativos resultantes da combinação característica das ações

\begin{tabular}{|c|c|c|c|c|c|c|c|c|}
\hline Tensão & $\begin{array}{c}\text { V2 } \\
(\text { vão 1-2) }\end{array}$ & $\begin{array}{c}\text { V2 } \\
\text { (vão 2-3) }\end{array}$ & $\begin{array}{c}\text { V2 } \\
(\text { vão 3-4) }\end{array}$ & $\begin{array}{c}\text { V3 } \\
\text { (vão 1-2) }\end{array}$ & $\begin{array}{c}\text { V3 } \\
\text { (vão 2-3) }\end{array}$ & $\begin{array}{c}\text { V3 } \\
\text { (vão 3-4) }\end{array}$ & V4 & V6 \\
\hline $\begin{array}{c}\sigma_{\mathrm{ct.car}} \\
\left(\mathrm{kN/cm}{ }^{2}\right)\end{array}$ & 26,5 & 26,5 & 32,6 & 26,5 & 26,5 & 23,0 & 18,4 & 21,2 \\
\hline
\end{tabular}

O procedimento simplificado do modelo fissurado também não é aplicável para as vigas transversais, uma vez que a relação $L_{v 7} / L_{v 6}$ é inferior a 0,6 . Nesse caso o ponto de inflexão da seção fissurada é encontrado de forma iterativa. As Figuras 3.20 e Figura 3.21 ilustram o comportamento das vigas contínuas longitudinais e transversais V3 e V6 para o procedimento simplificado e iterativo, respectivamente. 


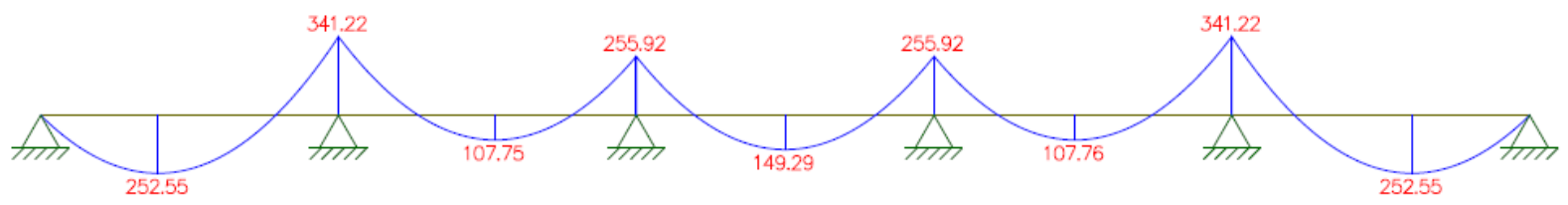

(a)

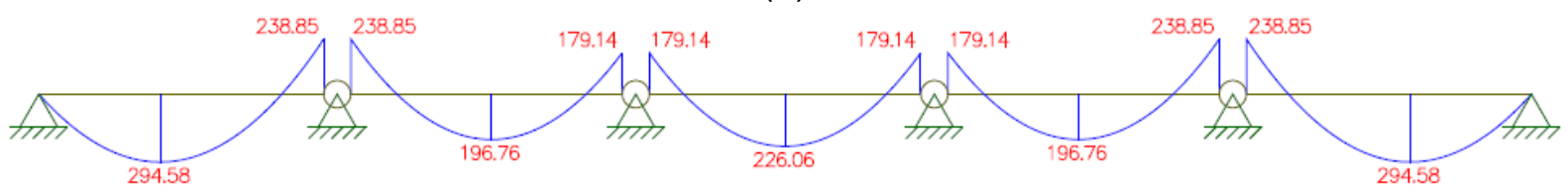

(b)

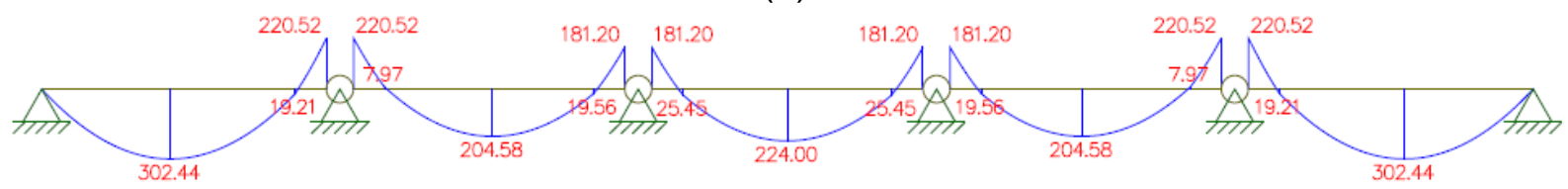

(c)

Figura 3.20 - Procedimento simplificado - viga V3: (a) modelo não fissurado sem redução; (b) modelo não fissurado com $30 \%$ de redução; (c) modelo fissurado com $15 \%$ de redução

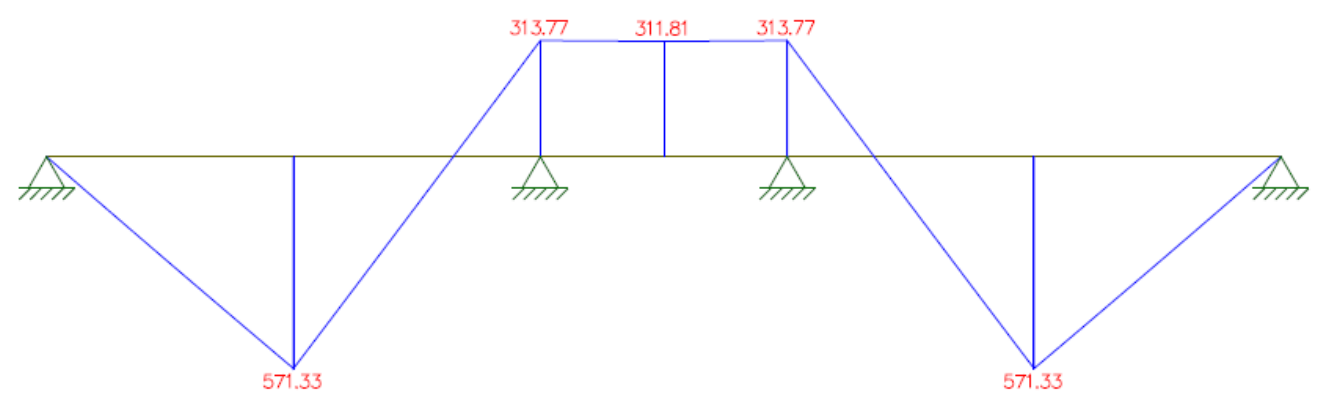

(a)

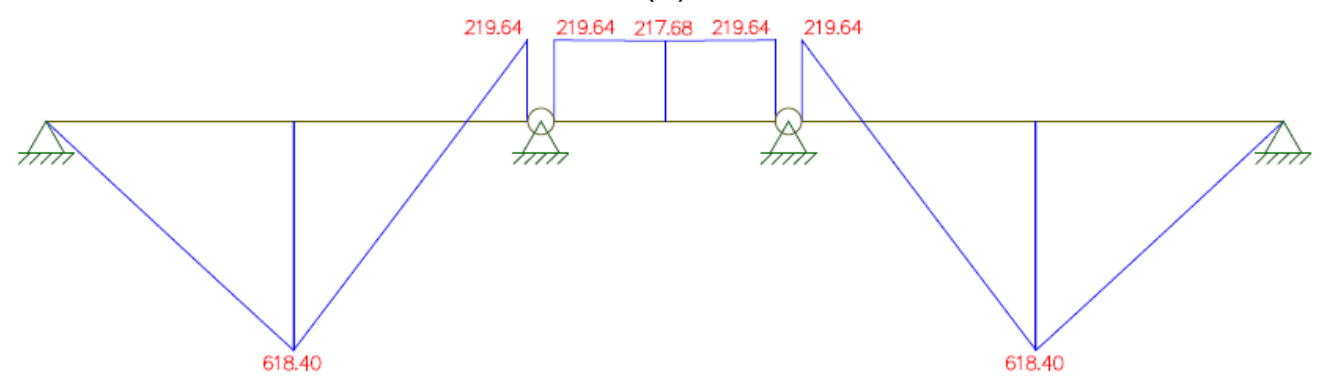

(b)

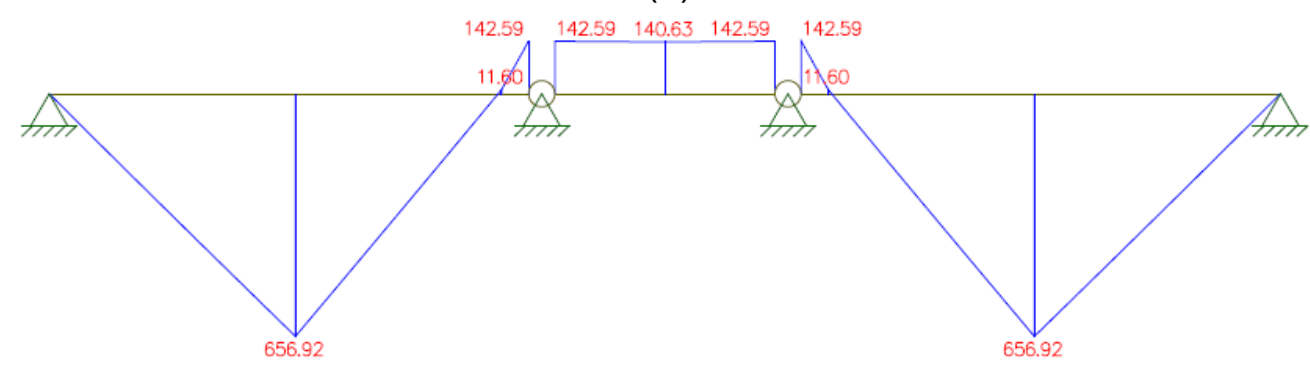

(c)

Figura 3.21 - Procedimento iterativo - viga V6: (a) modelo não fissurado sem redução; (b) modelo não fissurado com $30 \%$ de redução; (c) modelo fissurado com $15 \%$ de redução 
Ainda na Figura 3.21 pode-se destacar que mesmo com a contribuição da armadura os momentos fletores sobre os apoios são inferiores aos momentos fletores dos vãos.

A Tabela 3.8 apresenta os momentos fletores críticos para a combinação de ações gravitacionais calculados pela análise linear sem redistribuição dos momentos fletores e os desvios percentuais entre os modelos de análise desses esforços. Pode-se observar pela distribuição dos esforços que o sistema contínuo não é eficiente para as vigas transversais.

Tabela 3.8 - Momentos fletores críticos da combinação C4 e desvios percentuais entre esses esforços calculados com os modelos não fissurados sem redução, não fissurados com $30 \%$ redução e fissurados com $15 \%$ de redução

\begin{tabular}{|c|c|c|c|c|c|c|c|c|c|c|c|}
\hline & \multicolumn{2}{|c|}{ Modelos } & Flexão ${ }^{(a)}$ & $\begin{array}{c}\text { V2 } \\
\text { (VÃO 1-2) }\end{array}$ & $\begin{array}{c}\mathrm{V} 2 \\
(\mathrm{VÃO} 2-3)\end{array}$ & $\begin{array}{c}\text { V2 } \\
\text { (VÃO 3-4) }\end{array}$ & $\begin{array}{c}\text { V3 } \\
\text { (VÃO 1-2) }\end{array}$ & $\begin{array}{c}\text { V3 } \\
\text { (VÃO 2-3) }\end{array}$ & $\begin{array}{c}\text { V3 } \\
\text { (VÃO 3-4) }\end{array}$ & V4 & V6 \\
\hline \multirow{2}{*}{$\sum_{i}^{\infty} \frac{\widehat{E}}{\Sigma}$} & \multirow{2}{*}{\multicolumn{2}{|c|}{ Não-fissurado sem redução }} & $\mathrm{n}$ & 189,46 & 189,46 & 142,09 & 341,22 & 341,22 & 255,92 & 168,21 & 313,77 \\
\hline & & & $p$ & 140,22 & 59,83 & 82,89 & 252,55 & 107,75 & 149,29 & 297,62 & 571,33 \\
\hline \multirow{6}{*}{ 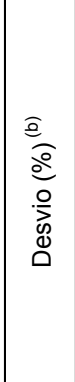 } & \multirow{2}{*}{$\begin{array}{c}\text { Não-fissurado } \\
\text { com } 30 \% \text { de } \\
\text { redução }\end{array}$} & \multirow{2}{*}{$\begin{array}{c}\text { Não-fissurado } \\
\text { sem redução }\end{array}$} & $\mathrm{n}$ & -30 & -30 & -30 & -30 & -30 & -30 & -30 & -30 \\
\hline & & & $\mathrm{p}$ & 17 & 83 & 51 & 17 & 83 & 51 & 8 & 8 \\
\hline & \multirow{2}{*}{$\begin{array}{l}\text { Fissurado } \\
\text { com } 15 \% \text { de } \\
\text { redução }\end{array}$} & \multirow{2}{*}{$\begin{array}{c}\text { Não-fissurado } \\
\text { sem redução }\end{array}$} & $\mathrm{n}$ & -33 & -33 & -27 & -35 & -35 & -29 & -54 & -55 \\
\hline & & & $p$ & 18 & 84 & 47 & 20 & 90 & 50 & 15 & 15 \\
\hline & \multirow{2}{*}{$\begin{array}{l}\text { Não-fissurado } \\
\text { com } 30 \% \text { de } \\
\text { redução }\end{array}$} & \multirow{2}{*}{$\begin{array}{l}\text { Fissurado } \\
\text { com } 15 \% \text { de } \\
\text { redução }\end{array}$} & $\mathrm{n}$ & 4 & 4 & -4 & 8 & 8 & -1 & 52 & 54 \\
\hline & & & $p$ & -1 & -1 & 3 & -3 & -4 & 1 & -6 & -6 \\
\hline
\end{tabular}

Esse fato justifica-se pela influência dos carregamentos e comprimentos das vigas V5 e V7 no comportamento estrutural das vigas adjacentes V4 e V6, respectivamente. As vigas internas dos eixos são praticamente descarregadas e possuem o vão equivalente apenas à metade do vão das vigas extremas.

Na sequência é calculada a bitola das vigas V3 (vão crítico) e V6 para as combinações gravitacionais a fim de analisar o desempenho delas frente ao sistema estrutural. 
Tabela 3.9 - Cálculo das vigas V3 (vão 1-2) e V6 variando o sistema estrutural entre contínuo e biapoiado

\begin{tabular}{|c|c|c|c|c|c|c|c|c|c|c|}
\hline Viga & $\begin{array}{c}\text { Sistema } \\
\text { estrutural }\end{array}$ & Bitola & $\begin{array}{c}\text { Barras } \\
(\mathrm{mm})\end{array}$ & Interação & $\begin{array}{c}\mathrm{M}_{\text {Rd.p }} \\
(\mathrm{kNm})\end{array}$ & $\frac{\mathrm{M}_{\text {Sd.p }}}{\mathrm{M}_{\text {Rd }}}$ & $\begin{array}{c}\mathrm{M}_{\text {Rd.n }} \\
(\mathrm{kNm})\end{array}$ & $\frac{\mathrm{M}_{\text {Sd.n }}}{\mathrm{M}_{\text {Rd.dist }}}$ & $\begin{array}{c}\delta_{\max } \\
(\mathrm{mm})\end{array}$ & $\frac{\delta_{\max }}{\delta_{\text {lim }}}$ \\
\hline V3 (vão 1-2) & contínuo & W $410 \times 38,8$ & $10 \times 8$ & completa & 468,03 & 0,65 & 253,62 & 0,87 & 20,17 & 0,78 \\
\hline V3 & biapoiado & W $460 \times 52,0$ & $12 \times 6,3$ & completa & 661,45 & 0,61 & - & - & 21,22 & 0,83 \\
\hline V6 & contínuo & W $460 \times 60,0$ & $6 \times 8$ & completa & 675,86 & 0,97 & 376,24 & 0,38 & 22,75 & 1,00 \\
\hline V6 & biapoiado & W $460 \times 68,0$ & $8 \times 6,3$ & completa & 795,67 & 0,93 & - & - & 20,66 & 0,90 \\
\hline
\end{tabular}

De acordo com a Tabela 3.9, o emprego do sistema contínuo às vigas das filas, representada pela viga V3 (vão 1-2), resulta em uma redução de $25 \%$ na massa linear do perfil, enquanto que sobre as vigas dos eixos, expresso pela viga V6, essa redução atinge apenas $12 \%$. Sendo assim, na direção dos eixos, as vigas contínuas só serão viáveis em virtude da necessidade de garantir a estabilidade lateral da estrutura, visto que se trata de ligações onerosas e complexas.

Normalmente, nas vigas não escoradas, os deslocamentos governam o dimensionamento e assim torna-se desnecessário a interação completa entre os materiais, pois além da folga na resistência à flexão, o grau de interação aço e concreto tem pouca influência sobre os deslocamentos desses sistemas construtivos empregados a edifícios escritórios.

Outra situação interessante que abrange às vigas escoradas é o fato das bitolas catalogadas dos perfis muitas vezes apresentarem a resistência ou rigidez à flexão além do necessário e, independente do estado limite crítico, pode-se economizar no número de conectores amenizando o desperdício de material. A Tabela 3.10 traz o cálculo das vigas do Edifício Modelo 1 e ilustra essa situação.

Ainda sobre o número de conectores também pode-se destacar no quadro seguinte que uma redução de $50 \%$ neste número conduz a uma perda de resistência a flexão de aproximadamente $15 \%$ enquanto que uma redução $30 \%$ conduz a uma perda inferior a 10\%. Quanto aos deslocamentos, a primeira redução conduz a um acréscimo de $22 \%$ e $17 \%$ nas vigas biapoiadas e contínuas, respectivamente, enquanto que a segunda atinge respectivos acréscimos de $10 \%$ e $7 \%$. 


\begin{tabular}{|c|c|c|c|c|c|c|c|c|c|c|c|c|c|c|c|c|c|c|}
\hline$\zeta$ & ๙ & $\uparrow$ & & 8 & 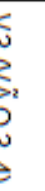 & 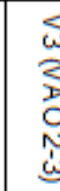 & & 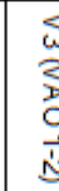 & & & 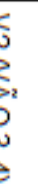 & 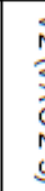 & : & 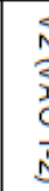 & 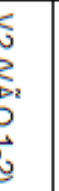 & $\leq$ & & 产 \\
\hline 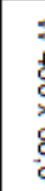 & 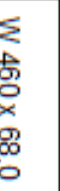 & $\begin{array}{l}\$ \\
t \\
c \\
x \\
f \\
0\end{array}$ & & 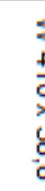 & $\begin{array}{l}5 \\
5 \\
5 \\
0 \\
0 \\
0\end{array}$ & 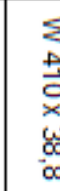 & & 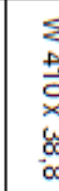 & & 8 & o & 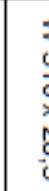 & . & . & . & 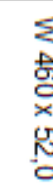 & & $\frac{\mathrm{g}}{\frac{\mathrm{g}}{\omega}}$ \\
\hline & 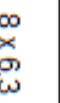 & $\begin{array}{l}0 \\
x \\
0 \\
a\end{array}$ & & হ & & 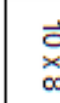 & & $\underset{\alpha}{\vec{c}}$ & & > & & & $\begin{array}{l}1 \\
x \\
x\end{array}$ & (3) & $\begin{array}{l}1 \\
0 \\
0\end{array}$ & $\begin{array}{l}\vec{N} \\
\stackrel{x}{a} \\
\vdots \\
\omega\end{array}$ & & 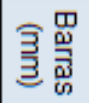 \\
\hline$\vec{ज}$ & $\mathrm{~N}$ & 0 & $\vec{\omega}$ & $\infty$ & $\Rightarrow$ & $\infty$ & $\vec{v}$ & $\overrightarrow{0}$ & N & $v$ & $\overrightarrow{0}$ & $v$ & $\overrightarrow{0}$ & $\infty$ & $\vec{N}$ & $\vec{N}$ & $\stackrel{\sim}{A}$ & בू \\
\hline ర్ & $\mid \begin{array}{l}\frac{8}{3} \\
\frac{\frac{3}{0}}{\frac{9}{9}} \\
\frac{9}{\omega}\end{array}$ & ठ̀ & $\frac{8}{\frac{3}{3}}$ & ज्ञ & 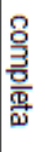 & o. & $\begin{array}{l}\frac{8}{3} \\
\frac{3}{3} \\
\frac{\bar{g}}{6}\end{array}$ & 망 & 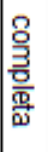 & పे & $\begin{array}{l}\frac{8}{3} \\
\frac{3}{3} \\
\frac{0}{10}\end{array}$ & \% & $\frac{8}{\frac{3}{3}} \frac{\overline{3}}{\frac{0}{0}}$ & б̆ & $\frac{8}{\frac{3}{3}}$ & 용 & $\frac{8}{\frac{3}{3}}$ & 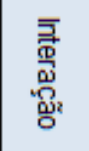 \\
\hline 悶 & 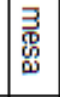 & 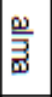 & 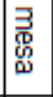 & 崩 & 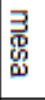 & 岕 & 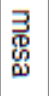 & 岕 & 艿 & 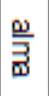 & 胥 & 岕 & 艿 & 艿 & 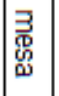 & 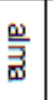 & 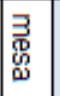 & $\sum_{0}$ \\
\hline $\begin{array}{l}\tilde{w} \\
\text { जu } \\
\text { N }\end{array}$ & \begin{tabular}{|l|}
\multicolumn{1}{c}{} \\
0 \\
9 \\
9
\end{tabular} & $\begin{array}{l}\vec{\omega} \\
\stackrel{\sigma}{\sigma} \\
\sigma\end{array}$ & \begin{tabular}{|l|} 
\\
0 \\
0 \\
0 \\
0
\end{tabular} & $\begin{array}{l}\frac{\omega}{\sigma} \\
\frac{1}{N}\end{array}$ & 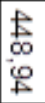 & \begin{tabular}{|c|}
$\omega$ \\
$\tilde{J}$ \\
$\stackrel{N}{N}$
\end{tabular} & 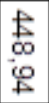 & 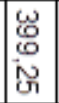 & \begin{tabular}{|l} 
\\
\\
0 \\
$o$ \\
0 \\
\end{tabular} & $\begin{array}{l}\tilde{p} \\
\tilde{N} \\
\vec{\omega} \\
\end{array}$ & $\begin{array}{l}\tilde{G} \\
\Phi \\
\vec{\omega}\end{array}$ & 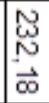 & \begin{tabular}{|l} 
\\
$\bar{G}$ \\
$\vec{\omega}$
\end{tabular} & 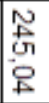 & 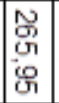 & 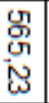 & $\begin{array}{l}\mathscr{O} \\
\overrightarrow{\vec{A}} \\
\text { से }\end{array}$ & 촐륭 \\
\hline$\vec{\circ}$ & $\begin{array}{l}\circ \\
\stackrel{0}{\circ}\end{array}$ & $\begin{array}{l}0 \\
\text { o } \\
\text { g }\end{array}$ & \begin{tabular}{l}
0 \\
$\stackrel{0}{0}$ \\
\hdashline \\
\end{tabular} & 잉 & 응 & 웅 & 웅 & $\stackrel{0}{\perp}$ & 品 & 䠐 & $\begin{array}{l}\text { O० } \\
\text { \& }\end{array}$ & $\stackrel{\nexists}{\ddagger}$ & \& & 这 & 이 & 옥 & 웅 & 艿| \\
\hline 1 & . & . &. & $\omega$ & $\omega$ & 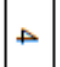 & $A$ & $A$ & $A$ & 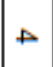 & 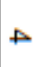 & or & or & or & or & ' & . & ב্ं \\
\hline 1 & ' & 1 & 1 & 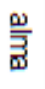 & $\frac{\omega}{\bar{\Xi}}$ & 訔 & 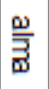 & 岕 & 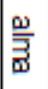 & 岂 & $\stackrel{\omega}{\bar{\Xi}}$ & 岕 & 岸 & 岂 & 惢 & ' & 1. & $\sum_{0}$ \\
\hline 1 & 1 & 1 & 1 & \begin{tabular}{l} 
N \\
0 \\
$\vdots$ \\
\multirow{E}{*}{}
\end{tabular} & \begin{tabular}{|l}
$\tilde{N}$ \\
0 \\
0 \\
0
\end{tabular} & $\mid \begin{array}{c}\tilde{N} \\
\tilde{W} \\
\text { जे }\end{array}$ & $\begin{array}{l}N \\
\tilde{W} \\
0 \\
\tilde{W}\end{array}$ & 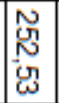 & $\begin{array}{l}\text { 岱 } \\
\text { 员 }\end{array}$ & 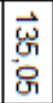 & 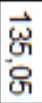 & 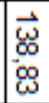 & \begin{tabular}{|l}
$\vec{\omega}$ \\
$\ddot{\omega}$ \\
$\ddot{\omega}$
\end{tabular} & $\vec{f}$ & \begin{tabular}{|l|}
$\overrightarrow{ \pm}$ \\
$\vec{\infty}$
\end{tabular} & , & 1 & 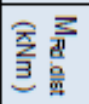 \\
\hline 1 & ' & ' & 1 & $\begin{array}{l}\circ \\
\text { o } \\
\text { o }\end{array}$ & $\stackrel{\circ}{0}$ & 잉 & $\begin{array}{l}\circ \\
\text { : } \\
\text { N }\end{array}$ & $\begin{array}{l}\circ \\
\text { OO } \\
\text { N }\end{array}$ & 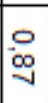 & ने & $\stackrel{0}{*}$ & ب & 总 & 足 & 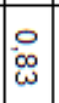 & ' & ' & 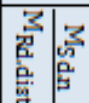 \\
\hline $\begin{array}{l}\overrightarrow{0} \\
\vec{\circ} \\
\dot{\circ}\end{array}$ & \begin{tabular}{|l|}
$\overrightarrow{0}$ \\
$\overrightarrow{\overrightarrow{+}}$ \\
$\dot{+}$
\end{tabular} & \begin{tabular}{|l|}
$\overrightarrow{0}$ \\
o \\
$\omega$ \\
$\omega$
\end{tabular} & 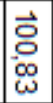 & $\begin{array}{l}\overrightarrow{\text { o }} \\
\text { 응 }\end{array}$ & \begin{tabular}{|l|}
$\overrightarrow{0}$ \\
$\stackrel{\circ}{\circ}$ \\
$\stackrel{\circ}{\circ}$
\end{tabular} & 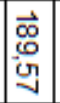 & $\begin{array}{l}\overrightarrow{0} \\
\text { on } \\
\text { on }\end{array}$ & \begin{tabular}{|l|} 
\\
0 \\
0 \\
0 \\
8 \\
\end{tabular} & $\begin{array}{l}\text { N } \\
\text { on } \\
0 \\
8\end{array}$ & \begin{tabular}{|l|} 
\\
\\
$\circ$ \\
\end{tabular} & $\begin{array}{l}\circ \\
: \\
\circ\end{array}$ & 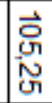 & 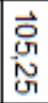 & $\begin{array}{l}\overrightarrow{\vec{N}} \\
\overrightarrow{\vec{A}}\end{array}$ & \begin{tabular}{|l|}
$\overrightarrow{\mathrm{N}}$ \\
$\overrightarrow{\vec{A}}$ \\
$\dot{A}$
\end{tabular} & $\begin{array}{l}\overrightarrow{0} \\
\overrightarrow{0} \\
\overrightarrow{0}\end{array}$ & \begin{tabular}{|l|}
$\overrightarrow{0}$ \\
$\overrightarrow{0}$ \\
$\overrightarrow{0}$
\end{tabular} & 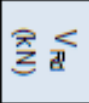 \\
\hline 品 & 唨 & $\stackrel{\circ}{\overrightarrow{0}}$ & $\stackrel{0}{\overrightarrow{0}}$ & O & 逼 & $\begin{array}{l}0 \\
8 \\
8\end{array}$ & 웅 & 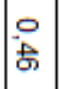 & 足 & 음 & $\overline{8}$ & 응 & 这 & 吕 & 怘 & $\stackrel{\circ}{\stackrel{O}{\infty}}$ & 品 & 局 绐 \\
\hline $\begin{array}{l}\text { N } \\
\text { 今 } \\
\text { o }\end{array}$ & 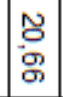 & $\begin{array}{l}N \\
\stackrel{N}{\omega} \\
\omega\end{array}$ & $\begin{array}{l}\tilde{y} \\
0 \\
0 \\
\end{array}$ & 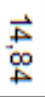 & $\mid \begin{array}{l}\vec{\omega} \\
\omega \\
\omega\end{array}$ & 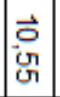 & $\begin{array}{l}\overrightarrow{0} \\
\vec{N}\end{array}$ & $\mid \begin{array}{c}\tilde{w} \\
\mathcal{N} \\
\omega\end{array}$ & $\stackrel{\vec{O}}{\vec{*}}$ & 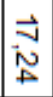 & $\begin{array}{l}\vec{\sigma} \\
\omega \\
\text { v }\end{array}$ & $\vec{N}$ & $\vec{N}$ & $\begin{array}{l}\mathrm{O} \\
\mathrm{N} \\
\mathrm{N}\end{array}$ & 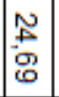 & $\begin{array}{l}\tilde{M} \\
0 \\
0 \\
\end{array}$ & 出 & 雪复 \\
\hline 웅 & 잉 & 응 & 웅 & 응 & 우N & $\stackrel{0}{\circ}$ & 怘 & \begin{tabular}{l|} 
\\
용 \\
N
\end{tabular} & 음 & 옹 & $\begin{array}{l}\circ \\
\stackrel{9}{\circ} \\
+\end{array}$ & 웅 & $\stackrel{\circ}{\circ}$ & $\vec{\omega}$ & 용 & $\vec{\circ}$ & \begin{tabular}{|l|}
0 \\
$\infty$ \\
$\infty$ \\
$\omega$ \\
\end{tabular} & 害| \\
\hline$\stackrel{N}{\vec{\omega}}$ & $\stackrel{N}{\overrightarrow{0}}$ & $\vec{c}$ & $\vec{c}$ & $\stackrel{\omega}{\sim}$ & $\stackrel{\omega}{\sim}$ & $\begin{array}{c}\omega \\
\beth \\
\beth\end{array}$ & $\stackrel{\omega}{\sim}$ & $\underset{\omega}{\omega}$ & $\underset{\omega}{\omega}$ & $\begin{array}{l}N \\
\tilde{w} \\
\mathcal{N}\end{array}$ & $\stackrel{N}{\omega}$ & $\stackrel{N}{\sim}$ & N & $\frac{N}{\sim}$ & $\mid \begin{array}{c}N \\
\tilde{w} \\
\sigma_{N}\end{array}$ & $\begin{array}{l}\omega \\
\mathbb{N} \\
\mathbb{O}\end{array}$ & \begin{tabular}{|l}
$\omega$ \\
$\mathbb{N}$ \\
$\mathbb{O}$
\end{tabular} & 嶌 \\
\hline $\overrightarrow{\vec{A}}$ & $\overrightarrow{\overrightarrow{\vec{A}}}$ & $\vec{\circ}$ & $\overrightarrow{0}$ & $\vec{\psi}$ & $\overrightarrow{\tilde{\omega}^{\prime}}$ & $\overrightarrow{\tilde{\varphi}^{\prime}}$ & $\overrightarrow{\tilde{\omega}}$ & $\overrightarrow{\tilde{\omega}^{\prime}}$ & $\overrightarrow{\tilde{\omega}^{\prime}}$ & $\overrightarrow{\text { 잉 }}$ & $\vec{\circ}$ & $\overrightarrow{\text { 잉 }}$ & 잉 & 당 & $\overrightarrow{\text { 잉 }}$ & $\overrightarrow{\vec{\perp}}$ & $\overrightarrow{\vec{A}}$ & 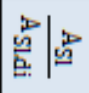 \\
\hline 우 & 品 & 总 & 总 & $\overrightarrow{\tilde{N}}$ & $\overrightarrow{0}$ & $\vec{N}$ & $\overrightarrow{\vec{v}}$ & $\vec{N}$ & $\vec{O}$ & $\overrightarrow{8}$ & 응 & $\overrightarrow{8}$ & $\overrightarrow{8}$ & 8 & $\overrightarrow{8}$ & $\stackrel{\circ}{\circ}$ & o & 雪品 \\
\hline$\vec{\omega}$ & $\vec{\omega}$ & 0 & $\vec{\omega}$ & 10 & 1 & $\overrightarrow{\mathrm{G}}$ & 10 & $\overrightarrow{\mathrm{I}}$ & 1 & 0 & & 0 & 10 & 16 & $\overrightarrow{8}$ & 0 & $\vec{\omega}$ & 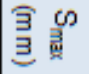 \\
\hline
\end{tabular}


$\mathrm{Na}$ padronização das vigas do piso buscou-se adotar bitolas com a mesma altura de forma a facilitar a passagem de dutos e fixação de forros. Com base na resistência e rigidez à flexão das seções das vigas apresentadas na Tabela 3.10 pode-se dividir o vigamento em duas bitolas. Uma bitola para atender as vigas biapoiadas calculadas em função da viga V6 e a outra para englobar as vigas contínuas governadas, por sua vez, pela viga V3 com vão entre os eixos 1 e 2.

Essa padronização é apresentada na segunda coluna da Tabela 3.11. A divisão das bitolas das vigas resulta em um aumento de aproximadamente $25 \%$ no peso do vigamento, enquanto que para um único perfil (W $460 \times 68$ ), esse aumento ultrapassa os 45\%. Assim, em casos como esse, sistemas de pisos tornam-se mais econômicos quando além de apresentarem o menor caminho das cargas até os pilares, apresentarem uma distribuição das alturas das vigas mais homogênea.

Com base na padronização para dois perfis, o consumo de aço do vigamento foi avaliado em função do sistema construtivo, material e tipo de fabricação do perfil conforme o quadro abaixo.

Tabela 3.11 - Padronização do sistema horizontal do Edifício Modelo 1

\begin{tabular}{|c|c|c|c|c|c|c|c|c|}
\hline \multirow{2}{*}{$\begin{array}{c}\text { SISTEMA } \\
\text { CONSTRUTNO } \\
\text { PERFIL }\end{array}$} & \multicolumn{4}{|c|}{ Escorado } & \multicolumn{4}{|c|}{ Não-escorado } \\
\hline & W & W & VS & $\mathrm{PS}^{(\mathrm{b})}$ & W & W & $\mathrm{PS}^{(\mathrm{b})}$ & $\mathrm{PS}^{(\mathrm{b})}$ \\
\hline AÇO (ASTM) & A572 G50 & A36 & A572 G50 & A572 G50 & A572 G50 & A36 & A572 G50 & A572 G50 (c) \\
\hline V1 & W $410 \times 75$ & W $530 \times 74$ & VS $450 \times 71$ & PS $450 \times 65$ & W $530 \times 74$ & W $530 \times 74$ & VS $500 \times 73$ & PS $450 \times 37^{\text {(c) }}$ \\
\hline V2 & W $410 \times 38,8$ & W $530 \times 66$ & VS $450 \times 60$ & PS $450 \times 37$ & W $530 \times 66$ & W $530 \times 66$ & PS $500 \times 53$ & PS $450 \times 37^{(\mathrm{c})}$ \\
\hline V3 & W $410 \times 38,8$ & W $530 \times 66$ & VS $450 \times 60$ & PS $450 \times 37$ & W $530 \times 66$ & W $530 \times 66$ & PS $500 \times 53$ & PS $450 \times 37^{(\mathrm{c})}$ \\
\hline V4 e V5 & W $410 \times 75$ & W $530 \times 74$ & VS $450 \times 71$ & PS $450 \times 65$ & W $530 \times 74$ & W $530 \times 74$ & VS $500 \times 73$ & PS $450 \times 65^{\text {(c) }}$ \\
\hline V6 e V7 & W $410 \times 75$ & W $530 \times 74$ & VS $450 \times 71$ & PS $450 \times 65$ & W $530 \times 74$ & W $530 \times 74$ & VS $500 \times 73$ & PS $450 \times 65^{(c)}$ \\
\hline CONSUMO (t/puto.) & 22,7 & 27,4 & 25,7 & 20,3 & 27,4 & 27,4 & 24,9 & 17,8 \\
\hline DESVIO (\%) ${ }^{\text {(a) }}$ & 0 & 21 & 13 & -11 & 21 & 21 & 9 & -22 \\
\hline \multicolumn{9}{|c|}{ (a) valores negativos indicam que o consumo da segunda coluna é maior } \\
\hline
\end{tabular}

Nas vigas escoradas calculadas para o aço ASTM A36 pode-se destacar a redução por volta de $20 \%$ nas resistências à flexão. Dessa maneira os perfis sofrem um aumento na altura das bitolas, uma vez que as vigas V3 (VÃO 1-2) e V6 tem o dimensionamento governado pela resistência à flexão (Tabela 3.10). A proximidade da massa linear dos perfis contínuos e biapoiados ilustra a dificuldade em padronizar o vigamento para a mesma altura frente às bitolas catalogadas do perfil $\mathrm{W}$. 
Tal proximidade também é verificada no calculo do vigamento com perfil soldado padronizado (VS). Porém, neste caso, o fato é decorrente da instabilidade na região de momento negativo dos elementos componentes dos perfis com bitolas mais leves e aço ASTM A572 G50. O emprego do perfil não padronizado (PS) apresenta-se como excelente alternativa para a solução desse sistema horizontal.

As propriedades geométricas das seções PS são apresentadas na Tabela 4.3. Vale ressaltar que a largura mínima das mesas das vigas deve obedecer às larguras mínimas de apoio das lajes. Essas larguras determinam o valor da resistência ao esmagamento da alma da fôrma (MANUAL [...], 2007). Para as fôrmas incorporadas com $75 \mathrm{~mm}$ de altura adota-se $75 \mathrm{~mm}$ na largura dos apoios externos e $150 \mathrm{~mm}$ nos apoios internos.

Essas observações, exceto a viabilidade econômica do aço ASTM A 36, naturalmente, também são verificadas para os sistemas construtivos não escorados. As vigas não escoradas analisadas favorecem o emprego do aço ASTM A36 que, devido à folga nas resistências, não tem nenhum prejuízo na redução das mesmas.

O aumento do consumo de aço nas vigas não escoradas em relação às vigas escoradas deve-se ao fato do dimensionamento daquelas ser, normalmente, governado pelo limite de deslocamentos excessivos. Esse quadro é decorrente, principalmente, dos deslocamentos da seção de aço (considerado biapoiado independente da continuidade da viga após a cura) submetido às ações permanentes atuantes antes do endurecimento do concreto.

A partir do desempenho das vigas não escoradas demonstrado nas Tabelas 3.12 a 3.143.143.14, observa-se que essas vigas quando submetidas a uma contraflecha equivalente ao deslocamento das ações permanentes atuantes antes da cura do concreto tornam o vigamento extremamente econômicas atingindo uma redução de $30 \%$ do consumo de aço em relação às vigas calculadas sem a contraflecha. 
Tabela 3.12 - Cálculo das vigas mistas não escoradas sob contraflecha segundo a combinação C4: estado limite último, deslocamento e contraflecha da seção de aço

\begin{tabular}{|c|c|c|c|c|c|c|}
\hline \multirow{2}{*}{ Viga } & \multirow{2}{*}{ Bitola } & \multirow{2}{*}{ Barras $(\mathrm{mm})$} & \multicolumn{4}{|c|}{ Seção de aço isolada (antes da cura) } \\
\cline { 4 - 8 } & & $\begin{array}{c}\mathrm{M}_{\text {a.Rd.p }} \\
(\mathrm{kNm})\end{array}$ & $\frac{\mathrm{M}_{\mathrm{a} . S d}}{\mathrm{M}_{\mathrm{a} . \mathrm{Rd}}}$ & $\begin{array}{c}\delta_{\mathrm{Ga}} \\
(\mathrm{mm})\end{array}$ & $\begin{array}{c}\delta_{0} \\
(\mathrm{~mm})\end{array}$ \\
\hline \multirow{2}{*}{ V1 } & VS $500 \times 73$ & $12 \times 6,3 \mathrm{~mm}$ & 570,00 & 0,36 & 11,52 & 0,00 \\
\cline { 4 - 8 } & PS $450 \times 37$ & $12 \times 6,3 \mathrm{~mm}$ & 226,13 & 0,90 & 36,04 & 36,04 \\
\hline \multirow{2}{*}{ V3 (VÃO 1-2) } & PS $500 \times 53$ & $8 \times 8 \mathrm{~mm}$ & 398,14 & 0,51 & 17,65 & 0,00 \\
\cline { 2 - 8 } & PS $450 \times 37$ & $10 \times 8 \mathrm{~mm}$ & 226,13 & 0,90 & 36,04 & 36,04 \\
\hline \multirow{2}{*}{ V6 } & VS $500 \times 73$ & $8 \times 6,3 \mathrm{~mm}$ & 570,00 & 0,65 & 13,38 & 0,00 \\
\cline { 2 - 7 } & PS $450 \times 65$ & $8 \times 6,3 \mathrm{~mm}$ & 466,57 & 0,79 & 18,85 & 18,85 \\
\hline
\end{tabular}

Tabela 3.13 - Cálculo das vigas mistas não escoradas sob contraflecha segundo a combinação C4: estados limites últimos da seção mista aço e concreto

\begin{tabular}{|c|c|c|c|c|c|c|c|c|c|c|c|}
\hline \multirow[b]{2}{*}{ Viga } & \multicolumn{11}{|c|}{ Seção mista aço-concreto (depois da cura) } \\
\hline & $\mathrm{n}_{\mathrm{cs} . \mathrm{p}}$ & Interação & $\mathrm{LNP}_{\mathrm{p}}$ & $\begin{array}{l}\mathrm{M}_{\text {Rd.p }} \\
(\mathrm{kNm})\end{array}$ & $\frac{M_{\text {Sd.p }}}{M_{\text {Rd.p }}}$ & $\mathrm{n}_{\mathrm{cs} . \mathrm{n}}$ & $\mathrm{LNP}_{\mathrm{n}}$ & $\begin{array}{c}M_{\text {dist.Rd.n }} \\
(\mathrm{kNN})\end{array}$ & $\frac{\mathrm{M}_{\text {Sd.n }}}{\mathrm{M}_{\text {dist.Rd.n }}}$ & $\begin{array}{l}\mathrm{V}_{\mathrm{Rd}} \\
(\mathrm{kN})\end{array}$ & $\frac{\mathrm{V}_{\mathrm{Sd}}}{\mathrm{V}_{\mathrm{Rd}}}$ \\
\hline \multirow{2}{*}{ V1 } & 12 & $50 \%$ & alma & 814,98 & 0,50 & - & - & - & - & 453,49 & 0,40 \\
\hline & 10 & $50 \%$ & alma & 411,92 & 0,98 & - & - & - & - & 458,63 & 0,39 \\
\hline \multirow{2}{*}{ V3 (VÃO 1-2) } & 10 & $50 \%$ & alma & 598,03 & 0,50 & 3 & alma & 380,42 & 0,62 & 453,49 & 0,48 \\
\hline & 10 & $50 \%$ & alma & 409,41 & 0,73 & 3 & alma & 237,99 & 0,98 & 458,63 & 0,48 \\
\hline \multirow{2}{*}{ V6 } & 22 & completa & mesa & 888,59 & 0,82 & - & - & - & - & 453,49 & 0,41 \\
\hline & 22 & completa & mesa & 743,24 & 0,98 & - & - & - & - & 468,34 & 0,39 \\
\hline
\end{tabular}

Tabela 3.14 - Cálculo das vigas mistas não escoradas sob contraflecha segundo a combinação C4: estados limites de serviço da seção mista aço e concreto

\begin{tabular}{|c|c|c|c|c|c|c|c|c|c|}
\hline \multirow{2}{*}{ Viga } & \multicolumn{7}{|c|}{ Seção mista aço-concreto (depois da cura) } \\
\cline { 2 - 10 } & $\begin{array}{c}\Phi_{\max } \\
(\mathrm{mm})\end{array}$ & $\begin{array}{c}\mathrm{A}_{\text {sl.di }} \\
\left(\mathrm{cm}^{2}\right)\end{array}$ & $\frac{\mathrm{A}_{\mathrm{Sl}}}{\mathrm{A}_{\mathrm{Sl.di}}}$ & $\begin{array}{c}\mathrm{S}_{\mathrm{ad}} \\
(\mathrm{mm})\end{array}$ & $\begin{array}{c}\mathrm{S}_{\max } \\
(\mathrm{mm})\end{array}$ & $\begin{array}{c}\delta_{\text {final }} \\
(\mathrm{mm})\end{array}$ & $\begin{array}{c}\delta_{\text {tot }} \\
(\mathrm{mm})\end{array}$ & $\begin{array}{c}\delta_{\max } \\
(\mathrm{mm})\end{array}$ & $\begin{array}{c}\delta_{\max } \\
\delta_{\lim }\end{array}$ \\
\hline \multirow{2}{*}{ V1 } & - & 3,29 & 1,14 & 95 & 130 & 8,99 & 20,51 & 20,51 & 0,80 \\
\cline { 2 - 11 } & - & 3,29 & 1,14 & 95 & 130 & 19,92 & 55,96 & 19,92 & 0,77 \\
\hline \multirow{2}{*}{ V3 (VÃO 1-2) } & 16 & 3,71 & 1,08 & 145 & 150 & 7,41 & 25,06 & 25,06 & 0,97 \\
\cline { 2 - 11 } & 16,0 & 3,71 & 1,35 & 115 & 150 & 15,91 & 48,50 & 12,46 & 0,48 \\
\hline \multirow{2}{*}{ V6 } & - & 2,19 & 1,14 & 95 & 130 & 8,84 & 22,22 & 22,22 & 0,97 \\
\cline { 2 - 10 } & - & 2,19 & 1,14 & 95 & 130 & 11,51 & 30,37 & 11,51 & 0,50 \\
\hline
\end{tabular}

A viga V3 (VÃO 1-2) com contraflecha é a viga calculada no APÊNDICE B. 
3.8.3.2 Avaliações adicionais: $C_{d i s t}, \delta_{2 \alpha}, f_{c k}$ e $t_{c}$

Os valores de $M_{\text {dist.Rd.n }}$ das vigas da Tabela 3.10 foram analisados para as duas possibilidades de se avaliar a flambagem lateral distorcional. Uma pelo uso das Tabelas 3.3 e 3.4, encontrando o valor de $C_{\text {dist, }}$ e a outra pelo uso da equação 3.38 , calculando o valor de $C_{b}$. Com base na Tabela 3.15 pode-se observar que o segundo método é muito conservador para as vigas em questão. Como as tabelas de $\mathrm{C}_{\text {dist }}$ não abrangem as principais possiblidades de carregamento nas vigas de edifícios, o dimensionamento num caso não tabelado pode desperdiçar resistência.

Tabela 3.15 - Desvio entre os momentos fletores resistentes de cálculo $M_{\text {dist.Rd.n }}$ e $M_{R d . n}$ das vigas escoradas (interação completa) segundo a determinação de $C_{\text {dist }}$ pelos coeficientes $\mathrm{C}_{\text {dist }}$ e $\mathrm{C}_{\mathrm{b}}$

\begin{tabular}{|c|c|c|c|c|c|c|}
\hline VIGA & \multicolumn{3}{|c|}{ V2 } & \multicolumn{3}{|c|}{ V3 } \\
\hline VÃO & $1-2$ & $2-3$ & $3-4$ & $1-2$ & $2-3$ & $3-4$ \\
\hline $\begin{array}{l}\mathrm{M}_{\mathrm{Rd} . \mathrm{n}} \\
(\mathrm{kNm})\end{array}$ & 163,71 & 163,71 & 163,71 & 286,96 & 286,96 & 286,96 \\
\hline $\begin{array}{l}\left(\mathrm{M}_{\text {dist.Rd. }}\right)_{\text {Cdist }} \\
(\mathrm{kNNm})\end{array}$ & 147,18 & 139,63 & 135,05 & 253,62 & 238,53 & 229,64 \\
\hline Desvio (\%) ${ }^{(a)}$ & -10 & -15 & -18 & -12 & -17 & -20 \\
\hline $\begin{array}{c}\left(\mathrm{M}_{\text {dist.Rd.n. }}\right)_{\mathrm{Cb}} \\
(\mathrm{kNm})\end{array}$ & 109,15 & 65,92 & 66,12 & 232,50 & 140,44 & 140,97 \\
\hline Desvio (\%) (a) & -33 & -60 & -60 & -19 & -51 & -51 \\
\hline
\end{tabular}

A Tabela 3.16 reúne os valores dos deslocamentos das vigas escoradas calculados pelo procedimento alternativo, proposto pela EN 1994-1-1:2004, representado aqui por $\delta_{2 \alpha}$, e o procedimento convencional, que faz uso da sobreposição das flechas resultantes dos efeitos de curta duração e longa duração na seção mista, representado aqui por $\delta_{\text {final. }}$ 
Tabela 3.16 - Desvio entre os deslocamentos $\delta_{2 \alpha}$ e $\delta_{\text {final }}$ das vigas escoradas com interação completa

\begin{tabular}{|c|c|c|c|c|c|c|}
\hline VIGA & \multicolumn{3}{|c|}{ V2 } & \multicolumn{3}{|c|}{ V3 } \\
\hline VÃO & $1-2$ & $2-3$ & $3-4$ & $1-2$ & $2-3$ & $3-4$ \\
\hline$\delta_{\text {final }}(\mathrm{mm})$ & 24,69 & 12,33 & 16,37 & 20,17 & 10,12 & 13,39 \\
\hline$\delta_{2 a}(\mathrm{~mm})$ & 22,97 & 12,37 & 15,85 & 19,07 & 10,29 & 13,14 \\
\hline Desvio (\%) ${ }^{(a)}$ & $-6,97$ & 0,32 & $-3,18$ & $-5,45$ & 1,68 & $-1,87$ \\
\hline
\end{tabular}

Com base no quadro acima, ainda que desfavorável ao limite de deslocamento excessivo, no procedimento alternativo o desvio crítico $(7 \%)$ relativo ao procedimento convencional aplicado é baixo. Assim, frente à redução de duas análises elásticas na avaliação dos deslocamentos, a alternativa torna-se bastante interessante para o pré-dimensionamento das vigas em questão.

Ainda foi analisado o comportamento da viga V1 da Tabela 3.10 a partir de duas pequenas alterações, compatíveis com o projeto. Uma na resistência característica do concreto e outra na espessura da laje.

Tabela 3.17 - Análise da viga escorada V1 frente à variação da resistência característica do concreto e espessura da laje

\begin{tabular}{|c|c|c|c|c|c|c|c|c|c|}
\hline Bitola & $\begin{array}{c}\mathrm{t}_{\mathrm{c}} \\
(\mathrm{mm})\end{array}$ & $\begin{array}{c}\mathrm{f}_{\mathrm{ck}} \\
\left(\mathrm{kN} / \mathrm{cm}^{2}\right)\end{array}$ & Interação & $\mathrm{LNP}_{\mathrm{p}}$ & $\mathrm{M}_{\mathrm{Rd}}$ & $\frac{M_{\text {Sd.p }}}{M_{\text {Rd.p }}}$ & $\mathrm{LNE}_{\mathrm{p}}$ & $\begin{array}{c}\delta_{\text {final }} \\
(\mathrm{mm})\end{array}$ & $\frac{\delta_{\text {final }}}{\delta_{\max }}$ \\
\hline W $460 \times 52$ & 65 & 2 & $100 \%$ & mesa & 661,45 & 0,61 & alma & 21,22 & 0,83 \\
\hline W $460 \times 52$ & 65 & 3,5 & $100 \%$ & laje & 716,79 & 0,57 & alma & 19,45 & 0,76 \\
\hline W $410 \times 75$ & 65 & 2 & $100 \%$ & mesa & 806,73 & 0,50 & mesa & 18,63 & 0,72 \\
\hline W $410 \times 75$ & 65 & 3,5 & $100 \%$ & mesa & 946,70 & 0,43 & alma & 16,95 & 0,66 \\
\hline W $460 \times 52$ & 75 & 2 & $100 \%$ & mesa & 701,00 & 0,60 & alma & 20,61 & 0,80 \\
\hline
\end{tabular}

No estudo do emprego do concreto com $\mathrm{f}_{\mathrm{ck}}=3,5 \mathrm{kN} / \mathrm{cm}^{2}$, observou-se pela Tabela 3.17 um acréscimo na resistência à flexão de $8 \%$ e 17\% para as bitolas W 460 x 52 e W 410 x 75, respectivamente. Essa divergência é decorrente da posição da linha neutra plástica $\left(\operatorname{LNP}_{\mathrm{p}}\right)$. Quanto aos deslocamentos, ambas seções apresentam a linha neutra elástica $\left(\mathrm{LNE}_{\mathrm{p}}\right)$ fora do concreto, resultando em um alívio em torno de $9 \%$.

Vale lembrar que o acréscimo relativo ao aço ASTM A36 na resistência à flexão com o emprego do aço ASTM A572 G50 gira em torno de 25\%. Essa solução 
é bastante atraente para o ganho de resistência em função da adição de aproximadamente $5 \%$ no custo do $\mathrm{kg}$ do aço. Portanto, o $\mathrm{f}_{\mathrm{ck}}$ da laje nesse projeto deve objetivar apenas o dimensionamento da mesma.

Já aumentando a espessura do concreto acima das nervuras para $75 \mathrm{~mm}$, observa-se no quadro anterior uma elevação de $6 \%$ na resistência à flexão seguida, porém, da elevação das solicitações devido ao aumento da carga de concreto. Assim, há uma variação de apenas $1 \%$ na relação entre a solicitação e a resistência à flexão da bitola W $460 \times 52$. Portanto, trata-se de uma solução não atraente.

\subsubsection{Comentário final}

A partir do pré-dimensionamento das vigas mistas de aço e concreto apresentados na Figura 1.2, pode-se destacar:

- emprega-se de ligações de resistência total nas vigas transversais deste projeto apenas na necessidade de estabilização lateral da estrutura no dimensionamento global;

- um projeto arquitetônico elaborado em função das características do material empregado na estrutura resulta em uma analise estrutural mais fácil, uma vez que o processo alternativo à análise rígido plástica é muito trabalhoso, além disso, pode resultar numa economia expressiva na estrutura;

- o uso de escoras ou, no caso das vigas não escoradas, contraflechas, resultou em um vigamento bastante eficiente estruturalmente e, ainda, o último caso resulta em maiores áreas livres no pavimento e economia ao eliminar o emprego de escoramentos;

- o procedimento alternativo de se considerar os efeitos de longa duração recomendado pela EN 1994-1-1:2004 demonstra-se bastante atraente para as vigas não escoradas porque cerca de metade dos deslocamentos são provenientes das ações antes da cura do concreto e dessa maneira os efeitos do erro de aproximação são minimizados;

- a verificação da flambagem lateral com distorção pelo procedimento alternativo trazido pela ABNT NBR 8800:2008 através da verificação da 
flambagem lateral com torção de uma seção de aço isolada com condições de travamento semelhante ao perfil de uma seção mista apresenta-se bastante conservador resultando em um dimensionamento antieconômico;

- a presença da LNP $_{\mathrm{p}}$ no perfil da seção mista de aço ASTM A572 G50 e concreto com $\mathrm{f}_{\mathrm{ck}}$ de $2 \mathrm{kN} / \mathrm{cm}^{2}$ acentua a eficiência das lajes mistas com fôrma de aço incorporada combinado a esses materiais, uma vez que o concreto tracionado tem contribuição desprezada na resistência e rigidez a flexão das vigas mistas;

- o ganho de resistência à flexão da viga mista com o aumento do $f_{c k}$ do concreto deve ser estudado com cautela de forma a evitar os casos em que a $\mathrm{LNP}_{\mathrm{P}}$ corta a laje. 



\section{CAPÍTULO 4: ESTABILIDADE E ANÁLISE ESTRUTURAL}

\subsection{GENERALIDADES}

O dimensionamento de estruturas de aço, segundo as recomendações normativas, é dividido em duas etapas: análise estrutural e dimensionamento dos elementos. As considerações necessárias para garantir a estabilidade global da estrutura devem ser admitidas em uma das duas etapas.

Tradicionalmente, os projetos estruturais são desenvolvidos considerando a estrutura perfeita, sem imperfeições iniciais e baseados em uma análise elástica linear, situação, essa, confortável para o projetista devido à facilidade de modelagem e avaliação estrutural que, no entanto, está longe de representar o estado real.

Nesse capítulo serão apresentados os critérios de estabilidade e análise estrutural recomendado pela ABNT NBR 8800:2008 para verificação dos estados limites últimos e estados limites de serviço de um edifício de múltiplos andares em aço.

\subsection{ESTADO LIMITE ÚLTIMO}

Kanchalai e Le Wu (1979) destacam os efeitos de instabilidade como uma das principais preocupações da análise estrutural, uma vez que, reduzem significativamente a capacidade resistente dos pórticos e pilares ao esforço normal combinado ou não ao de flexão. A contabilização desses efeitos em uma análise racional é objeto de estudo até a atualidade. A proposta desse item é apresentar as devidas considerações trazidas pela ABNT NBR 8800:2008. 


\subsubsection{CLASSIFICAÇÃO DA ESTRUTURA QUANTO AOS SISTEMAS RESISTENTES DE AÇÕES HORIZONTAIS}

$\mathrm{Na}$ análise da estrutura é possível identificar subestruturas, que por meio de sua rigidez, são responsáveis por resistir grande parcela das ações horizontais. Essas subestruturas, denominadas subestrutura de contraventamento, são representadas por quadros treliçados, paredes de cisalhamento e pórticos nos quais a estabilidade é assegurada pela rigidez à flexão das barras e pela capacidade de transmissão de momentos das ligações.

Os elementos que não recebem essa atribuição, denominados elementos contraventados, devem ter as forças que o estabilizam aplicadas na subestrutura responsável pela mesma. Já os elementos que possuem o comportamento independente do restante da estrutura são denominados elementos isolados.

Essa divisão adotada pela ABNT NBR 8800:2008 substitui a classificação do sistema estrutural (estrutura contraventada e não contraventada) tomada pela versão anterior, ABNT NBR 8800:1986, que não estabelece um critério de análise da eficiência do sistema de contraventamento.

\subsubsection{CLASSIFICAÇÃO DA ESTRUTURA QUANTO À SENSIBILIDADE A DESLOCAMENTOS LATERAIS}

O parâmetro de classificação das estruturas quanto à deslocabilidade, conforme a ABNT NBR 8800:2008, é definido pela razão do deslocamento relativo do andar a base obtida numa análise de segunda ordem $\left(\mathrm{u}_{2}\right)$ e aquele obtido em uma análise de primeira ordem $\left(\mathrm{u}_{1}\right)$, em todos os andares e combinações últimas.

Quando em todos os andares essa razão é inferior a 1,1, classifica-se a estrutura como de pequena deslocabilidade. Para valores entre 1,1 e 1,4, classificase a estrutura como de média deslocabilidade. Por último, para valores superiores a 1,4 , trata-se a estrutura como de grande deslocabilidade.

A norma brasileira ainda permite utilizar o coeficiente $B_{2}$ como parâmetro dessa classificação. Dória (2007) aponta o contraste entre a classificação quanto à deslocabilidade $\left(u_{2} / u_{1}\right)$ e a influência dos efeitos de segunda ordem $\left(B_{2}\right)$ para as 
combinações de ações gravitacionais, e ainda destaca a coerência dos resultados empregando o parâmetro $B_{2}$, tanto para a combinação das ações gravitacionais quanto para a combinação de ações em que atua o vento.

As implicações de cada grupo na determinação dos esforços serão expostas no item 4.2.7.

\subsubsection{EFEITOS QUE CONTRIBUEM PARA A PERDA DE ESTABILIDADE DOS PÓRTICOS}

Dentre os principais fatores que influenciam a estabilidade da estrutura e devem ser considerados no projeto, pode-se destacar (GALAMBOS, 1998):

- Efeito P- $\Delta$ : força axial associada à rotação da corda (Figura 4.1);

- Efeito P-ס: força axial associada aos deslocamentos de eixo da barra em relação à corda (Figura 4.1);

- Imperfeições geométricas iniciais de natureza local (elemento) e global (pórtico) (Figura 4.2);

- Tensões residuais (Figura 4.3);

- Plastificação ao longo do elemento;

- Condições de vínculo dos elementos;

- Sistema estrutural (ligações e estruturas de contraventamento).

A avaliação dos efeitos $\mathrm{P}-\Delta$ e $\mathrm{P}-\delta$ (Figura 4.1) podem ser realizados através de uma análise estrutural de segunda ordem ou por meio de métodos aproximados de amplificação dos esforços internos. A análise dos modelos desse trabalho se baseia no método da amplificação dos esforços (ver item 4.2.5) sugerido pela ABNT NBR 8800:2008. 


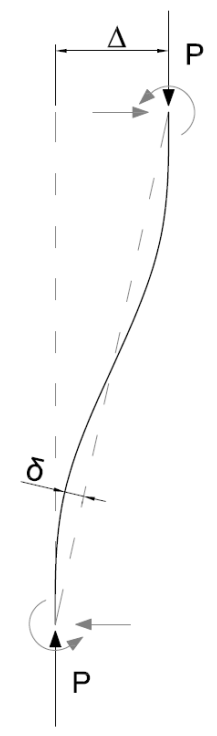

Figura 4.1 - Efeitos P-A e P-ठ (ASCE, 1997)

Quanto às imperfeições geométricas iniciais, caracterizam-se: pelo desalinhamento do elemento (local), decorrente do processo de fabricação, armazenagem e transporte; e pelo desalinhamento da estrutura (global), resultante do processo de montagem (Figura 4.2).

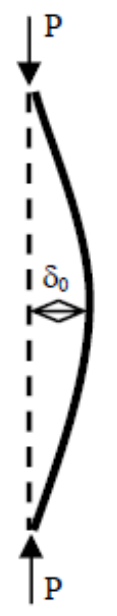

(a)

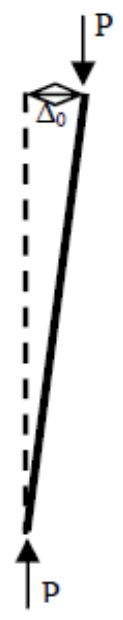

(b)

Figura 4.2 - Imperfeições geométricas iniciais (DÓRIA, 2007)

As imperfeições geométricas iniciais locais nas barras podem ser representadas através elementos finitos curvos com valor máximo ajustável a norma vigente, conforme proposto por Chan e Zhou (1995). Nas estruturas cuja 
estabilidade é controlada pelo efeito P-ঠ essas imperfeições geométricas apresentaram uma contribuição significativa na perda de capacidade.

Vale destacar que as imperfeições locais já estão incluídas nas expressões de dimensionamento das barras comprimidas por meio da curva de resistência (ABNT NBR 8800:2008), portanto, no caso de se considerar esse fenômeno na análise deve-se tomar medidas no dimensionamento para evitar a dupla consideração.

Imperfeições geométricas iniciais globais, assim como as locais, podem ser inseridas diretamente na determinação da geometria do modelo, porém não se trata de um procedimento prático. O Método da Análise Direta, adotado pela ABNT NBR 8800:2008, propõe representar as imperfeições globais através da utilização de forças horizontais fictícias aplicadas aos níveis dos pavimentos (ver item 4.2.6).

As tensões residuais, responsáveis pela antecipação das deformações plásticas na seção, são originadas principalmente no processo de fabricação. Essas tensões surgem tanto nos perfis laminados quanto nos perfis soldados. Segundo Galambos (1998), no processo de laminação, tensões auto-equilibradas resultantes do gradiente térmico da seção transversal do perfil podem atingir cerca de $30 \%$ da resistência ao escoamento $\left(f_{y}\right)$ do aço (Figura 4.3).

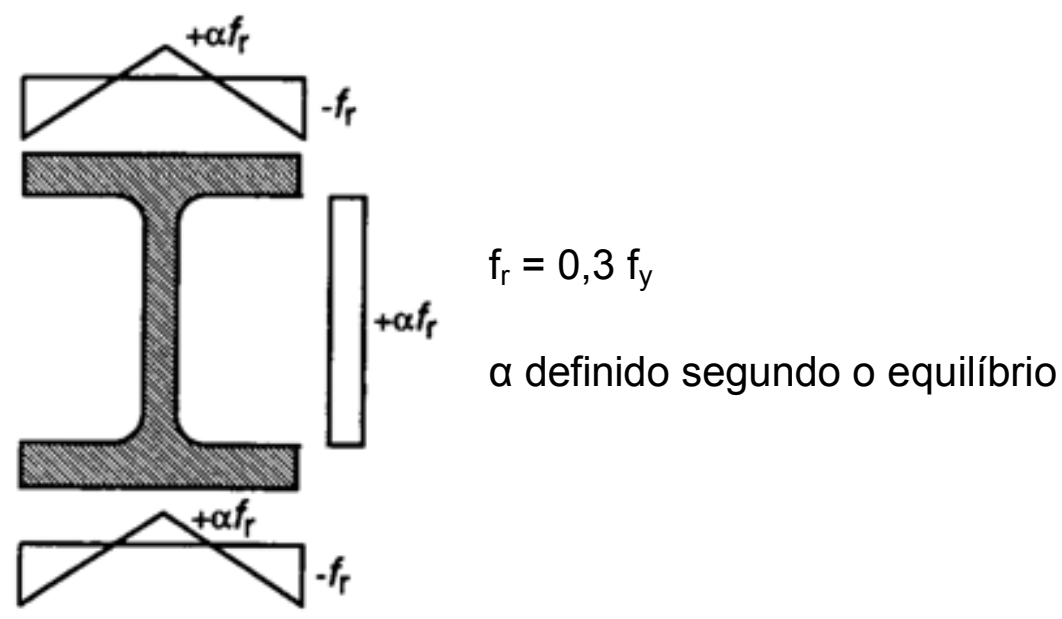

Figura 4.3 - Diagrama de tensões residuais procedente do processo de laminação (GALAMBOS, 1998) 
Essa imperfeição de material é considerada no Método da Análise Direta através da redução das rigidezes axial e à flexão de todos os elementos da estrutura inclusive os que não são estabilizantes.

O processo de plastificação de um elemento pertencente a um pórtico consiste na propagação da plastificação ao longo da seção mais solicitada (transversalmente) e em seguida ao longo de seu comprimento (longitudinalmente). Essa representação em uma análise numérica não é trivial, visto que, são necessárias ferramentas que capturem o comportamento da plastificação no elemento.

As condições de vinculação da estrutura e dos elementos entre si são facilmente compreendidas e modeladas. A representação de diversos tipos de vinculação de apoio e ligações semirrígidas viga-pilar já está disponível nos programas de análise estrutural utilizados nos escritórios de engenharia. Enfim, estruturas de contraventamento compostas por barras e painéis também podem ser inseridas sem dificuldades na análise (COMPUTER AND STRUCTURES INC., 2009).

\subsubsection{SOLICITAÇÕES DE COMPRESSÃO E FLEXÃO COMBINADAS}

A verificação de barras submetidas à flexão composta pelas normas de estrutura de aço é realizada através de expressões de interação que definem uma superfície de escoamento em função do momento fletor e força normal solicitante atuando simultaneamente na barra.

A ABNT NBR 8800:2008 adota as seguintes expressões de interação:

$$
\begin{aligned}
& \frac{N_{S d}}{N_{R d}}+\frac{8}{9}\left(\frac{M_{x, S d}}{M_{x, R d}}+\frac{M_{y, S d}}{M_{y, R d}}\right) \leq 1,0 \quad \text { para } \quad \frac{N_{S d}}{N_{R d}} \geq 0,2 \\
& \frac{N_{S d}}{2 N_{R d}}+\left(\frac{M_{x, S d}}{M_{x, R d}}+\frac{M_{y, S d}}{M_{y, R d}}\right) \leq 1,0 \quad \text { para } \quad \frac{N_{S d}}{N_{R d}}<0,2
\end{aligned}
$$


Nas expressões 4.1 e 4.2, seguem:

$N_{S d}$ e $N_{R d}$ esforço normal solicitante e resistente de cálculo de compressão ou tração, respectivamente;

$M_{x, S d}$ e $M_{y, S d}$ momentos fletores solicitantes de cálculo em relação aos eixos $x$ e y da seção transversal, respectivamente;

$M_{x, R d}$ e $M_{y, R d}$ momentos fletores resistentes de cálculo em relação aos eixos $x$ e y da seção transversal, respectivamente.

Analisando as equações 4.1 e 4.2, Dória (2007) discuti as estratégias de avaliação da estabilidade de pórticos deslocáveis. Para os procedimentos que envolvem o cálculo do comprimento efetivo, o aumento do comprimento real do elemento acarreta na diminuição da força normal resistente de cálculo $\left(\mathrm{N}_{\mathrm{Rd}}\right)$. Essa metodologia resulta no acréscimo de ambas as expressões.

Em contrapartida, a análise de segunda ordem em conjunto com o Método da Análise Direta aplicados aos elementos com seu comprimento real $(k=1)$ acarreta no aumento dos momentos solicitantes $\left(M_{x}, s_{d}\right.$ e $\left.M_{y}, s d\right)$. Essa metodologia também resulta no acréscimo das expressões 4.1 e 4.2 .

A partir dessa avaliação, observa-se que, além da análise de segunda ordem, os métodos de avaliação aproximada dos efeitos desestabilizantes das imperfeições iniciais buscam representar o comportamento dos elementos submetidos à flexocompressão sem recorrer à avaliação do comprimento efetivo de flambagem.

No APÊNDICE C é apresentado o cálculo de um pilar isolado I sob solicitações combinadas. Essa planilha também foi desenvolvida no Mathcad (PARAMETRIC TECHNOLOGY CORPORATION, 2007).

\subsubsection{EFEITOS DE SEGUNDA ORDEM}

Uma barra submetida à ação combinada das solicitações de compressão e flexão deverá ser verificada para o acréscimo de momentos fletores e deslocamentos originados da força axial associada a deslocamentos transversais do eixo e corda da barra, P- $\delta$ e P- $\Delta$, respectivamente. 
A ABNT NBR 8800:2008, assim como ANSI/AISC 360-10, adota o método da amplificação dos esforços como uma aproximação aceitável para uma análise de segunda ordem. Esse método consiste na amplificação dos esforços internos obtidos por meio de análises de primeira ordem. Através dos fatores $B_{1}$ e $B_{2}$, estimam-se os esforços solicitantes de segunda ordem, conforme as equações:

$\mathrm{M}_{\mathrm{Sd}}=\mathrm{B}_{1} \mathrm{M}_{\mathrm{nt}}+\mathrm{B}_{2} \mathrm{M}_{\mathrm{lt}}$

$\mathrm{N}_{\mathrm{Sd}}=\mathrm{N}_{\mathrm{nt}}+\mathrm{B}_{2} \mathrm{~N}_{\mathrm{lt}}$

Nas equações 4.3 e 4.4, a partir de duas análises elásticas lineares, tem-se:

$M_{S d}$ e $N_{S d}$ momento fletor e força axial solicitante de cálculo, respectivamente;

$\mathrm{M}_{\mathrm{nt}}$ e $\mathrm{N}_{\mathrm{nt}}$ momento fletor e a força axial solicitante de cálculo, respectivamente, devido às combinações adequadas, na estrutura com os deslocamentos horizontais impedidos por apoios fictícios (estrutura nt Figura 4.4b);

$\mathrm{M}_{\mathrm{lt}}$ e $\mathrm{N}_{\mathrm{lt}}$ momento fletor e a força axial solicitante de cálculo, respectivamente, decorrentes da remoção das contenções da análise da estrutura nt e aplicação das respectivas reações como carregamento (estrutura It Figura 4.4c).

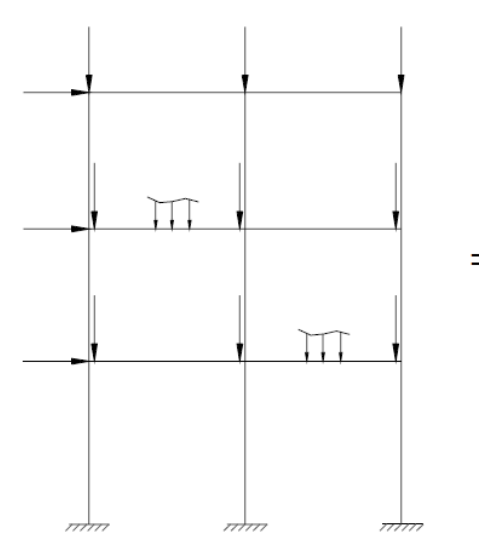

(a)

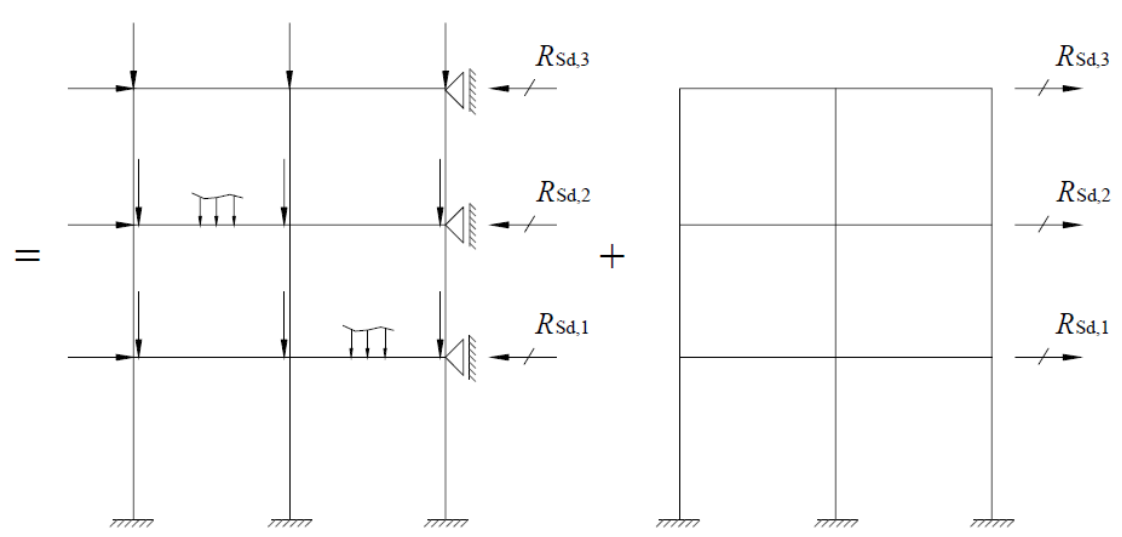

(b)

(c)

Figura 4.4 - Modelos para análises: (a) estrutura original; (b) estrutura nt; (c) estrutura It (ABNT NBR 8800:2008) 
A principal vantagem apresentada pelo método da amplificação dos esforços é a contabilização dos efeitos $\mathrm{P}-\delta$ e $\mathrm{P}-\Delta$ separadamente, facilitando a visualização da contribuição de cada parte à instabilidade.

Dentre as desvantagens pode-se destacar (AL-MASHARY; CHEN, 1990):

- método restrito a pórticos retangulares;

- não considera a redistribuição dos esforços, ou seja, apresenta uma correção localizada (amplificação) sobre os esforços internos dos elementos;

- dificuldade de avaliação dos pontos de aplicação das contenções nodais (estrutura nt) e interpretação do cálculo dos parâmetros $C_{m}$ e K;

- os momentos fletores críticos totais, obtidos pela soma da contribuição dos momentos fletores de cada efeito (expressão 4.3), nem sempre possuem a seção crítica em comum, podendo assim, gerar resultados imprecisos;

- não se consegue prever corretamente os momentos nas extremidades das vigas, visto que as ações normais são de baixa compressão ou de tração;

- necessidade de duas análises de primeira ordem para cada combinação de ações.

A amplificação dos deslocamentos laterais não será abordada nesse trabalho. Esse trabalho se concentrou em verificar os deslocamentos para uma análise de primeira ordem (ver item 4.3), conforme prescrito pela norma brasileira de aço. A apresentação seguinte dos efeitos será restrita a amplificação dos esforços normais e fletores.

\subsubsection{Efeito P- $\delta$}

A influência do efeito P-ס é facilmente visualizada numa viga-pilar birrotulada solicitada por carregamentos transversais, momentos de extremidade e uma força axial. Na Figura 4.5 as solicitações (MA, MB, Q e w) provocam esforços e deslocamentos primários, $M_{l}$ e $v_{l}$, respectivamente. Por sua vez, a atuação da força axial $(P)$ sobre esses deslocamentos, denominada efeito $\mathrm{P}-\bar{\delta}$, irá resultar em esforços e deslocamentos secundários, $M_{\|}$e $v_{\|}$, respectivamente. 


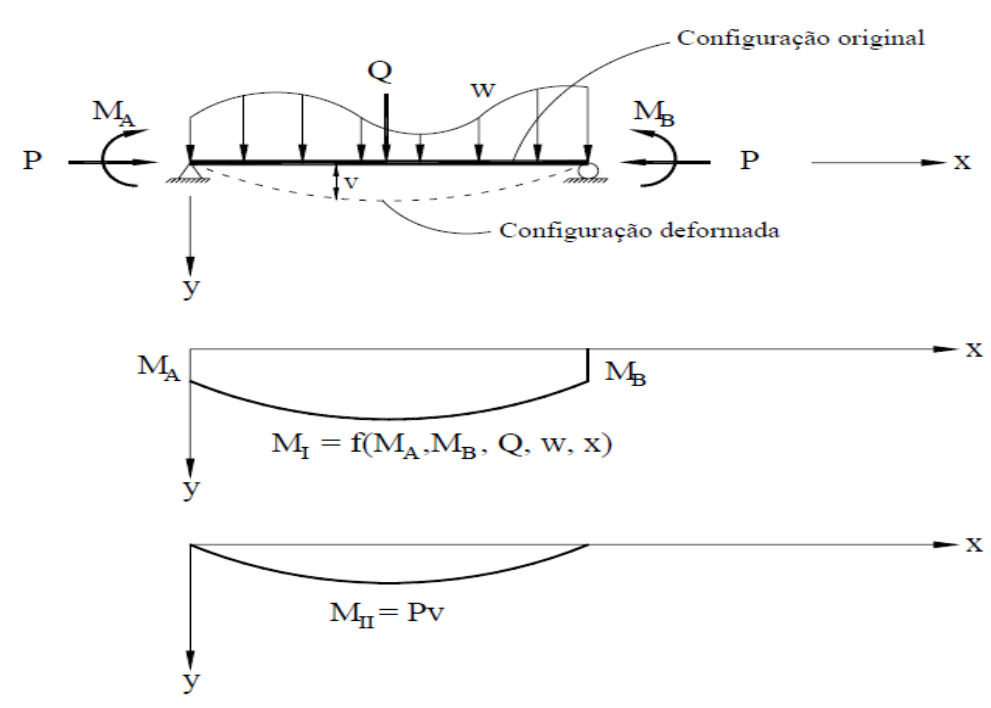

Figura 4.5 - Efeito P-ס (AVAKIAN, 2007)

A amplificação dos esforços devido a esse efeito é representada pelo fator $B_{1}$, expressão a seguir, e deduzida em Salmon e Johnson (1996). Essa equação admite que a perda de estabilidade ocorra apenas no plano de flexão e que o momento fletor de segunda ordem assume uma forma senoidal.

$\mathrm{B}_{1}=\frac{\mathrm{C}_{\mathrm{m}}}{1-\frac{\mathrm{N}_{\mathrm{Sd} 1}}{\mathrm{~N}_{\mathrm{e}}}}$

Na expressão 4.5, seguem as seguintes definições:

$\mathrm{N}_{\mathrm{Sd} 1}$ força axial de compressão solicitante de cálculo na barra obtido por uma análise de primeira ordem da estrutura original $\left(\mathrm{N}_{\mathrm{Sd} 1}=\mathrm{N}_{\mathrm{nt}}+\mathrm{N}_{\mathrm{lt}}\right)$;

$\mathrm{N}_{\mathrm{e}}$ força axial crítica de flambagem elástica da barra no plano de flexão analisado, calculado com o comprimento real da estrutura, considerando, em função do nível de deslocabilidade, a imperfeição inicial de material.

O coeficiente $C_{m}$ é definido para as barras submetidas a carregamentos transversais por meio de uma análise racional. A expressão a seguir satisfaz esse requisito (SALMON; JOHNSON, 1996):

$\mathrm{C}_{\mathrm{m}}=1+\left(\frac{\pi^{2} \mathrm{EI} \delta_{1}}{\mathrm{M}_{n t} \mathrm{~L}^{2}}-1\right) \frac{\mathrm{N}_{\mathrm{Sd} 1}}{\mathrm{~N}_{\mathrm{e}}}$ 
Onde se definem na expressão 4.6:

$M_{n t}$ momento fletor solicitante de cálculo no meio do vão, obtido em análise de primeira ordem, devido o carregamento transversal (estrutura nt);

$\delta_{1}$ deslocamento transversal no meio do vão, obtido em análise elástica de primeira ordem, devido o carregamento transversal (estrutura nt);

El rigidez à flexão da barra considerada;

L comprimento da barra considerada.

O termo em parênteses da expressão anterior, para barras birrotuladas submetidas a carregamento transversal uniformemente distribuído, é positivo, porém muito baixo $(0,028)$. Para outros casos usuais (SALMON; JOHNSON, 1996) de carregamentos transversais e vinculações em pórticos, esse valor apresenta-se negativo, portanto, as normas permitem adotar, conservadoramente, $\mathrm{Cm}$ igual a 1,0.

No caso das barras flexo-comprimidas sem carregamento transversal, isto é, submetidas a momento fletor e à força axial nas extremidades, foi adotado o momento uniforme equivalente na definição de uma formulação com mesmo formato da equação 4.5. Esse conceito elimina a necessidade de se encontrar a posição do momento e deslocamento máximo na barra, através de uma nova definição para $C_{m}$.

$$
C_{m}=0,6-0,4 \frac{M_{1}}{M_{2}}
$$

$\mathrm{Na}$ expressão 4.7, $\mathrm{M}_{1}$ e $\mathrm{M}_{2}$ são o maior e menor, respectivamente, momentos fletores solicitantes de cálculo, em valor absoluto, nas extremidades das barras pertencentes à estrutura nt. A razão é tomada como positiva quando os momentos provocarem curvatura reversa e negativa quando provocarem curvatura simples.

Vale destacar, que para barras sob força transversal, $C_{m}$ é parte integrante do coeficiente de aplicação B1, já para as barras sem força transversal e com momentos aplicados nas extremidades, $C_{m}$ é um fator de uniformização dos momentos. 


\subsubsection{Efeito $P-\Delta$}

$\mathrm{Na}$ avaliação do efeito global de $2^{\mathrm{a}}$ ordem, Salmon e Johnson (1996), utilizam uma barra que representa um pavimento qualquer da estrutura. Essa barra é submetida a todas as ações desse pavimento, isto é, uma força axial de intensidade igual ao somatório de todas as forças axiais nos pilares do pavimento $\left(\Sigma N_{S d}\right)$ e a uma força horizontal igual ao somatório das forças cortantes nos pilares mencionados $\left(\Sigma \mathrm{H}_{\mathrm{Sd}}\right)$.

A atuação das forças horizontais $\left(\Sigma \mathrm{H}_{S \mathrm{~d}}\right)$ nessa barra irá desloca-la até a posição de equilíbrio de primeira ordem $\left(\Delta_{1 h}\right)$. Quando as forças verticais $\left(\Sigma N_{S d}\right)$ interagirem com o deslocamento de primeira ordem, o momento fletor, $\Sigma \mathrm{H}_{\mathrm{Sd}}$ h, será acrescido de $\Sigma N_{S d} \Delta_{1 h}$. Assim, o deslocamento lateral relativo atinge seu valor final $\left(\Delta_{2 h}\right)$ na posição deformada da estrutura. A Figura 4.6 traz esse comportamento.

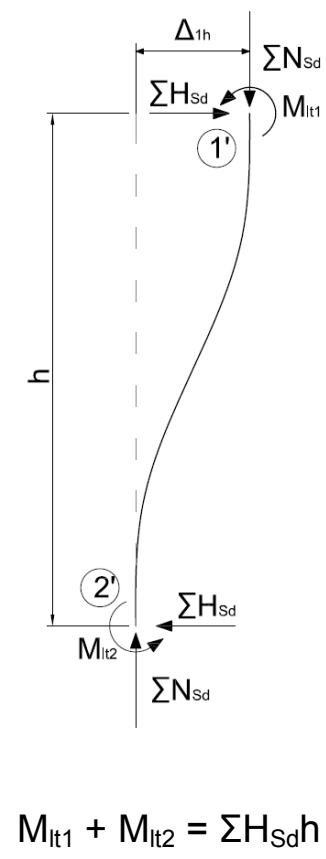

(a)

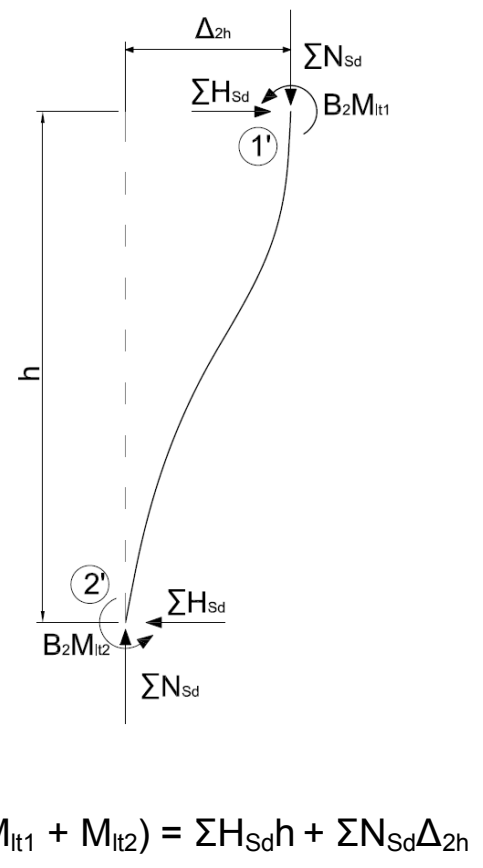

(b)

Figura 4.6 - Resumo das forças atuantes em um pilar pertencente a um pórtico de um edifício de múltiplo andares (a) análise de primeira ordem; (b) análise de segunda ordem (SALMON; JOHNSON, 1996)

Admitindo que o comportamento em cada andar seja independente e que a rigidez $(R)$ da estrutura analisada em primeira ordem seja a mesma em segunda ordem, é possível relacionar os deslocamentos de primeira e segunda ordem 
fazendo uso de uma força lateral equivalente ao momento fletor decorrente dos efeitos globais de segunda ordem $\left(\sum \mathrm{N}_{\mathrm{Sd}} \Delta_{2 \mathrm{~h}} / \mathrm{h}\right)$.

$\mathrm{R}=\frac{\sum \mathrm{H}_{\mathrm{Sd}}}{\Delta_{1 \mathrm{~h}}}=\frac{\sum \mathrm{H}_{\mathrm{Sd}}+\frac{\sum \mathrm{N}_{\mathrm{Sd}} \Delta_{2 \mathrm{~h}}}{\mathrm{~h}}}{\Delta_{2 \mathrm{~h}}}$

Resolvendo a expressão 4.8 é possível definir o deslocamento final total $\left(\Delta_{2 h}\right)$ :

$$
\begin{aligned}
& \Delta_{2 h}=\left(\frac{1}{1-\frac{\Delta_{1 h} \sum N_{S d}}{h \sum H_{S d}}}\right) \Delta_{1 h}=B_{2} \Delta_{1 h} \\
& B_{2}=\frac{1}{1-\frac{\Delta_{1 h} \sum N_{S d}}{h \sum H_{S d}}}
\end{aligned}
$$

Nas expressões 4.8 e 4.9, seguem:

$\Delta_{1 \mathrm{~h}}$ deslocamento relativo entre dois pavimentos consecutivos, obtidos em análise de primeira ordem na estrutura original ou estrutura It;

$\Sigma \mathrm{H}_{\mathrm{Sd}}$ somatório das forças horizontais de cálculo no pavimento considerado que produzem $\Delta_{1 h}$

$\Sigma \mathrm{N}_{\mathrm{Sd}}$ somatório das forças gravitacionais no andar considerado;

h altura do referido pavimento.

O fator de amplificação dado pela expressão 4.9 é recomendado pelas normas ABNT NBR 8800:2008 e ANSI/AISC 360-10 aos momentos fletores de primeira ordem, porém foi introduzido um coeficiente $R_{m}$.

$$
\mathrm{B}_{2}=\frac{1}{1-\frac{\Delta_{1 \mathrm{~h}} \sum \mathrm{N}_{\mathrm{Sd}}}{\mathrm{R}_{\mathrm{m}} \mathrm{h} \sum \mathrm{H}_{\mathrm{Sd}}}}
$$

O coeficiente de ajuste $R_{m}$ contabiliza a influência do efeito P- $\delta$ no P- $\Delta$. Quando a resistência às ações horizontais é garantida pela rigidez a flexão dos 
subsistemas de contraventamento é igual a 0,85. Para demais estruturas, deve-se tomar esse valor igual a 1,0 .

Chen e Lui (1991) acrescentam às limitações desse método, o fato dos resultados serem adequados apenas para estruturas que exibem deformações a esforços cortantes. Isso é decorrente do desenvolvimento do coeficiente de amplificação P- $\Delta$ ao considerar que cada andar do edifício tem comportamento independente em relação aos demais pavimentos do pórtico.

\subsubsection{MÉTODO DA ANÁLISE DIRETA}

O Método da Análise Direta (Direct Analysis Method) proposto pela ANSI/AISC 360-10 consiste em considerar as imperfeições geométricas globais e as imperfeições de material por meio de forças horizontais fictícias ( $\xi \Sigma \mathrm{P}_{\mathrm{i}}$ igual a $0,2 \%$ do valor das cargas gravitacionais de cálculo no andar considerado) e da redução da rigidez axial $\left(\mathrm{EA}_{\mathrm{Red}}=0,8 \mathrm{EA}\right)$ e à flexão $\left(\mathrm{EI}_{\mathrm{Red}}=0,8 \tau_{\mathrm{b}} \mathrm{EI}\right)$, respectivamente.

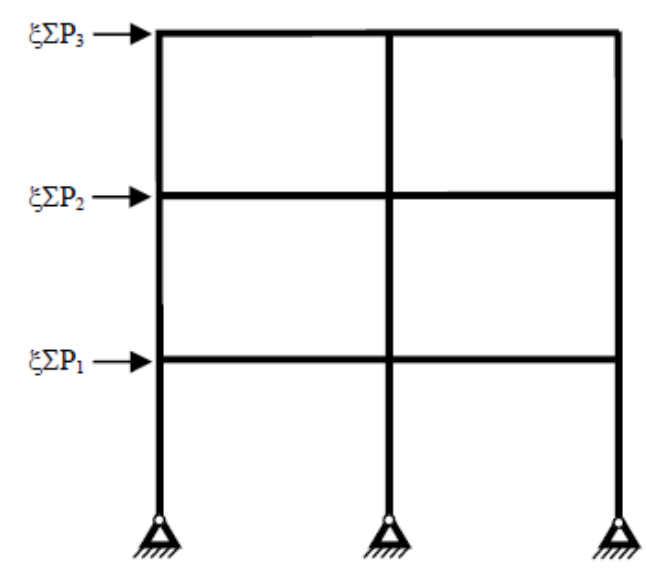

Figura 4.7 - Esquema das forças horizontais fictícias ( $\left.\xi \Sigma \mathrm{P}_{\mathrm{i}}\right)$ (DÓRIA, 2007)

O parâmetro $\tau_{b}$ é definido segundo dois intervalos, a saber:

$$
\tau_{b}= \begin{cases}1,0 & \text { se } \frac{N_{S d}}{N_{y}} \leq 0,5 \\ 4,0 \frac{N_{S d}}{N_{y}}\left(1-\frac{N_{S d}}{N_{y}}\right) & \text { se } \frac{N_{S d}}{N_{y}}>0,5\end{cases}
$$


$\mathrm{Na}$ expressão $4.11, \mathrm{~N}_{S d}$ e $\mathrm{N}_{\mathrm{y}}$ são a força normal solicitante e força normal correspondente ao escoamento da seção transversal da barra, respectivamente. Desde que seja somado $0,1 \%$ da carga gravitacional aplicado sobre os pilares e demais elementos resistentes do pavimento, pode-se adotar $\tau_{\mathrm{b}}$ igual a 1,0. Esse procedimento caracteriza a forma que esse método é apresentado na ABNT NBR 8800:2008.

\subsubsection{DETERMINAÇÃO DOS ESFORÇOS SOLICITANTES}

A ABNT NBR 8800:2008 prescreve os esforços solicitantes na estrutura conforme sua classificação quanto à deslocabilidade (item 4.2.2). As recomendações da norma brasileira para cada categoria são apresentadas a seguir.

\subsubsection{Pequena deslocabilidade}

Os efeitos das imperfeições geométricas iniciais globais devem ser levados em conta diretamente na análise, por meio da consideração, em cada andar, de um deslocamento horizontal relativo interpavimento de $h / 333$, sendo $h$ a altura do andar.

Outra forma de avaliar esses efeitos é aplicar em cada andar uma força horizontal fictícia igual a $0,3 \%$ do valor das cargas gravitacionais de cálculo aplicadas em todos os pilares e outros elementos resistentes a cargas verticais, correspondente apenas ao andar em questão. Não é necessário somá-las às reações horizontais de apoio.

Os efeitos dessas imperfeições geométricas devem ser considerados independentemente em duas direções ortogonais em planta da estrutura no sentido que proporcione o maior efeito desestabilizador. Nas estruturas que não são carregadas lateralmente esse efeito deve ser entendido como um carregamento lateral mínimo.

Os efeitos das imperfeições iniciais de material não precisam ser considerados na análise. 
A norma ainda recomenda para estruturas de pequena deslocabilidade desconsiderar os efeitos globais de segunda ordem desde que sejam atendidas as seguintes exigências:

- as forças axiais solicitantes de cálculo de todas as barras cuja rigidez à flexão contribua para a estabilidade lateral da estrutura, em cada uma das combinações últimas de ações, não sejam superiores a $50 \%$ da força axial correspondente ao escoamento da seção transversal dessas barras;

- os efeitos das imperfeições geométricas iniciais globais sejam adicionados às respectivas combinações, inclusive àquelas em que atuem ações variáveis devidas ao vento.

Nesse caso os efeitos locais de segunda ordem continuam sendo calculados de acordo com o item 4.2.5.1, porém, utilizando as grandezas da estrutura original (Figura 4.4a) para definição de seu valor.

\subsubsection{Média deslocabilidade}

Os efeitos das imperfeições geométricas iniciais globais devem ser considerados conforme o recomendado para estruturas de pequena deslocabilidade, portanto, esses efeitos devem ser entendidos como um carregamento lateral mínimo da estrutura, ou seja, considerados nas combinações gravitacionais ou nas estruturas que não são carregadas lateralmente.

As imperfeições iniciais de material devem ter seus efeitos levados em conta na análise. Essa recomendação é realizada através da redução das rigidezes axial e à flexão das barras para $80 \%$ dos valores originais.

\subsubsection{Grande deslocabilidade}

Nas estruturas com grande deslocabilidade, alternativamente à análise rigorosa que leve em conta as não linearidades geométricas e de material, pode-se utilizar o procedimento de análise para as estruturas de média deslocabilidade. Essa opção pode ser empregada, desde que os efeitos das imperfeições geométricas 
iniciais globais sejam adicionados às combinações últimas de ações em que atuem as ações variáveis devidas ao vento.

\subsubsection{ANÁLISE TRIDIMENSIONAL}

Os efeitos de segunda ordem induzidos pela torção global da estrutura também devem ser considerados na análise, principalmente em edifícios de médio e grande porte. Nessas construções os sistemas resistentes a forças horizontais estão concentrados nos núcleos de serviço geralmente próximos ao centro do edifício.

Nair ${ }^{1}$ (1975 apud Galambos, 1998, p. 630) pesquisou o comportamento de configurações estruturais usuais em edifícios de múltiplos andares. Seus estudos concluem que no sistema estrutural I (Figura 4.8) o modo crítico de ruptura é a torção global. Essa instabilidade em conjunto com as duas translações ortogonais não são capturados pela análise de pórticos planos.
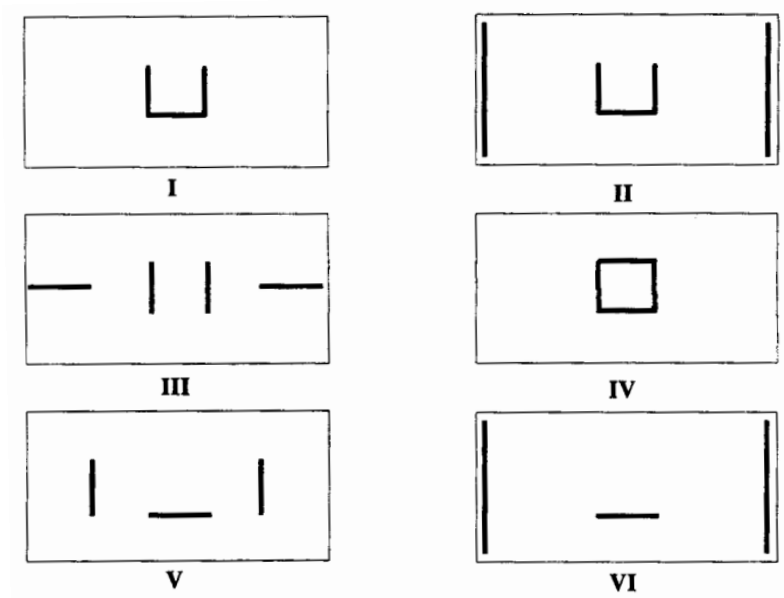

Figura 4.8 - Disposição dos sistemas responsáveis pela resistência às ações laterais

Para investigar o modo de torção precisamente é necessária uma análise tridimensional de segunda ordem que inclua as considerações do Método da Análise Direta e/ou a excentricidade devido o carregamento lateral que irá acentuar a ação da torção.

\footnotetext{
${ }^{1}$ NAIR, R.S. Overall elastic stability of multistory buildings. ASCE. Journal Structures Div., v.10, n. ST12, p. 2487-2503, 1975.
} 
A análise elástico-linear tridimensional da estrutura estudada nesse trabalho será realizada no SAP 2000 (COMPUTER AND STRUCTURES INC., 2009), software de grande difusão nos escritórios de engenharia. Além disso, serão adotadas as seguintes simplificações e medidas para adaptar o método de amplificação dos esforços à análise tridimensional:

- as combinações referentes às solicitações totais críticas de cada lance e iteração, obtidos pela expressão 4.3 e 4.4, foram assumidas iguais à combinação correspondente ao maior valor resultante das expressões $4.1 \mathrm{e}$ 4.2 aplicadas à estrutura original (Figura 4.4a);

- a cada iteração e combinação crítica são definidas uma estrutura nt e It (Figuras 4.44.44.4b e 4.4c);

- a estrutura nt é definida sem a consideração do efeito diafragma proporcionado pelas lajes de forma a eliminar o comportamento não condizente das reações nas contenções nodais;

- os fatores de amplificação $B_{1}$ e $B_{2}$ sobre os momentos fletores dos pilares no plano de flexão referente à direção do vento também são aplicados aos momentos fletores ortogonais a esse plano.

Simploriamente, redistribuição dos esforços nas vigas para o equilíbrio dos efeitos de segunda ordem sobre os pilares não foram verificados e seu dimensionamento fica com a mesma folga $(10 \%)$ adotada nos demais elementos.

A classificação da estrutura quanto à sensibilidade aos deslocamentos laterais, por simplicidade, foi adotada segundo a combinação última de ações que oferecer, além de forças horizontais, a maior resultante de força gravitacional. Essa classificação é avaliada sem a consideração das imperfeições iniciais de material e, no caso desse trabalho, através do parâmetro $B_{2}$ (ABNT NBR 8800:2008). 


\subsubsection{EXEMPLO: VERIFICAÇÃO DOS ESTADOS LIMITES ÚLTIMOS DE UM EDIFÍCIO ESCRITÓRIO COM ESTRUTURA METÁLICA E 20 PAVIMENTOS}

No pré-dimensionamento dos pilares do Edifício Modelo 1 (Figura 1.3) apresentado na Tabela 4.1, admite-se conforme Sales (1995) que as seções variem a cada quatro andares e faz-se a verificação para os esforços de compressão dos pilares centrais, obtidos pelas ações de peso próprio e sobrecarga na área de influência dos elementos, sem a redução proposta pela ABNT NBR 6120:1980.

Atentando para a ocorrência de flexão nos dois planos da seção, admite-se para o pré-dimensionamento do perfil, que os esforços dessa verificação inicial representem $75 \%$ da resistência à compressão $\left(N_{R d}\right)$ da seção. Assim, chega-se aos seguintes valores:

Tabela 4.1 - Edifício Modelo 1 - Pré-dimensionamento dos pilares

\begin{tabular}{|c|c|c|}
\hline Lance & $\mathrm{N}_{\mathrm{Rd}}(\mathrm{kN})$ & Bitola \\
\hline $1^{\circ}$ & 10807,6 & CVS $650 \times 413$ \\
\hline $2^{\circ}$ & 8646,06 & CVS $650 \times 326$ \\
\hline $3^{\circ}$ & 6484,56 & CVS $650 \times 234$ \\
\hline $4^{\circ}$ & 4323,04 & CVS $650 \times 211$ \\
\hline $5^{\circ}$ & 2161,52 & CVS $650 \times 211$ \\
\hline
\end{tabular}

Para verificação do comportamento do sistema estrutural quanto aos estados limites últimos, o Edifício Modelo 1 foi expandido para mais três modelos. No Edifício Modelo 2 (Figura 4.9) foram acrescentados outriggers à meia altura e no topo. Já os Edifícios Modelos 3 e 4 (Figuras 4.10 e 4.11) partem do Edifício Modelo 2, porém com variação da posição do outrigger e do número de núcleos metálicos treliçados e de ligações rígidas.

Com os outriggers localizados nos eixos extremos, o belt tuss, comumente empregado com o outrigger, não é utilizado no sistema de estabilização para distribuir os esforços axiais, uma vez que não foi observado um aumento expressivo na bitola dos pilares a sotavento ao ponto de governarem o dimensionamento dos pilares da fachada de nenhum arranque dos modelos analisados. 


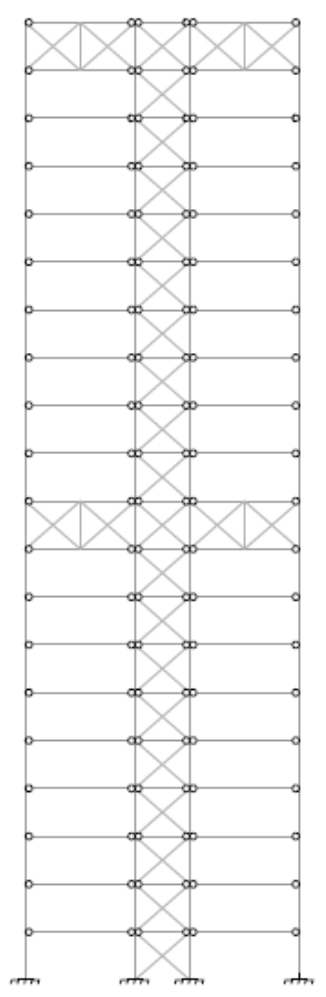

(a)

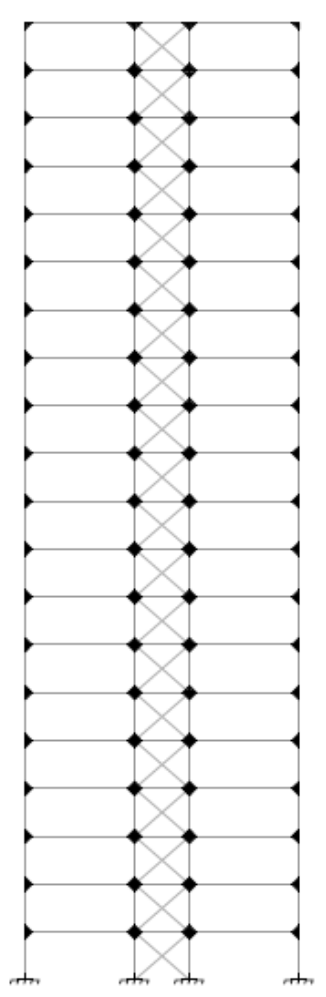

(b)

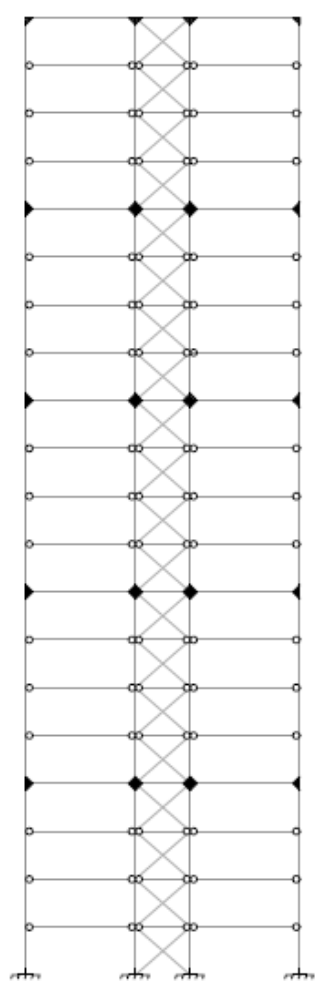

(c)

Figura 4.9 - Edifício Modelo 2 - Elevação dos eixos: (a) 1 e 6; (b) 2 e 5; (c) 3 e 4

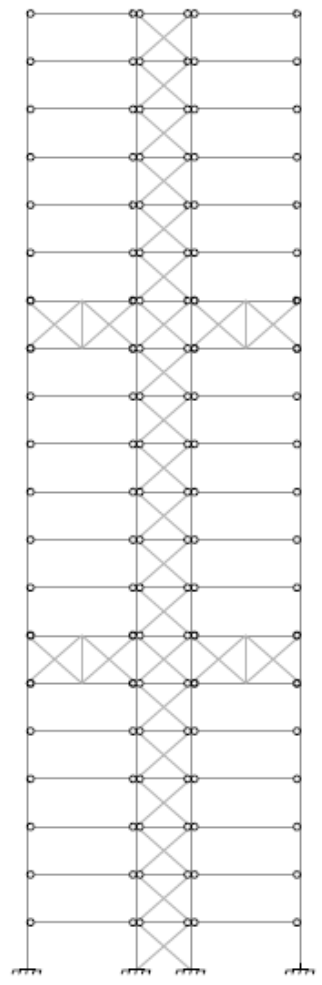

(a)

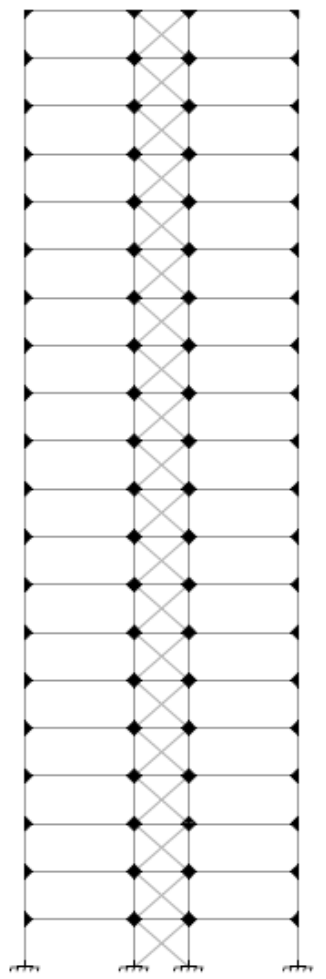

(b)

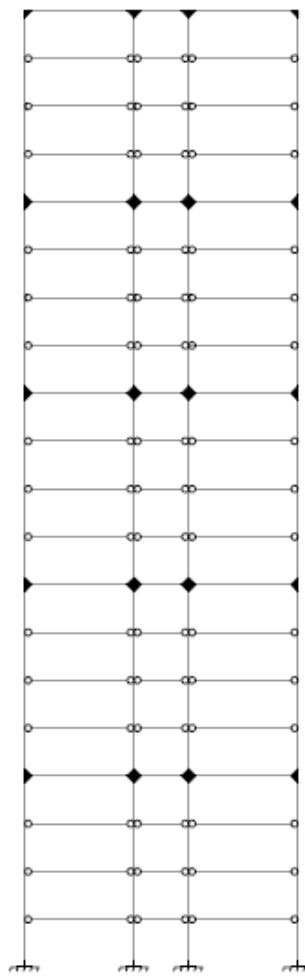

(c)

Figura 4.10 - Edifício Modelo 3 - Elevação dos eixos: (a) 1 e 6; (b) 2 e 5; (c) 3 e 4 


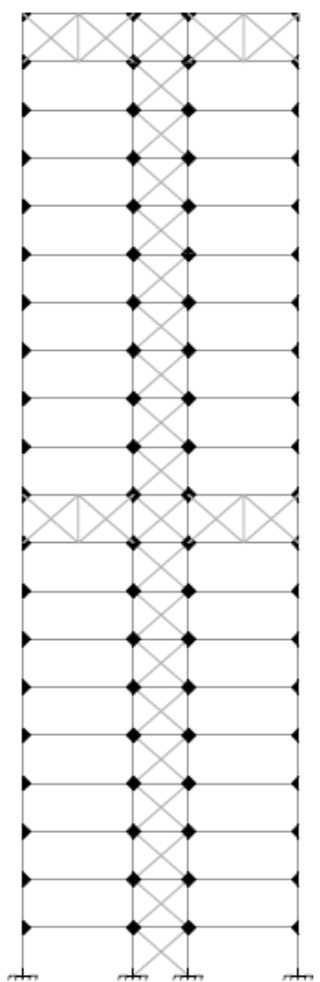

(a)

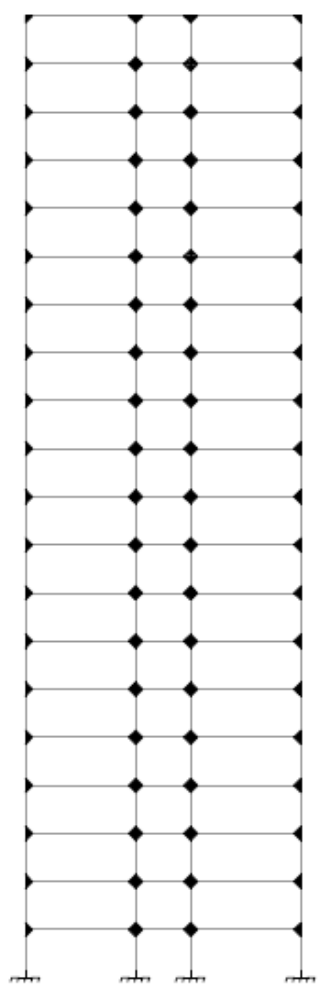

(b)

Figura 4.11 - Edifício Modelo 4 - Elevação dos eixos (a) 1 e 6; (b) 2 a 5

A combinação de ações com maior ação gravitacional no nível da fundação foi empregada na classificação da deslocabilidade dos modelos desse trabalho (item 4.2.8). Essa simplificação é governada pela combinação C2 (expressão 2.3) aplicada para o vento incidindo tanto na direção dos eixos quanto na direção das filas. Dessa maneira os modelos se enquadram na classe de média deslocabilidade.

Esse fato, de acordo com o item 4.2.7, resulta no acréscimo das forças horizontais fictícias (FHF) às combinações gravitacionais (expressão 2.5) e a redução da rigidez axial e à flexão dos elementos.

Na verificação dos esforços nos pilares, as seções críticas encontram-se nas combinações de ações com o vento incidindo na direção dos eixos (Tabela 4.2) dos modelos. Dessa forma, salvo onde explicito o emprego do vento na direção das filas, as expressões de combinações apresentadas no item 2.3 se referem unicamente as ações horizontais, quando presentes, na direção dos eixos. 
A padronização do dimensionamento dos pilares, visando favorecer a economia de material e execução da estrutura, foi realizada para duas filas (externas e internas) e para cinco lances (grupo de quatro pavimentos).

A Tabela 4.2 apresenta um resumo do dimensionamento dos pilares referentes aos edifícios modelos estudados nesse trabalho. Observa-se uma pequena variação nas bitolas dos perfis entre os modelos 1 e 2 . Isso se justifica pelo sistema estrutural dos eixos 2 e 5 , comum entre esses modelos, englobar a maioria das seções críticas e pela proximidade da contribuição estrutural global dos sistemas empregados nos eixos 1 e 6 .

O Edifício Modelo 4, apesar de conservar os núcleos treliçados nos eixos das extremidades, apresenta características de sistemas aporticados. Destacando-se como a estrutura com melhor distribuição de cargas sobre a fundação. Isso é verificado, ao comparar com o Edifício Modelo 2, a redução dos esforços normais sobre os pilares internos do primeiro lance.

Em seguida, na Tabela 4.3 são mostradas as propriedades dos perfis soldados PS empregados no dimensionamento e que não são padronizados pela ABNT NBR 5884:2005. 


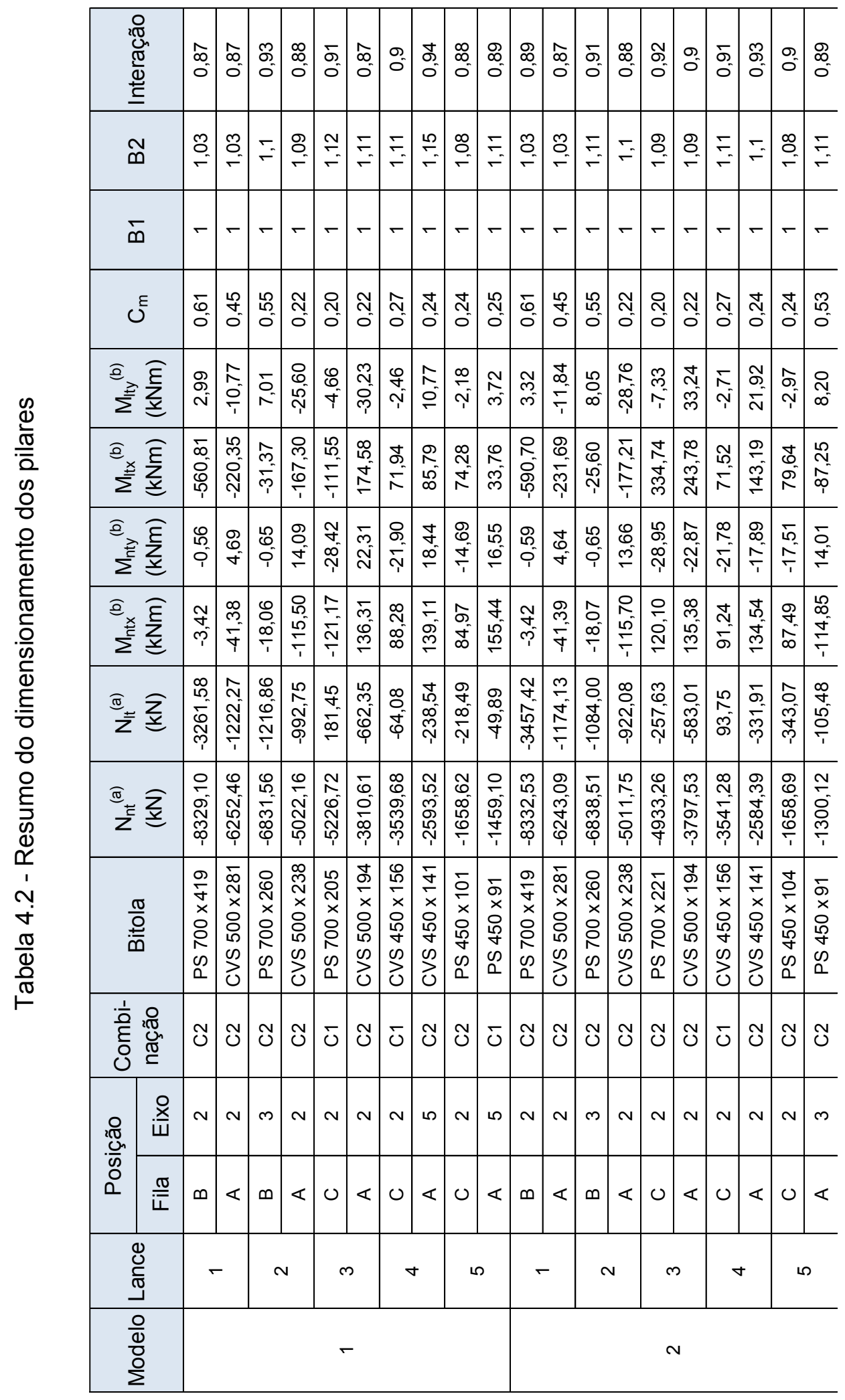




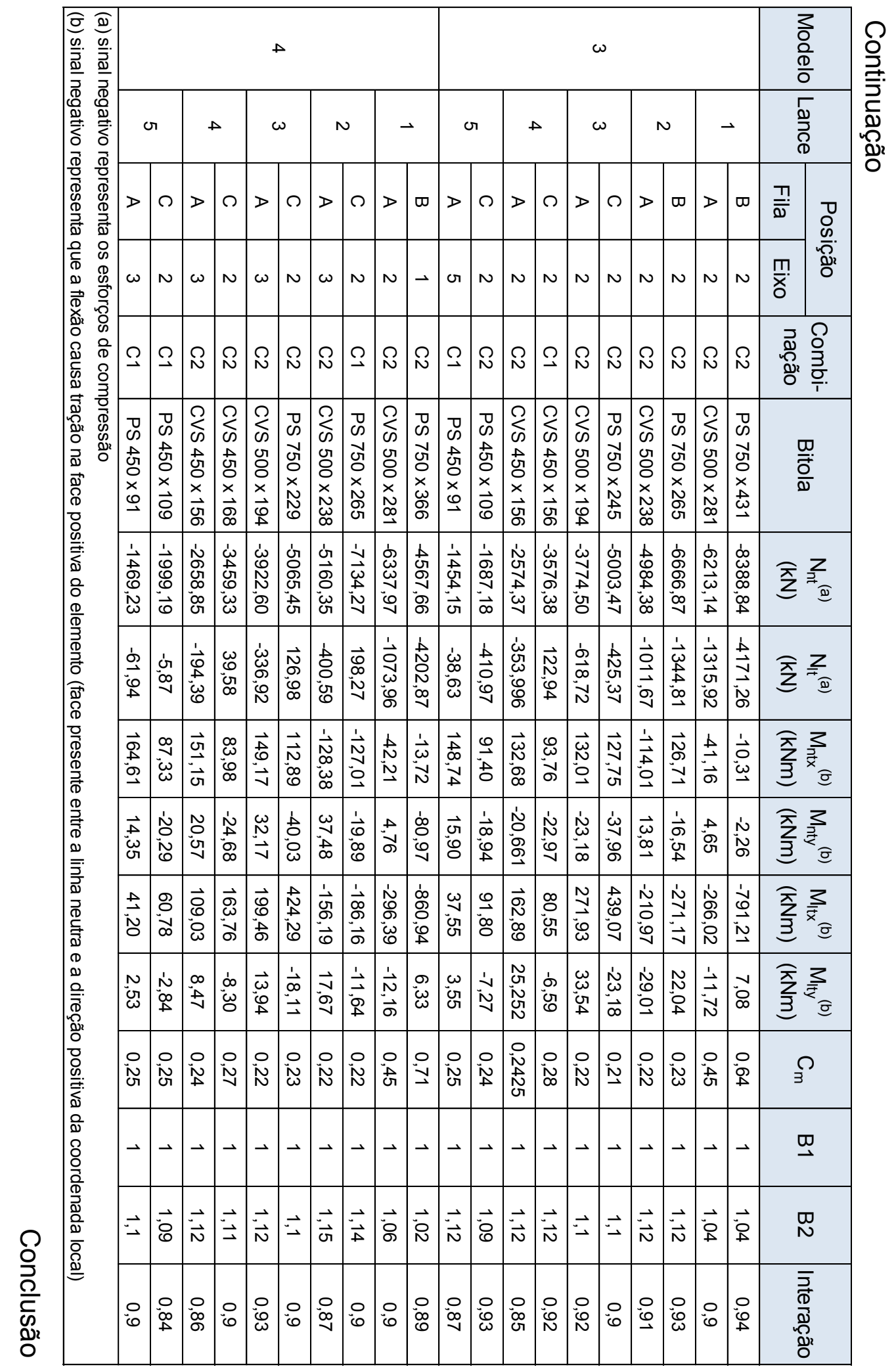


Tabela 4.3 - Propriedades geométricas dos perfis

\begin{tabular}{|c|c|c|c|c|c|}
\hline Bitola & \begin{tabular}{|c|} 
Classificação \\
NBR 5884:2005
\end{tabular} & $\mathrm{d}(\mathrm{mm})$ & $b_{f}(m m)$ & $\mathrm{t}_{\mathrm{f}}(\mathrm{mm})$ & $t_{w}(m m)$ \\
\hline PS $750 \times 431$ & VS & 750 & 450 & 44,5 & 22,4 \\
\hline PS $750 \times 366$ & VS & 750 & 450 & 37,5 & 19 \\
\hline PS $750 \times 265$ & VS & 750 & 450 & 25 & 16 \\
\hline PS $750 \times 245$ & VS & 750 & 450 & 25 & 12,5 \\
\hline PS $750 \times 229$ & VS & 750 & 450 & 25 & 9,5 \\
\hline PS $700 \times 419$ & VS & 700 & 400 & 50 & 22,4 \\
\hline PS $700 \times 260$ & VS & 700 & 400 & 31,5 & 12,5 \\
\hline PS $700 \times 221$ & VS & 700 & 400 & 25 & 12,5 \\
\hline PS $700 \times 205$ & VS & 700 & 400 & 22,4 & 12,5 \\
\hline PS $550 \times 92$ & VS & 550 & 200 & 19 & 8 \\
\hline PS $550 \times 86$ & VS & 550 & 180 & 19 & 8 \\
\hline PS $550 \times 65$ & VS & 550 & 200 & 12,5 & 6,3 \\
\hline PS $550 \times 64$ & VS & 550 & 160 & 12,5 & 8 \\
\hline PS $550 \times 56$ & VS & 550 & 150 & 9,5 & 8 \\
\hline PS $500 \times 53$ & VS & 500 & 150 & 12,5 & 6,3 \\
\hline PS $450 \times 109$ & VS & 450 & 280 & 19 & 8 \\
\hline PS $450 \times 104$ & VS & 450 & 280 & 19 & 6,3 \\
\hline PS $450 \times 101$ & VS & 450 & 280 & 19 & 6,3 \\
\hline PS $450 \times 97$ & VS & 450 & 280 & 16 & 8 \\
\hline PS $450 \times 91$ & VS & 450 & 280 & 16 & 6,3 \\
\hline
\end{tabular}

A composição de uma seção soldada resulta em economia da seção adquirida com a otimização da esbeltez limite dos elementos constituintes. Essa opção não acrescenta muito os custos na fabricação perante os perfis padronizados.

As Figuras 4.12, 4.14, 4.16 e 4.18 expõem a distribuição do coeficiente $B_{2}$ resultante da rigidez lateral da estrutura It aplicada à equação 4.10 para as combinações de ações críticas. Ainda que esses valores resultem dos modelos com as rigidezes reduzidas, pode-se precipitadamente classificar o modelo 1 como de grande deslocabilidade e, no caso do modelo 3 , encontrar um valor negativo sem significado físico.

Entretanto, quando esses gráficos são comparados ao parâmetro $B_{2}$ obtido por meio da rigidez lateral da estrutura original (Figuras 4.13, 4.15, 4.17 e 4.19), fica evidente a deficiência do parâmetro $B_{2}$ ao analisar o elemento isolado da estrutura. Isso é verificado nas situações em que o valor da resultante da cortante $\left(\Sigma \mathrm{H}_{\mathrm{Sd}}\right)$ é relativamente baixo frente ao deslocamento interpavimento $\left(\Delta_{1 \mathrm{~h}}\right)$ correspondente. 


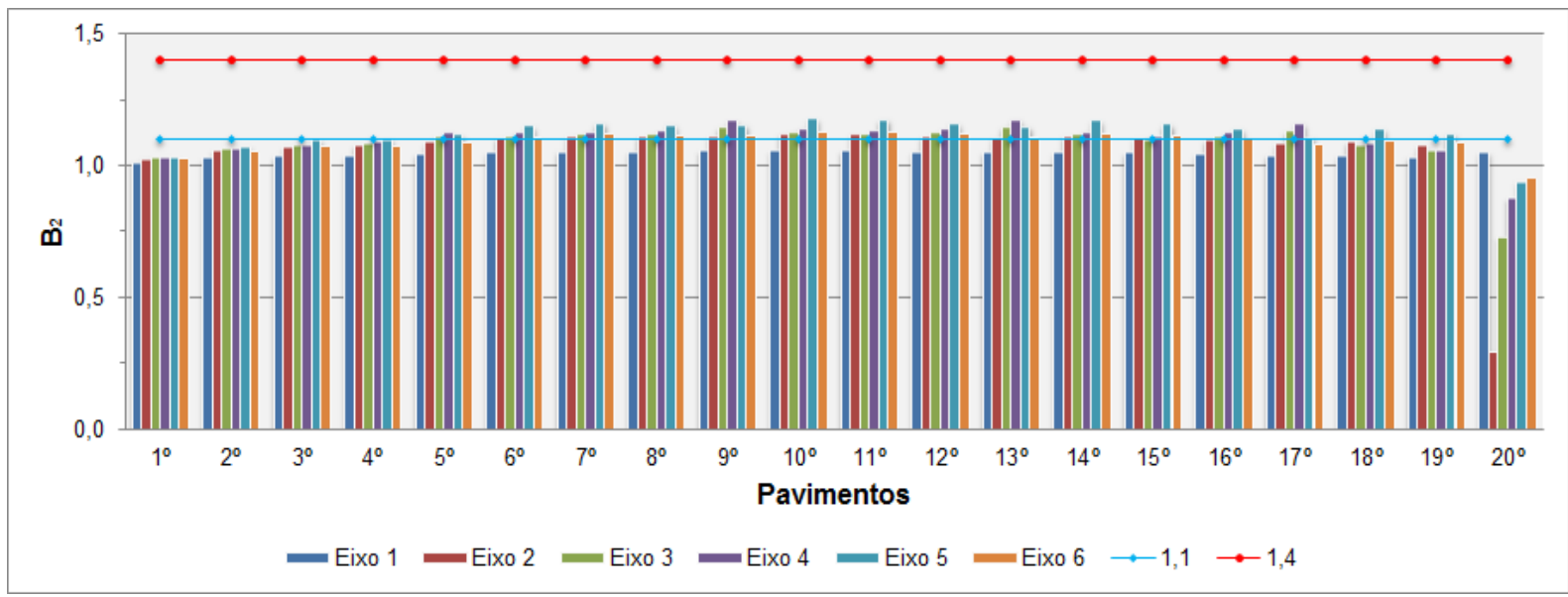

(a)

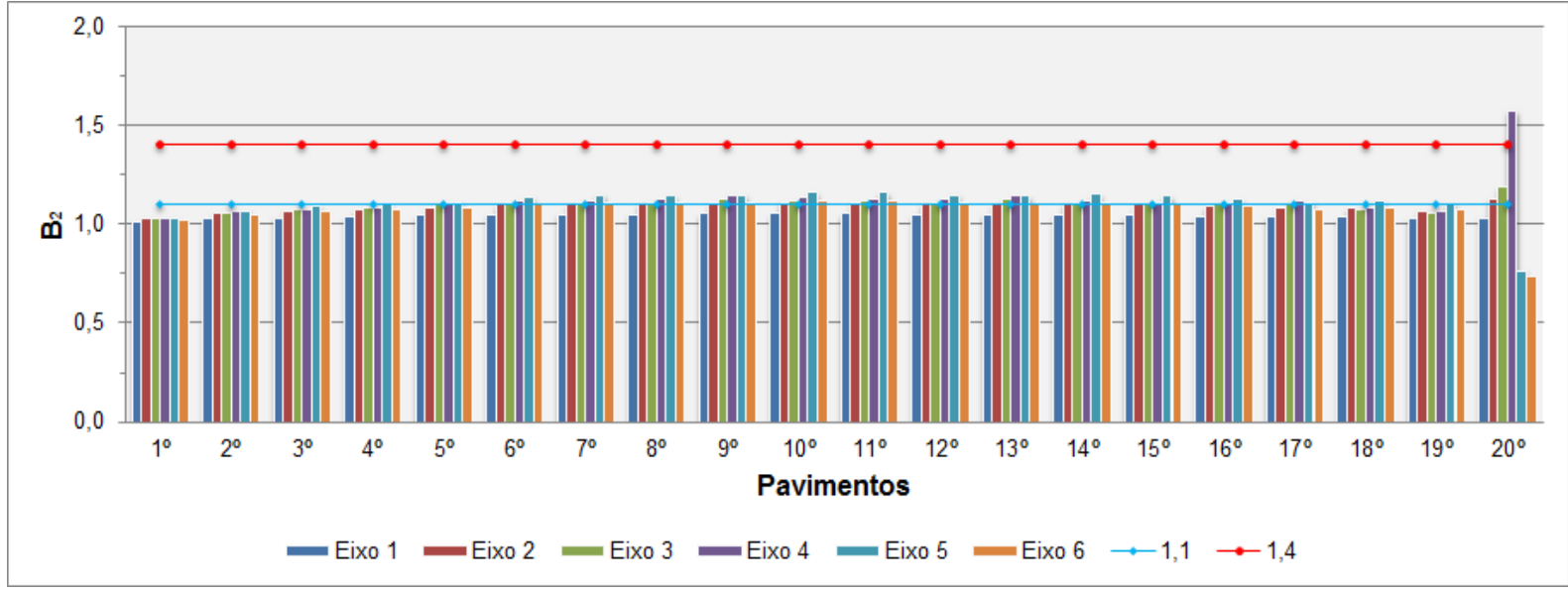

(b)

Figura 4.12 - Modelo 1 - Parâmetro $\mathrm{B}_{2}$ calculado com a rigidez lateral obtida na estrutura It: combinação (a) C1 e (b) C2

Tabela 4.4 - Modelo 1 - Resumo da distribuição do parâmetro B2 calculado para a rigidez lateral obtida na estrutura It

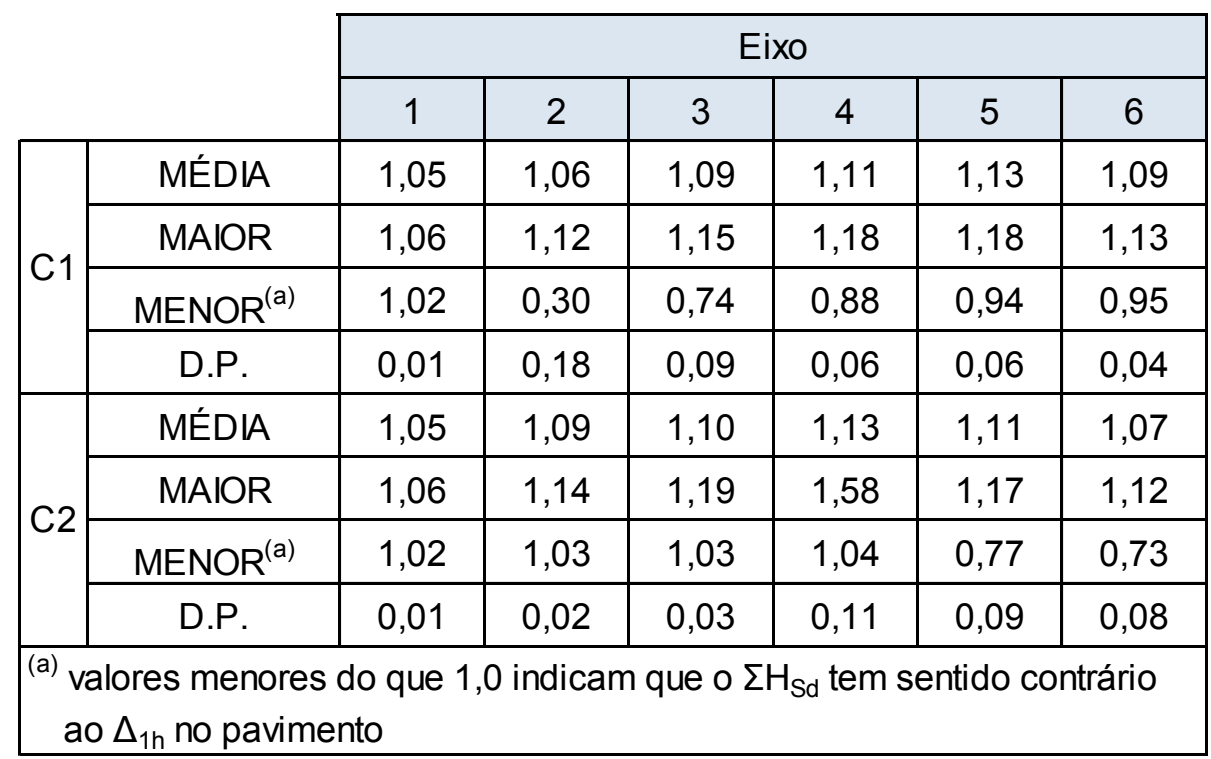




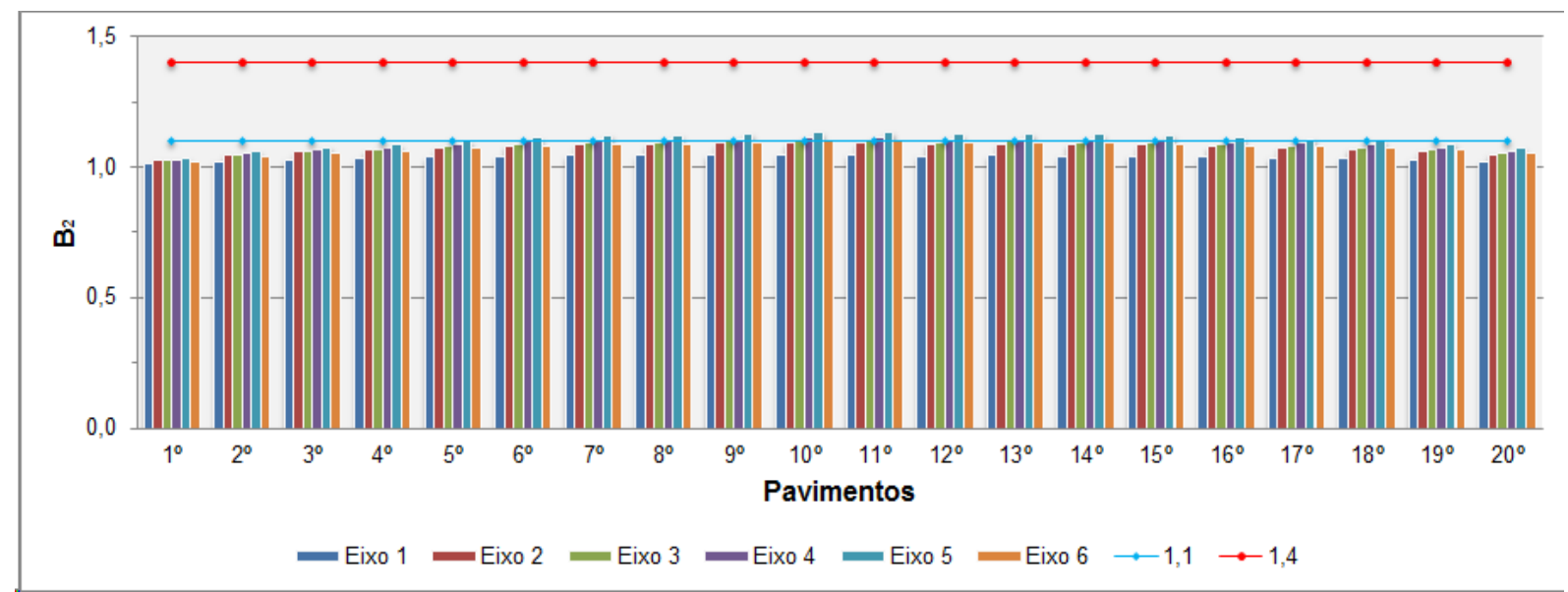

(a)

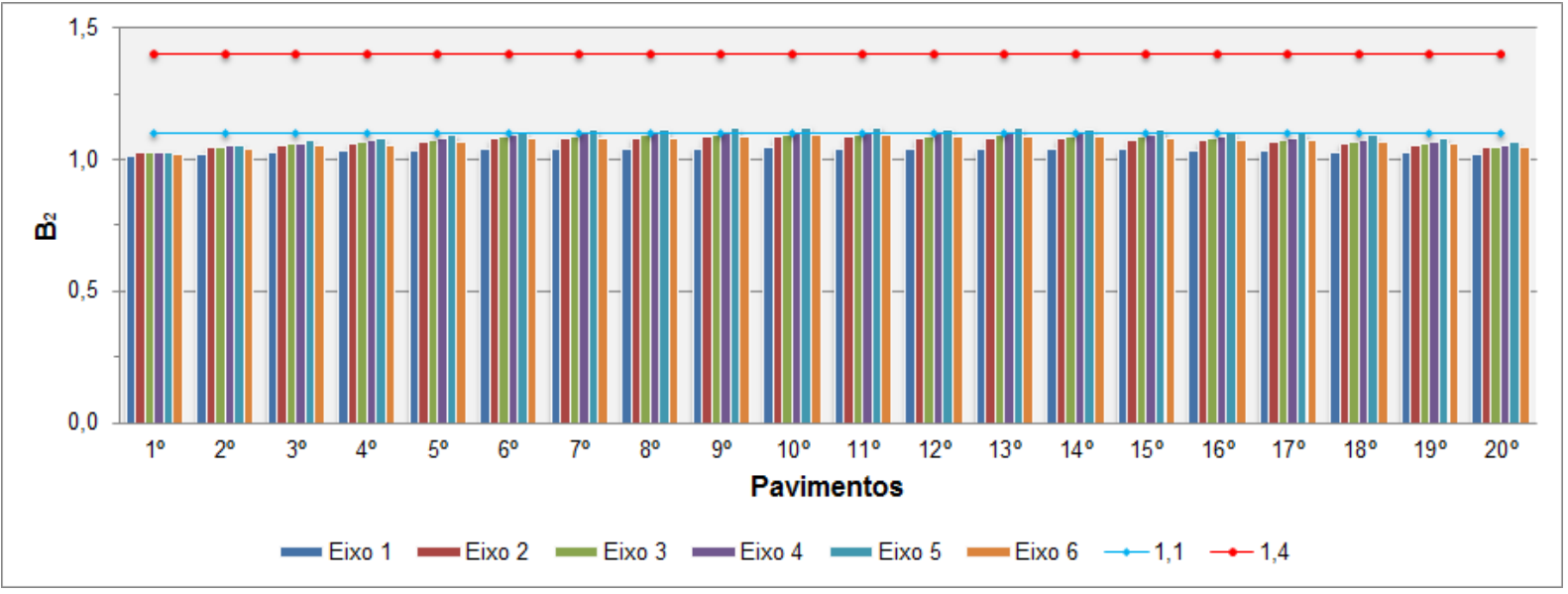

(b)

Figura 4.13 - Modelo 1 - Parâmetro B2 calculado com a rigidez lateral obtida na estrutura original: combinação (a) C1 e (b) C2

Tabela 4.5 - Modelo 1- Resumo da distribuição do parâmetro B2 calculado para a rigidez lateral obtida na estrutura original

\begin{tabular}{|c|c|c|c|c|c|c|c|}
\hline & \multicolumn{6}{|c|}{ Eixo } \\
\hline & & 1 & 2 & 3 & 4 & 5 & 6 \\
\hline \multirow{4}{*}{ C1 } & MÉDIA & 1,04 & 1,08 & 1,08 & 1,09 & 1,11 & 1,07 \\
\hline & DESVIO $(\%)^{(a)}$ & $-1,07$ & 1,70 & $-0,54$ & $-1,44$ & $-1,89$ & $-1,34$ \\
\hline & MAIOR & 1,05 & 1,10 & 1,10 & 1,12 & 1,13 & 1,10 \\
\hline & D.P. & 0,01 & 0,02 & 0,02 & 0,02 & 0,03 & 0,02 \\
\hline \multirow{4}{*}{$\mathrm{C} 2$} & MÉDIA & 1,04 & 1,07 & 1,08 & 1,08 & 1,10 & 1,07 \\
\hline & DESVIO $(\%)^{(a)}$ & $-0,93$ & $-2,09$ & $-2,46$ & $-4,27$ & $-0,99$ & $-0,25$ \\
\hline & MAIOR & 1,05 & 1,09 & 1,10 & 1,11 & 1,13 & 1,09 \\
\hline & D.P. & 0,01 & 0,02 & 0,02 & 0,02 & 0,03 & 0,02 \\
\hline
\end{tabular}




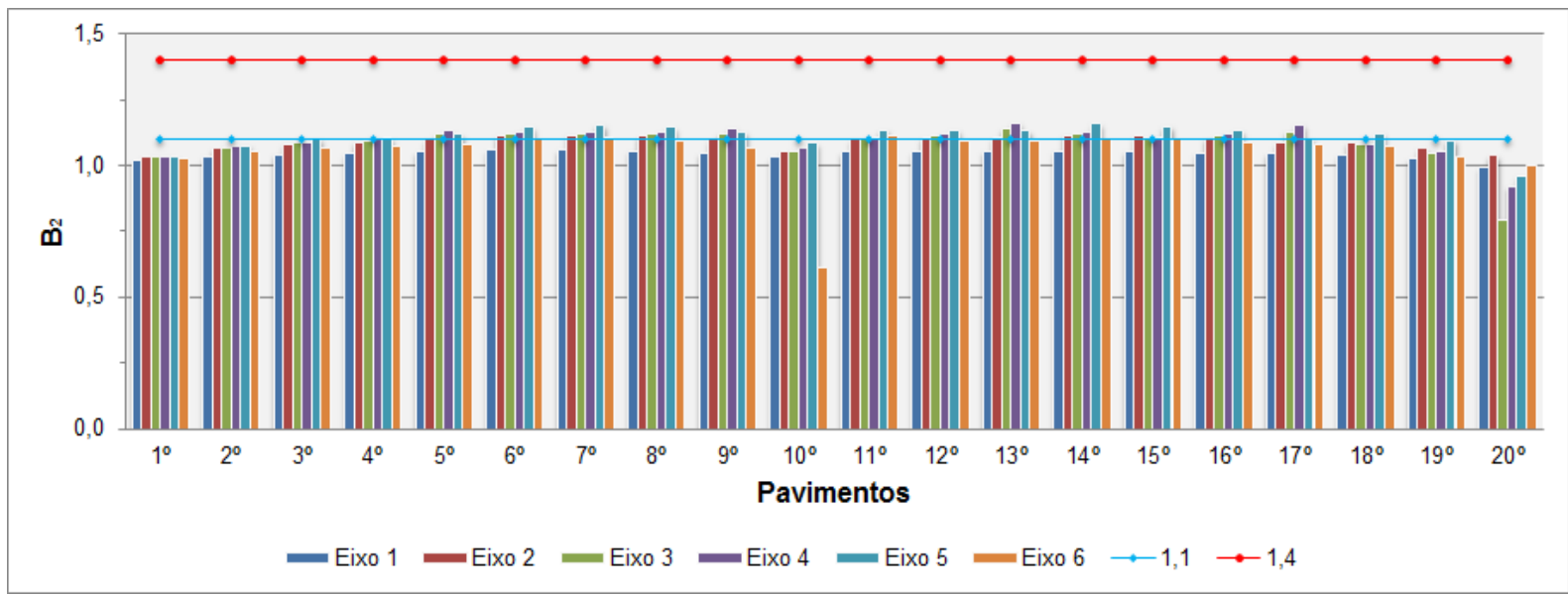

(a)

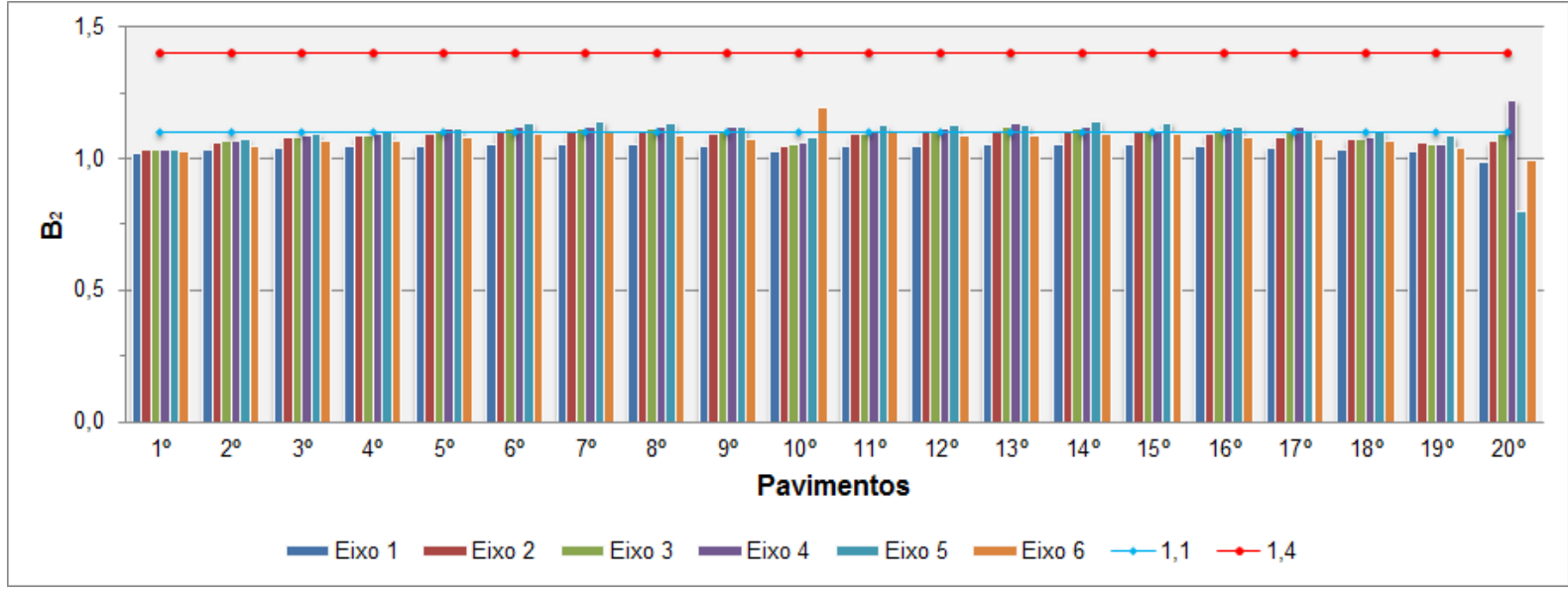

(b)

Figura 4.14 - Modelo 2 - Parâmetro $B_{2}$ calculado com a rigidez lateral obtida na estrutura It: combinação (a) C1 e (b) C2

Tabela 4.6 - Modelo 2 - Resumo da distribuição do parâmetro B2 calculado para a rigidez lateral obtida na estrutura It

\begin{tabular}{|c|c|c|c|c|c|c|c|}
\hline & \multicolumn{6}{|c|}{ Eixo } \\
\hline & & 1 & 2 & 3 & 4 & 5 & 6 \\
\hline \multirow{4}{*}{ C1 } & MÉDIA & 1,05 & 1,09 & 1,09 & 1,10 & 1,11 & 1,05 \\
\hline & MAIOR & 1,06 & 1,12 & 1,14 & 1,16 & 1,16 & 1,11 \\
\hline & MENOR $^{(a)}$ & 0,99 & 1,03 & 0,80 & 0,92 & 0,96 & 0,61 \\
\hline & D.P. & 0,02 & 0,03 & 0,07 & 0,05 & 0,05 & 0,11 \\
\hline \multirow{4}{*}{$\mathrm{C} 2$} & MÉDIA & 1,04 & 1,09 & 1,09 & 1,11 & 1,10 & 1,08 \\
\hline & MAIOR & 1,06 & 1,11 & 1,12 & 1,22 & 1,14 & 1,19 \\
\hline & MENOR $^{(a)}$ & 0,99 & 1,03 & 1,04 & 1,04 & 0,80 & 1,00 \\
\hline & D.P. & 0,02 & 0,02 & 0,02 & 0,04 & 0,08 & 0,04 \\
\hline \multicolumn{8}{|c|}{$\begin{array}{l}\text { (a) valores menores do que } 1,0 \text { indicam que o } \Sigma \mathrm{H}_{\mathrm{Sd}} \text { tem sentido contrário } \\
\text { ao } \Delta_{1 \mathrm{~h}} \text { no pavimento }\end{array}$} \\
\hline
\end{tabular}




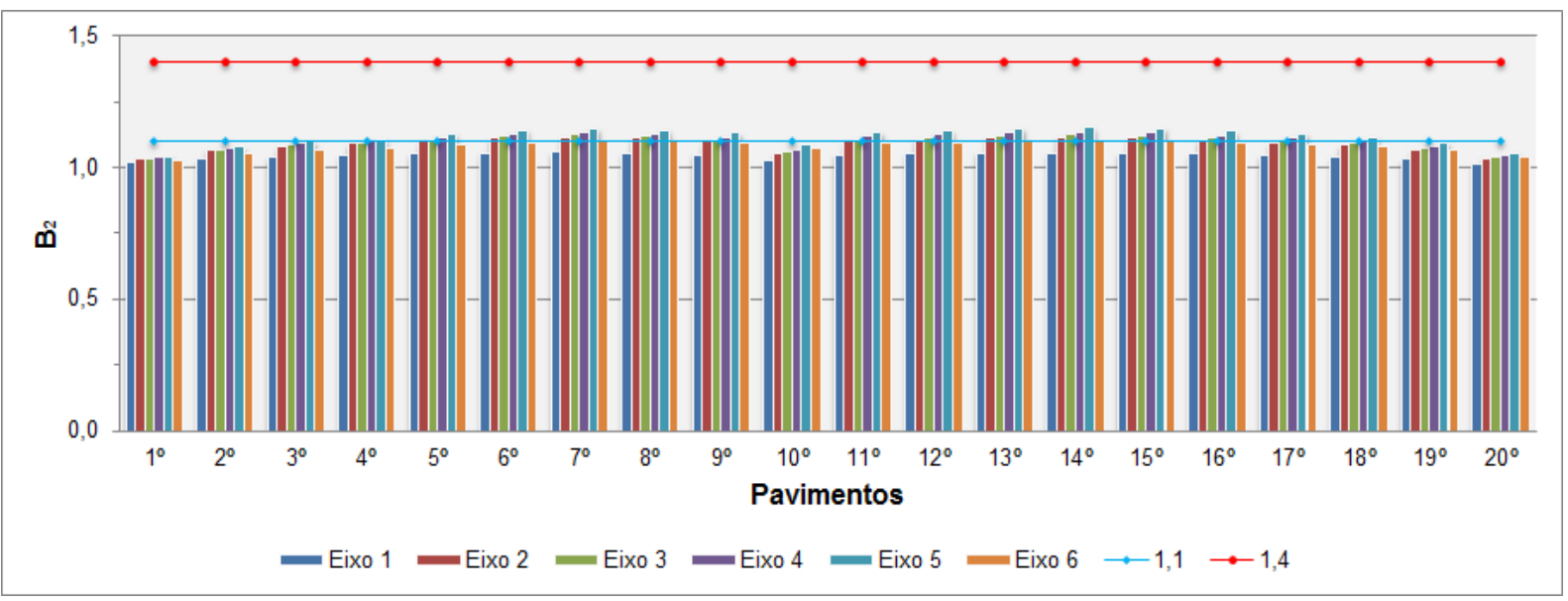

(a)

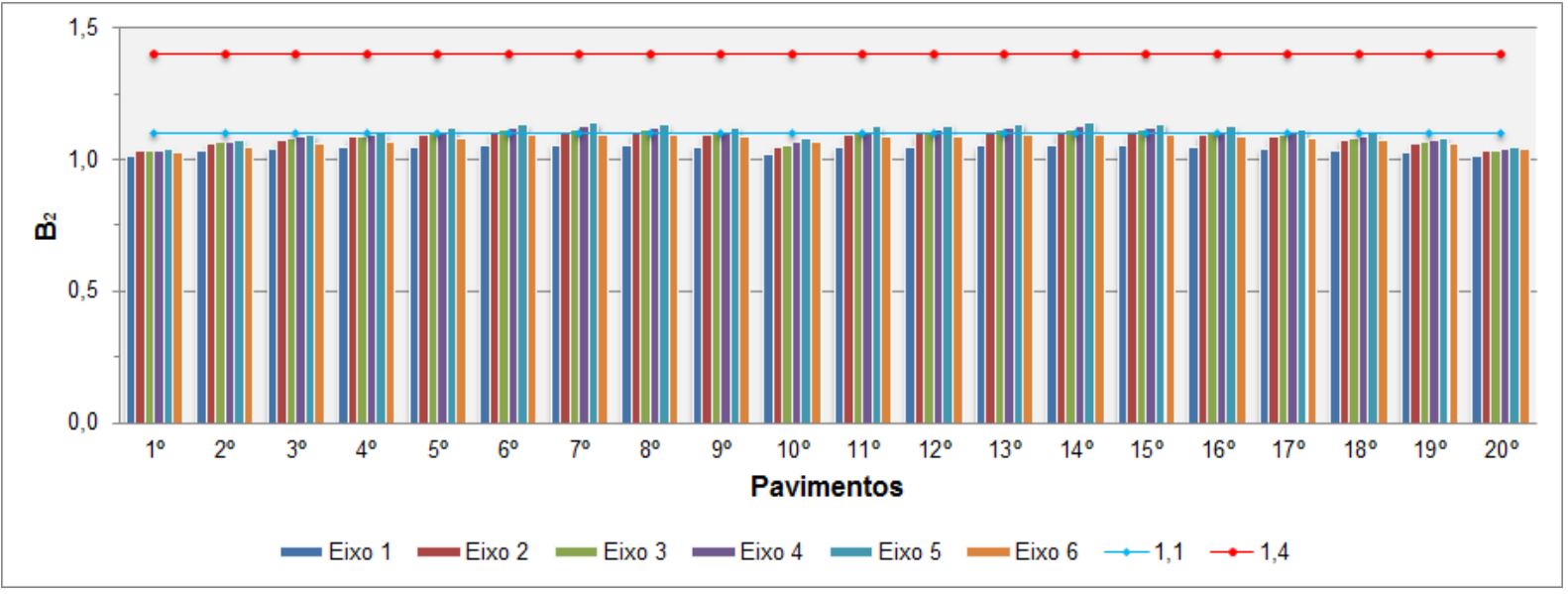

(b)

Figura 4.15 - Modelo 2 - Parâmetro B2 calculado com a rigidez lateral obtida na estrutura original: combinação (a) C1 e (b) C2

Tabela 4.7 - Modelo 2 - Resumo da distribuição do parâmetro B2 calculado para a rigidez lateral obtida na estrutura original

\begin{tabular}{|c|c|c|c|c|c|c|c|}
\hline & \multicolumn{6}{|c|}{ Eixo } \\
\hline & & 1 & 2 & 3 & 4 & 5 & 6 \\
\hline \multirow{4}{*}{ C1 } & MÉDIA & 1,05 & 1,09 & 1,10 & 1,11 & 1,12 & 1,08 \\
\hline & DESVIO $(\%)^{(a)}$ & 0,12 & 0,11 & 1,20 & 0,61 & 0,71 & 2,67 \\
\hline & MAIOR & 1,06 & 1,12 & 1,13 & 1,14 & 1,15 & 1,10 \\
\hline & D.P. & 0,01 & 0,03 & 0,03 & 0,03 & 0,03 & 0,02 \\
\hline \multirow{4}{*}{$\mathrm{C} 2$} & MÉDIA & 1,04 & 1,08 & 1,09 & 1,10 & 1,11 & 1,08 \\
\hline & DESVIO $(\%)^{(a)}$ & 0,15 & $-0,09$ & $-0,20$ & $-0,75$ & 1,31 & $-0,22$ \\
\hline & MAIOR & 1,06 & 1,11 & 1,12 & 1,13 & 1,14 & 1,10 \\
\hline & D.P. & 0,01 & 0,02 & 0,03 & 0,03 & 0,03 & 0,02 \\
\hline
\end{tabular}




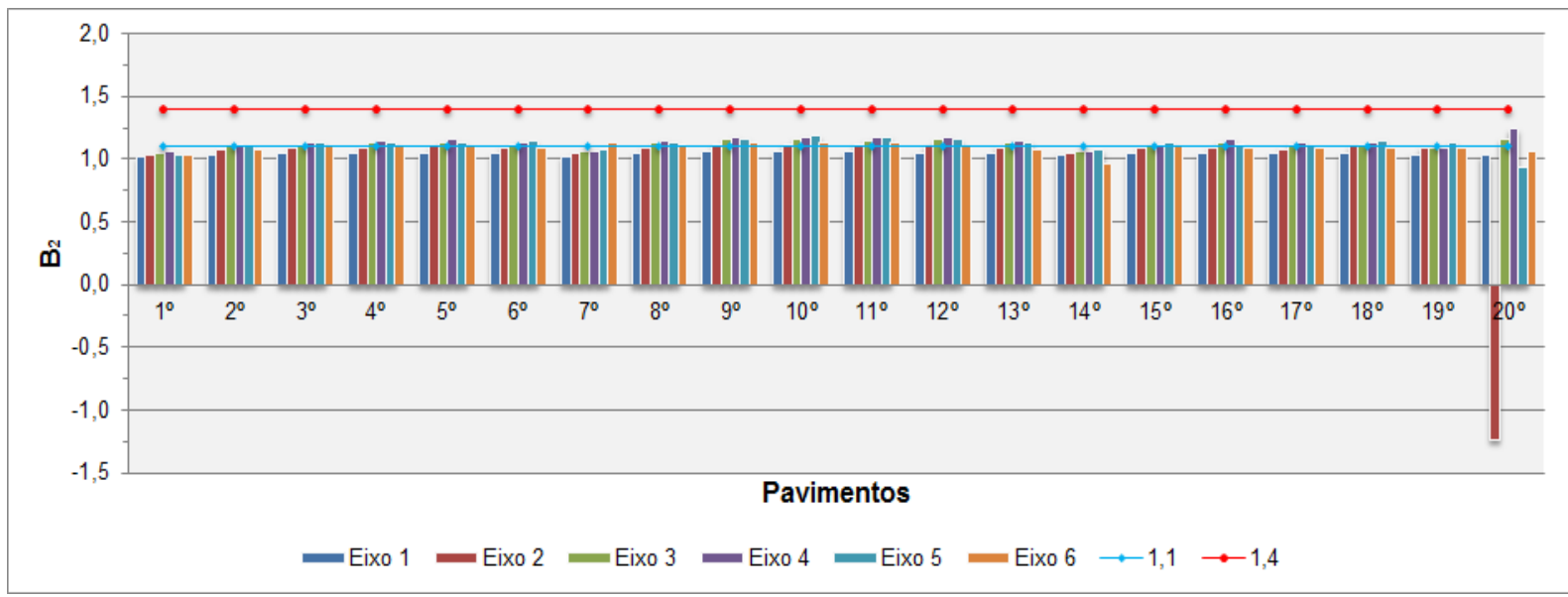

(a)

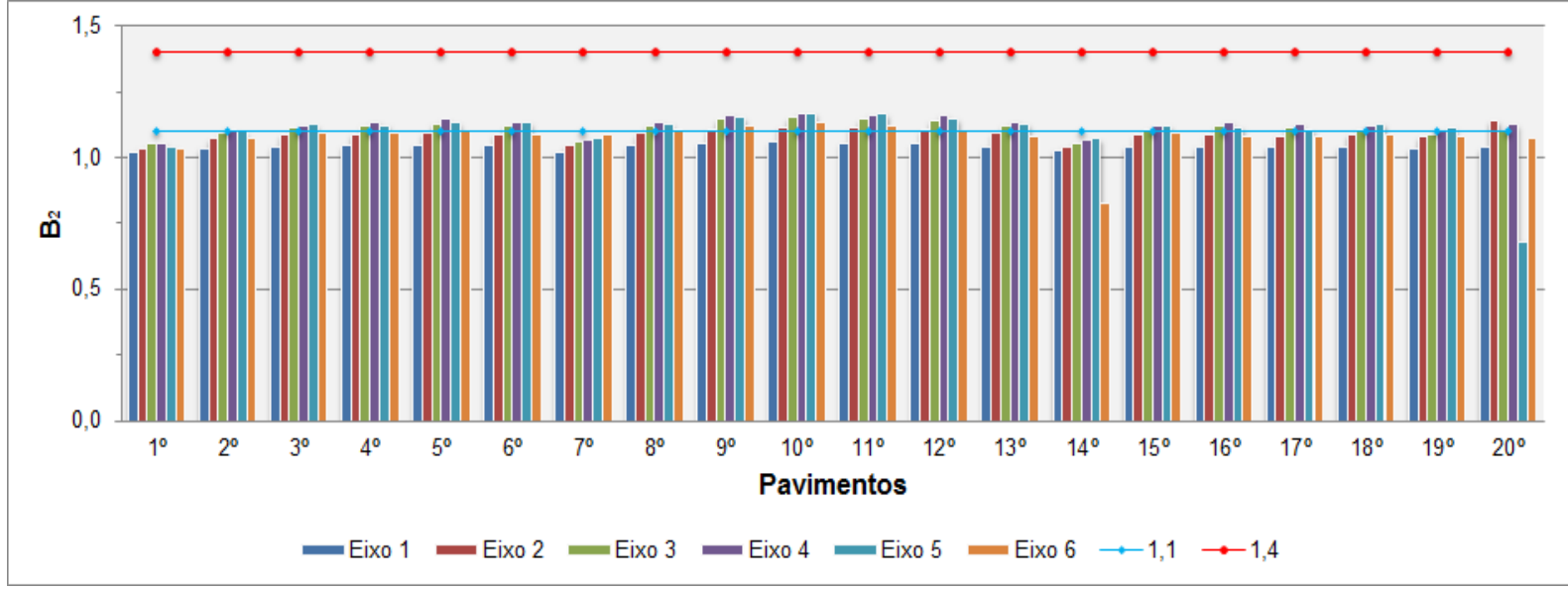

(b)

Figura 4.16 - Modelo 3 - Parâmetro $B_{2}$ calculado com a rigidez lateral obtida na estrutura It: combinação (a) C1 e (b) C2

Tabela 4.8 - Modelo 3 - Resumo da distribuição do parâmetro B2 calculado para a rigidez lateral obtida na estrutura It

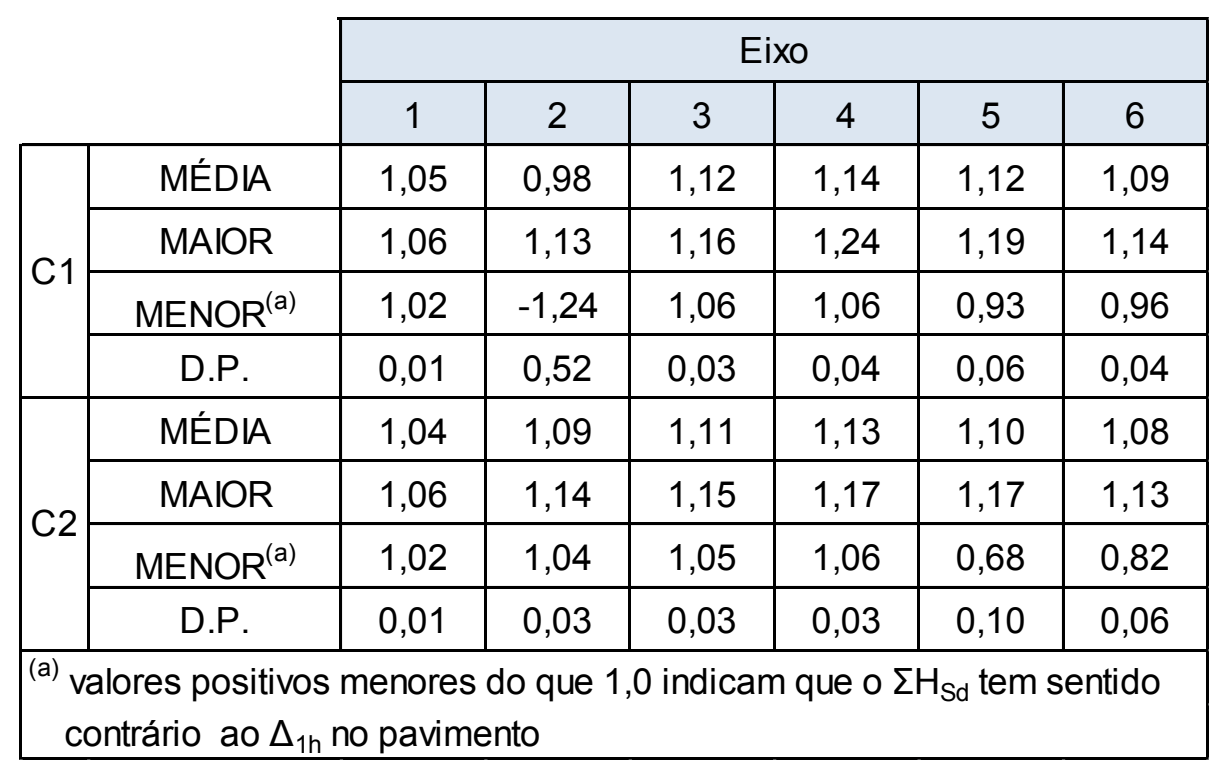




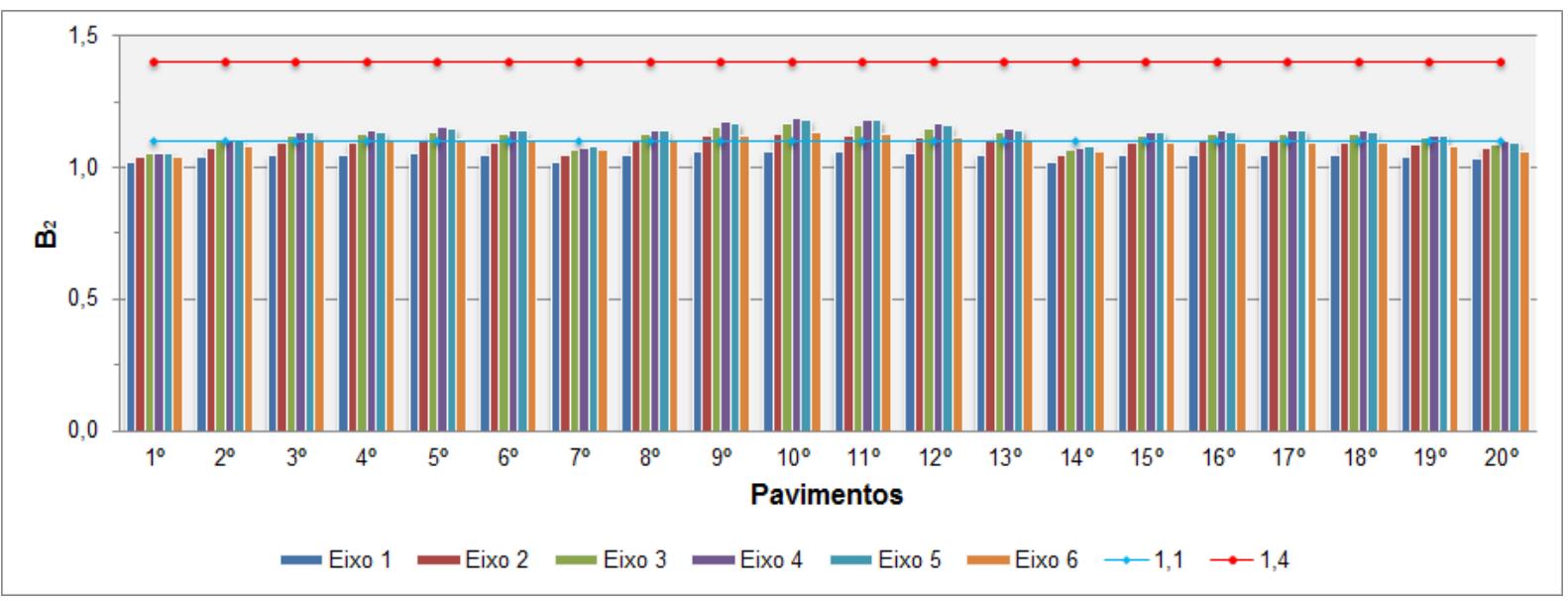

(a)

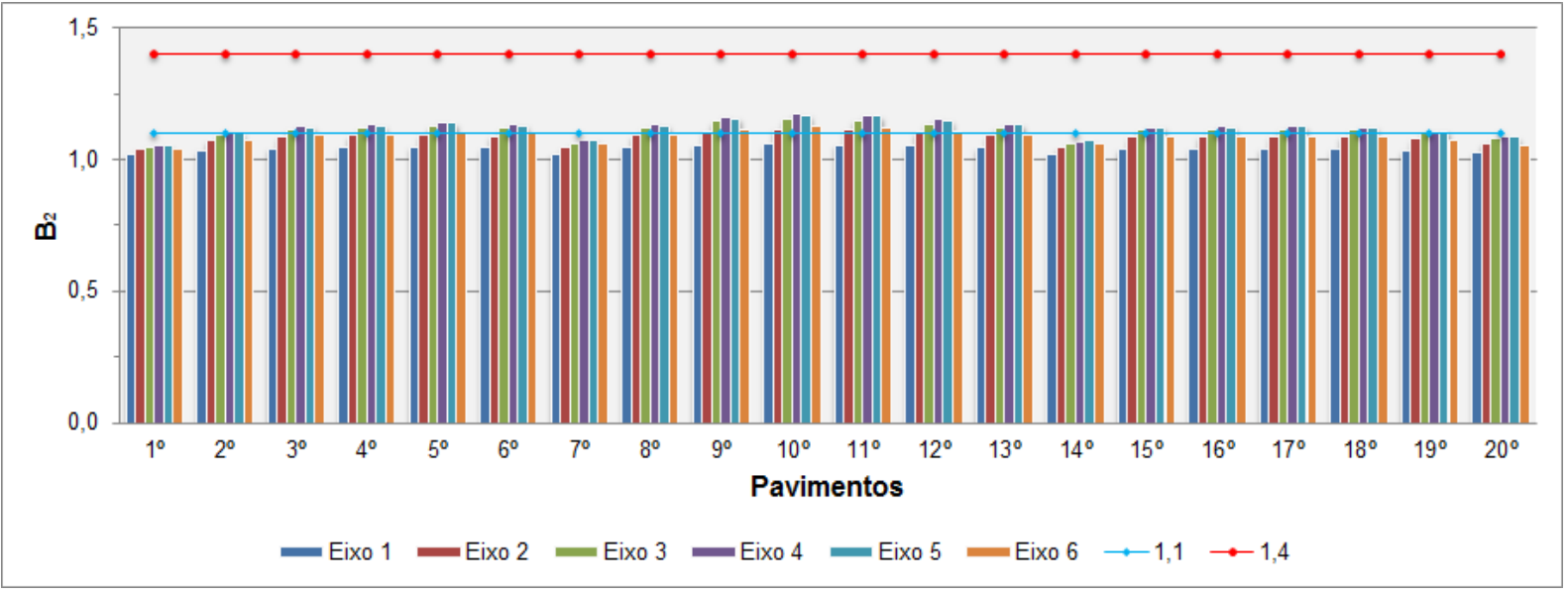

(b)

Figura 4.17 - Modelo 3 - Parâmetro B2 calculado com a rigidez lateral obtida na estrutura original: combinação (a) C1 e (b) C2

Tabela 4.9 - Modelo 3 - Resumo da distribuição do parâmetro B2 calculado para a rigidez lateral obtida na estrutura original

\begin{tabular}{|c|c|c|c|c|c|c|c|}
\hline & \multicolumn{6}{|c|}{ Eixo } \\
\hline & & 1 & 2 & 3 & 4 & 5 & 6 \\
\hline \multirow{4}{*}{ C1 } & MÉDIA & 1,05 & 1,09 & 1,12 & 1,13 & 1,13 & 1,09 \\
\hline & DESVIO (\%) $)^{(a)}$ & $-0,08$ & 12,00 & $-0,29$ & $-0,60$ & 1,09 & 0,32 \\
\hline & MAIOR & 1,06 & 1,13 & 1,17 & 1,19 & 1,18 & 1,13 \\
\hline & D.P. & 0,01 & 0,02 & 0,03 & 0,03 & 0,03 & 0,02 \\
\hline \multirow{4}{*}{$\mathrm{C} 2$} & MÉDIA & 1,04 & 1,09 & 1,11 & 1,12 & 1,12 & 1,09 \\
\hline & DESVIO $(\%)^{(a)}$ & 0,01 & 0,02 & 0,03 & 0,03 & 0,03 & 0,02 \\
\hline & MAIOR & 1,06 & 1,12 & 1,16 & 1,17 & 1,17 & 1,12 \\
\hline & D.P. & 1,02 & 1,04 & 1,05 & 1,05 & 1,05 & 1,04 \\
\hline
\end{tabular}




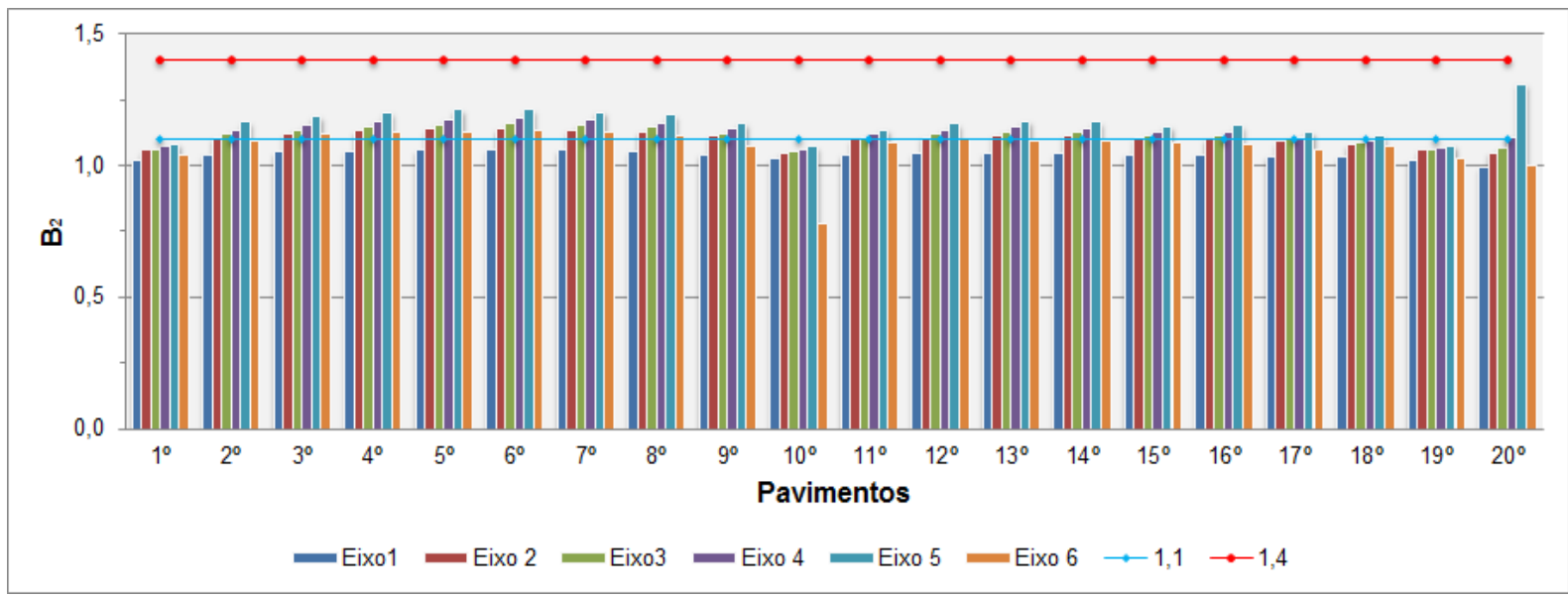

(a)

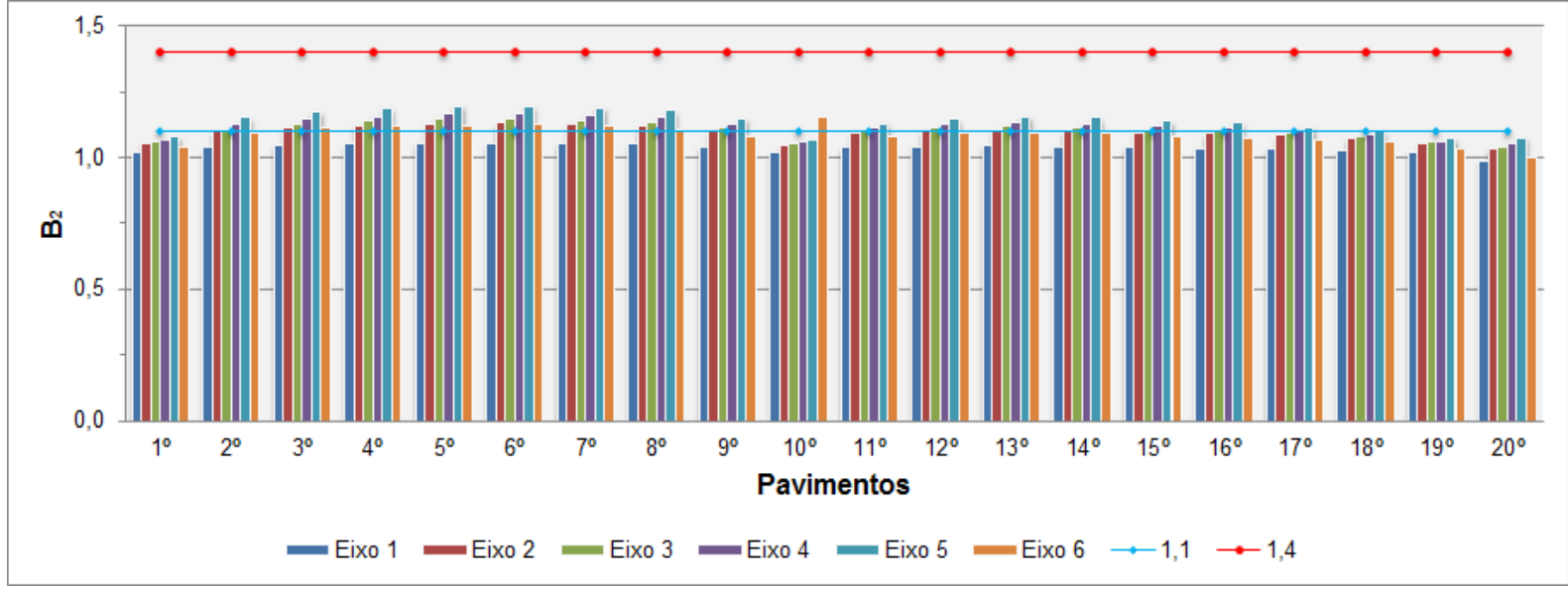

(b)

Figura 4.18 - Modelo 4 - Parâmetro $B_{2}$ calculado com a rigidez lateral obtida na estrutura It: combinação (a) C1 e (b) C2

Tabela 4.10 - Modelo 4 - Resumo da distribuição do parâmetro B2 calculado para a rigidez lateral obtida na estrutura It

\begin{tabular}{|c|c|c|c|c|c|c|c|}
\hline & \multicolumn{6}{|c|}{ Eixo } \\
\hline & & 1 & 2 & 3 & 4 & 5 & 6 \\
\hline \multirow{4}{*}{ C1 } & MÉDIA & 1,04 & 1,10 & 1,12 & 1,13 & 1,16 & 1,07 \\
\hline & MAIOR & 1,06 & 1,14 & 1,16 & 1,18 & 1,31 & 1,14 \\
\hline & MENOR $^{(a)}$ & 1,00 & 1,05 & 1,06 & 1,06 & 1,07 & 0,78 \\
\hline & D.P. & 0,02 & 0,03 & 0,03 & 0,04 & 0,06 & 0,08 \\
\hline \multirow{4}{*}{ C2 } & MÉDIA & 1,04 & 1,10 & 1,11 & 1,12 & 1,14 & 1,09 \\
\hline & MAIOR & 1,06 & 1,13 & 1,15 & 1,17 & 1,20 & 1,15 \\
\hline & MENOR $^{(a)}$ & 0,99 & 1,04 & 1,04 & 1,06 & 1,07 & 1,00 \\
\hline & D.P. & 0,02 & 0,03 & 0,03 & 0,04 & 0,04 & 0,04 \\
\hline \multicolumn{8}{|c|}{$\begin{array}{l}\text { (a) valores menores do que } 1,0 \text { indicam que o } \Sigma \mathrm{H}_{\mathrm{Sd}} \text { tem sentido contrário } \\
\text { ao } \Delta_{1 \mathrm{~h}} \text { no pavimento }\end{array}$} \\
\hline
\end{tabular}




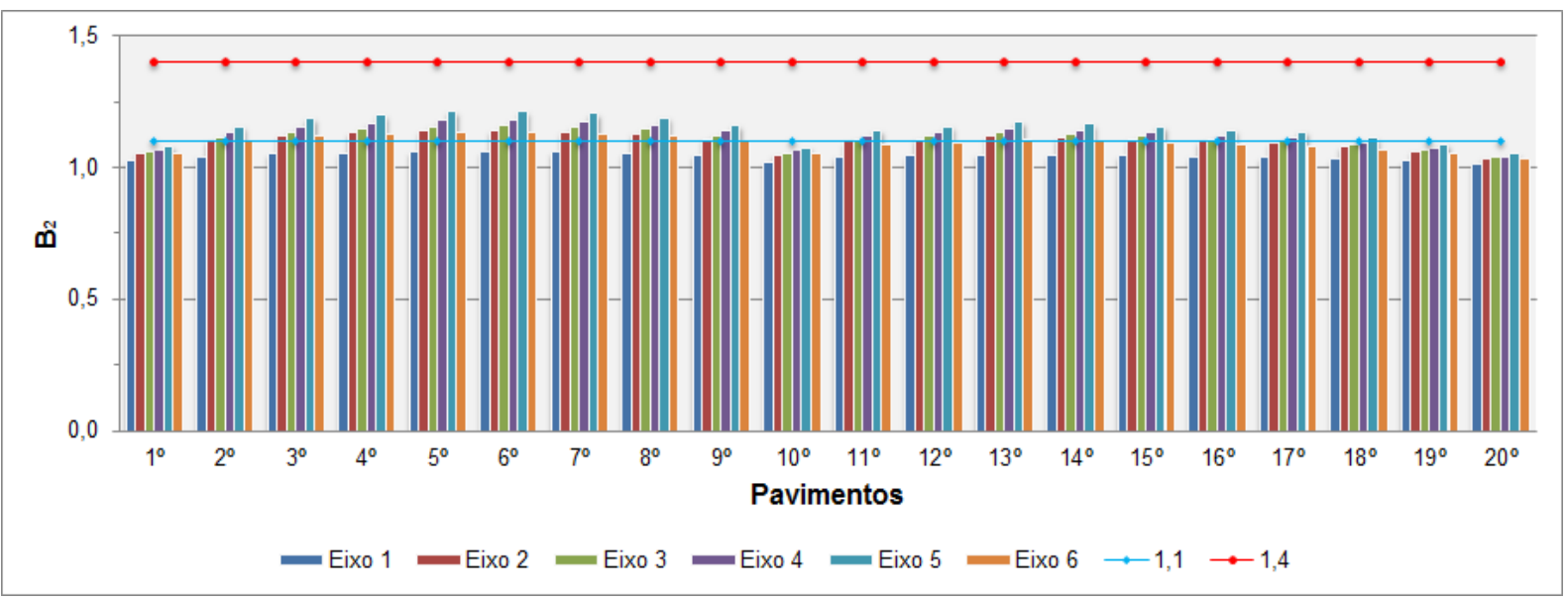

(a)

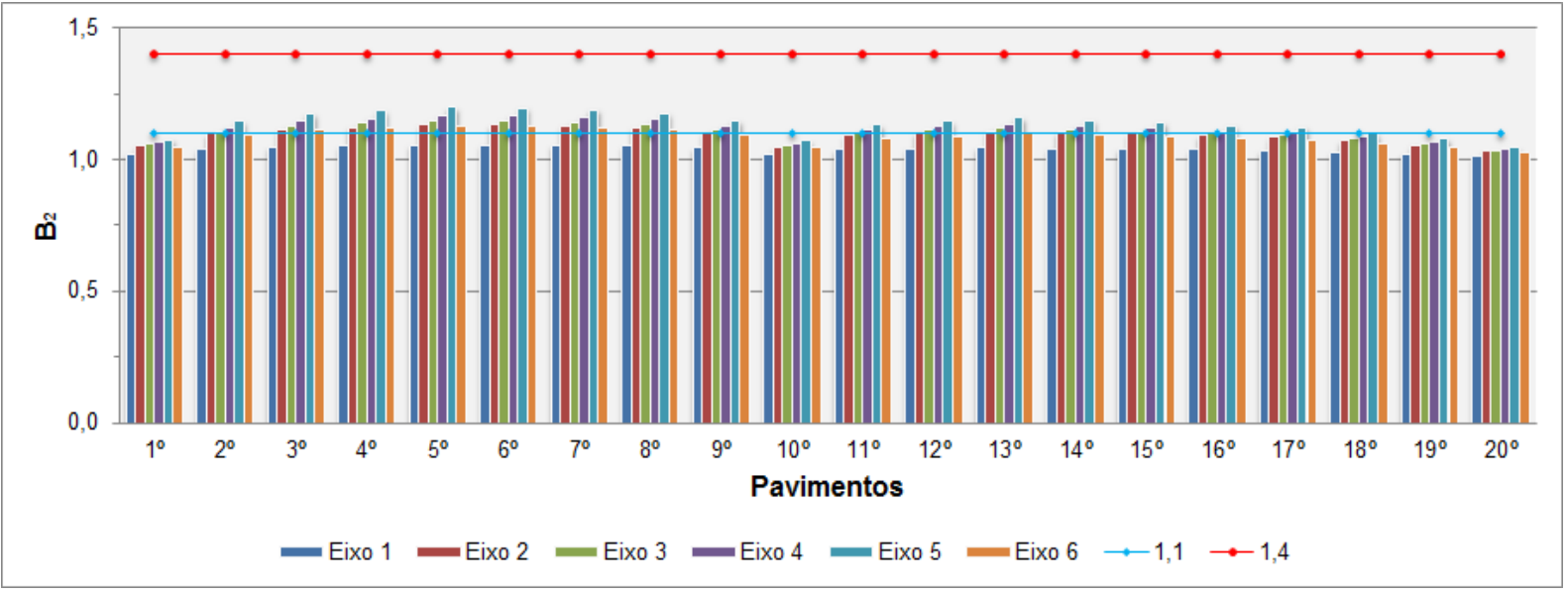

(b)

Figura 4.19 - Modelo 4 - Parâmetro B2 calculado com a rigidez lateral obtida na estrutura original: combinação (a) C1 e (b) C2

Tabela 4.11 - Modelo 4 - Resumo da distribuição do parâmetro B2 calculado para a rigidez lateral obtida na estrutura original

\begin{tabular}{|c|c|c|c|c|c|c|c|}
\hline & \multicolumn{6}{|c|}{ Eixo } \\
\hline & & 1 & 2 & 3 & 4 & 5 & 6 \\
\hline \multirow{4}{*}{ C1 } & MÉDIA & 1,04 & 1,10 & 1,11 & 1,13 & 1,15 & 1,09 \\
\hline & DESVIO $(\%)^{(a)}$ & 0,16 & $-0,13$ & $-0,13$ & $-0,16$ & $-0,20$ & 1,52 \\
\hline & MAIOR & 1,06 & 1,14 & 1,16 & 1,18 & 1,21 & 1,13 \\
\hline & D.P. & 0,01 & 0,03 & 0,04 & 0,04 & 0,05 & 0,03 \\
\hline \multirow{4}{*}{$\mathrm{C} 2$} & MÉDIA & 1,04 & 1,10 & 1,11 & 1,12 & 1,14 & 1,09 \\
\hline & DESVIO $(\%)^{(a)}$ & 0,15 & $-0,01$ & $-0,02$ & $-0,04$ & $-0,10$ & 0,00 \\
\hline & MAIOR & 1,06 & 1,13 & 1,15 & 1,17 & 1,20 & 1,13 \\
\hline & D.P. & 0,01 & 0,03 & 0,03 & 0,04 & 0,04 & 0,03 \\
\hline
\end{tabular}


Nos modelos desse trabalho, tal fato é decorrente da inversão do sentido das forças horizontais a meia altura (região da treliça horizontal) e dessa possibilidade em conjunto com a baixa intensidade dessas forças na cobertura. Esses comportamentos estruturais provocam valores elevados de $B_{2}$ ou menores do que 1,0 quando $\Sigma H_{S d}$ está no sentido ou não de $\Delta_{1 h}$, respectivamente.

Conforme as Tabelas 4.5, 4.7, 4.9 e 4.11 o desvio das médias de $B_{2}$ ao longo dos pavimentos empregando a rigidez lateral da estrutura original em relação à estrutura It, excluindo dessa os eixos que não são fieis a representação da rigidez da estrutura, é igual a apenas - $1 \%$.

Outro fator favorável ao cálculo da rigidez lateral pela estrutura original é o baixo nível de dispersão (D.P.) de $\mathrm{B}_{2}$ ao longo dos pavimentos. Esse comportamento é condizente às estruturas simétricas nas duas direções com o mesmo desnível entre os pavimentos e pequena variação na intensidade das cargas nos pavimentos superiores.

Os dimensionamentos dos modelos foram realizados para a rigidez lateral da estrutura It, porém com base na discursão acima, os valores de $B_{2}$ que sofrem expressiva variação em relação aos pavimentos adjacentes foram eliminados. A partir disso, o número de seções críticas, concentradas no nível inferior de cada lance, não sofreu acréscimo decorrente de um elemento em especifico sob um parâmetro com valor de grande expressão.

A Tabela 4.12 reúne o resumo do dimensionamento das vigas. Pode-se destacar a inclusão pela ABNT NBR 8800:2008 da contribuição das barras na resistência à flexão. Dessa maneira, consegue-se padronizar as vigas contínuas economizando no peso dos perfis.

Nessa tabela também se observa que a bitola das vigas contínuas V6 e V7 do Modelo 3 sofreu um pequeno aumento para conter o momento fletor negativo. $O$ aumento da resistência à flexão é buscado alterando a bitola do perfil porque o número de barras adotado apresenta-se no limite tolerável para evitar a flambagem local da alma na região de momento negativo. 
Tabela 4.12 - Resumo do dimensionamento das vigas

\begin{tabular}{|c|c|c|c|c|c|c|c|c|c|}
\hline Modelo & Posição & Bitola & $\begin{array}{c}\text { Barras } \\
(\mathrm{mm})\end{array}$ & \begin{tabular}{|c} 
Interação \\
$(\%)$
\end{tabular} & Tipo & Combinação & $\begin{array}{l}\mathrm{M}_{\mathrm{Sd}}{ }^{(\mathrm{a})} \\
(\mathrm{kNm})\end{array}$ & $\frac{\mathrm{M}_{\mathrm{Sd}}}{\mathrm{M}_{\mathrm{Rd}}}$ & $\frac{\delta_{\max }^{(\mathrm{b})}}{\delta_{\lim }}$ \\
\hline \multirow{10}{*}{1} & Eixos & \multirow{6}{*}{ PS $550 \times 86$} & \multirow{2}{*}{$4 \times 12,5$} & \multirow{2}{*}{50} & \multirow{6}{*}{ contínua } & C3 & 296,49 & 0,34 & \multirow{2}{*}{0,41} \\
\hline & & & & & & $\mathrm{C} 2$ & $-536,54$ & 0,80 & \\
\hline & Eixos & & \multirow{2}{*}{$8 \times 12,5$} & \multirow{2}{*}{50} & & C1 & 437,96 & 0,46 & \multirow{2}{*}{0,74} \\
\hline & 2 e 5 & & & & & $\mathrm{C} 2$ & $-656,23$ & 0,90 & \\
\hline & \multirow{3}{*}{$\begin{array}{l}\text { Eixos } \\
3 \text { e } 4\end{array}$} & & \multirow{2}{*}{$6 \times 12,5$} & \multirow{2}{*}{50} & & C1 & 433,84 & 0,46 & \multirow{2}{*}{0,74} \\
\hline & & & & & & $\mathrm{C} 2$ & $-630,89$ & 0,90 & \\
\hline & & PS $550 \times 65,2$ & $8 \times 6,3$ & 70 & biapoiada & $\mathrm{C} 4$ & 731,88 & 0,87 & 0,97 \\
\hline & \multirow{2}{*}{ Filas } & \multirow{2}{*}{ PS $550 \times 56$} & \multirow{2}{*}{$8 \times 8$} & \multirow{2}{*}{50} & \multirow{2}{*}{ contínua } & $\mathrm{C}_{1}{ }^{(\mathrm{c})}$ & 221,29 & 0,34 & \multirow{2}{*}{0,88} \\
\hline & & & & & & $\mathrm{C} 2^{(\mathrm{c})}$ & $-310,96$ & 0,81 & \\
\hline & $\mathrm{V} 1$ & PS $550 \times 65,2$ & $12 \times 6,3$ & 50 & biapoada & $\mathrm{C} 4$ & 407,43 & 0,51 & 0,77 \\
\hline \multirow{9}{*}{2} & $\begin{array}{l}\text { Eixos } \\
1 \text { e } 6\end{array}$ & PS $550 \times 65,2$ & $5 \times 6,3$ & 50 & biapoiada & C4 & 383,42 & 0,54 & 0,55 \\
\hline & Eixos & \multirow{4}{*}{ PS $550 \times 86$} & \multirow{2}{*}{$10 \times 12,5$} & \multirow{2}{*}{50} & \multirow{4}{*}{ contínua } & C1 & 437,19 & 0,46 & \multirow{2}{*}{0,74} \\
\hline & 2 e 5 & & & & & $\mathrm{C} 2$ & $-664,23$ & 0,88 & \\
\hline & & & $4 \times 125$ & 50 & & C1 & 430,25 & 0,46 & 074 \\
\hline & $\begin{array}{l}\text { EIxOS } \\
3 \text { e } 4\end{array}$ & & $4 \times 12,0$ & 30 & & $\mathrm{C} 2$ & $-606,35$ & 0,90 & 0,14 \\
\hline & & PS $550 \times 65,2$ & $8 \times 6,3$ & 70 & biapoiada & $\mathrm{C} 4$ & 731,88 & 0,87 & 0,97 \\
\hline & Filas & $P S 550 \times 56$ & $8 \times 8$ & 50 & contínua & $\mathrm{C}^{(\mathrm{c})}$ & 215,06 & 0,33 & 088 \\
\hline & 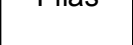 & & & ( & 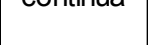 & $\mathrm{C} 2^{(\mathrm{c})}$ & $-322,59$ & 0,84 & 0,00 \\
\hline & $\mathrm{V} 1$ & PS $550 \times 65,2$ & $12 \times 6,3$ & 50 & biapoada & $\mathrm{C} 4$ & 407,43 & 0,51 & 0,77 \\
\hline & $\begin{array}{l}\text { Eixos } \\
1 \text { e } 6\end{array}$ & PS $550 \times 65,2$ & $5 \times 6,3$ & 50 & biapoiada & C4 & 383,42 & 0,54 & 0,55 \\
\hline & Eixos & & $10 \times 12.5$ & 50 & & C1 & 441,90 & 0,44 & 0,68 \\
\hline & 2 e 5 & $P S 550 \times 92$ & & & contínua & $\mathrm{C} 2$ & $-669,53$ & 0,82 & \\
\hline 3 & & 年 & $6 \times 125$ & 50 & 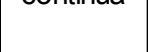 & C1 & 428,88 & 0,45 & 068 \\
\hline & $\begin{array}{l}\text { EIXOS } \\
3 \text { e } 4\end{array}$ & & & & & $\mathrm{C} 2$ & $-576,79$ & 0,75 & 0,00 \\
\hline & & PS $550 \times 65,2$ & $8 \times 6,3$ & 70 & biapoiada & C4 & 731,88 & 0,87 & 0,97 \\
\hline & Filas & $P S 550 \times 56$ & $8 \times 8$ & 50 & contínua & C1 & 211,87 & 0,33 & 088 \\
\hline & rilds & $10500 \times 50$ & $0 \times 0$ & 50 & cominiud & $\mathrm{C} 2^{(\mathrm{c})}$ & $-354,23$ & 0,92 & 0,00 \\
\hline & V1 & PS $550 \times 65,2$ & $12 \times 6,3$ & 50 & biapoada & C4 & 407,43 & 0,51 & 0,77 \\
\hline & Eixos & & $5 \times 8$ & 50 & & C3 & 277,74 & 0,29 & 041 \\
\hline & 1 e 6 & & $5 \times 0$ & 50 & & $\mathrm{C} 2$ & $-532,52$ & 0,83 & 0,41 \\
\hline & Eixos & $D C 550 \times 06$ & $10 \times 8$ & 50 & sontínu & C1 & 434,40 & 0,46 & 074 \\
\hline & 2 e 5 & 年 & $10 \times 0$ & 30 & continua & $\mathrm{C} 2$ & $-607,02$ & 0,90 & 0,14 \\
\hline 4 & Eixos & & $8 \times 8$ & 50 & & C1 & 435,05 & 0,46 & 0.74 \\
\hline & 3 e 4 & & & & & $\mathrm{C} 2$ & $-587,62$ & 0,89 & $0, r+4$ \\
\hline & Filas & PS $550 \times 56$ & $12 \times 8$ & 50 & contínua & $\mathrm{C}^{(\mathrm{c})}$ & 217,20 & 0,33 & 0.87 \\
\hline & 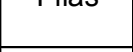 & & $12 \wedge 0$ & & 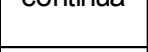 & $\mathrm{C} 2^{(\mathrm{c})}$ & $-367,72$ & 0,90 & 0,01 \\
\hline & V1 & PS $550 \times 65,2$ & $12 \times 6,3$ & 50 & biapoada & C4 & 407,43 & 0,51 & 0,77 \\
\hline $\begin{array}{l}\text { desl } \\
\text { forç }\end{array}$ & ateral inc & dentidos para a ce na direção & $\begin{array}{l}\text { ombinaçãc } \\
\text { das filas }\end{array}$ & a & $\begin{array}{l}\text { da vic } \\
\text { gravit }\end{array}$ & $\begin{array}{l}\text { o tracior } \\
\text { is }(\mathrm{C} 4)\end{array}$ & & & \\
\hline
\end{tabular}


Por fim, a Tabela 4.13 engloba o consumo de aço dos perfis que atendem aos estados limites últimos. O consumo por metro quadrado dos modelos é da mesma ordem. Diante desse quadro pode-se afirmar que a melhor solução estrutural será dominada pelo modelo que, além de atender aos estados limites de serviço, destacar-se no nível de execução.

Tabela 4.13 - Resumo do consumo de aço

\begin{tabular}{|c|c|c|c|c|c|}
\hline \multirow{2}{*}{ Modelo } & \multirow{2}{*}{$\begin{array}{c}\text { Pilares } \\
(\mathrm{t})\end{array}$} & \multirow{2}{*}{$\begin{array}{c}\text { Vigas } \\
(\mathrm{t})\end{array}$} & \multirow{2}{*}{$\begin{array}{c}\text { Diagonais } \\
(\mathrm{t})\end{array}$} & \multicolumn{2}{|c|}{ Total } \\
\cline { 5 - 6 } & & & $(\mathrm{t})$ & $\mathrm{kg} / \mathrm{m}^{2}$ \\
\hline 1 & 350,45 & 512,88 & 90,11 & 953,43 & 52,97 \\
\hline 2 & 353,64 & 496,24 & 98,96 & 948,84 & 52,71 \\
\hline 3 & 363,89 & 502,24 & 76,83 & 942,95 & 52,39 \\
\hline 4 & 352,30 & 525,36 & 54,70 & 932,35 & 51,80 \\
\hline
\end{tabular}

\subsection{ESTADOS LIMITE DE SERVIÇO}

A composição do sistema estrutural e o dimensionamento de seus elementos devem ser de maneira que apresentem adequada rigidez a fim de que possam atender os limites de flecha, deslocamento lateral, vibração, entre outras restrições que asseguram o uso previsto para a estrutura. Embora na maioria dos casos a segurança não seja afetada pelos estados limites de serviço, economicamente ignora-los podem trazer consequências substanciais.

Três indícios gerais no comportamento estrutural são indicativos do comprometimento do serviço da estrutura de aço (ANSI/AISC 360-10):

- Deslocamentos excessivos (deformação ou rotação, flecha e deslocamento lateral) que podem afetar a aparência, a função ou a drenagem de um edifício, ou possam causar danos a elementos não estruturais (divisória, fechamento, forro, etc.) e suas ligações devido à transferência de carga;

- Vibrações excessivas produzidas pelas atividades da ocupação do prédio, equipamentos mecânicos ou efeitos da ação do vento que possam resultar em desconforto ou mau funcionamento dos equipamentos; 
- Danos excessivos localizados (plastificação localizada, flambagem, deslizamento ou fissuração) ou deterioração (ações intempéries) durante a vida útil da estrutura.

No estudo dos estados limites de serviço dos modelos apresentados nesse trabalho são verificados apenas os deslocamentos laterais através de uma análise elástica tridimensional de primeira ordem.

\subsubsection{DESLOCAMENTOS LATERAIS}

O deslocamento lateral de um edifício é um estado limite causado predominantemente pela ação do vento. Conforme West e Fisher (2003), o intervalo de recorrência recomendado para determinação da ação do vento aplicado em verificações de natureza não catastrófica é de 10 anos, o que corresponde aproximadamente a $75 \%$ da pressão do vento com período de retorno de 50 anos. Na prática, para verificação dos deslocamentos laterais tem-se empregado o mesmo intervalo para os estados limites últimos (50 ou 100 anos).

O controle dos danos aos fechamentos e partições é atribuído aos limites das flechas das vigas, conforme capítulo anterior, em conjunto à restrição do deslocamento horizontal de topo dos pilares em relação á base e ao deslocamento horizontal relativo entre dois pisos consecutivos.

Usualmente, a forma de avaliação dos danos aos elementos não estruturais é realizada apenas por meio da componente horizontal da distorção, não incluindo o potencial dano provocado pelo deslocamento vertical, oriundo do encurtamento diferencial entre os pilares do painel avaliado, nem excluindo a rotação de corpo rígido do painel que por si só não traz prejuízo aos fechamentos e repartições. 
A partir da análise estrutural de primeira ordem do edifício, conhecido os deslocamentos x e y dos vértices de cada painel, Charney (1990) propõe uma medida de controle dos danos através da média global da distorção (Rockey et al., 1975) de cada painel ABCD (Figura 4.20), definindo assim a medida do índice de deslocamento lateral (DMI):

$\mathrm{DMI}=0,5\left[\frac{\left(\mathrm{X}_{\mathrm{A}}-\mathrm{X}_{\mathrm{C}}\right)}{\mathrm{H}}+\frac{\left(\mathrm{X}_{\mathrm{B}}-\mathrm{X}_{\mathrm{D}}\right)}{\mathrm{H}}+\frac{\left(\mathrm{Y}_{\mathrm{D}}-\mathrm{Y}_{\mathrm{C}}\right)}{\mathrm{L}}+\frac{\left(\mathrm{Y}_{\mathrm{B}}-\mathrm{Y}_{\mathrm{A}}\right)}{\mathrm{L}}\right]$

$\mathrm{DMI}=0,5\left(\mathrm{D}_{1}+\mathrm{D}_{2}+\mathrm{D}_{3}+\mathrm{D}_{4}\right)$

Nas equações 4.12 e 4.13, tem-se:

$\mathrm{X}_{\mathrm{i}} \quad$ deslocamento horizontal do ponto i;

$Y_{i} \quad$ deslocamento vertical do ponto $i ;$

$D_{1}=\left(X_{A}-X_{C}\right) / H$, componente horizontal da distorção;

$D_{2}=\left(X_{B}-X_{D}\right) / H$, componente horizontal da distorção;

$D_{3}=\left(Y_{D}-Y_{C}\right) / L$, componente vertical da distorção;

$D_{4}=\left(Y_{B}-Y_{A}\right) / L$, componente vertical da distorção.

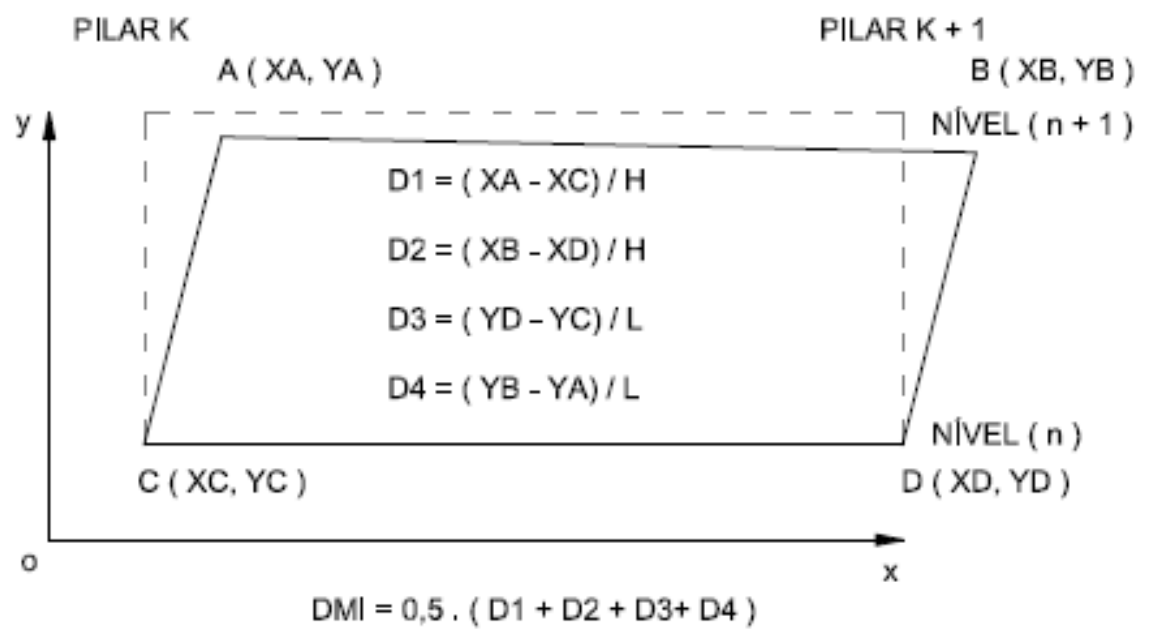

Figura 4.20 - Medida do índice de deslocamento 
Os componentes $D_{1}$ e $D_{2}$, usuais na limitação dos danos, são decorrentes dos deslocamentos horizontais enquanto que $D_{3}$ e $D_{4}$ são causados pelo encurtamento dos pilares.

Uma vez determinado o valor DMI, deve-se compara-lo ao índice de danos do deslocamento lateral (DDI) cujo valor é definido experimentalmente e representa o limite de prejuízo aceitável nos materiais componentes dos fechamentos e partições. Griffis (1993) reúne os limites de deslocamentos recomendados para aplicação de diversos elementos não estruturais comumente empregados em edifícios.

Cabe salientar que os limites de controle de deslocamentos laterais em edifícios sob a ação do vento não garantem o nível de conforto necessário aos usuários quanto à percepção do movimento da estrutura (TALLIN; ELLINGWOOD, 1984). Islam, Ellingwood e Corotis (1990) demostram a importância da contribuição da massa e do amortecimento, que, juntamente com a rigidez, representam os parâmetros que afetam predominantemente a aceleração dos edifícios altos.

\subsubsection{AVALIAÇÃO NORMATIVA DOS DESLOCAMENTOS LATERAIS}

A ABNT NBR 8800:2008 faz recomendações à combinação e, em seus anexos, aos limites a serem respeitados para verificação dos deslocamentos laterais. A seguir é demostrado uma breve abordagem desse assunto conforme ABNT NBR 8800:2008, o ANSI/AISC 360-10, a EN 1993-1-1:2005 e a ABNT NBR 6118:2003.

A propósito da combinação de ações a ser aplicada, apesar de os danos a vedação causada por movimentos laterais excessivos ser um estado limite irreversível, dá a entender que a ABNT NBR 8800:2008 os inclui às combinações frequentes de serviço (equações 2.9 a 2.8) quando define essa combinação. Entretanto, no anexo de verificação dos deslocamentos máximos a norma brasileira avalia danos a paredes e forros com a combinação rara de serviço.

Na verificação dos deslocamentos laterais a ANSI/AISC 360-10 recomenda a seguinte expressão (ASCE/SEI 7-10):

$D+0,5 L+W_{a}$ 
Da equação 4.14, vale as seguintes definições:

D valor característico das ações permanentes;

L $\quad$ valor característico das ações variáveis;

$\mathrm{W}_{\mathrm{a}} \quad$ valor característico da ação do vento.

A velocidade do vento aplicada na expressão 4.14 fica a critério de um acordo entre o engenheiro calculista da obra segundo as funções da edificação a serem atendidas.

A EN 1993-1-1:2005 especifica a combinação característica das ações para obter os deslocamentos laterais, dada pela equação 3.4 .

A ABNT NBR 6118:2003 ao contrário da ABNT NBR 8800:2008, recomenda a combinação frequente de serviço, porém com limites bastante rigorosos para os deslocamentos globais $(H / 1700)$ e para os interpavimentos $\left(H_{i} / 850\right)$, sendo $H$ e $H_{i}$ as distâncias do topo da estrutura à base e o desnível entre dois pavimentos vizinhos, respectivamente.

Em relação aos deslocamentos horizontais, a ABNT NBR 8800:2008 limita em $\mathrm{H} / 400$ e $\mathrm{h} / 500$ os deslocamentos do topo dos pilares em relação à base e o deslocamento relativo entre dois pavimentos consecutivos, respectivamente. Os parâmetros $\mathrm{H}$ e h referem-se às distâncias avaliadas.

Conforme a ANSI/AISC $360-10$ os valores típicos de limites para os deslocamentos de topo estão entre $\mathrm{H} / 100$ e $\mathrm{H} / 600$ e para os deslocamentos interpavimentos h/200 e h/600. Essa norma, na ausência de estudos específicos, recomenda os limites de deslocamentos laterais interpavimentos para diversos elementos não estruturais reunidos em Griffis (1993).

Enfim, o anexo nacional da versão portuguesa da EN 1993-1-1:2005 recomenda $h_{0} / 500$ para os deslocamentos da estrutura global e h/300 para os deslocamentos interpavimentos, sendo $h_{0}$ e $h$ as distâncias do topo da estrutura à base e interpavimentos, respectivamente. 


\subsubsection{EXEMPLO: VERIFICAÇÃO DOS ESTADOS LIMITES DE SERVIÇO DE UM EDIFÍCIO ESCRITÓRIO COM ESTRUTURA METÁLICA E 20 PAVIMENTOS}

\subsubsection{Deslocamentos laterais}

$\mathrm{Na}$ determinação dos deslocamentos laterais dos modelos (ver item 4.2.9) verificados na direção dos eixos (Figura 4.21) foi empregada a combinação rara de serviço. Essa combinação ajusta-se as equações 3.4 e 4.14, visto que, em edifício escritório o fator de redução $\left(\psi_{1}\right)$ da sobrecarga no piso equivale à média dos multiplicadores 0,7 e 0,5 aplicados nas respectivas expressões.

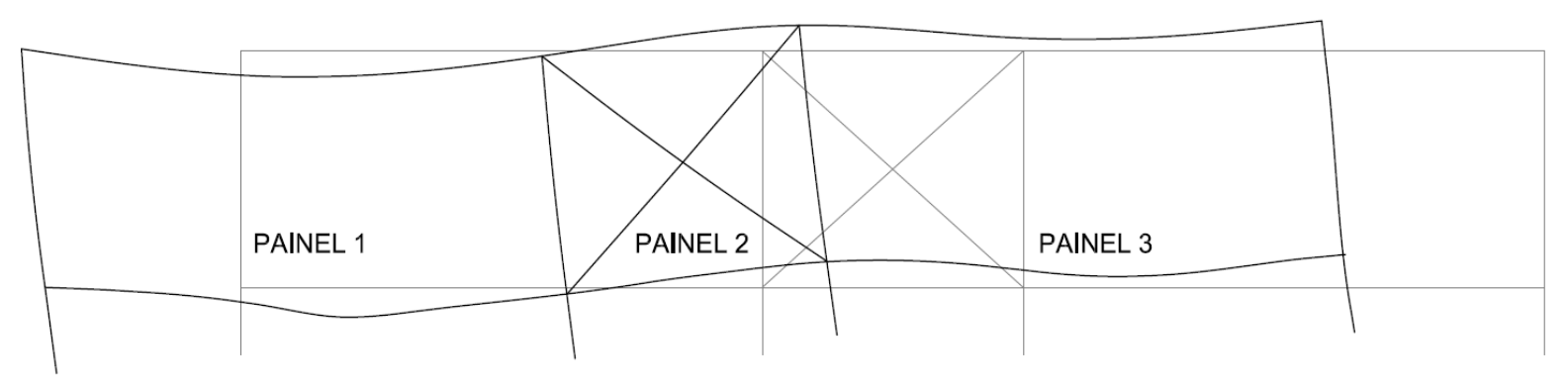

Figura 4.21 - Forma da estrutura deslocada (cobertura) sob vento incidindo no eixo y

As combinações raras de serviço aplicadas para o vento como ação variável principal (C10) foram avaliadas para os seguintes casos:

- Combinação rara de serviço admitindo a ação variável devido ao vento com intensidade de 50 anos (CRS);

- Combinação rara de serviço admitindo a ação variável devido ao vento com intensidade de 10 anos (CRS1);

- Combinação rara de serviço desconsiderando o efeito de excentricidade do vento com intensidade de 50 anos (CRS2).

A definição do sistema estrutural e dimensionamento dos modelos foram baseados na combinação CRS. Além das combinações raras de serviço, foram avaliados os deslocamentos resultantes da combinação frequente de serviço para a ação vento equivalente a um período de recorrência de 50 anos (CFS). 
O limite adotado na verificação dos deslocamentos laterais global dos modelos foi $\mathrm{H} / 400$. Os limites $\mathrm{H} / 1700$ e $\mathrm{h}_{0} / 500$ (ver tópico 4.3.2) também foram avaliados para as combinações definidas acima e são visualizados nas Figuras 4.22 a 4.25. Nesses gráficos, é visível a eficiência do sistema outrigger quando comparamos os Modelos 1 e 2. Vale salientar também que o limite $H / 1700$ para a combinação CFS tem rigor próximo à linha $h_{0} / 500$ para CRS.

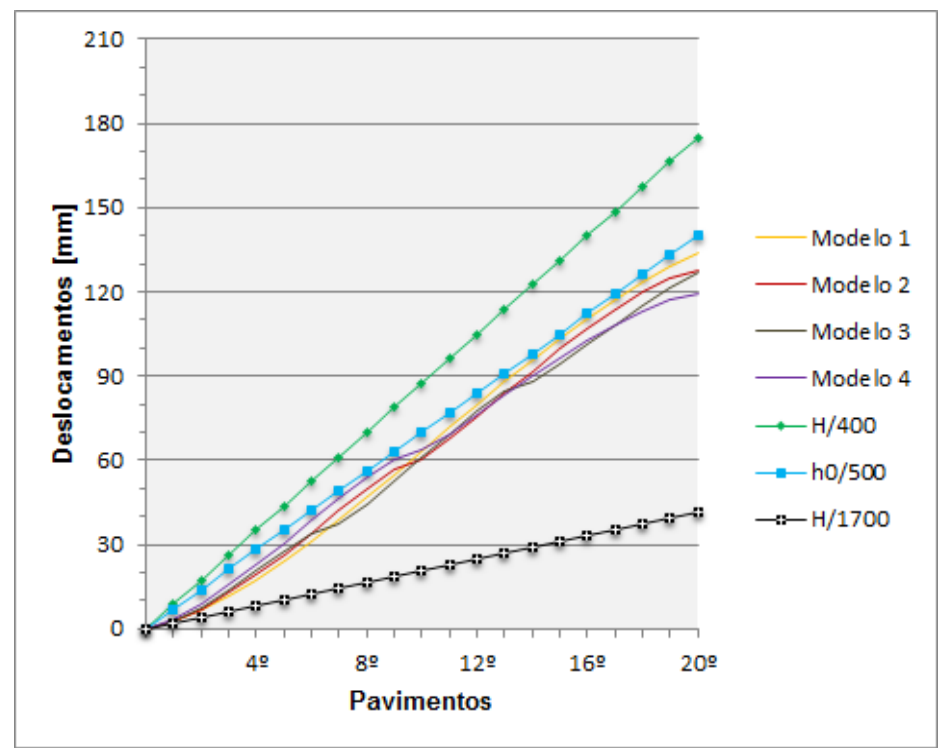

Figura 4.22 - Gráfico do deslocamento horizontal de topo dos pilares em relação à base: CRS

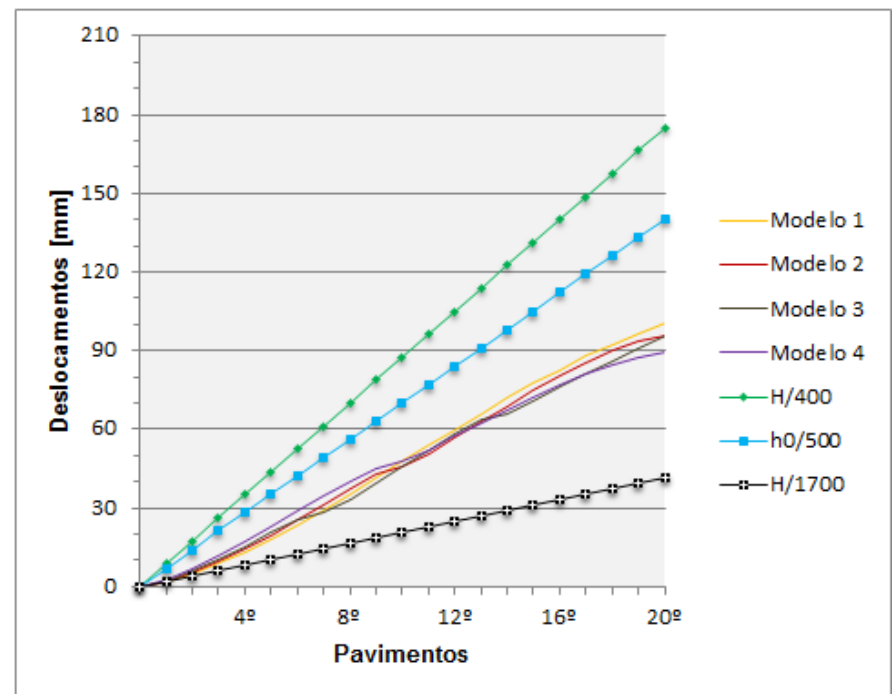

Figura 4.23 - Gráfico do deslocamento horizontal de topo dos pilares em relação à base: CRS1 


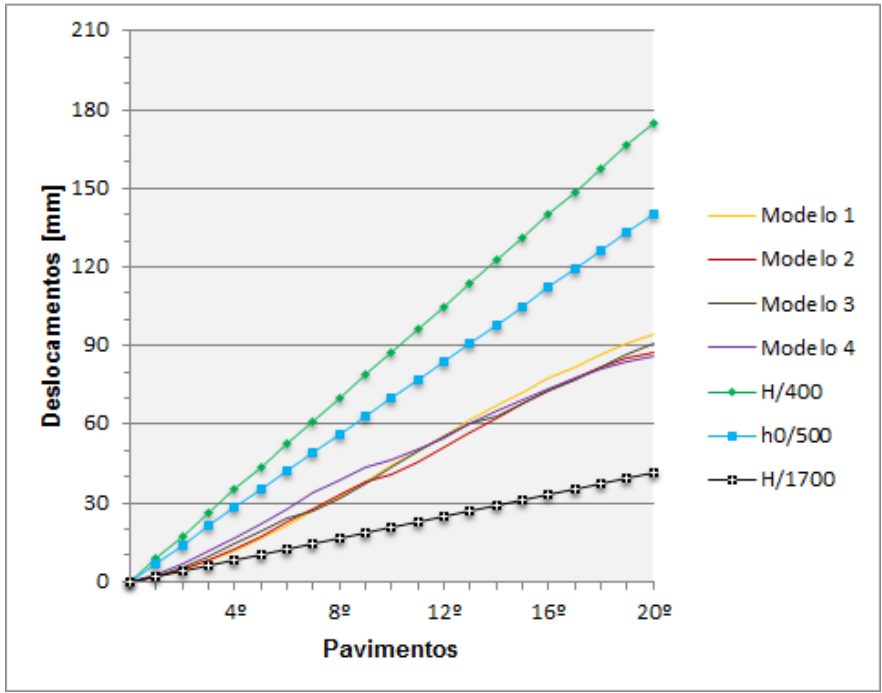

Figura 4.24 - Gráfico do deslocamento horizontal de topo dos pilares em relação à base: CRS2

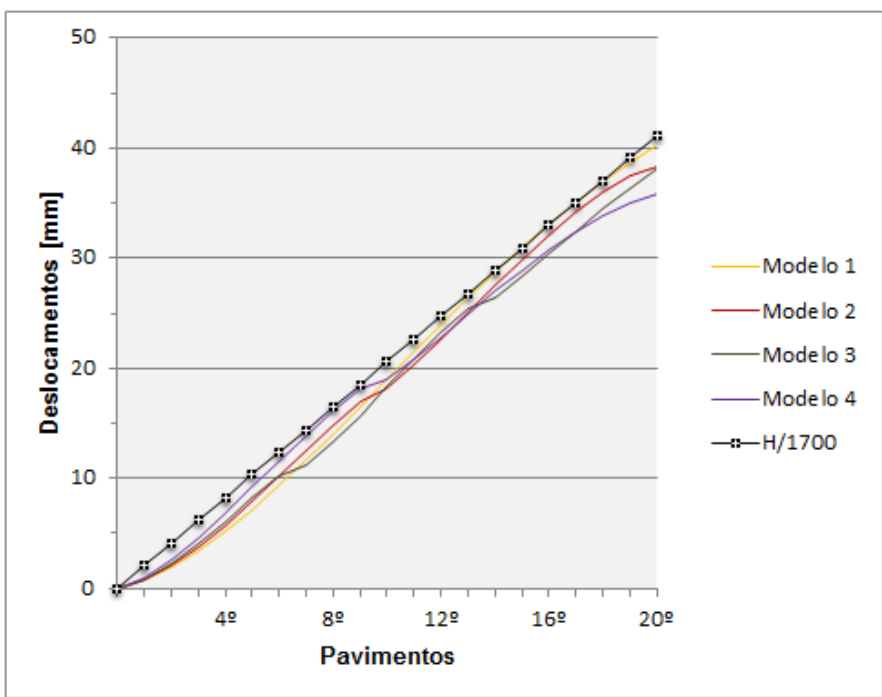

Figura 4.25 - Gráfico do deslocamento horizontal de topo dos pilares em relação à base: CFS

Nas fachadas dos modelos pesquisados, foram adotados módulos unitizados (window wall), enquanto que nas divisórias, foram combinadas estruturas de aço galvanizado com chapas de gesso de alta resistência mecânica e acústica (gypsum drywall). Ambos possuem, de acordo com Griffis (1993), o limite de deslocamento lateral interpavimento igual a $\mathrm{h} / 400$. Portanto, essa foi a restrição aplicada no dimensionamento dos modelos.

Os valores dos deslocamentos laterais interpavimentos para a combinação CRS e o limite h/400 a ser atendido são representados nos gráficos das Figuras 4.26 a 4.29. Notam-se nos painéis com presença de diagonais de contraventamento, painéis 1 e 3 (Figura 4.21) dos eixos com treliça horizontal e painel 2 dos eixos com treliça vertical, que os deslocamentos são de ordem desprezível para os danos. 
Esse fato se deve a exclusão da rotação de corpo rígido nos deslocamentos interpavimentos pelo método proposto por Charney (1990).

As Figuras 4.30 a 4.33 mostram os deslocamentos laterais interpavimentos para as combinações CRS, CRS1, CRS2 e CFS, assim como, os limites h/300, $\mathrm{h} / 400, \mathrm{~h} / 500$ e $\mathrm{H}_{\mathrm{i}} / 850$ apresentados no item 4.3.2. Observa-se uma folga muito grande no controle dos danos ao compararmos h/500 para a combinação CFS com o limite $\mathrm{h} / 400$ para a combinação CRS. Essa folga também é expressiva para as restrições $\mathrm{h} / 300$ e $\mathrm{H}_{\mathrm{i}} / 850$ aplicadas às combinações CRS e CFS, respectivamente.

Vale destacar nos deslocamentos laterais globais e interpavimentos a folga em relação aos respectivos limites, H/400 e h/400 para as combinações CRS1 e CRS2. A definição do sistema estrutural e verificação do dimensionamento para o primeiro caso pode representar uma redução do custo da estrutura, já sobre o segundo caso, implicaria a sérios problemas na funcionalidade do edifício.

Nas Tabelas 4.14 a 4.17 são apresentadas as diferenças percentuais dos deslocamentos interpavimentos críticos em relação aos limites estudados. 


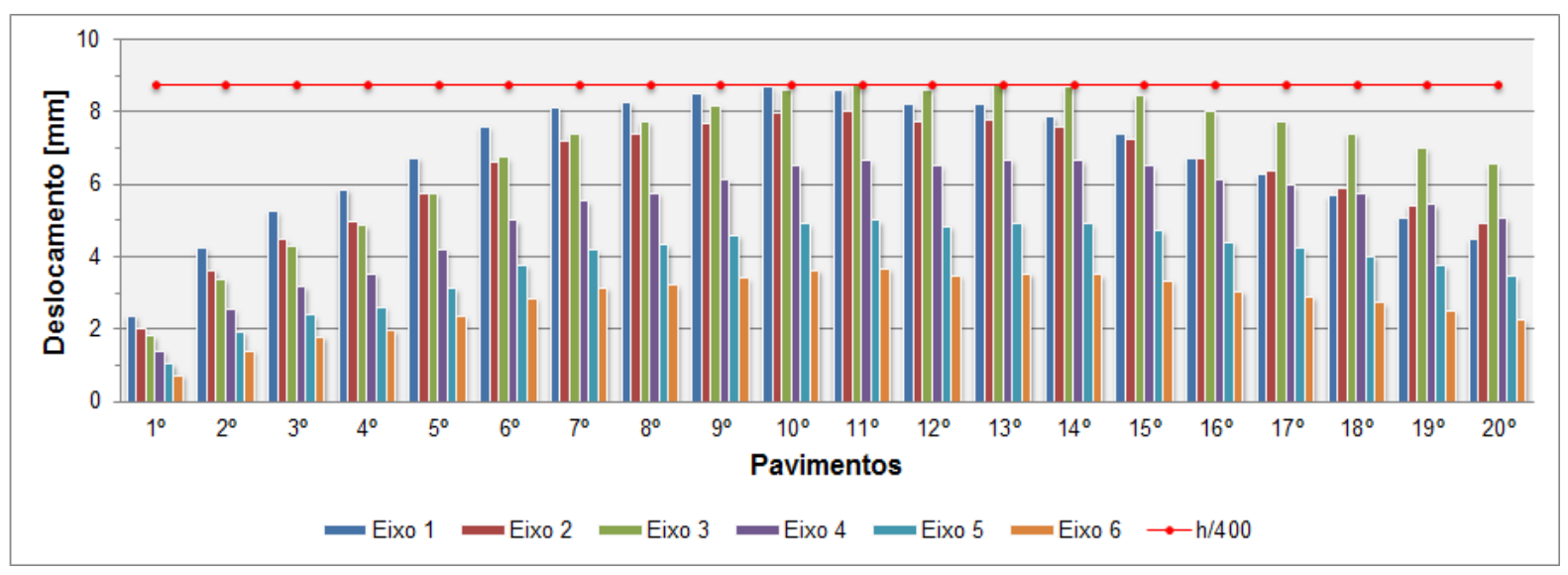

(a)

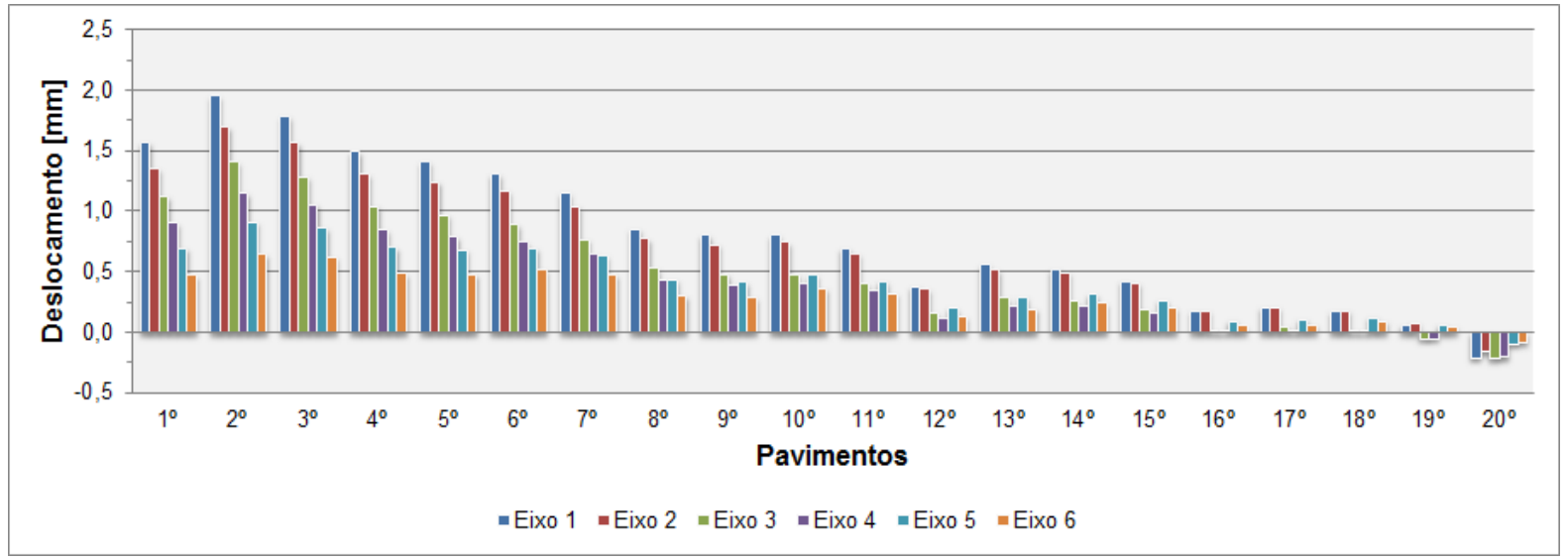

(b)

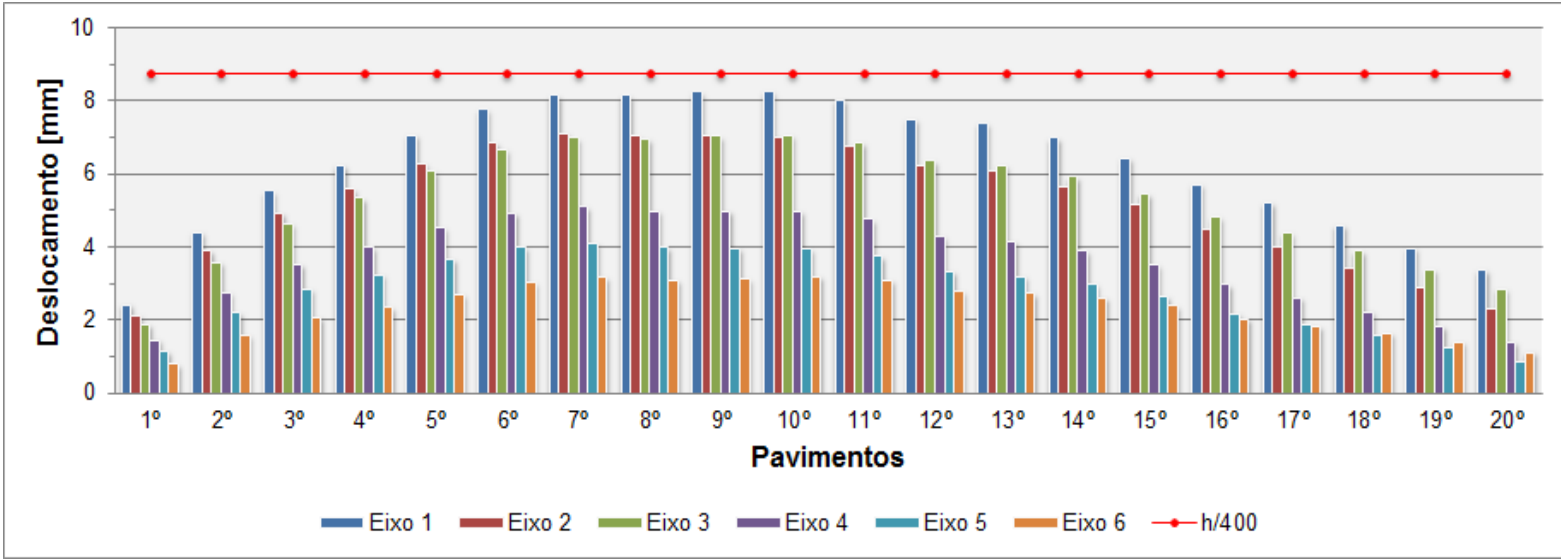

(c)

Figura 4.26 - Modelo 1 - Gráfico dos deslocamentos laterais interpavimentos: (a) painel 1; (b) painel 2; (c) painel 3

Os valores negativos nas Figuras 4.26 a 4.29 correspondem a um deslocamento relativo de sentido contrário a força horizontal aplicada. 


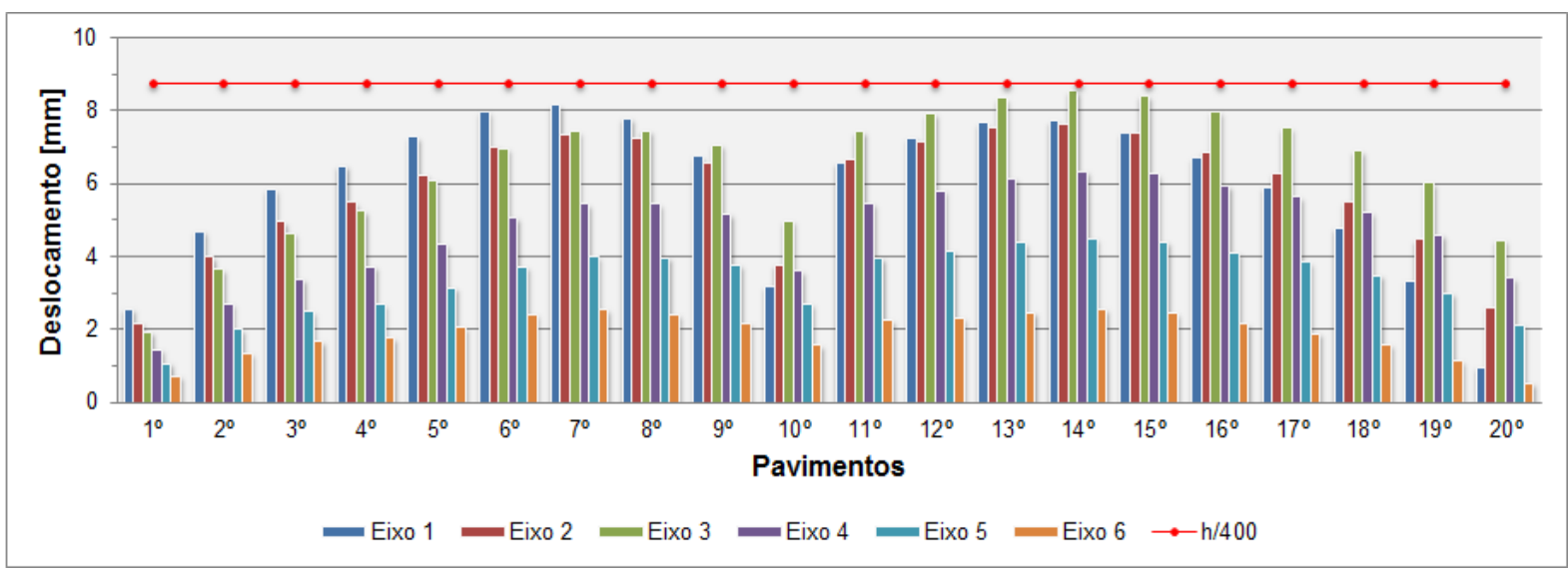

(a)

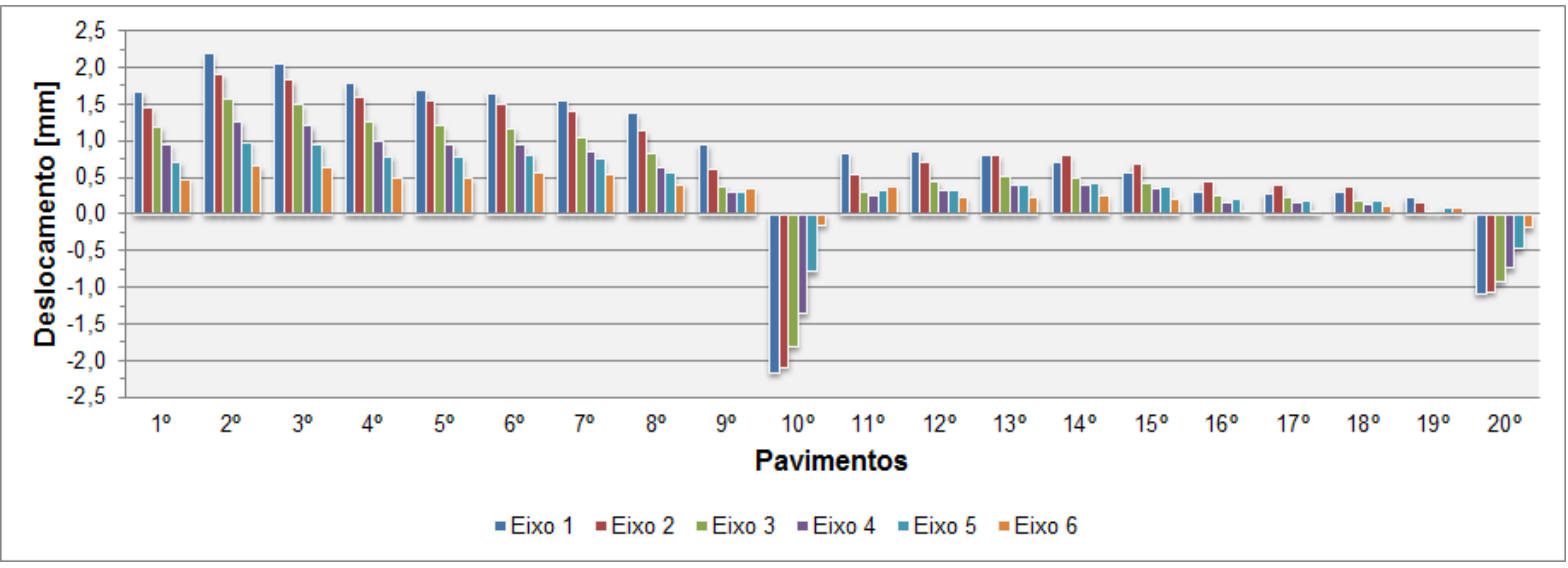

(b)

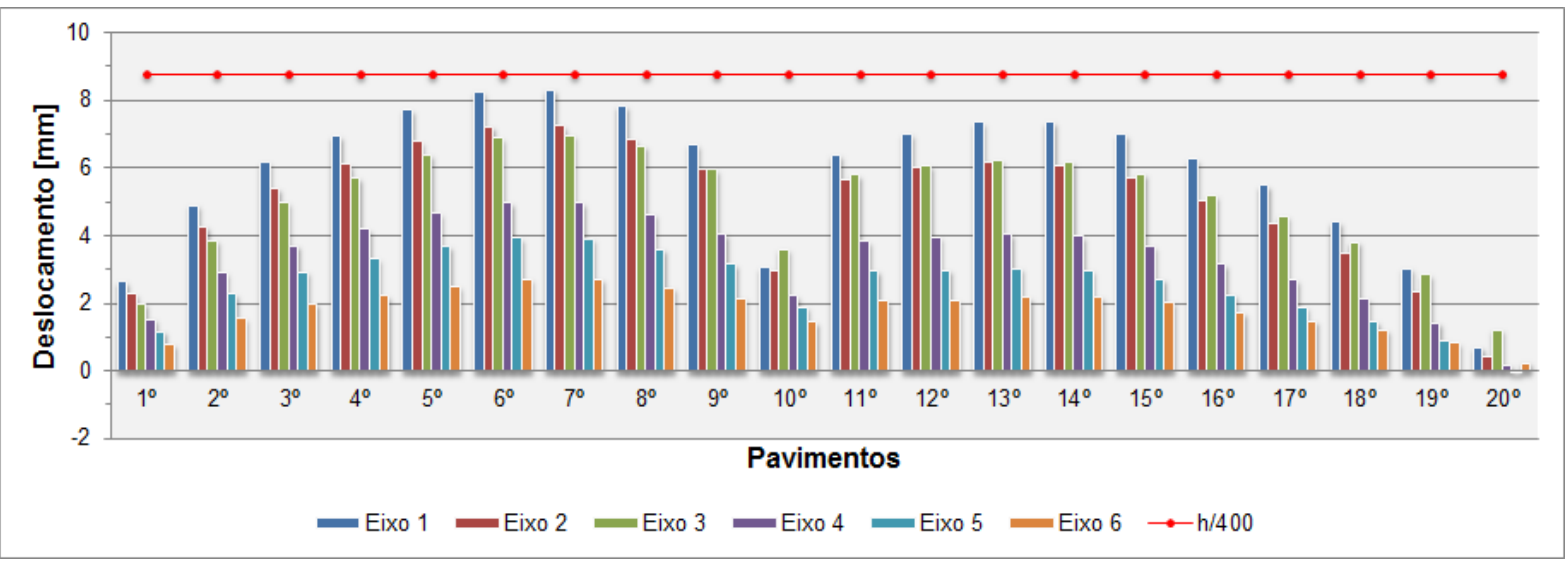

(c)

Figura 4.27 - Modelo 2 - Gráfico dos deslocamentos laterais interpavimentos: (a) painel 1; (b) painel 2; (c) painel 3 


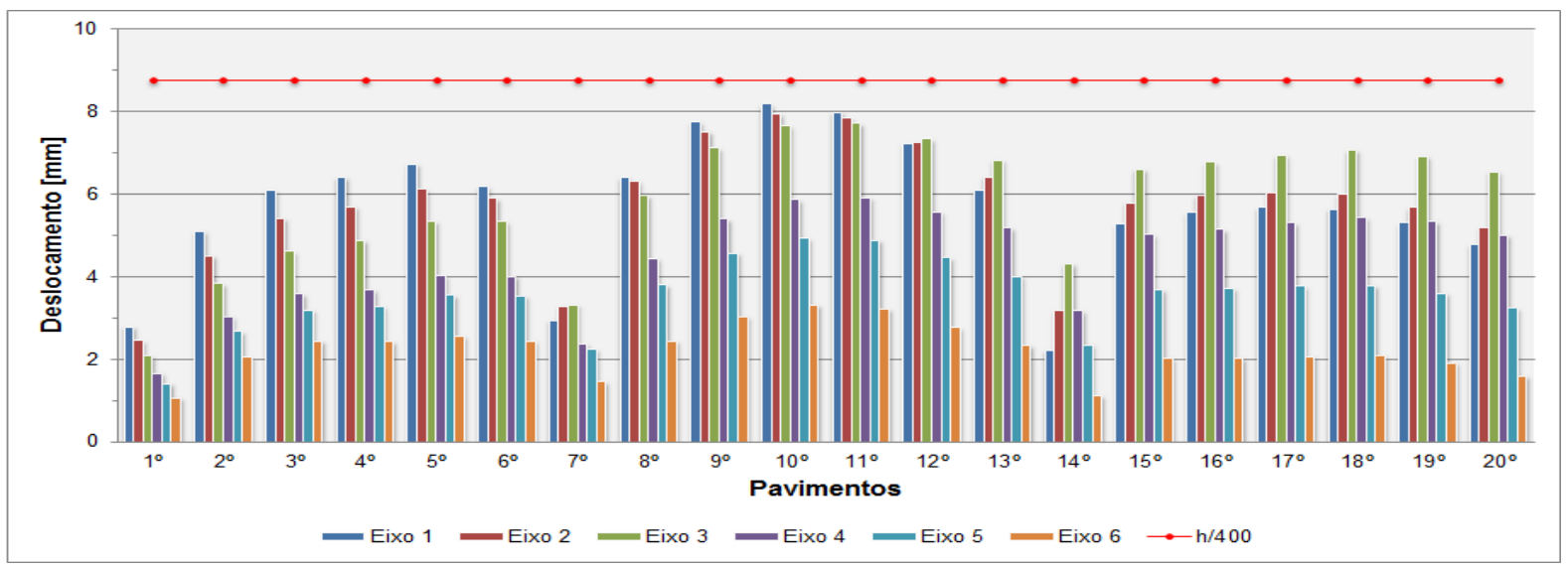

(a)

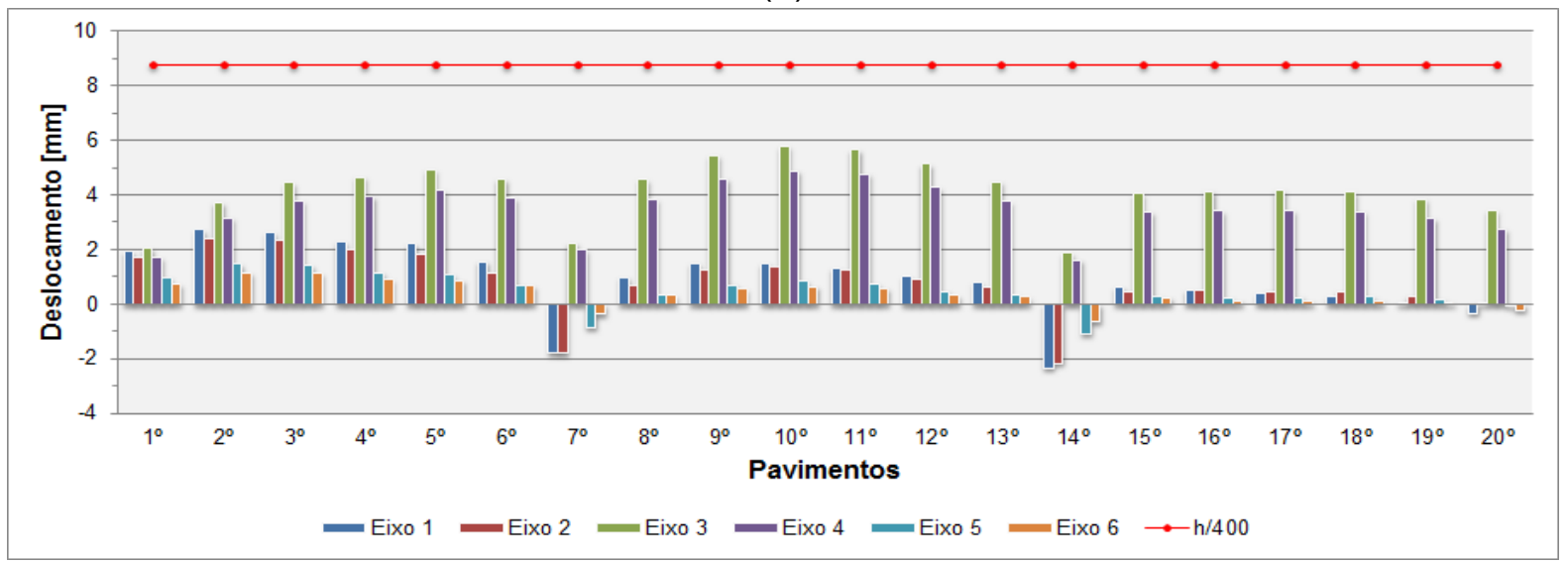

(b)

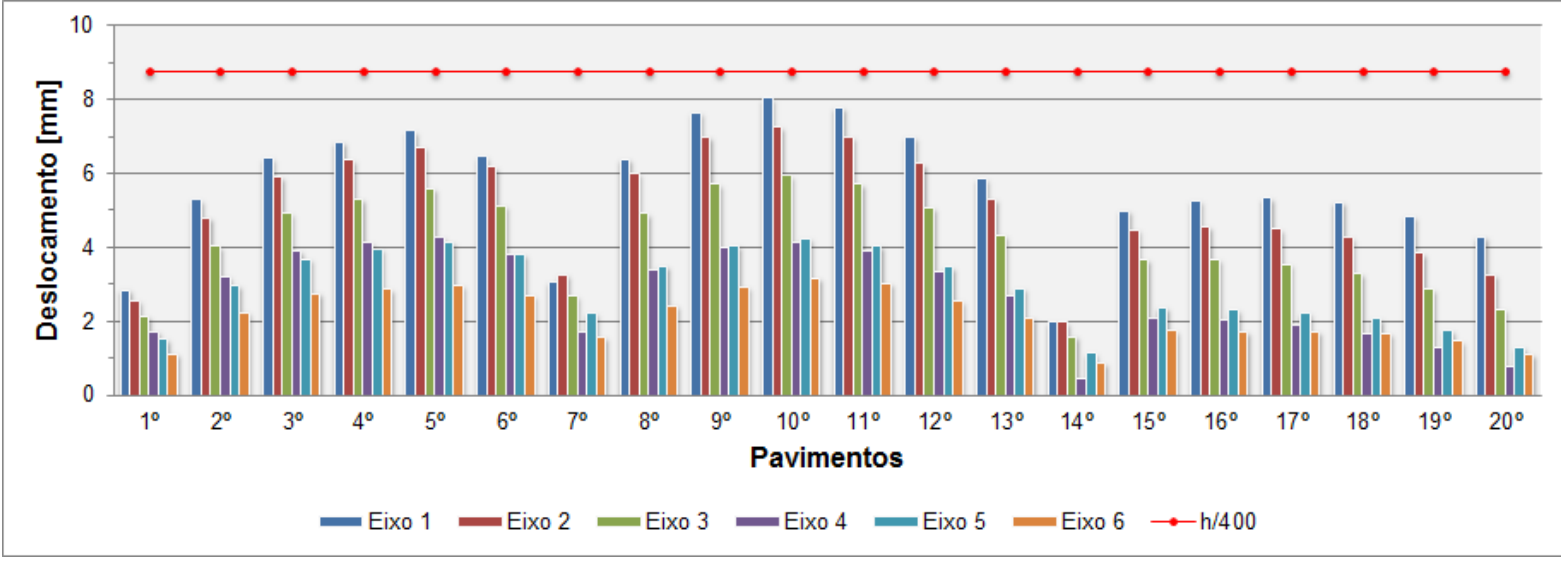

(c)

Figura 4.28 - Modelo 3 - Gráfico dos deslocamentos laterais interpavimentos: (a) painel 1; (b) painel 2; (c) painel 3 


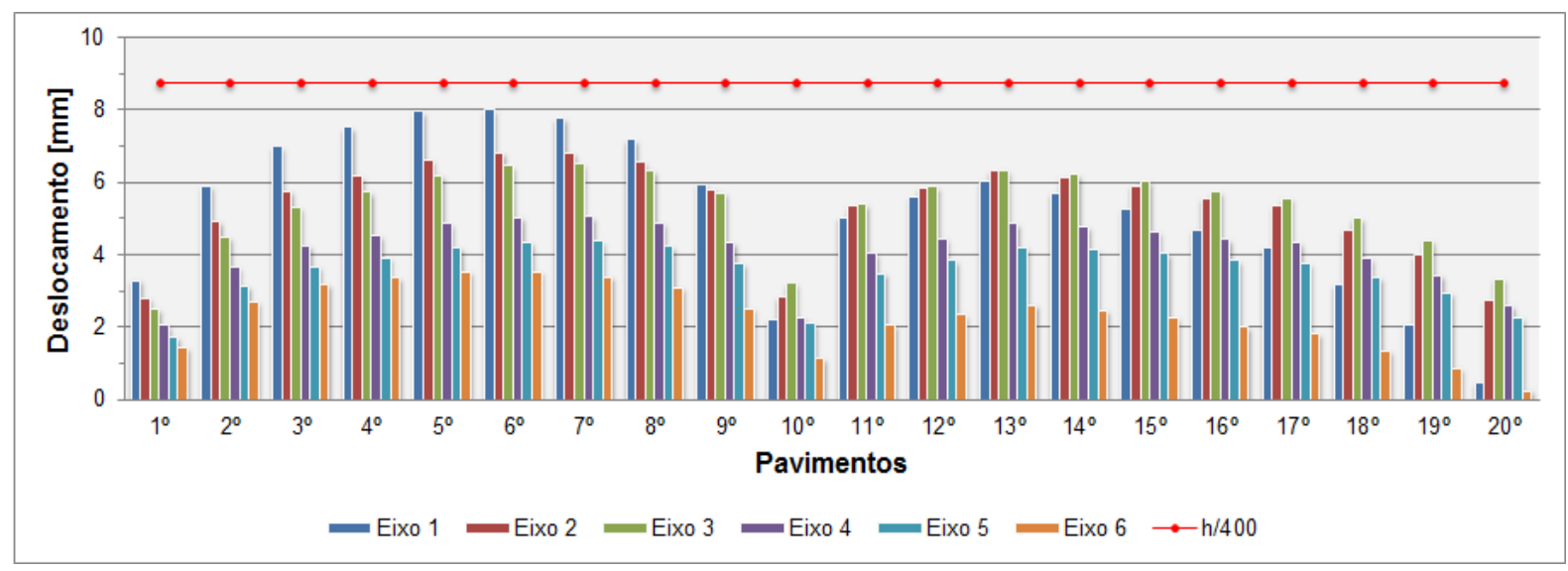

(a)

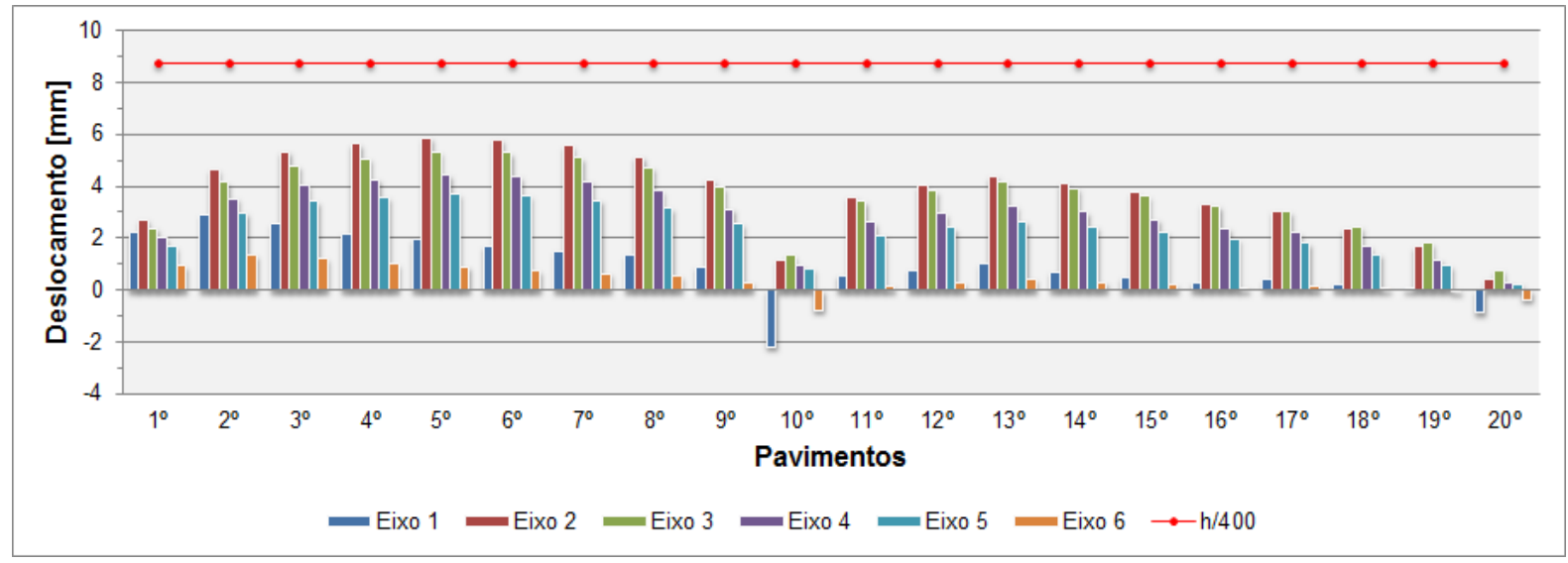

(b)

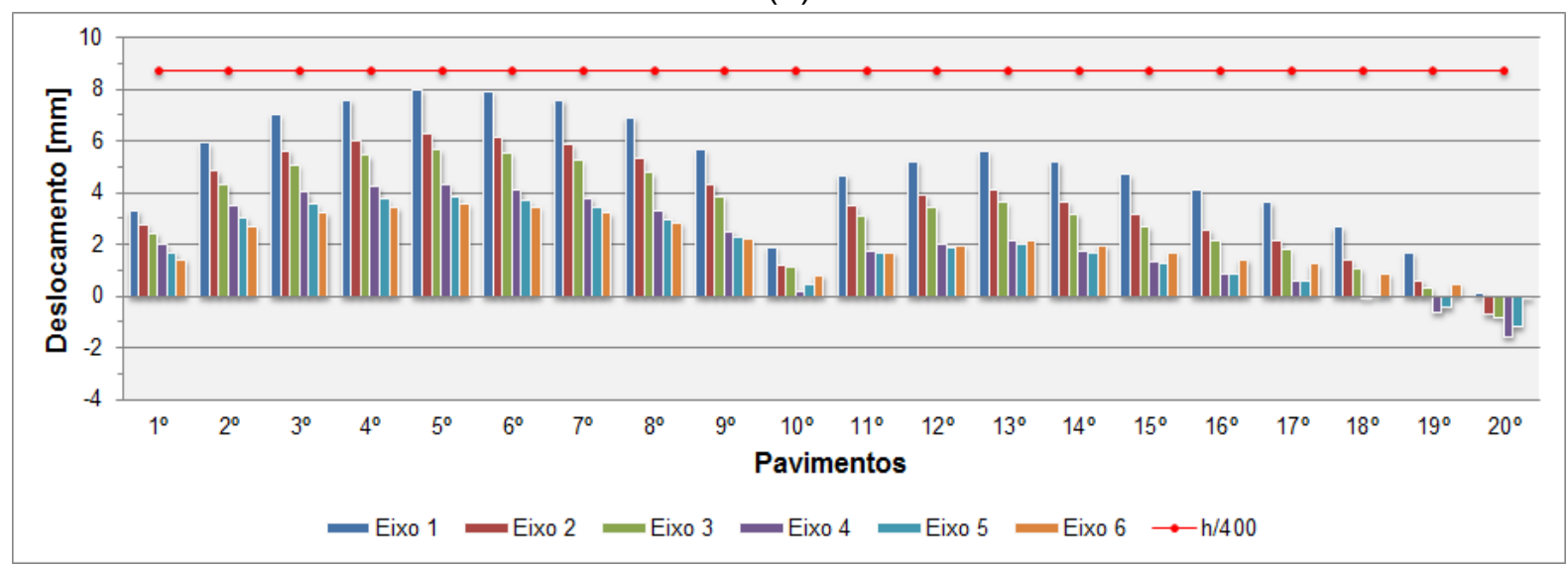

(c)

Figura 4.29 - Modelo 4 - Gráfico dos deslocamentos laterais interpavimentos: (a) painel 1;

(b) painel 2; (c) painel 3 


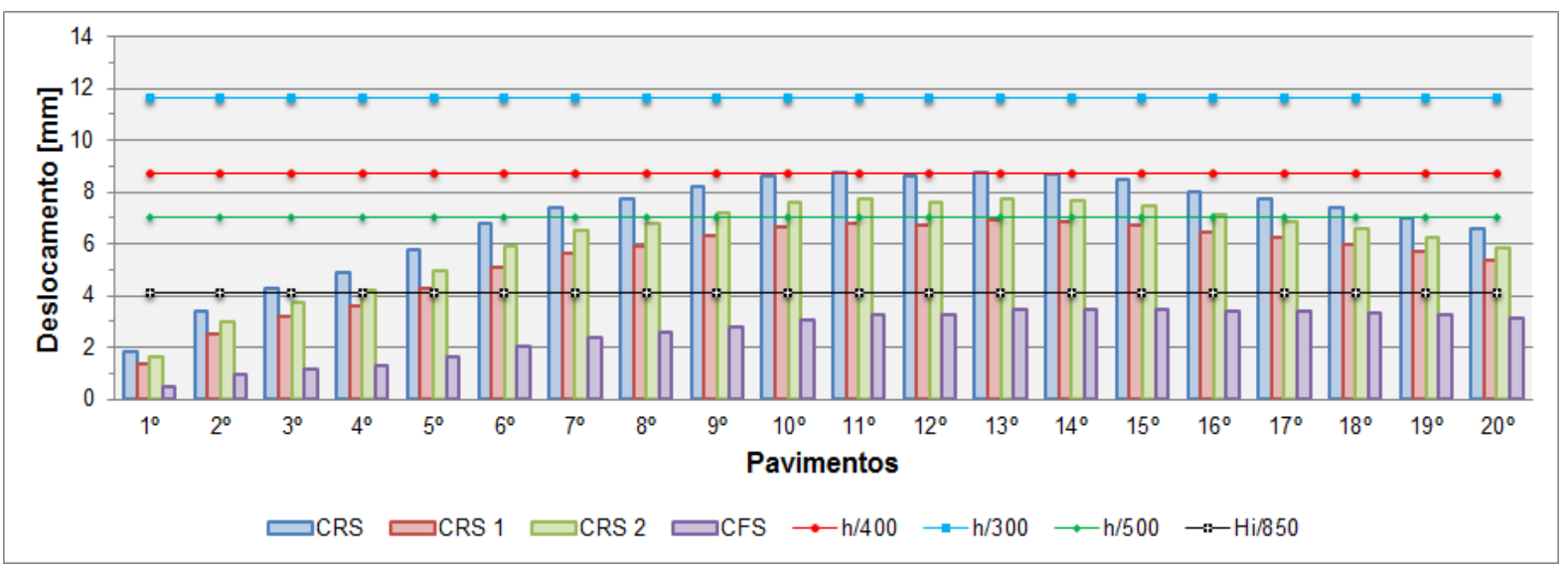

Figura 4.30 - Modelo 1 - Gráfico dos deslocamentos interpavimentos críticos (painel 1; eixo 3): comparativo das combinações de ações e limites

Tabela 4.14 - Modelo 1 - Diferenças percentuais dos deslocamentos interpavimentos críticos (painel 1; eixo 3) segundo as combinações CRS, CRS1, CRS2 e CFS em relação aos limites $\mathrm{h} / 400, \mathrm{~h} / 300, \mathrm{~h} / 500$ e $\mathrm{H}_{\mathrm{i}} / 850$

\begin{tabular}{|c|c|c|c|c|c|}
\hline & CRS & CRS1 & CRS2 & CFS & \\
\hline Média (\%) & $-20,51$ & $-38,07$ & $-30,09$ & $-70,29$ & \multirow{3}{*}{$\mathrm{h} / 400$} \\
\hline Maior desvio (\%) & 0,35 & $-21,14$ & $-11,53$ & $-59,97$ & \\
\hline Menor desvio (\%) & $-79,15$ & $-84,46$ & $-81,55$ & $-94,02$ & \\
\hline Média (\%) & $-40,38$ & $-53,56$ & $-47,57$ & $-77,72$ & \multirow{3}{*}{$\mathrm{h} / 300$} \\
\hline Maior desvio (\%) & $-24,74$ & $-40,85$ & $-33,65$ & $-69,97$ & \\
\hline Menor desvio (\%) & $-84,36$ & $-88,35$ & $-86,17$ & $-95,52$ & \\
\hline Média (\%) & $-0,64$ & $-22,59$ & $-12,61$ & $-62,86$ & \multirow{3}{*}{$\mathrm{h} / 500$} \\
\hline Maior desvio (\%) & 25,43 & $-1,42$ & 10,58 & $-49,96$ & \\
\hline Menor desvio (\%) & $-73,93$ & $-80,58$ & $-76,94$ & $-92,53$ & \\
\hline Média (\%) & 68,91 & 31,59 & 48,56 & $-36,86$ & \multirow{3}{*}{$\mathrm{H}_{\mathrm{i}} / 850$} \\
\hline Maior desvio (\%) & 113,24 & 67,59 & 87,99 & $-14,93$ & \\
\hline Menor desvio (\%) & $-55,69$ & $-66,98$ & $-60,80$ & $-87,30$ & \\
\hline \multicolumn{6}{|c|}{$\begin{array}{l}\text { * sinal negativo significa que o limite relacionado é maior do que } \\
\text { o valor da combinação em questão }\end{array}$} \\
\hline
\end{tabular}




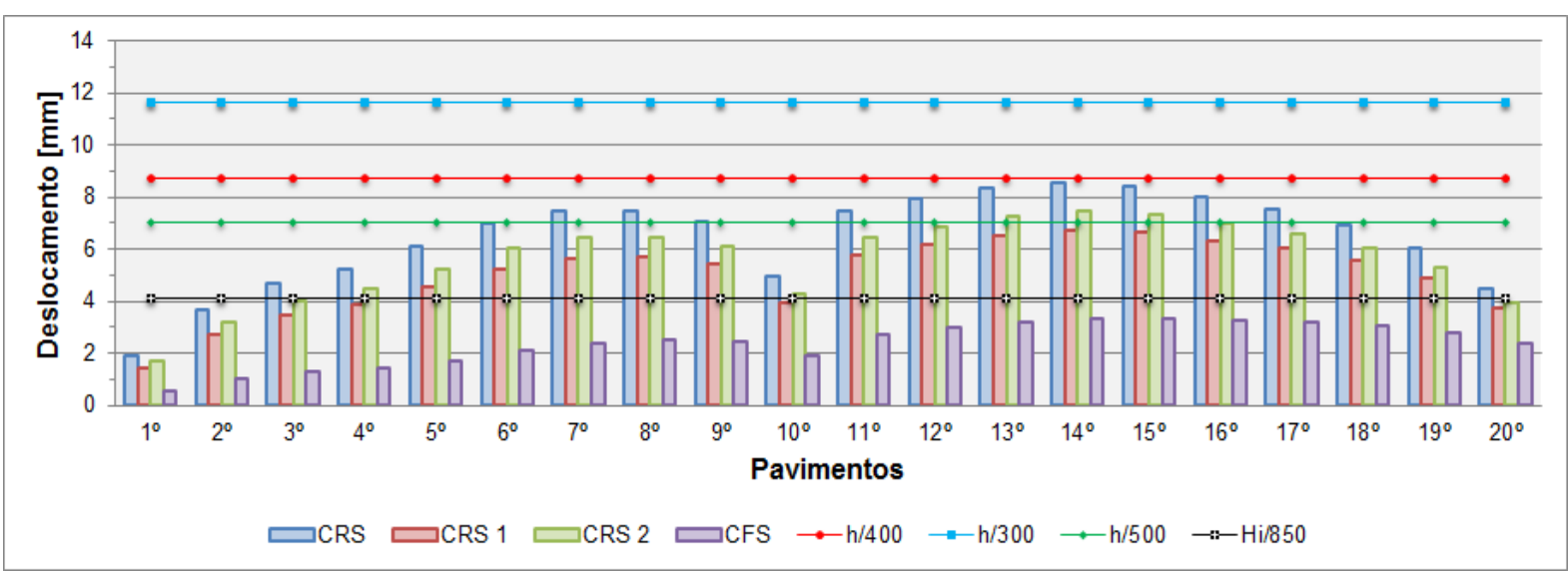

Figura 4.31 - Modelo 2 - Gráfico dos deslocamentos interpavimentos críticos (painel 1; eixo 3): comparativo das combinações de ações e limites

Tabela 4.15 - Modelo 2 - Diferenças percentuais dos deslocamentos interpavimentos críticos (painel 1; eixo 3) segundo as combinações CRS, CRS1, CRS2 e CFS em relação aos limites $h / 400, h / 300, h / 500$ e $\mathrm{H}_{i} / 850$

\begin{tabular}{|c|c|c|c|c|c|}
\hline & CRS & CRS1 & CRS2 & CFS & \\
\hline Média (\%) & $-26,07$ & $-42,53$ & $-35,75$ & $-72,71$ & \multirow{3}{*}{$h / 400$} \\
\hline Maior desvio (\%) & $-2,16$ & $-23,24$ & $-14,74$ & $-61,62$ & \\
\hline Menor desvio (\%) & $-77,87$ & $-83,50$ & $-80,54$ & $-93,63$ & \\
\hline Média (\%) & $-44,56$ & $-56,90$ & $-51,82$ & $-79,53$ & \multirow{3}{*}{$h / 300$} \\
\hline Maior desvio (\%) & $-26,62$ & $-42,43$ & $-36,05$ & $-71,21$ & \\
\hline Menor desvio (\%) & $-83,40$ & $-87,62$ & $-85,40$ & $-95,23$ & \\
\hline Média (\%) & $-7,59$ & $-28,17$ & $-19,69$ & $-65,89$ & \multirow{3}{*}{$h / 500$} \\
\hline Maior desvio (\%) & 22,30 & $-4,05$ & 6,58 & $-52,02$ & \\
\hline Menor desvio (\%) & $-72,33$ & $-79,37$ & $-75,67$ & $-92,04$ & \\
\hline Média (\%) & 57,09 & 22,12 & 36,52 & $-42,01$ & \multirow{3}{*}{$\mathrm{H}_{;} / 850$} \\
\hline Maior desvio (\%) & 107,91 & 63,12 & 81,19 & $-18,44$ & \\
\hline Menor desvio (\%) & $-52,97$ & $-64,94$ & $-58,65$ & $-86,47$ & \\
\hline
\end{tabular}




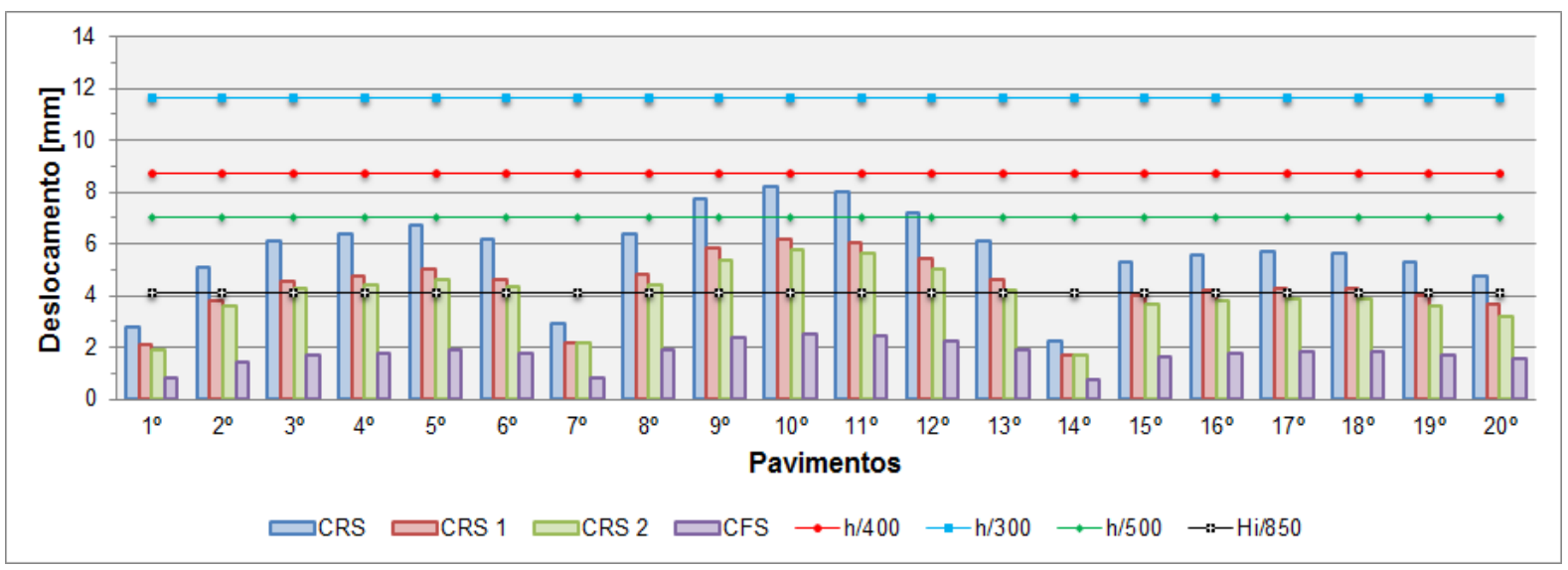

Figura 4.32 - Modelo 3 - Gráfico dos deslocamentos interpavimentos críticos (painel 1; eixo 1): comparativo das combinações de ações e limites

Tabela 4.16 - Modelo 3 - Diferenças percentuais dos deslocamentos interpavimentos críticos (painel 1; eixo 3) segundo as combinações CRS, CRS1, CRS2 e CFS em relação aos limites $\mathrm{h} / 400, \mathrm{~h} / 300, \mathrm{~h} / 500 \mathrm{e} \mathrm{H}_{\mathrm{i}} / 850$

\begin{tabular}{|c|c|c|c|c|c|}
\hline & CRS & CRS1 & CRS2 & CFS & \\
\hline Média (\%) & $-34,55$ & $-50,81$ & $-54,55$ & $-80,13$ & \multirow{3}{*}{$\mathrm{h} / 400$} \\
\hline Maior desvio (\%) & $-6,40$ & $-29,59$ & $-34,19$ & $-71,41$ & \\
\hline Menor desvio (\%) & $-74,49$ & $-80,52$ & $-80,83$ & $-91,48$ & \\
\hline Média (\%) & $-50,92$ & $-63,11$ & $-65,91$ & $-85,09$ & \multirow{3}{*}{$\mathrm{h} / 300$} \\
\hline Maior desvio (\%) & $-29,80$ & $-47,19$ & $-50,64$ & $-78,56$ & \\
\hline Menor desvio (\%) & $-80,87$ & $-85,39$ & $-85,62$ & $-93,61$ & \\
\hline Média (\%) & $-18,19$ & $-38,51$ & $-43,19$ & $-75,16$ & \multirow{3}{*}{$h / 500$} \\
\hline Maior desvio (\%) & 17,01 & $-11,99$ & $-17,74$ & $-64,26$ & \\
\hline Menor desvio (\%) & $-68,11$ & $-75,65$ & $-76,03$ & $-89,35$ & \\
\hline Média (\%) & 39,07 & 4,53 & $-3,42$ & $-57,77$ & \multirow{3}{*}{$\mathrm{Hi} / 850$} \\
\hline Maior desvio (\%) & 98,91 & 49,62 & 39,84 & $-39,25$ & \\
\hline Menor desvio (\%) & $-45,78$ & $-58,61$ & $-59,26$ & $-81,90$ & \\
\hline $\begin{array}{l}{ }^{\text {sinal }} \\
\text { o valo }\end{array}$ & 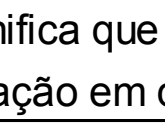 & 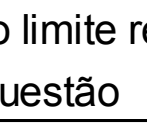 & & $m a$ & e \\
\hline
\end{tabular}




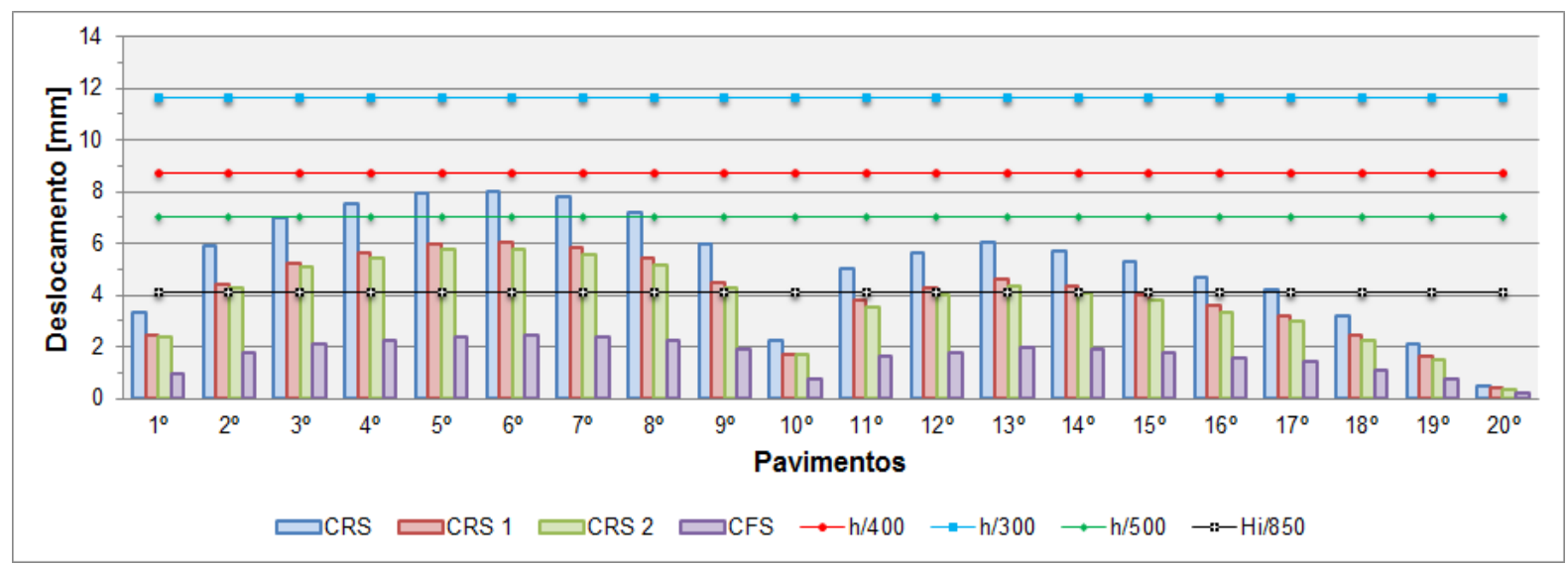

Figura 4.33 - Modelo 4 - Gráfico dos deslocamentos interpavimentos críticos (painel 1; eixo 1): comparativo das combinações de ações e limites

Tabela 4.17 - Modelo 4 - Diferenças percentuais dos deslocamentos interpavimentos críticos (painel 1; eixo 3) segundo as combinações CRS, CRS1, CRS2 e CFS em relação aos limites $\mathrm{h} / 400, \mathrm{~h} / 300, \mathrm{~h} / 500$ e $\mathrm{H}_{\mathrm{i}} / 850$

\begin{tabular}{|c|c|c|c|c|c|}
\hline & CRS & CRS1 & CRS2 & CFS & \\
\hline Média (\%) & $-39,78$ & $-54,44$ & $-56,68$ & $-80,92$ & \multirow{3}{*}{$h / 400$} \\
\hline Maior desvio (\%) & $-8,23$ & $-31,06$ & $-33,83$ & $-72,19$ & \\
\hline Menor desvio (\%) & $-94,65$ & $-95,51$ & $-95,80$ & $-97,16$ & \\
\hline Média (\%) & $-54,84$ & $-65,83$ & $-67,51$ & $-85,69$ & \multirow{3}{*}{$h / 300$} \\
\hline Maior desvio (\%) & $-31,17$ & $-48,30$ & $-50,37$ & $-79,14$ & \\
\hline Menor desvio (\%) & $-95,99$ & $-96,63$ & $-96,85$ & $-97,87$ & \\
\hline Média (\%) & $-24,73$ & $-43,05$ & $-45,85$ & $-76,14$ & \multirow{3}{*}{$h / 500$} \\
\hline Maior desvio (\%) & 14,71 & $-13,83$ & $-17,28$ & $-65,23$ & \\
\hline Menor desvio (\%) & $-93,32$ & $-94,38$ & $-94,75$ & $-96,45$ & \\
\hline Média (\%) & 27,96 & $-3,19$ & $-7,95$ & $-59,45$ & \multirow{3}{*}{$\mathrm{H}_{\mathrm{i}} / 850$} \\
\hline Maior desvio (\%) & 95,01 & 46,49 & 40,62 & $-40,90$ & \\
\hline Menor desvio (\%) & $-88,64$ & $-90,45$ & $-91,07$ & $-93,96$ & \\
\hline
\end{tabular}


Sobre a variação da posição das treliças horizontais no Edifício Modelo 3, pode-se observar na Figura 4.34 uma redução no deslocamento de topo em relação ao Edifício Modelo 3.1 (estrutura com as treliças localizadas no topo e a meia altura) igual a 8,4\%. Já em relação aos deslocamentos interpavimentos, este modelo apresenta uma distribuição danosa às fachadas, conforme traz a Figura 4.35.

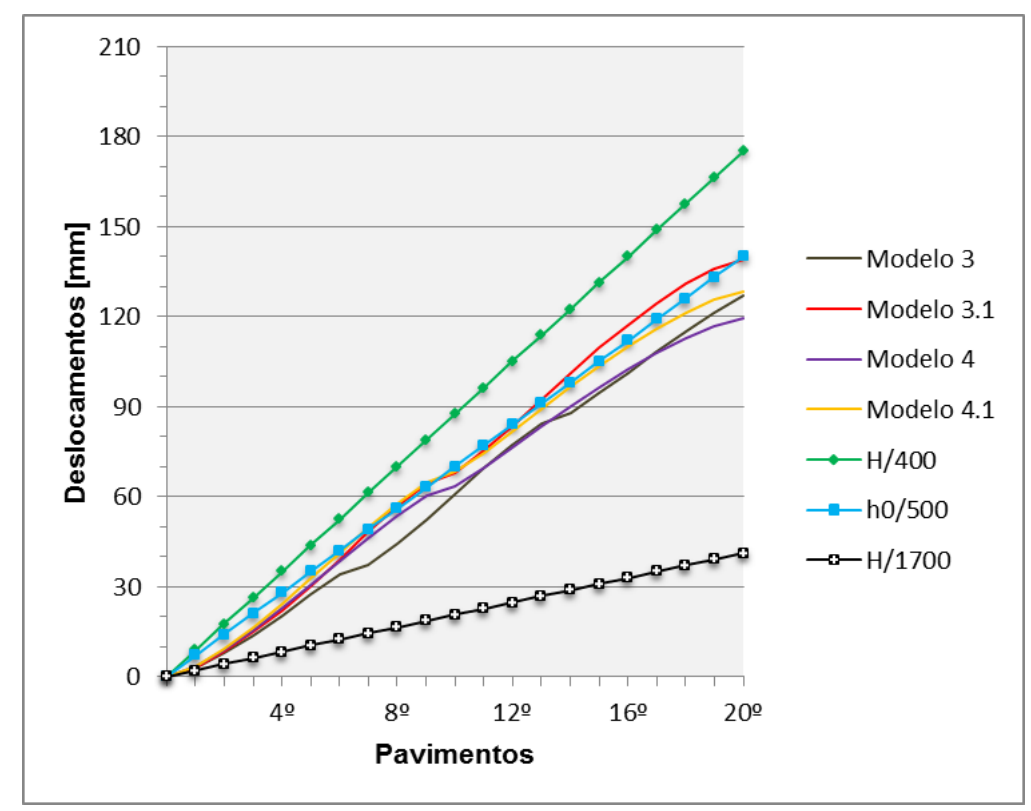

Figura 4.34 - Gráfico do deslocamento horizontal de topo dos pilares em relação à base variando o sistema estrutural do Edifício Modelo 3 e a rigidez da estrutura na análise do Edifício Modelo 4: CRS

Com relação à contabilização na análise da estrutura dos efeitos da fissuração do concreto nas vigas mistas contínuas, o Edifício Modelo 4.1 foi verificado conforme as prescrições do ANSI/AISC 360-10 (equação 3.6). Pode-se constatar na Figura 4.34 um aumento de 7,3\% no deslocamento do topo desse modelo em relação do Edifício Modelo 4 que, assim como os demais modelos analisados, considera a rigidez da seção não fissurada nos elementos de viga.

Ainda com relação ao Modelo 4.1, na Figura 4.36 pode-se destacar um aumento nos deslocamentos interpavimentos de aproximadamente $10 \%$ em alguns níveis. 


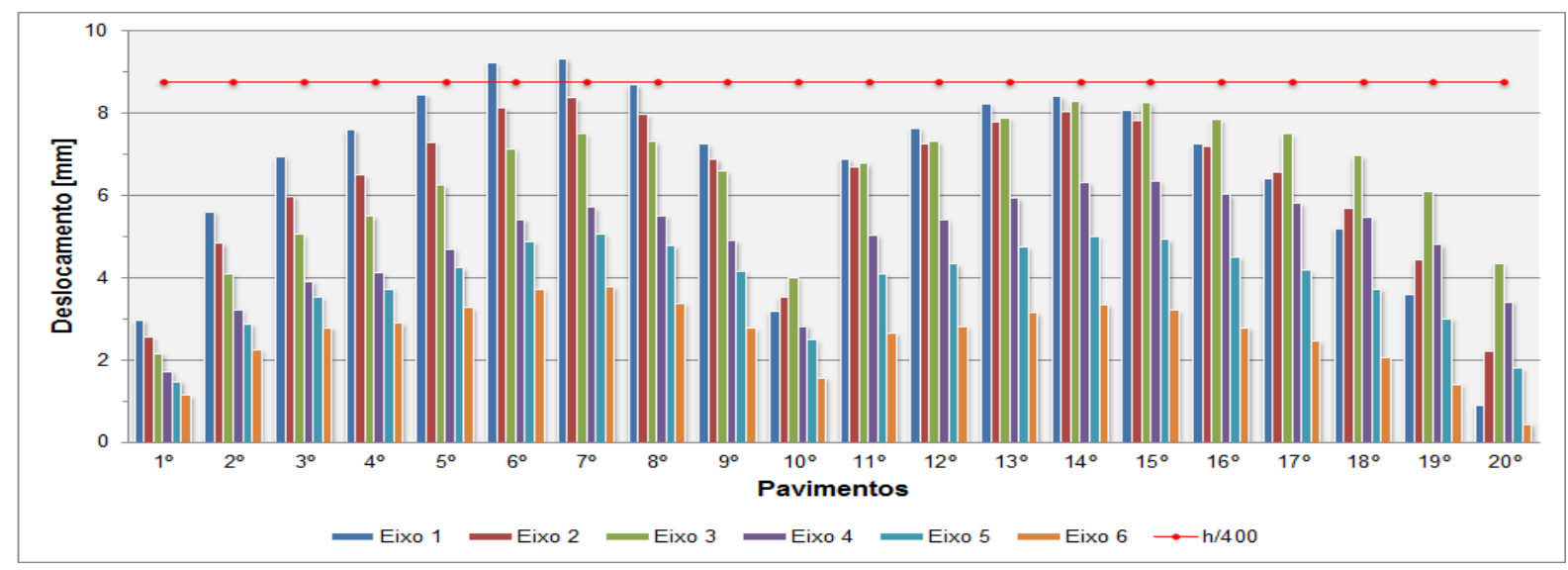

(a)

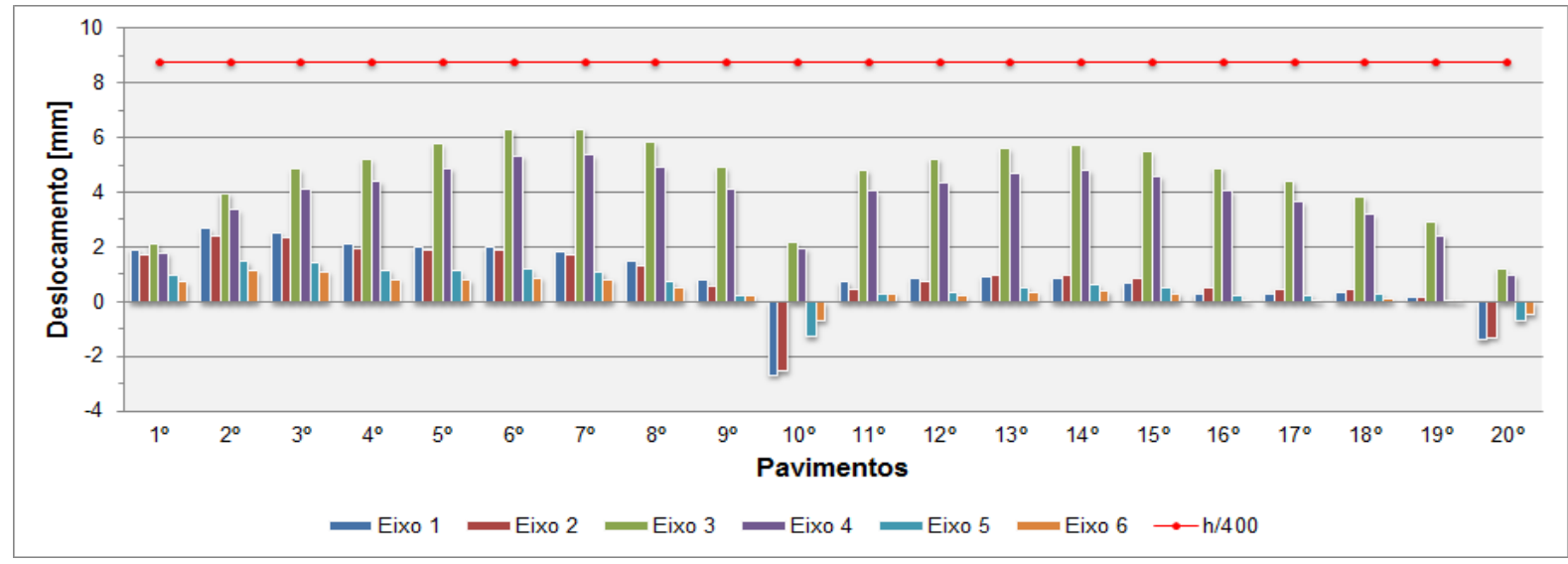

(b)

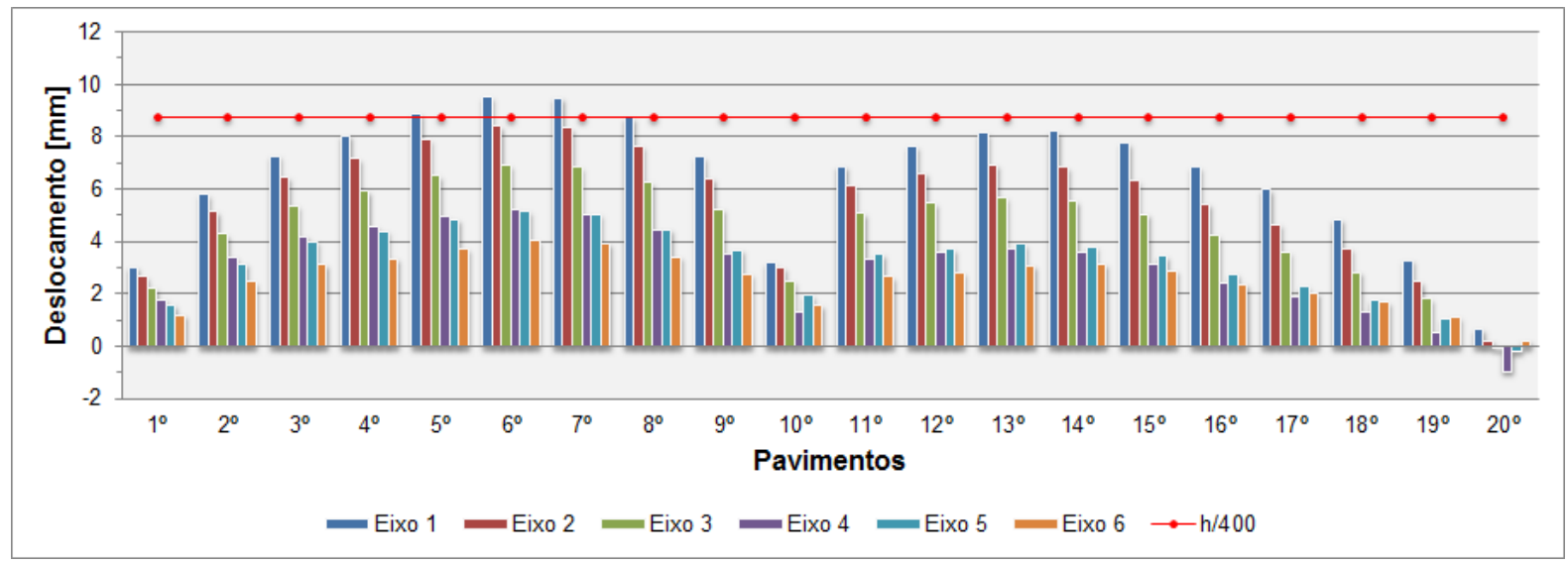

(c)

Figura 4.35 - Modelo 3.1 - Gráfico dos deslocamentos laterais: (a) painel 1; (b) painel 2; (c) painel 3

Os valores negativos nas Figuras 4.35 e 4.36 correspondem a um deslocamento relativo de sentido contrário a força horizontal aplicada. 


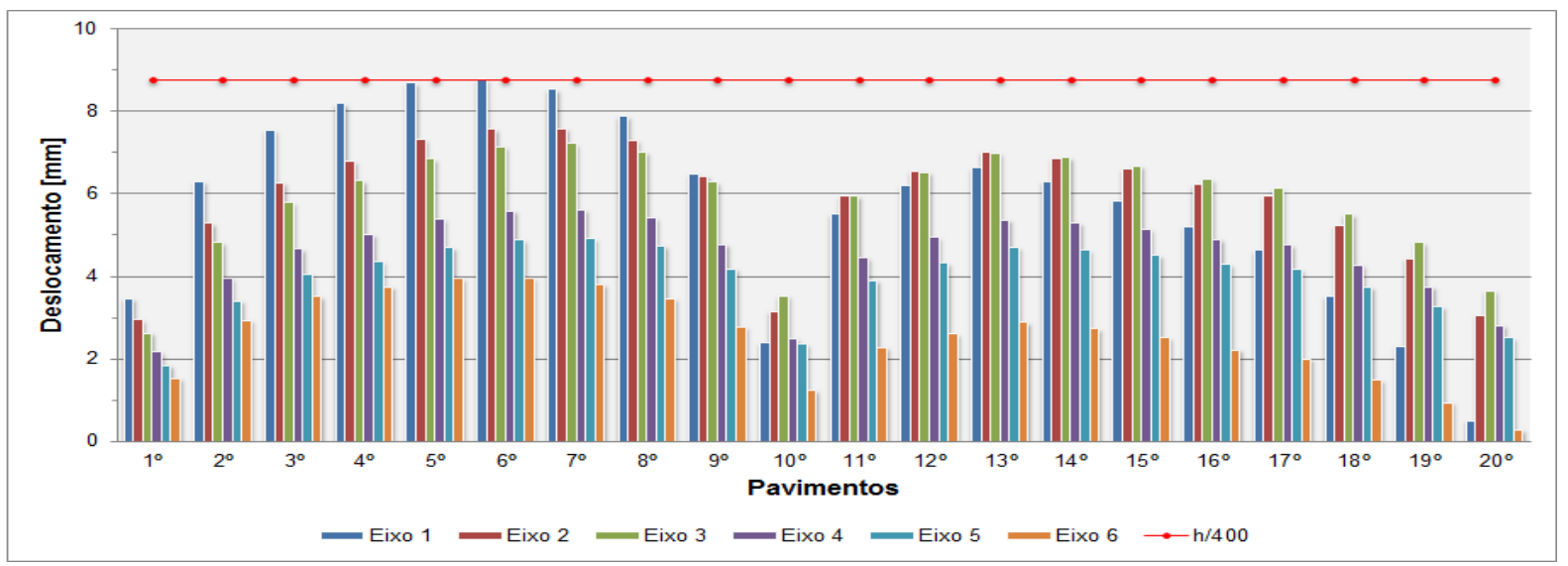

(a)

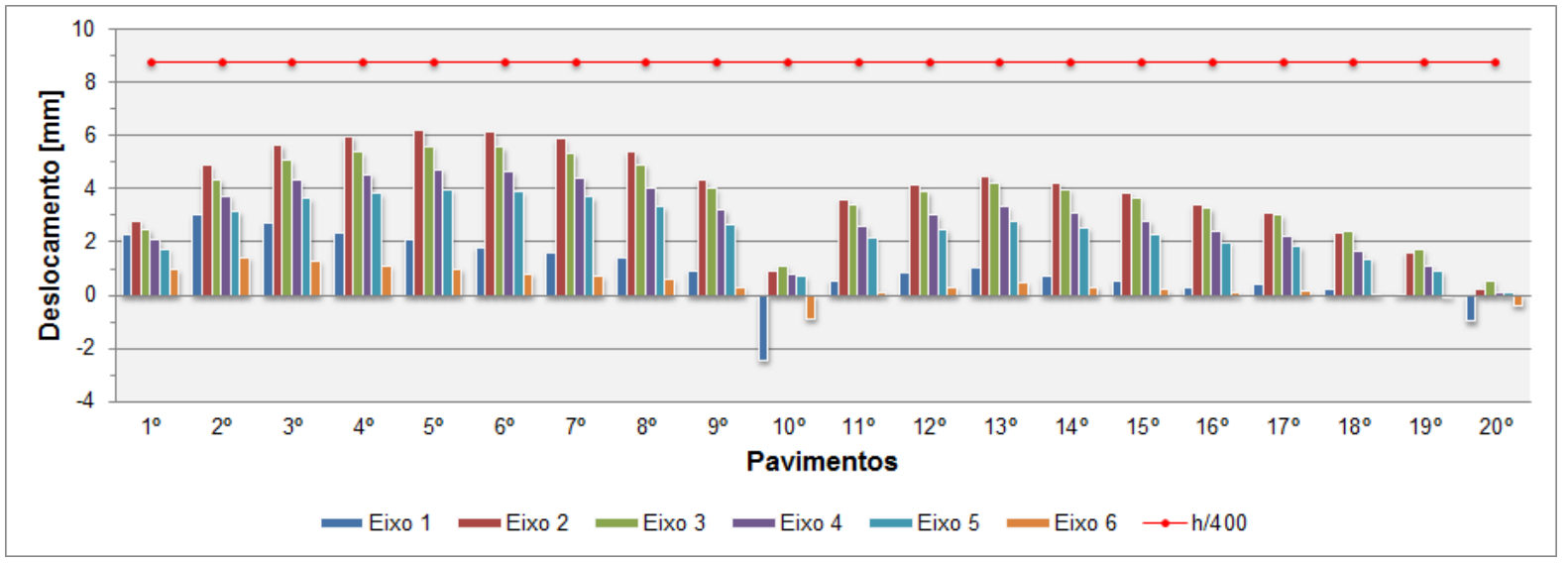

(b)

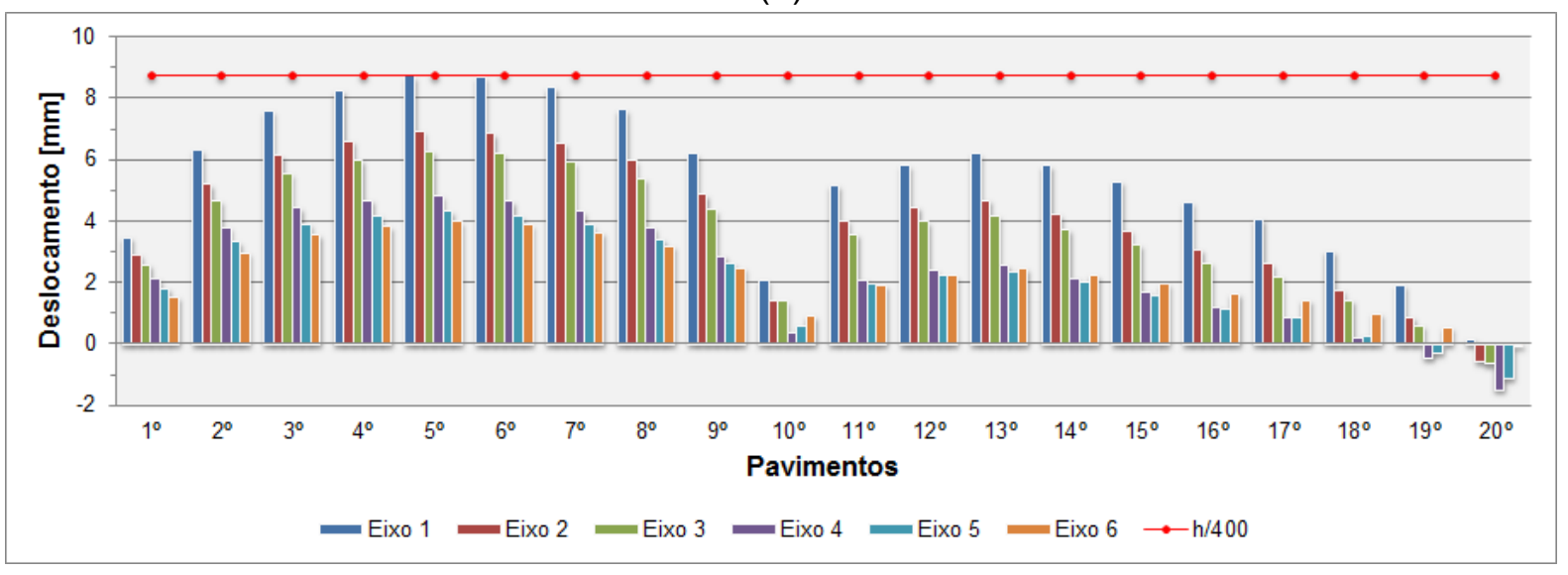

(c)

Figura 4.36 - Modelo 4.1 - Gráfico dos deslocamentos laterais interpavimentos: (a) painel 1; (b) painel 2; (c) painel 3 


\subsection{COMENTÁRIO FINAL}

Apesar de os estados limites de serviço nesse trabalho serem apresentados depois dos estados limites últimos, na definição da configuração do sistema estrutural de cada modelo e, posteriormente, do dimensionamento realizado após o pré-dimensionamento dos elementos da estrutura, foi respeitado a seguinte sequência: verificação dos estados limites de serviço, classificação quanto à deslocabilidade e, por último, verificação dos estados limites últimos. Essa ordem obedece ao grau de dificuldade de cálculo de cada etapa.

A definição da configuração dos sistemas estruturais é baseada em várias simulações para diversas possibilidades. A seguir são listados os fatores determinantes nessa fase:

- os eixos 1 e 6 no Modelo 1 são completamente enrijecidos para, em conjunto com a grande rigidez lateral dos eixos 2 e 5 , a estrutura atender os limites de deslocamentos de topo e interpavimentos;

- os eixos 2 e 5 são enrijecidos nos Modelos 2 e 3 porque a viga apresenta mesa colaborante de concreto nos dois lados do eixo e consequentemente considerável rigidez a flexão, além disso, nessa localização a estrutura apresenta uma boa resistência à torção.

- os eixos 2 e 5 enrijecidos nos Modelos 2 e 3 favorecem o controle dos deslocamentos interpavimentos da estrutura, uma vez que esses efeitos sofrem influência da rigidez dos pórticos adjacentes;

- o número de ligações rígidas nos eixos 3 e 4 nos Modelos 1 , 2 e 3 foi o mínimo necessário para que o eixo não exceda o limite de deslocamentos interpavimentos. No Modelo 4, esses eixos são completamente enrijecidos para aumentar suas contribuições no controle dos deslocamentos de topo da estrutura;

- a localização das treliças horizontais nos eixos 1 e 6, favorecida pela estrutura não ser aparente, evita áreas mortas no interior do edifício e, além disso, inibe a torção resultante da transferência das cargas aos núcleos; 
As bitolas das vigas transversais calculadas no item 3.8.3 tiveram que sofrer uma pequena elevação na altura para atenderem os esforços provenientes da estabilização horizontal da estrutura. Esse fato descarta o emprego de escoramentos e contraflechas nessas vigas. Na direção longitudinal consegue-se uma redução expressiva com esses artifícios construtivos, porém para padronizar o vigamento em uma única altura, as vigas longitudinais também os descartam.

A contribuição da fissuração do concreto das vigas contínuas não exerceu grande influência na análise dos esforços do Modelo 4.1. Já na verificação dos deslocamentos provoca um aumento de cerca de $7 \%$ nos deslocamentos de topo e $10 \%$ nos deslocamentos interpavimentos.

Com base no desempenho frente aos estados limites últimos e de serviço o Edifício Modelo 3 destaca-se em relação aos demais pelo menor número de ligações rígidas e de ligações para consolidar as diagonais de contraventamento ao núcleo. 



\section{CAPÍTULO 5: CONSIDERAÇÕES FINAIS}

\subsection{CONCLUSÃO}

No capítulo 2 é possível compreender o comportamento estrutural dos sistemas de estabilização verticais e horizontais mais usuais em edifícios com estrutura metálica.

Com base no capítulo 3 pode-se destacar a importância da elaboração do projeto arquitetônico de estruturas metálicas respeitando as limitações estruturais do mesmo. Quando isso não é possível, o capítulo 4 traz uma forma de se contornar situações desfavoráveis com soluções que oferecem maior liberdade estrutural ao aço, como no caso desse projeto, o uso de módulos unitizados.

No âmbito das vigas mistas, dentre os comentários finais desenvolvidos no capítulo correspondente, vale ressaltar:

- a interação parcial demonstra-se uma solução bastante oportuna, uma vez que a perda de resistência e rigidez à flexão pode ser inexpressiva frente à economia com o número de conectores;

- a presença de escoramento ou contraflecha também deve ser considerada quando cabível, visto que trazem grande economia no consumo de aço;

- o emprego de perfis soldados não padronizados pela ABNT nas vigas mistas diminui a perda de material principalmente dos sistemas contínuos, uma vez que os comprimentos das almas dos perfis soldados catalogados aplicáveis a esse projeto trabalhando com o aço ASTM A572 G50 apresentaram-se susceptíveis a instabilidade na região de momento negativo.

Quanto à avaliação final da estabilidade e análise estrutural também cabe salientar:

- o cálculo da rigidez lateral do sistema estrutural a partir da estrutura It pode induzir a interpretações equivocadas à deslocabilidade da estrutura estampando a falha do método ao considerar o comportamento do elemento 
independente da estrutura, entretanto não o desqualifica para avaliação dos efeitos de segunda ordem;

- é importante contabilizar os efeitos de torção proporcionados pelo vento na análise estrutural, uma vez que desprezá-los induz a uma resposta estrutural próxima a essa ação aplicada com período de retorno reduzido em 40 anos.

\subsection{SUGESTÕES PARA TRABALHOS FUTUROS}

Estudar a contribuição da resistência à tração do steel deck no cálculo do momento resistente negativo e a sua influência na instabilidade da alma do perfil.

Estudar a influência da fissuração do concreto presente nos elementos mistos na análise estrutural global de edifícios.

Estudar a importância dos efeitos de longa duração do concreto na análise estrutural global de edifícios compostos por elementos mistos de aço e concreto. 


\section{REFERÊNCIAS BIBLIOGRÁFICAS}

AI-MASHARY, F.; CHEN, W.F. Elastic second-order analysis for frame design. Journal Constructional Steel Research, v. 15, n. 4, p. 303-322, 1990.

ALCOA. Ancoragem telescópica: catálogo (BT 23). Catálogo de equipamentos para alçar módulos. <http://www.alcoa.com/brazil/catalog/extrusions/building/BT/ BT23.pdf> Acesso em: 5 mar. 2012.

ALVA, G.M.S. Sobre o projeto de edifícios em estrutura mista aço-concreto. 2000. 277 p. Dissertação (Mestrado em Engenharia de Estruturas) - Escola de Engenharia de São Carlos, Universidade de São Paulo, São Carlos, 2000.

AMERICAN SOCIETY OF CIVIL ENGINEERS - ASCE. Effective length and notional load approaches for assessing frame stability: implications for American steel design. By the Task Committee on Effective Length. New York, 1997.

ASCE/SEI 7-10: Minimum design loads for buildings and other structures. Reston, Virginia, 2010.608p.

AMERICAN INSTITUTE OF STEEL CONSTRUCTION - AISC. ANSI/AISC 360-10: Specification for structural steel buildings. Chicago, 2010. 552p.

AISC-LRFD-1986: Load and resistance factor design specification for structural steel buildings. Chicago, 1986.

ASSOCIAÇÃO BRASILEIRA DE NORMAS TÉCNICAS - ABNT. NB 14-1952: Cálculo e execução de estruturas de aço (edifícios). Rio de Janeiro, 1952.

ABNT NBR 5884:2005: Perfil I estrutural de aço soldado por arco elétrico: Requisitos gerais. Rio de Janeiro, 2005. 33 p.

ABNT NBR 6118:2003: Projeto de estruturas de concreto: Procedimento. Rio de Janeiro, 2003. 221 p.

ABNT NBR 6120:1980: Cargas para o cálculo de estruturas de edificações. Rio de Janeiro, 1980. 6 p.

ABNT NBR 6123:1988: Forças devidas ao vento em edificações: Procedimento. Rio de Janeiro, 1988. 110 p.

ABNT NBR 8800:1986: Projeto e execução de estruturas de aço em edifícios: Procedimento. Rio de Janeiro, 1986. 200 p.

ABNT NBR 8800:2008: Projeto de estruturas de aço e de estruturas mistas de aço e concreto de edifícios. Rio de Janeiro, 2008. 237 p. 
. ABNT NBR 14323:1999: Dimensionamento de estruturas de aço de edifícios em situação de incêndio: Procedimento. Rio de Janeiro, 1999. 46 p.

. ABNT NBR 14762:2010: Dimensionamento de estruturas de aço constituídas por perfis formados a frio. Rio de janeiro, 2010. $87 \mathrm{p}$.

AVAKIAN, A.C. Estruturas aporticadas mistas aço-concreto: avaliação de metodologias de análise. 2007. 158 p. Dissertação (Mestrado em Ciências de Engenharia Civil) - Universidade Federal do Rio de Janeiro, Rio de Janeiro, 2007.

BRITISH STANDARD. BS 5400-5:1979: Steel, concrete and composite bridges: Part 5: Code of practice for design of composite bridges. United Kingdom, Sheffield, 1979. $48 \mathrm{p}$.

CANADIAN STANDARDS ASSOCIATION - CSA. CAN/CSA S16.1:1984: Steel structures for buildings - limit states design. Ontario, Canadian, 1984.

CHAN, S.L.; ZHOU, Z.H. Second-order elastic analysis of frames using single imperfect element per member. Journal of Structural Engineering, v. 121, n. 6, p. 939-945, Jun. 1995.

CHARNEY, F.A. Wind drift serviceability limit state design of multistory buildings. Journal of wind engineering and industrial aerodynamics, Netherlands, v. 36, p. 203-212, 1990.

CHEN, W.F.; LUI, E.M. Stability Design of Steel Frames. Florida: CRC Press, 1991.

CHEN, W.F.; LUI, E.M. Handbook of structural engineering. 2. ed. Florida: CRC Press, 2005.

CISER. Stud bolts: catálogo. Catálogo de conectores de cisalhamento. Joinville, SC, 2012. <http://www.ciser.com.br/htcms/media/pdf/destaques/br/folheto-stud-bolts.pdf> Acesso em: 5 mar. 2012.

COMPUTER AND STRUCTURES INC. SAP2000 Advanced 14.0.0: Static and dynamic finite element analysis of structures. Berkeley, California, 2009.

CORRÊA, M.R.S. Aperfeiçoamento de modelos usualmente empregados no projeto de sistemas estruturais de edifícios. 1991. 342 p. Tese (Doutorado em Engenharia de Estruturas) - Escola de Engenharia de São Carlos, Universidade de São Paulo, São Carlos, 1991.

DE AZEVEDO, F.R.S. Copa do mundo 2014. Revista Arquitetura e Aço, Rio de Janeiro, jan. 2010, p.10-12. Entrevista concedida a Marineide Marques.

DEUTSCHE INDUSTRIE NORMEN. DIN 4114 (1952): Berechnungsgundlagen für stabilitätsfälle in stahlbau: Knickung, Kippung, Beulung. Germany, 1952. 
DÓRIA, A.S. Análise da estabilidade de pórticos planos de aço com base no conceito de forças horizontais fictícias. 2007. 107 p. Dissertação (Mestrado em Engenharia de Estruturas) - Escola de Engenharia de São Carlos, Universidade de São Paulo, São Carlos, 2007.

EUROPEAN CONVENTION FOR CONSTRUCTIONAL STEELWORK - ECCS Committee. Manual on the stability of steel structures. 2. ed. 1976

EUROPEAN COMMITTEE FOR STANDARDIZATION. EN 1994-1-1:2004: Eurocode 4: Design of composite steel and concrete structures: Part 1-1: General rules and rules for buildings. Brussels, Belgium, 2004. 122p. 2002. 88p.

EN 1990:2002: Eurocode: Basis of structural design. Brussels, Belgium,

EN 1992-1-1:2004: Eurocode 2: Design of concrete structures: Part 1-1: General rules and rules for buildings. Brussels, Belgium, 2004. 226p.

EN 1993-1-1:2005: Eurocode 3: Design of steel structures: Part:1-1: General rules and rules for buildings. Brussels, Belgium, 2005. 92p.

FABRIZZI, M.A. Contribuição para o projeto e dimensionamento de edifícios de múltiplos andares com elementos estruturais mistos aço-concreto. 2007. 233 p. Dissertação (Mestrado em Engenharia de Estruturas) - Escola de Engenharia de São Carlos, Universidade de São Paulo, São Carlos, 2007.

FAKURY, R.H. Sobre a revisão da norma brasileira de projeto de estruturas de aço e estruturas mistas de aço e concreto, a NBR 8800. Revista Escola de Minas, Ouro Preto, v. 60, n. 2, p. 233-239, 2007.

GALAMBOS, T.V. Guide to stability design criteria for metal structures. 5. ed. New York: John Wiley e Sons, 1998.

GRIFFIS, L.G. Serviceability limit states under wind load. Engineering Journal, AISC, v. 30, n. 1, p. 1-16, 1993.

INSTITUTO BRASILEIRO DE SIDERURGIA. Centro Brasileiro da Construção em Aço - IBS/CBCA. Edifícios de pequeno porte estruturados em aço. 3. ed. Rio de Janeiro, 2004. 75p.

. Viabilidade econômica. Rio de Janeiro, 2008. 84p.

INSTITUTO BRASILEIRO DE TELAS SOLDADAS - IBTS. Tabela de telas soldadas nervuradas: catálogo. São Paulo, 2011. <http://www.ibts.org.br/publicacoes.asp>. Acesso em: 5 mar. 2012.

ISLAM, M.S.; ELLINGWOOD, B.; COROTIS, R.B. Dynamic response of tall buildings to stochastic wind load. Journal of Structural Engineering, v. 116, n. 11, Nov. 1990. 
JOHNSON, R.P. Composite structures of steel and concrete: beams, slabs, columns, and frames for buildings. 3. ed. Blackwell Publishing, 2004.

JOHNSON, R.P.; ANDERSON, D. Designers' guide to EN 1994-1-1. Eurocode 4: design of composite steel and concrete structures: Part 1.1: general rules and rules for buildings. 1. ed. United Kingdom, London: Thomas Telford, 2004. 235p.

KANCHANALAI, T.; LE-WU, L. Analysis and design of framed columns under minor axis bending. Engineering Journal, v. 16, n. 2, p. 29-41, 1979.

MALITE, M. Sobre o cálculo de vigas mistas aço-concreto: ênfase em edifícios. 1990. 144p. Dissertação (Mestrado em Engenharia de Estruturas) - Escola de Engenharia de São Carlos, Universidade de São Paulo, São Carlos, 1990.

MANUAL técnico: especificações para projeto, manuseio e montagem. Betim, MG: Metform, 2007.

METFORM. Steel deck: catálogo. Catálogo para dimensionamento das lajes mistas à flexão. Betim, MG, 2011. <http://www.metform.com.br/steel-deck-catalogotecnico.php>. Acesso em: 5 mar. 2012.

MINISTÉRIO DO DESENVOLVIMENTO DA INDÚSTRIA E COMÉRCIO. Secretaria Especial de Desenvolvimento Industrial - MD/SDI. Manual brasileiro para cálculo de estruturas metálicas. 2. ed. v. 1. Brasília, DF, 1989.102 p.

PARAMETRIC TECHNOLOGY CORPORATION. Mathcad 14.0 M020: Solve and document your most complex engineering calculations. Needham, MA, USA, 2007.

PFEIL, W.; PFEIL, M. Estruturas de Aço: dimensionamento prático de acordo com a NBR 8800:2008. 8. ed. Rio de Janeiro: LTC, 2009.

Pontifícia Universidade Católica do Rio de Janeiro - PUC-Rio, Departamento de Engenharia Civil e Tecgraf/PUC-Rio Grupo de Tecnologia em Computação Gráfica. Ftool Versão Educacional 2.12: Two dimensional frame analysis tool. Rio de Janeiro, 2008.

QUEIROZ, G.; PIMENTA, R.J.; DA MATA, L.A.C. Elementos das estruturas mistas aço-concreto. Belo Horizonte: Editora O Lutador, 2001. 336p.

RIBEIRO, L.F.L. Utilização de “outrigger” em edifícios altos. 1990. 134 p. Dissertação (Mestrado em Ciências em Engenharia Civil) - Universidade Federal do Rio de Janeiro, COOPE, Rio de Janeiro, 1990.

ROCKEY, K.; EVANS, H.; GRIFFITHS, D; NETHERCOT, D. The finite element method: a basic introduction. New York: Halsted Press, 1975.

SÁLES, J.J. Estudo do projeto e da construção de edifícios de andares múltiplos com estrutura de aço. 1995. 257 p. Tese (Doutorado em Engenharia de Estruturas) - Escola de Engenharia de São Carlos, Universidade de São Paulo, São Carlos, 1995. 
SALMON, C.G.; JOHNSON, J.E. Steel structures: design and behavior, emphasizing load and resistance factor design. 4. ed. New York: Harper Collins, 1996.

SOUZA, A.S.C. Análise da estabilidade de edifícios de andares múltiplos em aço. Relatório final processo 07/03839-0 - Universidade Federal de São Carlos, São Carlos, 2009.

TALLIN, A.; ELLINGWOOD, B. Serviceability limit states: wind induced vibrations. Journal of Structural Engineering, v. 110, n. 10, Oct. 1984.

TARANATH, B.S. Wind and earthquake resistant buildings: structural analysis and design. New York: Marcel Dekker, 2005.

WEST, M.; FISHER, J. Serviceability Design Considerations for steel buildings. 2. ed. Chicago: AISC, 2003. 



\section{APÊNDICE A CÁLCULO DAS AÇÕES HORIZONTAIS DEVIDO AO VENTO SEGUNDO AS PRESCRIÇÕES DA ABNT NBR 6123:1988}




\section{APÊNDICE A: Cálculo das ações horizontais devido ao vento segundo as prescrições da NBR 6123:1988}

1 - Velocidade característica do vento

\section{1 - Velocidade básica do vento}

Gráfico de isopletas da velocidades $\quad V_{0}=40 \frac{\mathrm{m}}{\mathrm{s}}$
básica:.

\section{2 - Fator topográfico}

Terreno plano ou fracamente acidentado:... $S_{1}=1$

\section{3 - Fator estatístico}

Edificações para comércio e indústria com alto fator de ocupação:

$$
\mathrm{S}_{3}=1
$$

1.4 - Fator devido a rugosidade do terreno, dimensões da edificação e altura sobre o terreno

\subsection{1 - Categoria IV, classe C}

Fator de rajada:

$$
\mathrm{F}_{\mathrm{r}}=0.95
$$

Parâmetro b:

$$
\mathrm{b}=0.84
$$

Parâmetro p:

$$
\mathrm{p}=0.135
$$

Número de pavimentos:

$$
n_{\text {pav }}=20
$$

Comprimento do pé direito:

$$
L_{p d}=3.5 m
$$

$$
\mathrm{i}=1 . . \mathrm{n}_{\text {pav }}
$$

$z_{i}=i \cdot L_{p d}$

$$
\mathrm{s}_{2_{i}}=b \cdot F_{r} \cdot\left(\frac{z_{i}}{10 m}\right)^{p}
$$

\section{5 - Velocidade característica do vento}

$$
\mathrm{V}_{\mathrm{k}_{\mathrm{i}}}=\mathrm{V}_{0} \cdot \mathrm{S}_{1} \cdot \mathrm{S}_{2_{\mathrm{i}}} \cdot \mathrm{S}_{3}
$$

\section{2 - Pressão dinâmica}

$$
q_{i}=0.613 \cdot\left(v_{k_{i}} \cdot \frac{s}{m}\right)^{2} \cdot \frac{N}{m^{2}}
$$




\section{3 - Força global do vento na direção do fluxo (força de arrasto)}

Altura do edifício:

$$
h=70 m
$$

Comprimento da maior face do edifício:.....

$a=45 m$

Comprimento da menor face do edifício:.... $b=20 m$

Número de eixos de pórticos na maior face: $n_{e}=6$

Número de filas de pórticos na menor face: $n_{f}=4$

\section{1 - Vento incidindo na face maior}

\subsection{1 - Coeficiente de arrasto}

$$
\begin{aligned}
& \mathrm{I}_{1}=a=45 \mathrm{~m} \\
& \mathrm{I}_{2}=\mathrm{b}=20 \mathrm{~m} \\
& \frac{\mathrm{h}}{\mathrm{I}_{1}}=1.56 \\
& \frac{\mathrm{I}_{1}}{\mathrm{I}_{2}}=2.25
\end{aligned}
$$

Para edificações paralelepipédicas expostas a ventos de alta turbulência, temos:

$$
\mathrm{C}_{\mathrm{a}}=1.10
$$

3.1.2 - Força de arrasto atuando em cada eixo do respectivo pvto.

$$
F_{e . a_{i}}=\frac{C_{a} \cdot q_{i} \cdot a \cdot L_{p d}}{n_{e}}
$$

11

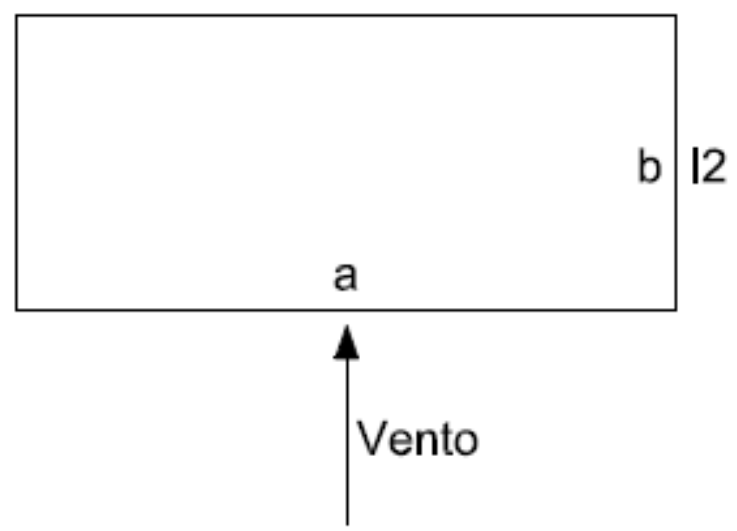

Figura 3.1 - Vento incidindo na maior face (NBR 6123:1988) 
3.2 - Vento incidindo na face menor

3.2.1 - Coeficiente de arrasto

$\mathrm{I}_{1}=\mathrm{b}=20 \mathrm{~m}$

$\mathrm{I}_{2}=\mathrm{a}=45 \mathrm{~m}$

$\frac{\mathrm{h}}{\mathrm{l}_{1}}=3.5$

$\frac{\mathrm{l}_{1}}{\mathrm{l}_{2}}=0.44$

Para edificações paralelepipédicas expostas a ventos de alta turbulência, temos:

$\mathrm{C}_{\mathrm{a}}=0.85$

3.2.2 - Força de arrasto atuando em cada fila do respectivo pvto.

$F_{e . b_{i}}=\frac{C_{a} \cdot q_{i} \cdot b \cdot L_{p d}}{n_{f}}$

12

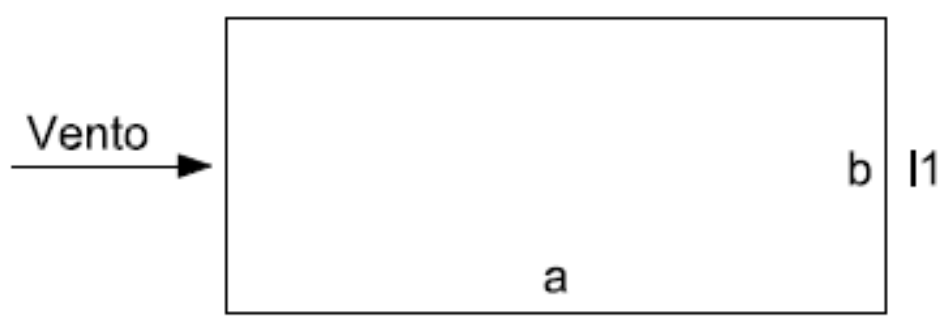

Figura 3.2 - Vento incidindo na menor face (NBR 6123:1988)

4 - Efeito de vizinhança

4.1 - Vento incidindo no lado maior, a

\subsection{1 - Excentricidade}
$\mathrm{e}_{\mathrm{a}}=0.15 \cdot \mathrm{a}$
$e_{a}=6.75 \cdot m$

4.1.2 - Resultante da força horizontal

$\mathrm{F}_{\mathrm{t} . \mathrm{a}_{\mathrm{i}}}=\mathrm{n}_{\mathrm{e}} \cdot \mathrm{F}_{\mathrm{e} . \mathrm{a}_{\mathrm{i}}}$

\subsection{3 - Momento torçor}

$\mathrm{M}_{\mathrm{ta}_{\mathrm{i}}}=\mathrm{F}_{\mathrm{t} \cdot \mathrm{a}_{\mathrm{i}}} \cdot \mathrm{e}_{\mathrm{a}}$ 
4.1.4 - Forças componentes dos binários sobre os eixos

$$
\begin{aligned}
& F_{\text {t.a. }}{ }_{\mathrm{i}} \\
& 22.5 \mathrm{~m} \\
& \mathrm{~F}_{\text {t.a. } 1_{\mathrm{i}}}=5 \cdot \mathrm{F}_{\text {t.a. } 3_{\mathrm{i}}} \\
& F_{\text {t.a.2 }} \\
& 13.5 \mathrm{~m} \\
& \mathrm{~F}_{\text {t.a. } 2_{\mathrm{i}}}=3 \cdot \mathrm{F}_{\text {t.a. } 3_{\mathrm{i}}}
\end{aligned}
$$
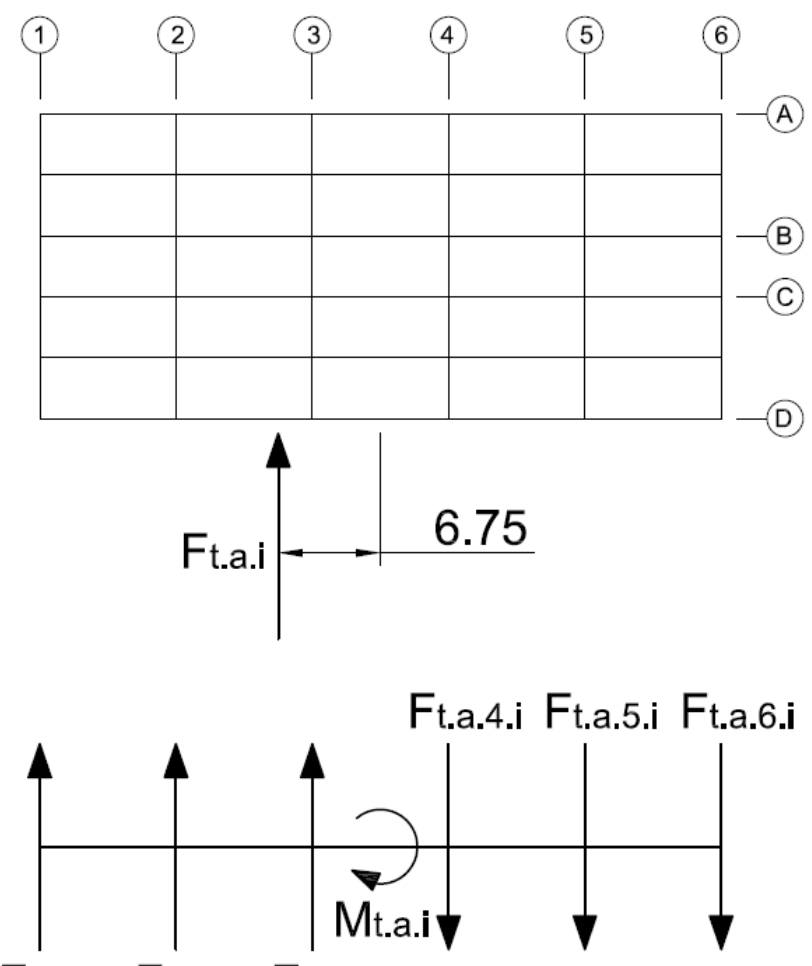

Ft.a.1.i Ft.a.2.i Ft.a.3.i

Figura 3.3 - Efeito de vizinhança: vento incidindo na maior face 
4.2 - Vento incidindo no lado menor, b

\subsection{1 - Excentricidade}

$\mathrm{e}_{\mathrm{b}}=0.15 \cdot \mathrm{b}$

$e_{b}=3 \cdot m$

\subsection{2 - Resultante da força horizontal}

$\mathrm{F}_{\mathrm{t} . \mathrm{b}_{\mathrm{i}}}=\mathrm{n}_{\mathrm{f}} \cdot \mathrm{F}_{\mathrm{e} \cdot \mathrm{b}_{\mathrm{i}}}$

\subsection{3 - Momento torçor}

$\mathrm{M}_{\mathrm{tb}_{\mathrm{i}}}=\mathrm{F}_{\mathrm{t} \cdot \mathrm{b}_{\mathrm{i}}} \cdot \mathrm{e}_{\mathrm{b}}$

4.2.4 - Forças componentes dos binários sobre as filas

$$
\begin{aligned}
& F_{\text {t.b.A }} \\
& 10 \mathrm{~m} \\
& F_{\text {t.b. }} A_{i}=5 \cdot F_{\text {t.b. }} \mathbf{B}_{i} \\
& F_{\text {t.b. }} \text { i }_{\text {i }} \\
& 2 m \\
& \mathrm{M}_{\mathrm{tb}_{\mathrm{i}}}=2 \cdot 10 \cdot \mathrm{F}_{\mathrm{t} . b . \mathrm{A}_{\mathrm{i}}}+2 \cdot 2 \cdot \mathrm{F}_{\mathrm{t} . \mathrm{b} . \mathrm{B}_{\mathrm{i}}}
\end{aligned}
$$

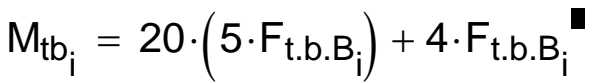

$$
\begin{aligned}
& F_{\text {t.b. }} B_{i}=\frac{M_{t b_{i}}}{104 m} \\
& F_{\text {t.b. }} A_{i}=5 \cdot F_{\text {t.b. }}{ }_{i}
\end{aligned}
$$

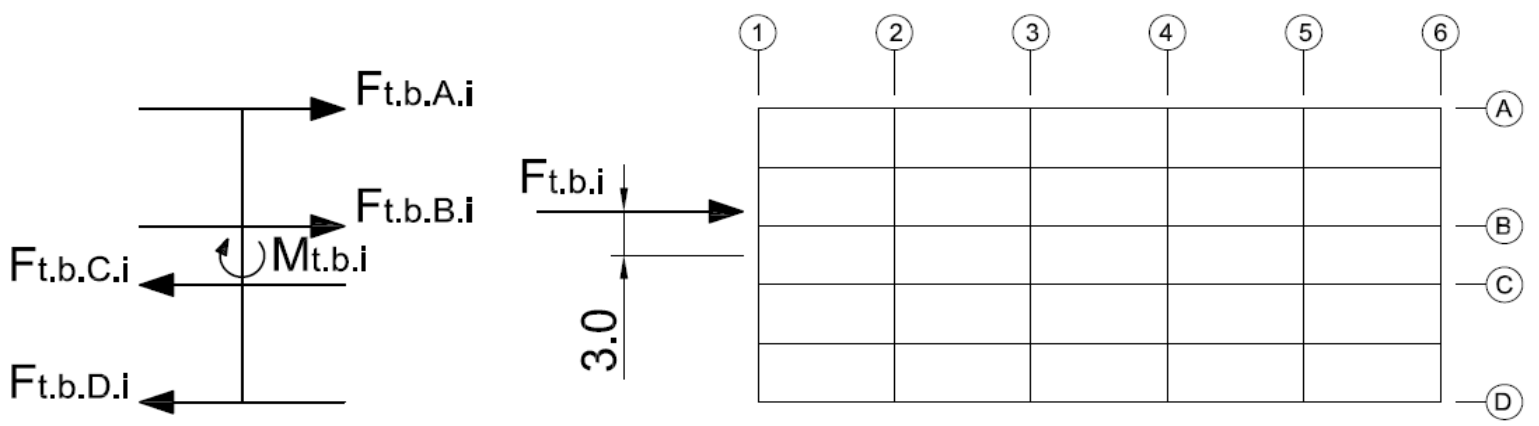

Figura 3.4 - Efeito de vizinhança: vento incidindo na menor face 
5 - Sobreposição das forças atuantes na edificação devidas ao vento

5.1 - Vento incidindo sobre os eixos ( lado maior, a)

Eixo 1:

$$
C V_{1_{i}}=F_{\text {e. } a_{i}}+F_{\text {t.a. } 1_{i}}
$$

Eixo 2

$$
C V_{2_{i}}=F_{\text {e. } a_{i}}+F_{\text {t.a. } 2_{i}}
$$

Eixo 3.

$$
C V_{3_{i}}=F_{e . a_{i}}+F_{\text {t.a. } 3_{i}}
$$

Eixo 4

$$
C V_{4_{i}}=F_{\text {e. } a_{i}}-F_{\text {t.a. } 3_{i}}
$$

Eixo 5:

$$
C V_{5_{i}}=F_{\text {e. } a_{i}}-F_{\text {t.a. } 2_{i}}
$$

Eixo 6:

$$
C V_{6_{i}}=F_{e . a_{i}}-F_{\text {t.a. } 1_{i}}
$$

5.2 - Vento incidindo sobre as filas (lado menor, b)

Fila A:

$$
C V_{A_{i}}=F_{e . b_{i}}+F_{\text {t.b. } A_{i}}
$$

Fila B:

$$
C V_{B_{i}}=F_{e . b_{i}}+F_{t . b . B_{i}}
$$

Fila C:

$$
C V_{C_{i}}=F_{e . b_{i}}-F_{\text {t.b. }} B_{i}
$$

Fila D:

$$
C V_{D_{i}}=F_{e . b_{i}}-F_{\text {t.b. }} A_{i}
$$





\section{APÊNDICE B CÁLCULO DE UMA VIGA MISTA CONTÍNUA NÃO ESCORADA SEGUNDO AS PRESCRIÇÕES DA ABNT NBR 8800:2008}




\section{APÊNDICE B: Cálculo de uma viga mista de alma cheia contínua não-escorada segundo a ABNT NBR 8800:2008}

\section{VIGA V3 (VÃO 1-2) CO NE CF PS A572G50 50\%}

\section{VERIFICAÇÃO DA SEÇÃO DE AÇO}

\section{1 - Dados de entrada}

\section{1 - Propriedades geométricas}

\subsection{1 - Perfil de aço ( Bitola = "PS 450 x 37" )}

Área bruta:

$$
A_{a}=46.54 \cdot \mathrm{cm}^{2}
$$

Altura do perfil.

$\mathrm{d}=450 \cdot \mathrm{mm}$

Largura da mesa:

$b_{f}=120 \cdot m m$

Espessura da mesa:

$\mathrm{t}_{\mathrm{f}}=8 \cdot \mathrm{mm}$

Área da mesa superior:

$A_{\text {af }}=9.6 \cdot \mathrm{cm}^{2}$

Altura da alma:

$\mathrm{h}=434 \cdot \mathrm{mm}$

Espessura da alma:

$t_{w}=6.3 \cdot \mathrm{mm}$

Área da alma:

$A_{a w}=27.34 \cdot \mathrm{cm}^{2}$

Raio de giração X:

$r_{\mathrm{ax}}=17.14 \cdot \mathrm{cm}$

Raio de giração Y:

$r_{a y}=2.23 \cdot \mathrm{cm}$

Momento de inércia $\mathrm{X}$ :

$I_{a x}=13670.19 \cdot \mathrm{cm}^{4}$

Momento de inércia Y:

$l_{\text {ay }}=231.3 \cdot \mathrm{cm}^{4}$

Momento de inércia a torção:

$\mathrm{J}=7.71 \cdot \mathrm{cm}^{4}$

Módulo elástico $X$ :

$\mathrm{W}_{\mathrm{ax}}=607.56 \cdot \mathrm{cm}^{3}$

Módulo elástico Y:

$\mathrm{W}_{\mathrm{ay}}=38.55 \cdot \mathrm{cm}^{3}$

Módulo plástico $X$ :

$Z_{a x}=720.98 \cdot \mathrm{cm}^{3}$

Módulo plástico Y:

$Z_{\text {ay }}=61.91 \cdot \mathrm{cm}^{3}$

Constante de empenamento:

$C_{w}=112971.35 \cdot \mathrm{cm}^{6}$ 


\subsection{2 - Sistema estrutural}

Comprimento do vão da viga :

$$
\mathrm{L}=9 \mathrm{~m}
$$

\section{2 - Propriedades mecânicas dos materiais}

\subsection{1 - Perfil de aço (ASTM A572 - Grau 50)}

Resistência ao escoamento

$$
\mathrm{f}_{\mathrm{y}}=34.5 \cdot \frac{\mathrm{kN}}{\mathrm{cm}^{2}}
$$

Resistência à ruptura à tração:

$$
\mathrm{f}_{\mathrm{u}}=45 \cdot \frac{\mathrm{kN}}{\mathrm{cm}^{2}}
$$

Tensões residuais:

$$
f_{r}=10.35 \cdot \frac{\mathrm{kN}}{\mathrm{cm}^{2}}
$$

Módulo de elasticidade longitudinal:

$$
\mathrm{E}=20000 \cdot \frac{\mathrm{kN}}{\mathrm{cm}^{2}}
$$

\section{3 - Coeficiente de ponderação e fator de redução}

\subsection{1 - Coeficiente de ponderação das ações (combinações normais)}

Açoes permanentes diretas agrupadas:.... $\gamma_{g 1}=1.3$

Demais ações variáveis, icluindo as decorrentes do uso e ocupação:

$$
\gamma_{q 1}=1.3
$$

\subsection{2 - Fator de redução das ações variáveis}

Locais em que há predominância de elevadas concentrações de pessoas:

$$
\psi_{0_{2}}=0.7 \quad \psi_{1_{2}}=0.6 \quad \psi_{2_{2}}=0.4
$$

\subsection{3 - Coeficientes de ponderação das resistências (combinações normais)} Escoamento do aço estrutural: $\gamma_{\mathrm{a} 1}=1.1$ 


\section{4 - Solicitação de cálculo}

1.4.1 - Ações antes da cura do concreto (resistência igual a 0,75 fck)

1.4.1.1 - Ações permanentes atuantes antes da cura do concreto

Viga de aço:

$$
\mathrm{F}_{\mathrm{G} 1 . \mathrm{k}}=0.7 \cdot \frac{\mathrm{kN}}{\mathrm{m}}
$$

Laje:

$$
F_{G 2 . k}=10.25 \cdot \frac{k N}{m}
$$

Fôrma incorporda:

$$
F_{\mathrm{G} 6 . k}=0.59 \cdot \frac{\mathrm{kN}}{\mathrm{m}}
$$

\subsubsection{2 - Ações variáveis atuantes antes da cura}

Sobrecarga de construção $\left(1 \mathrm{kN} / \mathrm{m}^{\wedge} 2\right): \ldots \ldots . . . \quad F_{\mathrm{Q} 1 . \mathrm{k}}=1 \frac{\mathrm{kN}}{\mathrm{m}^{2}} \cdot \mathrm{l}=4 \cdot \frac{\mathrm{kN}}{\mathrm{m}}$

\subsection{2 - Combinações últimas de construção}

\subsubsection{1 - Carregamento distribuído}

$$
\begin{aligned}
& F_{a . d}=\sum_{i=1}^{m}\left(\gamma_{g i} \cdot F_{G i . k}\right)+\gamma_{q 1} \cdot F_{Q 1 . k}+\sum_{j=2}^{n}\left(\gamma_{q j} \cdot \psi_{0 j . e f} \cdot F_{Q j . k}\right) \\
& F_{a . d}=\gamma_{g 1} \cdot\left(F_{G 1 . k}+F_{G 2 . k}+F_{G 6 . k}\right)+\gamma_{q 1} \cdot F_{Q 1 . k} \\
& F_{a . d}=20.2 \cdot \frac{\mathrm{kN}}{\mathrm{m}}
\end{aligned}
$$

\subsubsection{2 - Carregamento pontual}

$$
\begin{aligned}
& P_{a . d}=\sum_{i=1}^{m}\left(\gamma_{g i} \cdot P_{G i . k}\right)+\gamma_{q 1} \cdot P_{Q 1 . k}+\sum_{j=2}^{n}\left(\gamma_{q j} \cdot \psi_{0 j . e f} \cdot P_{Q j . k}\right) \\
& P_{a . d}=0 k N \\
& P_{a . d}=0 \cdot k N
\end{aligned}
$$

1.4.2.3 - Momento fletor solicitante (ligação não atinge sua rigidez antes da cura)

$$
M_{\text {a.Sd.p }}=\frac{F_{\text {a.d }} \cdot L^{2}}{8}+\frac{P_{a . d} \cdot L}{4} \quad M_{a . S d . p}=204.48 \cdot \mathrm{kN} \cdot \mathrm{m}
$$


1.4.3 - Combinações raras de serviço das ações permanentes

1.4.3.1 - Carregamento distribuído

$$
\begin{aligned}
& \mathrm{F}_{\text {Ga.rar }}=\sum_{\mathrm{i}=1}^{\mathrm{m}} \mathrm{F}_{\mathrm{Gi.k}} \\
& \mathrm{F}_{\text {Ga.rar }}=\mathrm{F}_{\mathrm{G} 1 . \mathrm{k}}+\mathrm{F}_{\mathrm{G} 2 . \mathrm{k}}+\mathrm{F}_{\mathrm{G} 6 . \mathrm{k}} \\
& \mathrm{F}_{\text {Ga.rar }}=11.54 \cdot \frac{\mathrm{kN}}{\mathrm{m}}
\end{aligned}
$$

1.4.3.2 - Carregamento pontual

$$
P_{\text {Ga.rar }}=\sum_{i=1}^{m} P_{\text {Gi.k }}
$$

$$
P_{\text {Ga.rar }}=0 \mathrm{kN} \quad \mathrm{P}_{\text {Ga.rar }}=0 \cdot \mathrm{kN}
$$

1.4.3.3 - Momento fletor solicitante

$\mathrm{M}_{\text {Ga.Srar.p }}=\frac{\mathrm{F}_{\text {Ga.rar }} \cdot \mathrm{L}^{2}}{8}+\frac{\mathrm{P}_{\text {Ga.rar }} \cdot \mathrm{L}}{4} \quad \mathrm{M}_{\text {Ga.Srar.p }}=116.79 \cdot \mathrm{kN} \cdot \mathrm{m}$

$\mathrm{M}_{\mathrm{Ga} . S r a r . n}=0 \mathrm{kN} \cdot \mathrm{m} \quad$ (ligação não atinge sua rigidez antes da cura) 
2 - Estados-limites últimos (ELU)

2.1 - Flambagem local alma - FLA

2.1.1 - Parâmetro de esbeltez

$$
\begin{array}{ll}
\lambda=\frac{\mathrm{h}}{\mathrm{t}_{\mathrm{w}}} & \lambda=68.89
\end{array}
$$

2.1.2 - Parâmetro de esbeltez correspondente à plastificação

$$
\lambda_{p}=3.76 \cdot \sqrt{\frac{E}{f_{y}}} \quad \lambda_{p}=90.53
$$

2.1.3 - Parâmetro de esbeltez correspondente ao início do escoamento

$$
\lambda_{r}=5.70 \cdot \sqrt{\frac{E}{f_{y}}} \quad \lambda_{r}=137.24
$$

2.1.4 - Momento resistente de cálculo para flambagem local da alma Momento de proporcionalidade:

$$
M_{r}=W_{a x} \cdot f_{y}=209.61 \cdot k N \cdot m
$$

Momento de plastificação:

$$
M_{p l}=Z_{a x} \cdot f_{y}=248.74 \cdot k N \cdot m
$$

$$
M_{R d a}=\mid \begin{aligned}
& \frac{M_{p l}}{\gamma_{a} 1} \text { if } \lambda \leq \lambda_{p} \\
& \frac{1}{\gamma_{a} 1} \cdot\left[M_{p l}-\left(M_{p l}-M_{r}\right) \cdot \frac{\lambda-\lambda_{p}}{\lambda_{r}-\lambda_{p}}\right] \text { if } \lambda_{p}<\lambda \leq \lambda_{r} \\
& \text { "'Viga esbelta!" if } \lambda>\lambda_{r}
\end{aligned}
$$

$M_{\text {Rda }}=226.13 \cdot \mathrm{kN} \cdot \mathrm{m} \quad$ Situação $=" \lambda<\lambda p^{\prime \prime}$

2.2 - Flambagem local da mesa - FLM

\subsection{1 - Parâmetro de esbeltez}

$$
\lambda=\frac{b_{f}}{2 \cdot t_{f}} \quad \lambda=7.5
$$

2.2.2 - Parâmetro de esbeltez correspondente à plastificação

$$
\begin{array}{ll}
\lambda_{p}=0.38 \sqrt{\frac{E}{f_{y}}} \quad \lambda_{p}=9.15
\end{array}
$$


2.2.3 - Parâmetro de esbeltez correspondente ao início do escoamento

$$
\lambda_{\mathrm{r}}=\mathrm{k}_{1} \cdot \sqrt{\frac{\mathrm{E}}{\frac{\mathrm{f}_{\mathrm{y}}-\mathrm{f}_{\mathrm{r}}}{k_{\mathrm{c}}}}}
$$

Onde: $k_{1}=0.95$ (perfil = "soldado" $)$

$$
\mathrm{k}_{\mathrm{c}}=0.482
$$

\subsection{4 - Momento resistente de cálculo para flambagem local da mesa}

Momento de proporcionalidade:

$$
M_{r}=W_{a x} \cdot\left(f_{y}-f_{r}\right)=146.73 \cdot k N \cdot m
$$

Momento de plastificação:

$$
\mathrm{M}_{\mathrm{pl}}=\mathrm{Z}_{\mathrm{ax}} \cdot \mathrm{f}_{\mathrm{y}}=248.74 \cdot \mathrm{kN} \cdot \mathrm{m}
$$

Momento fletor de flambagem elástica:........ $M_{\mathrm{cr}}=\frac{\mathrm{k}_{2} \cdot \mathrm{E} \cdot \mathrm{k}_{\mathrm{C}} \cdot \mathrm{W}_{\mathrm{ax}}}{\lambda^{2}}=936.97 \cdot \mathrm{kN} \cdot \mathrm{m}$

$$
M_{R d m}=\mid \begin{aligned}
& \frac{M_{p l}}{\gamma_{a 1}} \text { if } \lambda \leq \lambda_{p} \\
& \frac{1}{\gamma_{a 1}} \cdot\left[M_{p l}-\left(M_{p l}-M_{r}\right) \cdot \frac{\lambda-\lambda_{p}}{\lambda_{r}-\lambda_{p}}\right] \text { if } \quad \lambda_{p}<\lambda \leq \lambda_{r} \\
& \frac{M_{\mathrm{cr}}}{\gamma_{a 1}} \text { if } \lambda>\lambda_{r}
\end{aligned}
$$

Onde: $\mathrm{k}_{2}=0.9$ (perfil = "soldado" $)$

$$
\mathrm{k}_{\mathrm{c}}=0.482
$$

Situação $=" \lambda<\lambda p "$

$\mathrm{M}_{\mathrm{Rdm}}=226.13 \cdot \mathrm{kN} \cdot \mathrm{m}$

\section{3 - Flambagem lateral com torção - FLT}

Considera-se qua a fôrma de aço impede a flambagem lateral com torção.

\section{4 - Momento Resistente de Cálculo}

\subsection{1 - Momento resistente de cálculo para flambagem local da alma}

$\mathrm{M}_{\mathrm{Rda}}=226.13 \cdot \mathrm{kN} \cdot \mathrm{m}$ 
2.4.2 - Momento resistente cálculo para flambagem local da mesa $M_{R d m}=226.13 \cdot \mathrm{kN} \cdot \mathrm{m}$

2.4.3 - Momento limite para validade da análise elástica $\mathrm{M}_{\mathrm{lim}}=1.50 \cdot \mathrm{W}_{\mathrm{ax}} \cdot \frac{\mathrm{f}_{\mathrm{y}}}{\gamma_{\mathrm{a} 1}} \quad \mathrm{M}_{\mathrm{lim}}=285.83 \cdot \mathrm{kN} \cdot \mathrm{m}$

2.4.4 - Momento resistente de cálculo

$$
M_{\text {a.Rd.p }}=\min \left(M_{\text {Rda }}, M_{R d m}, M_{\text {lim }}\right) \quad M_{\text {a.Rd.p }}=226.13 \cdot \mathrm{kN} \cdot \mathrm{m}
$$

2.5 - Momento solicitante de cálculo

$\mathrm{M}_{\mathrm{a} . \mathrm{Sd} . \mathrm{p}}=204.48 \cdot \mathrm{kN} \cdot \mathrm{m}$

2.6 - Verificação da resistência ao momento fletor

Momento solicitante de cálculo $M_{a . S d . p}=204.48 \cdot \mathrm{kN} \cdot \mathrm{m}$

Momento resistente de cálculo: $M_{a . R d . p}=226.13 \cdot k N \cdot m$

$\frac{M_{a . S d . p}}{M_{a . R d . p}}=0.9$

Verificação_Ma.Sd.p = "ok!"

3 - Estados-limites de serviço de deslocamentos excecssivos

3.1 - Flecha crítica ( Vão = "EXTREMO" )

$\delta_{\mathrm{Ga}}=\frac{5 \cdot \mathrm{F}_{\mathrm{Ga} \cdot \mathrm{rar}} \cdot \mathrm{L}^{4}}{384 \cdot \mathrm{E} \cdot \mathrm{l}_{\mathrm{ax}}}+\frac{\mathrm{P}_{\mathrm{Ga} \cdot \mathrm{rar} \cdot \mathrm{L}^{3}}}{48 \cdot \mathrm{E} \cdot \mathrm{l}_{\mathrm{ax}}} \quad \delta_{\mathrm{Ga}}=36.04 \cdot \mathrm{mm}$

3.2 - Deslocamento máximo para vigas de piso

$\delta_{\lim }=\frac{\mathrm{L}}{350}$

$\delta_{\lim }=25.71 \cdot \mathrm{mm}$

3.3 - Verificação dos deslocamentos

$\frac{\delta_{\mathrm{Ga}}}{\delta_{\lim }}=1.4$

Verificação_do_ $\delta$ Ga $=$ "não ok!" 


\section{VERIFICAÇÃO DA SEÇÃO MISTA}

\section{1 - Dados de entrada}

\section{1 - Propriedades geométricas}

\subsection{1 - Perfil de aço ( Bitola = "PS 450 × 37" )}

Área bruta: $A_{a}=46.54 \cdot \mathrm{cm}^{2}$

Altura do perfil.

$\mathrm{d}=450 \cdot \mathrm{mm}$

Largura da mesa:

$b_{f}=120 \cdot m m$

Espessura da mesa:

$t_{f}=8 \cdot \mathrm{mm}$

Área da mesa superior:

$A_{a f}=b_{f} \cdot t_{f}=9.6 \cdot \mathrm{cm}^{2}$

Altura da alma:

$\mathrm{h}=434 \cdot \mathrm{mm}$

Distância entre os centróides das mesas:. $\quad h_{0}=h+t_{f}=442 \cdot m m$

Espessura da alma:

$t_{w}=6.3 \cdot m m$

Área da alma:

$A_{a w}=h \cdot t_{w}=27.34 \cdot \mathrm{cm}^{2}$

Raio de giração $X$ :

$r_{a x}=17.14 \cdot c m$

Raio de giração Y:

$r_{a y}=2.23 \cdot \mathrm{cm}$

Momento de inércia $\mathrm{X}$ :

$\mathrm{l}_{\mathrm{ax}}=13670.19 \cdot \mathrm{cm}^{4}$

Momento de inércia Y:

$I_{\text {ay }}=231.3 \cdot \mathrm{cm}^{4}$

Momento de inércia a torção:

$\mathrm{J}=7.71 \cdot \mathrm{cm}^{4}$

Módulo elástico $X$ :

$\mathrm{W}_{\mathrm{ax}}=607.56 \cdot \mathrm{cm}^{3}$

Módulo elástico Y:

$\mathrm{W}_{\mathrm{ay}}=38.55 \cdot \mathrm{cm}^{3}$

Módulo plástico X:

$\mathrm{Z}_{\mathrm{ax}}=720.98 \cdot \mathrm{cm}^{3}$

Módulo plástico Y:

$Z_{\text {ay }}=61.91 \cdot \mathrm{cm}^{3}$

Constante de empenamento:

$$
C_{w}=112971.35 \cdot \mathrm{cm}^{6}
$$

Distância do centróide até a face superior: $\quad d_{1}=\frac{d}{2}=225 \cdot \mathrm{mm}$ 


\subsection{2 - Conector de cisalhamento ("stud bolt")}

Diâmetro do fuste:

Área da seção transversal:

Comprimento antes da soldagem:

Redução pino após a solda:

Comprimento final:

Número de conectores entre o momento positivo máximo e o nulo:

Número de conectores entre o momento negativo máximo e o nulo:

Coeficiente para considerar o efeito de atuação de grupos:

Coeficiente para consideração da posição do conector:

$$
\mathrm{d}_{\mathrm{cs}}=19 \cdot \mathrm{mm}
$$

$A_{c s}=2.84 \cdot \mathrm{cm}^{2}$

$\mathrm{L}_{\mathrm{cs}}=135 \cdot \mathrm{mm}$

$\Delta \mathrm{L}_{\mathrm{cs}}=9 \cdot \mathrm{mm}$

$\mathrm{h}_{\mathrm{cs}}=\mathrm{L}_{\mathrm{cs}}-\Delta \mathrm{L}_{\mathrm{cs}}=126 \cdot \mathrm{mm}$

$\mathrm{n}_{\mathrm{cs} . \mathrm{p}}=10$

$n_{\text {cs.n }}=3$

\subsection{3 - Laje mista ("steel deck")}

Altura da pré-laje ou das nervuras da laje: $h_{F}=75 \cdot \mathrm{mm}$

Altura de concreto acima da pré-laje:

$\mathrm{t}_{\mathrm{c}}=65 \cdot \mathrm{mm}$

Largura média da mísula ou da nervura situada sobre o perfil de aço:

$b_{F}=137 \cdot m m$

Consumo de concreto:

$c_{\text {conc }}=0.1025 \cdot \frac{\mathrm{m}^{3}}{\mathrm{~m}^{2}}$

Espessura da fôrma incorporada:

$\mathrm{t}_{\mathrm{sd}}=1.25 \mathrm{~mm}$

Altura da argamassa de nivelamento:

$\mathrm{e}_{\mathrm{an}}=30 \mathrm{~mm}$

Largura de influência da laje:

$$
I=4 \mathrm{~m}
$$

Cobrimento nominal da armadura (Tabela 7.2 NBR 6118:2003):

$\mathrm{c}_{\mathrm{nom}}=20 \mathrm{~mm}$ 
Taxa geométrica mínima de armadura

longitudinal (Tabela 17.3 NBR 6118:2003): $\rho_{\min }=0.0015$

Taxa geométrica de armadura aderente

passiva (Tabela 19.1 NBR 6118:2003):...... $\rho_{\mathrm{s}}=\rho_{\min }=0.0015$

Área de armadura longitudinal dentro da

largura efetiva:

$A_{s l}=5.03 \cdot \mathrm{cm}^{2}$

Número de barras longitudinais:

$\mathrm{n}_{\phi}=10$ barras de $\phi=8 \cdot \mathrm{mm}$

Abertura máxima característica das

fissuras $($ Agressividade $=$ "moderada" $) .. . \quad w_{k}=0.3 \cdot \mathrm{mm}$

\subsection{4 - Sistema estrutural}

Tipo de viga mista (Viga_mista):

Sistema construtivo (Sistema_construtivo )

Posição do vão (Vão ):

Comprimento do vão da viga :

$\mathrm{L}=9000 \mathrm{~mm}$

Comprimento destravado :

$L_{b}=9000 m m$

Comprimento do vão adjacente:

$\mathrm{L}_{1}=9000 \mathrm{~mm}$

Comprimento do pé direito:

$\mathrm{L}_{p d}=3500 \mathrm{~mm}$

Comprimento do trecho de momento positivo:

$\mathrm{L}_{\mathrm{e}}=7200 \cdot \mathrm{mm}$

Trecho esquerdo ao eixo da viga $\left(T_{e}\right): \ldots .$.

Trecho direito ao ao eixo da viga $\left(T_{d}\right): \ldots \ldots$.

Distância entre eixo das vigas do trecho esquerdo:

$d_{v . e}=4000 m m$

Distância entre eixo das vigas do trecho direito:

$d_{v . d}=4000 m m$

Distância entre o eixo da viga e a borda da laje em balanço:

$d_{b}=0 m m$ 


\section{2 - Propriedades mecânicas dos materiais}

\subsection{1 - Perfil de aço (ASTM A572 - Grau 50)}

Resistência característica ao escoamento: $\mathrm{f}_{\mathrm{y}}=34.5 \frac{\mathrm{kN}}{\mathrm{cm}^{2}}$

Resistência característica à ruptura:............. $\mathrm{f}_{\mathrm{u}}=45 \frac{\mathrm{kN}}{\mathrm{cm}^{2}}$

Tensões residuais:

$f_{r}=0.3 f_{y}=10.35 \cdot \frac{\mathrm{kN}}{\mathrm{cm}^{2}}$

Módulo de elasticidade longitudinal:........... $\mathrm{E}=20000 \frac{\mathrm{kN}}{\mathrm{cm}^{2}}$

\subsection{2 - Conector de cisalhamento (aço baixo carbono)}

Resistência característica ao escoamento: $f_{y c s}=35 \frac{\mathrm{kN}}{\mathrm{cm}^{2}}$

Resistência característica à ruptura

$f_{u c s}=45 \frac{\mathrm{kN}}{\mathrm{cm}^{2}}$

\subsection{3 - Laje mista}

\subsubsection{1 - Concreto (C20)}

Resistência característica à compressão:.. $\mathrm{f}_{\mathrm{ck}}=2 \cdot \frac{\mathrm{kN}}{\mathrm{cm}^{2}}$

Resistência característica à tração:............... $\mathrm{f}_{\mathrm{ctm}}=0.3 \cdot\left(\frac{\mathrm{f}_{\mathrm{ck}}}{\mathrm{MPa}}\right)^{\frac{2}{3}} \cdot \mathrm{MPa}=0.22 \cdot \frac{\mathrm{kN}}{\mathrm{cm}^{2}}$

Módulo de Elasticidade Secante:.................. $\mathrm{E}_{\mathrm{c}}=0.85 \cdot 5600 \cdot \sqrt{\frac{\mathrm{f}_{\mathrm{ck}}}{\mathrm{MPa}}} \cdot \mathrm{MPa}$

$$
\mathrm{E}_{\mathrm{c}}=2128.74 \cdot \frac{\mathrm{kN}}{\mathrm{cm}^{2}}
$$

\subsubsection{2 - Fôrma incorporada (ASTM A653 - Grau 40)}

Resistência característica ao escoamento: $\mathrm{f}_{\mathrm{yF}}=28 \frac{\mathrm{kN}}{\mathrm{cm}^{2}}$ 


\section{$\underline{\text { 1.2.3.3 - Armadura (CA-50) }}$}

Resistência característica ao escoamento: $f_{y s}=50 \frac{\mathrm{kN}}{\mathrm{cm}^{2}}$

\subsection{4 - Ligação}

Capacidade de rotação:

$$
\beta_{\mathrm{vm}}=1
$$

\section{3 - Coeficiente de ponderação e fator de redução}

\subsection{1 - Coeficiente de ponderação das ações (combinações normais)}

Açoes permanentes diretas agrupadas:.... $\quad \gamma_{\mathrm{g} 1}=1.4$

Demais ações variáveis, icluindo as decorrentes do uso e ocupação:

$$
\gamma_{q 1}=1.5
$$

1.3.2 - Fatores de combinação $\left(\psi_{0}\right)$ e redução $\left(\psi_{1}\right.$ e $\left.\psi_{2}\right)$ para ações variáveis Pressão dinâmica do vento nas estruturas em geral:

$$
\psi_{0_{1}}=0.6 \quad \psi_{1_{1}}=0.3 \quad \psi_{2_{1}}=0
$$

Locais em que há predominância de elevadas concentrações de pessoas:

$$
\psi_{0_{2}}=0.7 \quad \psi_{1_{2}}=0.6 \quad \psi_{2_{2}}=0.4
$$

\subsection{3 - Coeficientes de ponderação das resistências (combinações normais)}

Escoamento do aço estrutural: $\gamma_{\mathrm{a} 1}=1.10$

Ruptura do aço estrutural:

$$
\gamma_{\mathrm{a} 2}=1.35
$$

Aço das armaduras:

$$
\gamma_{\mathrm{s}}=1.15
$$

Concreto:

$$
\gamma_{c}=1.40
$$

Conector: 


\section{4 - Solicitação de cálculo}

1.4.1 - Peso específico dos materiais de construção e valores mínimos das cargas e sobrecagas atuantes (NBR 6120: 1980)

\subsubsection{1 - Peso específico}

Peso específico do concreto:

$\gamma_{\text {conc }}=25 \frac{\mathrm{kN}}{\mathrm{m}^{3}}$

Peso específico do revestimento:

$\gamma_{\text {rev }}=19 \frac{\mathrm{kN}}{\mathrm{m}^{3}}$

\subsubsection{2 - Carregamento permanente}

Laje:

$$
G_{\text {laje }}=c_{c o n c} \cdot \gamma_{c o n c}=2.56 \cdot \frac{\mathrm{kN}}{\mathrm{m}^{2}}
$$

Argamassa de nivelamento:

$\mathrm{G}_{\mathrm{an}}=\mathrm{e}_{\mathrm{an}} \gamma_{\mathrm{rev}}=0.57 \cdot \frac{\mathrm{kN}}{\mathrm{m}^{2}}$

Acabamento (carpete):

$$
\mathrm{G}_{\mathrm{aca}}=0.05 \frac{\mathrm{kN}}{\mathrm{m}^{2}}
$$

Fôrro e serviços:

$$
\mathrm{G}_{\mathrm{fes}}=0.5 \frac{\mathrm{kN}}{\mathrm{m}^{2}}
$$

Fôrma incoporada:

$$
G_{F}=0.15 \cdot \frac{\mathrm{kN}}{\mathrm{m}^{2}}
$$

Divisórias móveis:

$$
\mathrm{G}_{\mathrm{div}}=1 \frac{\mathrm{kN}}{\mathrm{m}^{2}}
$$

\subsubsection{3 - Sobrecarga de utilização}

Escritório e cobertura:

$$
Q_{\text {sob }}=2 \frac{\mathrm{kN}}{\mathrm{m}^{2}}
$$

\subsection{2 - Ações}

1.4.2.1 - Ações permanentes responsáveis pelos esforços na seção mista

Viga de aço: $F_{\mathrm{G} 1 . \mathrm{k}}=0.7 \frac{\mathrm{kN}}{\mathrm{m}} \quad$ (valor adotado)

Laje:

$$
F_{G 2 . k}=1 \cdot G_{\text {laje }}=10.25 \cdot \frac{\mathrm{kN}}{\mathrm{m}}
$$


Argamassa de nivelamento:

$$
F_{G 3 . k}=I \cdot G_{a n}=2.28 \cdot \frac{\mathrm{kN}}{\mathrm{m}}
$$

Acabamento (carpete):

$$
F_{G 4 . k}=I \cdot G_{a c a}=0.2 \cdot \frac{\mathrm{kN}}{\mathrm{m}}
$$

Forros e serviços:

$$
F_{G 5 . k}=1 \cdot G_{f e s}=2 \cdot \frac{k N}{m}
$$

Fôrma incorporda:

$$
F_{G 6 . k}=1 \cdot G_{F}=0.59 \cdot \frac{\mathrm{kN}}{\mathrm{m}}
$$

Divisórias móveis:

$$
F_{G 7 . k}=1 \cdot G_{\text {div }}=4 \cdot \frac{\mathrm{kN}}{\mathrm{m}}
$$

1.4.2.2 - Ações variáveis responsáveis pelos esforços na seção mista

Escritório e cobertura:................................. $F_{\mathrm{Q} 1 . \mathrm{k}}=\mathrm{I} \cdot \mathrm{Q}_{\mathrm{Sob}}=8 \cdot \frac{\mathrm{kN}}{\mathrm{m}}$

1.4.2.3 - Ações permanentes responsáveis pelos deslocamentos na seção mista

Argamassa de nivelamento:

$F_{\mathrm{G} 3 . \mathrm{k}}=2.28 \cdot \frac{\mathrm{kN}}{\mathrm{m}}$

Acabamento (carpete):

$$
\mathrm{F}_{\mathrm{G} 4 . \mathrm{k}}=0.2 \cdot \frac{\mathrm{kN}}{\mathrm{m}}
$$

Forros e serviços:

$$
F_{G 5 . k}=2 \cdot \frac{k N}{m}
$$

Divisórias móveis:

$$
F_{G 7 . k}=4 \cdot \frac{k N}{m}
$$

\subsubsection{4 - Ações variáveis responsáveis pelos deslomentos na seção mista}

Escritório e cobertura:

$$
F_{Q 1 . k}=8 \cdot \frac{k N}{m}
$$




\subsection{3 - Combinações últimas normais}

\subsubsection{1 - Carregamento pontual $(\mathrm{P})$}

$P_{d}=\sum_{i=1}^{m}\left(\gamma_{g i} \cdot P_{G i . k}\right)+\gamma_{q 1} \cdot P_{Q 1 . k}+\sum_{j=2}^{n}\left(\gamma_{q j} \cdot \psi_{0 j} \cdot P_{Q j . k}\right)$

$\mathrm{P}_{\mathrm{d}}=0 \mathrm{kN}$

\subsubsection{2 - Carregamento distribuído (F)}

$F_{d}=\sum_{i=1}^{m}\left(\gamma_{g i} \cdot F_{G i . k}\right)+\gamma_{q 1} \cdot F_{Q 1 . k}+\sum_{j=2}^{n}\left(\gamma_{q j} \cdot \psi_{0 j} \cdot F_{Q j . k}\right)^{\text {I }}$
$F_{d}=\gamma_{g 1} \cdot\left(\begin{array}{l}F_{G 1 . k}+F_{G 2 . k}+F_{G 3 . k}+F_{G 4 . k} \cdots \\ +F_{G 5 . k}+F_{G 6 . k}+F_{G 7 . k}\end{array}\right)+\gamma_{q 1} \cdot F_{Q 1 . k}$

$F_{d}=40.02 \cdot \frac{\mathrm{kN}}{\mathrm{m}}$

1.4.3.3 - Análise global elástica-linear - modelo fissurado (EN 1994-1-1:2004)

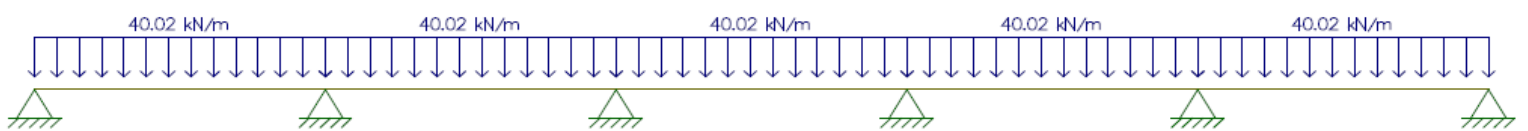

Figura 1.1 - Carregamento

A seção enquadra-se na Classe 2 pelo EN 1993-1-1:2005. Desta forma, de acordo com a Tabela 5.1 do EN 1994-1-1:2004 (2004), pode-se fazer a redistribuição de momento de até $15 \%$ para o modelo fissurado.

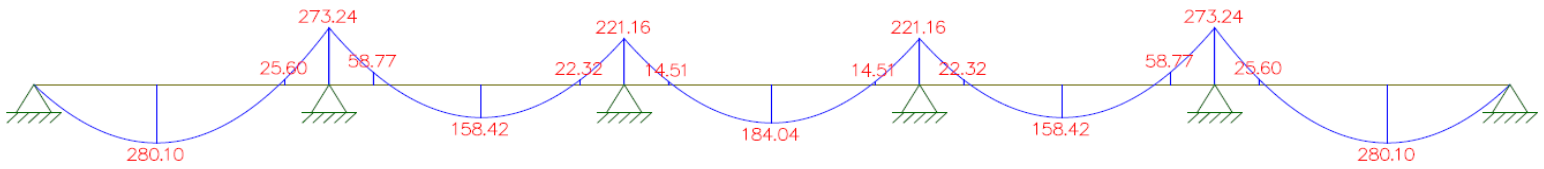

Figura 1.2 - Distribuição elástica dos momentos

Fazendo-se a redistribuição de 15\% (Figura 1.2):

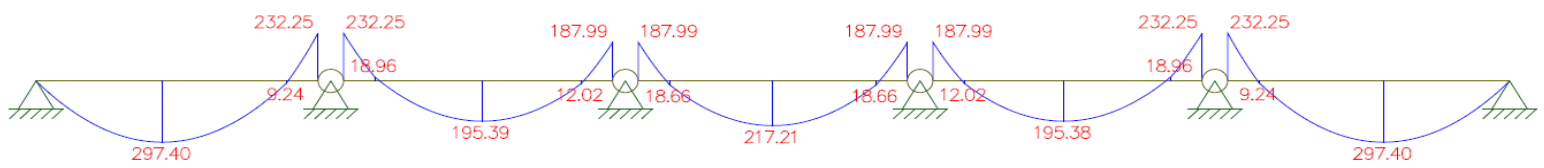

Figura 1.3 - Redistribuição dos momentos 
1.4.3.4 - Diagrama de momento fletor do vão analisado (1-6)

Diagrama_de_momento_fletor $=1 \quad$ (Vão = "EXTREMO" )

1.4.3.5 - Momento fletor solicitante positivo crítico

$M_{\text {Sd.p }}=297.4 \mathrm{kN} \cdot \mathrm{m} \quad($ Vão $=$ "EXTREMO" $)$

1.4.3.6 - Momento fletor solicitante negativo crítico

$M_{S d . n}=232.25 \mathrm{kN} \cdot \mathrm{m} \quad($ Vão $=$ "EXTREMO" $)$

1.4.3.7 - Esforco cortante crítico

$\mathrm{V}_{\mathrm{Sd}}=218 \mathrm{kN} \quad($ Vão $=$ "EXTREMO" )

\subsection{4 - Combinações raras de serviço}

$$
F_{\text {rar }}=\sum_{i=1}^{m} F_{G i . k}+F_{Q 1 . k}+\sum_{j=2}^{n}\left(\psi_{1 j} \cdot F_{Q j . k}\right)^{\text {I }}
$$

1.4.4.1 - Combinação dos carregamentos de curta duração $\left(E_{c}\right)$

1.4.4.1.1 - Sobrecarga subtraída parcela quase permanente

$$
F_{\text {rar }}=F_{Q 1 . k} \cdot\left(1-\psi_{2}\right) \quad F_{\text {rar }}=4.8 \cdot \frac{\mathrm{kN}}{\mathrm{m}}
$$

1.4.4.2 - Combinação dos carregamentos de longa duração ( $E_{c} / 3$ )

1.4.4.2.1 - Ações permanentes + parcela quase permanente da sobrecarga

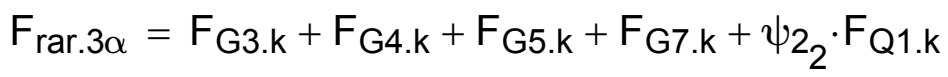

$$
\begin{aligned}
& F_{\text {rar. } 3 \alpha}=11.68 \cdot \frac{\mathrm{kN}}{\mathrm{m}}
\end{aligned}
$$

1.4.4.3 - Combinacão dos carregamentos para procedimento alternativo $\left(E_{\underline{c}} \underline{/ 2}\right)$

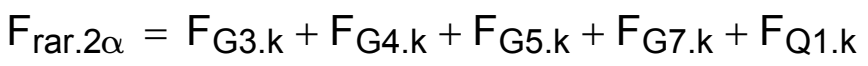

$$
\begin{aligned}
& F_{\text {rar. } 2 \alpha}=16.48 \cdot \frac{\mathrm{kN}}{\mathrm{m}}
\end{aligned}
$$


1.4.4.4 - Análise global elástica-linear - modelo não-fissurado (EN 1994-1-1:2004)

A seção enquadra-se na Classe 2 pelo EN 1993-1-1:2005. A redistribuição de momento é feita de acordo com a Figura 7.1 do EN 1994-1-1:2004, considerando o modelo não-fissurado.

1.4.4.4.1 - Análise dos carregamentos de curta duração

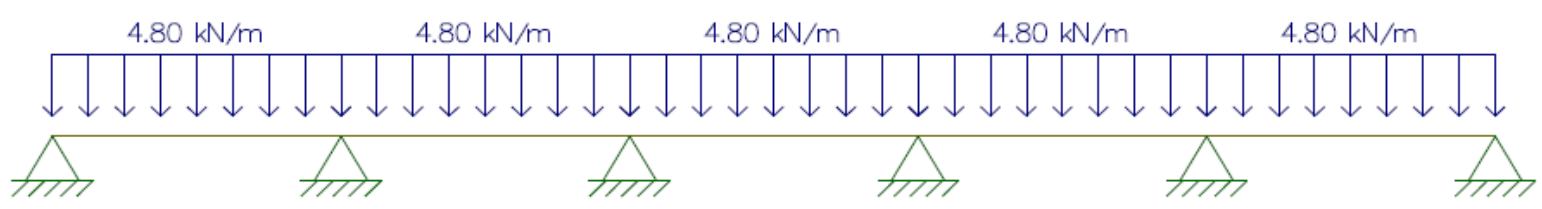

Figura 1.4 - Carregamento

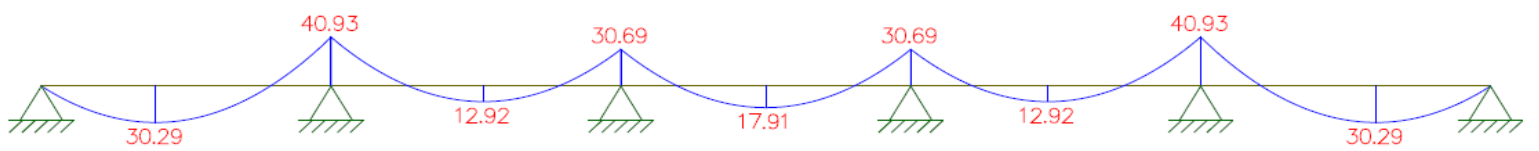

Figura 1.5 - Distribuição elástica dos momentos

Momento fletor solicitante positivo crítico referente às cargas de curta duração:

ML.Srar.p. $=30.29 \mathrm{kN} \cdot \mathrm{m} \quad$ (Vão = "EXTREMO" )

Momento fletor solicitante negativo crítico referente às cargas de curta duração:

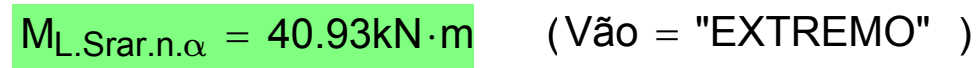

Fazendo-se a redistribuição dos momentos (item 3.1.8.3):

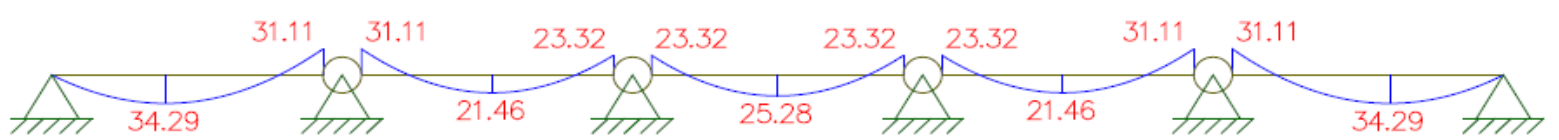

Figura 1.6 - Redistribuição dos momentos

Flecha referente aos carregamentos de curta duração:

$\delta_{\alpha}=3.10 \mathrm{~mm} \quad$ (Vão = "EXTREMO" ) 
1.4.4.4.2 - Análise dos carregamentos de longa duração

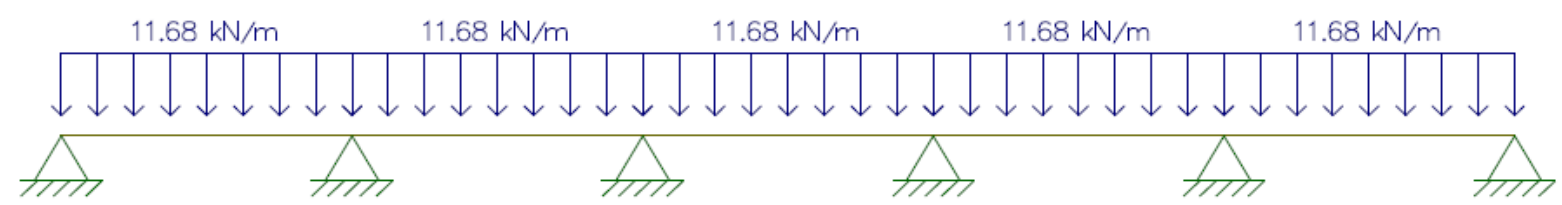

Figura 1.7 - Carregamento

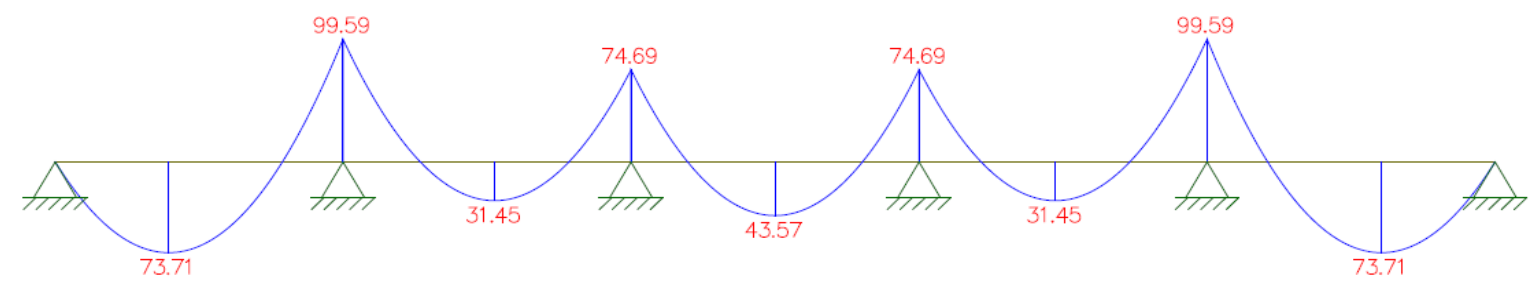

Figura 1.8 - Distribuição elástica dos momentos

Momento fletor solicitante positivo crítico referente às cargas de longa duração:

$M_{\mathrm{L} . S r a r . p .3 \alpha}=73.71 \mathrm{kN} \cdot \mathrm{m} \quad$ (Vão = "EXTREMO" )

Momento fletor solicitante negativo crítico referente às cargas de longa duração:

$\mathrm{M}_{\mathrm{L} . \text { Srar.n. } 3 \alpha}=99.59 \mathrm{kN} \cdot \mathrm{m} \quad($ Vão = "EXTREMO" $)$

Fazendo-se a redistribuição dos momentos (item 3.1.8.3):

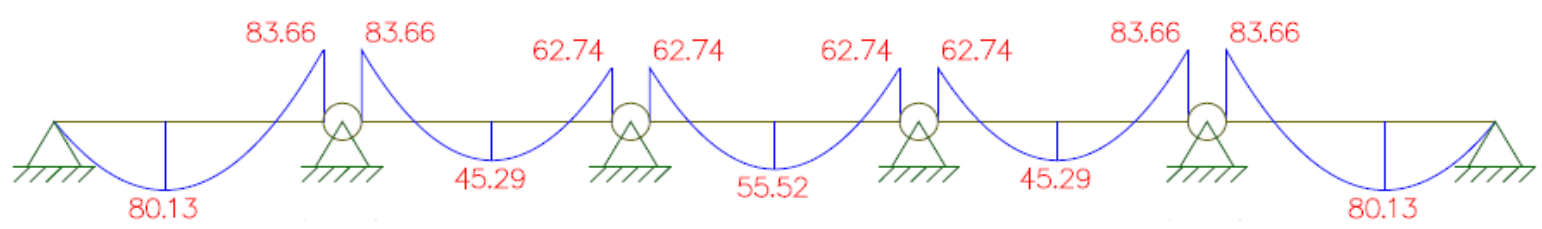

Figura 1.9 - Redistribuição dos momentos

Flecha referente aos carregamentos de longa duração:

$\delta_{3 \alpha}=9.26 \mathrm{~mm} \quad($ Vão $=$ "EXTREMO" ) 
1.4.4.4.3 - Análise para procedimento alternativo

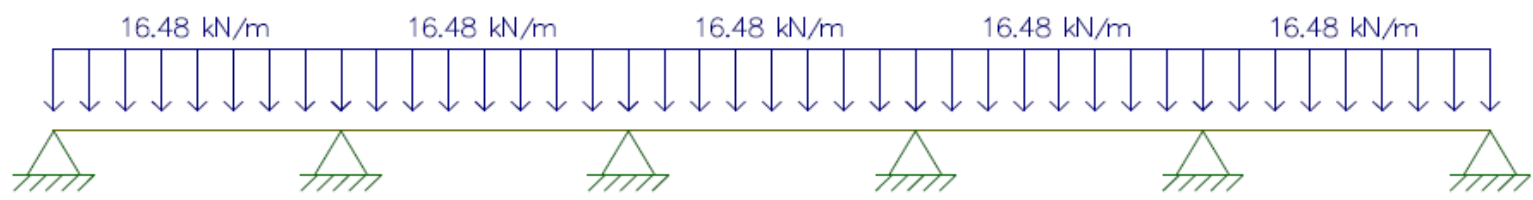

Figura 1.10 - Carregamento

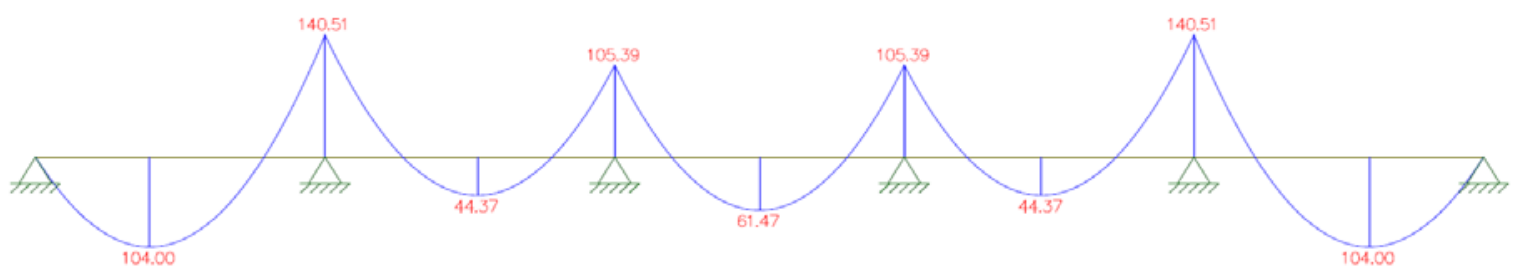

Figura 1.11 - Distribuição elástica dos momentos

Fazendo-se a redistribuição dos momentos (item 3.1.8.3):

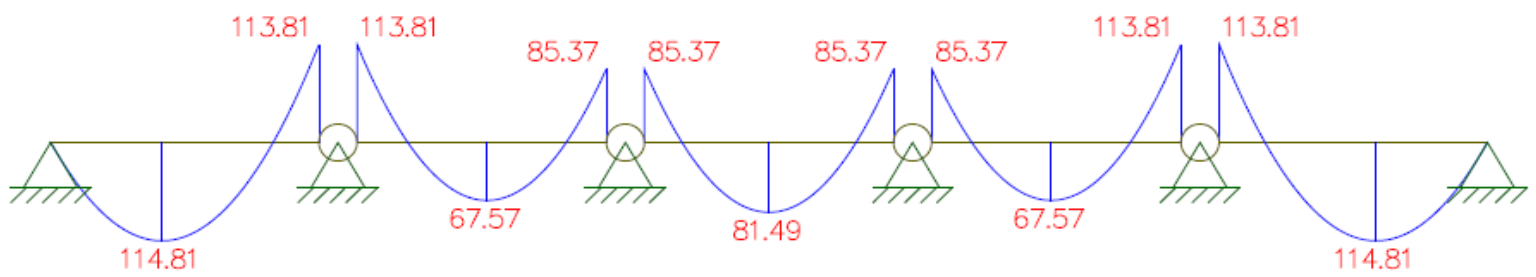

Figura 1.12 - Redistribuição dos momentos

Flecha referente ao procedimento alternativo (item 1.4.4.3):

$\delta_{2 \alpha}=11.94 \mathrm{~mm} \quad$ (Vão = "EXTREMO" )

\subsection{5 - Combinações frequentes de serviço}

$$
\begin{aligned}
& F_{\text {fre }}=\sum_{i=1}^{m} F_{G i . k}+\psi_{1} \cdot F_{Q 1 . k}+\sum_{j=2}^{n}\left(\psi_{2 j} \cdot F_{Q j . k}\right)^{I} \\
& F_{\text {fre }}=F_{G 3 . k}+F_{G 4 . k}+F_{G 5 . k}+F_{G 7 . k}+\psi_{1} \cdot F_{Q 1 . k} \\
& F_{\text {fre }}=13.28 \cdot \frac{\mathrm{kN}}{\mathrm{m}}
\end{aligned}
$$


1.4.5.1 - Análise global elástica-linear - modelo fissurado (EN 1994-1-1:2004)

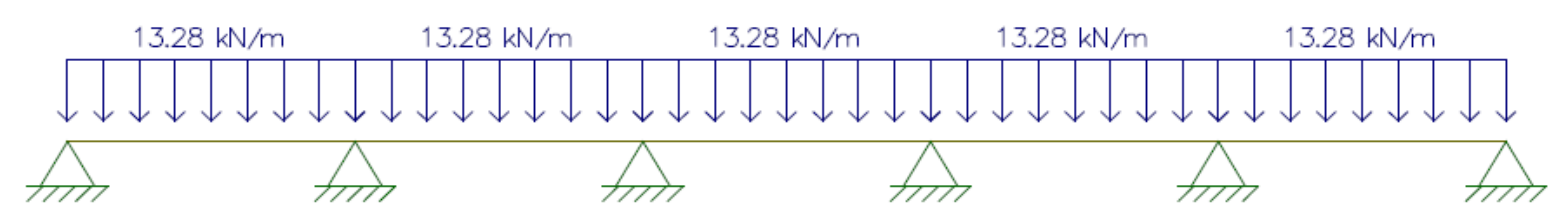

Figura 1.9 - Distribuição elástica dos momentos

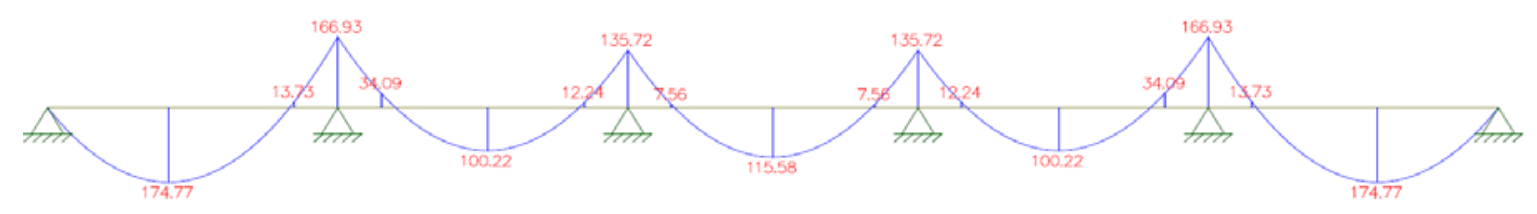

Figura 1.10 - Distribuição elástica dos momentos

1.4.5.2 - Momento fletor solicitante positivo crítico

$M_{\text {L.Sfre.p }}=92.95 \mathrm{kN} \cdot \mathrm{m} \quad($ Vão $=$ "EXTREMO" $)$

1.4.5.3 - Momento fletor solicitante negativo crítico

ML.Sfre.n $=90.67 \mathrm{kN} \cdot \mathrm{m} \quad($ Vão = "EXTREMO" $)$

\subsection{6 - Combinação característica - (EN 1990:2002)}

$E_{d}=\backslash\left\{G_{k, j} ; P ; Q_{k, 1} ; \psi_{0, i} \cdot Q_{k}, i\right\} j \geq 1 ; i>1$

Sendo:

$\mathrm{G}_{\mathrm{k}, \mathrm{j}}$ valor característico da ação permanente;

P valor representativo de uma ação de pré-esforço;

$Q_{k, 1}$ valor característico da ação variável de base da combinação 1

$\mathrm{Q}_{\mathrm{k}, \mathrm{i}} \quad$ valor característico da ação variável i;

$\psi_{0, \mathrm{i}}$ coeficiente para a determinação do valor de combinação de uma ação variável i.

Podendo a combinção de ações entre chaves ser expressa por:

$\sum_{j \geq 1} G_{k, j}+P+Q_{k, j}+\sum_{i>1}\left(\psi_{0, i} \cdot Q_{k}, i\right)$ 
Adaptando a expressão acima à NBR 8800:2008, segue:

1.4.6.1 - Carregamento pontual $(\mathrm{P})$

$P_{\text {car }}=\sum_{i=1}^{m} P_{G i, k}+P_{Q 1, k}+\sum_{j=2}^{n}\left(\psi_{0, j} \cdot P_{Q j, k}\right)$

$\mathrm{P}_{\text {car }}=0 \mathrm{kN}$

1.4.6.2 - Carregamento distribuído $(\mathrm{F})$

$$
\begin{aligned}
& F_{\text {car }}=\sum_{i=1}^{m} F_{G i, k}+F_{Q 1, k}+\sum_{j=2}^{n}\left(\psi_{0, j} \cdot F_{Q j, k}\right) \\
& F_{\text {car }}=\left(\begin{array}{l}
F_{G 1 . k}+F_{G 2 . k}+F_{G 3 . k}+F_{G 4 . k} \ldots \\
+F_{G 5 . k}+F_{G 6 . k}+F_{G 7 . k}
\end{array}\right)+F_{Q 1 . k} \\
& F_{\text {car }}=28.02 \cdot \frac{k N}{m}
\end{aligned}
$$

1.4.6.3 - Análise global elástica-linear - modelo não-fissurado (EN 1994-1-1:2004)

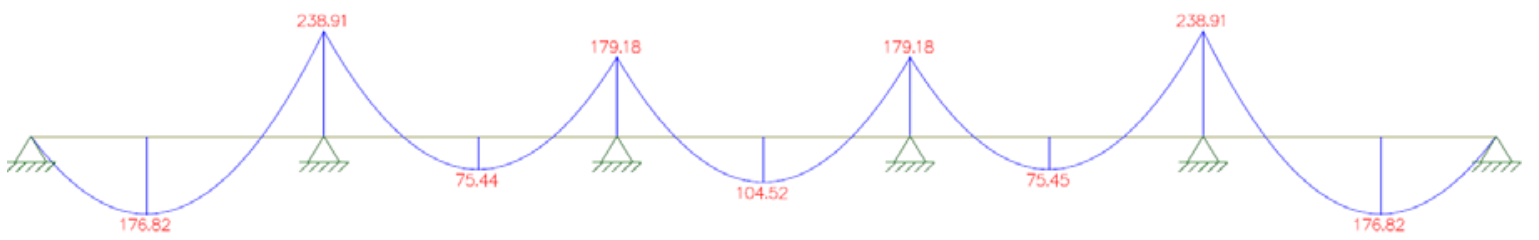

Figura 1.7 - Distribuição elástica dos momentos

1.4.6.3.1 - Momento fletor solicitante positivo crítico

$M_{\text {Scar.p }}=176.82 \mathrm{kN} \cdot \mathrm{m} \quad($ Vão $=$ "EXTREMO" $)$

1.4.6.3.2 - Momento fletor solicitante negativo crítico

$M_{\text {Scar.n }}=238.91 \mathrm{kN} \cdot \mathrm{m} \quad($ Vão = "EXTREMO" $)$ 


\section{2 - Estados-limites últimos (ELU)}

\section{1 - Verificação do momento fletor resistente de cálculo em regiões de momento positivo}

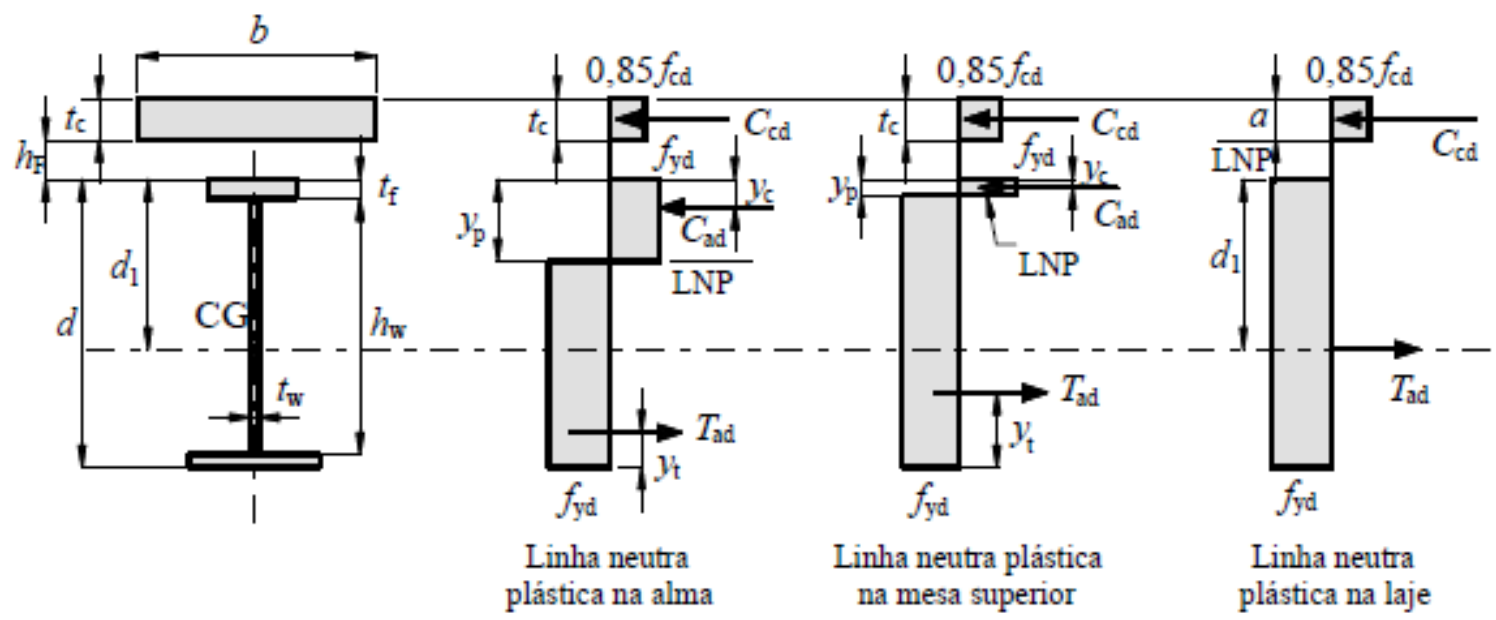

Figura 2.1 - Distribuição de tensões em vigas mistas de alma cheia sob momento positivo, $\frac{h}{t_{w}} \leq 3.76 \cdot \sqrt{\frac{E}{f_{y}}}$ e interação completa (NBR 8800:2008)

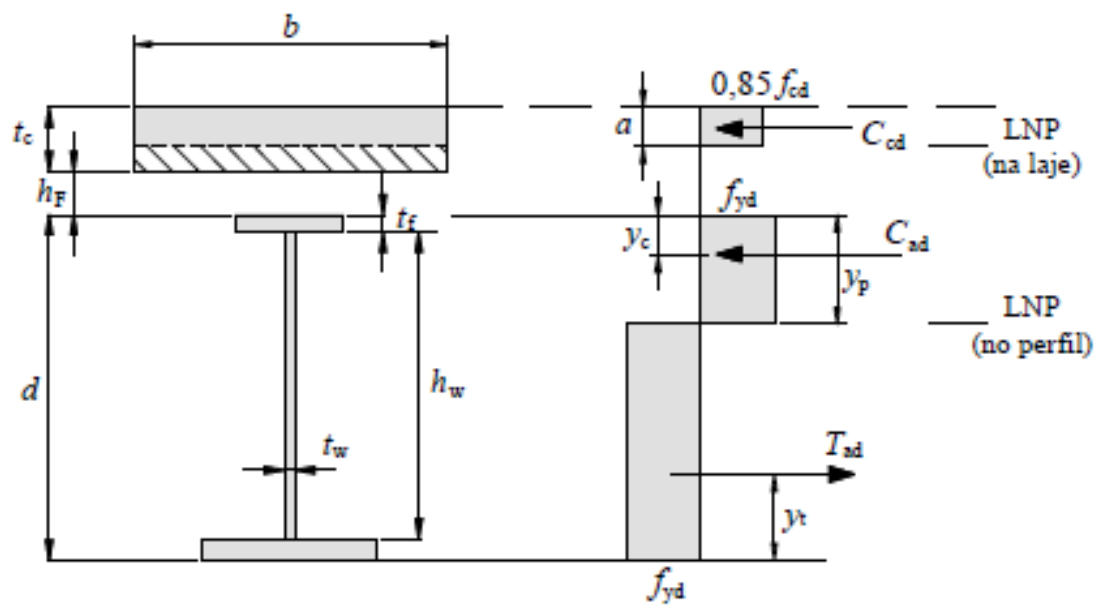

Figura 2.2 - Distribuição de tensões em vigas de alma cheia sob momento positivo,

$$
\frac{h}{t_{w}} \leq 3.76 \cdot \sqrt{\frac{E}{f_{y}}} \text { e interação parcial (NBR 8800:2008) }
$$




\subsection{1 - Determinação das resistências de cálculo}

2.1.1.1 - Resistência de cálculo ao escoamento do aço

$f_{y d}=\frac{f_{y}}{\gamma_{a 1}}$

$$
f_{y d}=31.36 \cdot \frac{\mathrm{kN}}{\mathrm{cm}^{2}}
$$

2.1.1.2 - Resistência de cálculo à compressão do concreto

$f_{c d}=\frac{f_{c k}}{\gamma_{c}}$

$$
\mathrm{f}_{\mathrm{cd}}=1.43 \cdot \frac{\mathrm{kN}}{\mathrm{cm}^{2}}
$$

2.1.1.3 - Resistência de cálculo ao escoamento das barras das armaduras

$$
f_{s d}=\frac{f_{y s}}{\gamma_{s}}
$$

$$
\mathrm{f}_{\mathrm{sd}}=43.48 \cdot \frac{\mathrm{kN}}{\mathrm{cm}^{2}}
$$

2.1.2 - Determinação da largura efetiva na região de momento positivo

$$
\begin{aligned}
& \mathrm{b}_{\mathrm{e}}=\mid \text { if Viga_mista }=\text { "BIAPOIADA" } \\
& \min \left(\frac{\mathrm{L}}{8}, \frac{\mathrm{d}_{\mathrm{V} . \mathrm{e}}}{2}\right) \text { if } \mathrm{T}_{\mathrm{e}}=\text { "INTERMEDIÁRIO" } \\
& \min \left(\frac{\mathrm{L}}{8}, \mathrm{~d}_{\mathrm{b}}\right) \text { if } \mathrm{T}_{\mathrm{e}}=\text { "BALANÇO" } \\
& \text { if Viga_mista }=\text { "CONTÍNUA" } \vee \text { Viga_mista }=\text { "SEMICONTÍNUA" } \\
& \min \left(\frac{4}{5} \cdot \frac{\mathrm{L}}{8}, \frac{\mathrm{d}_{\mathrm{V} . \mathrm{e}}}{2}\right) \text { if } \mathrm{T}_{\mathrm{e}}=\text { "INTERMEDIÁRIO" } \wedge \text { Vão = "EXTREMO" } \\
& \min \left(\frac{4}{5} \cdot \frac{\mathrm{L}}{8}, \mathrm{~d}_{\mathrm{b}}\right) \text { if } \mathrm{T}_{\mathrm{e}}=\text { "BALANÇO" } \wedge \text { Vão }=\text { "EXTREMO" } \\
& \min \left(\frac{7}{10} \cdot \frac{L}{8}, \frac{d_{\text {v.e }}}{2}\right) \text { if } T_{e}=\text { "INTERMEDIÁRIO" } \wedge \text { Vão = "INTERNO" } \\
& \min \left(\frac{7}{10} \cdot \frac{\mathrm{L}}{8}, \mathrm{~d}_{\mathrm{b}}\right) \text { if } \mathrm{T}_{\mathrm{e}}=\text { "BALANÇO" } \wedge \text { Vão = "INTERNO" } \\
& b_{e}=900 \cdot m m
\end{aligned}
$$




$$
\begin{aligned}
& \mathrm{b}_{\mathrm{d}}=\mid \text { if Viga_mista }=\text { "BIAPOIADA" } \\
& \min \left(\frac{\mathrm{L}}{8}, \frac{\mathrm{d}_{\mathrm{V} \cdot \mathrm{d}}}{2}\right) \text { if } \mathrm{T}_{\mathrm{d}}=\text { "INTERMEDIÁRIO" } \\
& \min \left(\frac{\mathrm{L}}{8}, \mathrm{~d}_{\mathrm{b}}\right) \text { if } \mathrm{T}_{\mathrm{d}}=\text { "BALANÇO" } \\
& \text { if Viga_mista }=\text { "CONTÍNUA" } \vee \text { Viga_mista }=\text { "SEMICONTÍNUA" } \\
& \min \left(\frac{4}{5} \cdot \frac{\mathrm{L}}{8}, \frac{\mathrm{d}_{\mathrm{v} . \mathrm{d}}}{2}\right) \text { if } \mathrm{T}_{\mathrm{d}}=\text { "INTERMEDIÁRIO" } \wedge \text { Vão = "EXTREMO" } \\
& \min \left(\frac{4}{5} \cdot \frac{\mathrm{L}}{8}, \mathrm{~d}_{\mathrm{b}}\right) \text { if } \mathrm{T}_{\mathrm{d}}=\text { "BALANÇO" } \wedge \text { Vão = "EXTREMO" } \\
& \min \left(\frac{7}{10} \cdot \frac{\mathrm{L}}{8}, \frac{\mathrm{d}_{\mathrm{V} \cdot \mathrm{d}}}{2}\right) \text { if } \mathrm{T}_{\mathrm{d}}=\text { "INTERMEDIÁRIO" } \wedge \text { Vão = "INTERNO" } \\
& \min \left(\frac{7}{10} \cdot \frac{\mathrm{L}}{8}, \mathrm{~d}_{\mathrm{b}}\right) \text { if } \mathrm{T}_{\mathrm{d}}=\text { "BALANÇO" } \wedge \text { Vão = "INTERNO" } \\
& b_{d}=900 \cdot m m \\
& b_{p}=b_{e}+b_{d} \\
& b_{p}=1800 \cdot m m
\end{aligned}
$$

\subsection{3 - Classificação da seção quanto a ocorrencia de flambagem local}

\subsubsection{1 - Parâmetro de esbeltez limite para seções compactas}

$\lambda_{p}=3.76 \cdot \sqrt{\frac{E}{f_{y}}}$

$$
\lambda_{p}=90.53
$$

\subsubsection{2 - Parâmetro de esbeltez limite para seções semicompactas}

$\lambda_{r}=5.70 \cdot \sqrt{\frac{E}{f_{y}}}$

$$
\lambda_{r}=137.24
$$

\subsubsection{3 - Índice de esbeltez da alma}

$$
\begin{array}{ll}
\lambda=\frac{\mathrm{h}}{\mathrm{t}_{\mathrm{w}}} & \lambda=68.89
\end{array}
$$

\subsubsection{4 - Classificação da seção}

$$
\text { Classificação_da_seção }=\mid \begin{aligned}
& \text { "compacta" if } \lambda \leq \lambda_{p} \\
& \text { "semicompacta" if } \lambda_{p}<\lambda \leq \lambda_{r} \\
& \text { "esbelta" if } \lambda>\lambda_{r}
\end{aligned}
$$

Classificação_da_seção = "compacta" 


\subsection{4 - Força resistente de cálculo dos conectores}

2.1.4.1 - Força resistente de cálculo de um conector:

$Q_{R d}=\min \left(\frac{1}{2} \cdot \frac{A_{c s} \cdot \sqrt{f_{c k} \cdot E_{c}}}{\gamma_{c s}}, \frac{R_{g} \cdot R_{p} \cdot A_{c s} \cdot f_{u c s}}{\gamma_{c s}}\right)$

$\mathrm{Q}_{\mathrm{Rd}}=74 \cdot \mathrm{kN}$

2.1.4.2 - Somatório das forças resistentes de cálculo individuais dos conectores de cisalhamento situados entre a seção do momento positivo máximo e a seção adjacente de momento nulo

$$
\sum_{n=1}^{n_{\text {cs.p }}} Q_{R d}=740 \cdot k N
$$

\subsection{5 - Tipo de interação entre o aço e o concreto}

2.1.5.1 - Máxima força resistente de cálculo à compressão da seção de concreto

$0.85 \cdot \mathrm{f}_{\mathrm{cd}} \cdot \mathrm{b}_{\mathrm{p}} \cdot \mathrm{t}_{\mathrm{c}}=1420.71 \cdot \mathrm{kN}$

\subsubsection{2 - Máxima força resistente de cálculo à tração da seção de aço}

$A_{a} \cdot f_{y d}=1459.73 \cdot k N$

\subsubsection{3 - Tipo de interação entre o aço eo concreto}

$$
\text { Interação }=\mid \begin{array}{ll}
\text { "completa" } & \text { if } \sum_{n=1}^{n_{\text {cs.p }}} Q_{R d} \geq A_{a} \cdot f_{y d} \wedge 0.85 \cdot f_{c d} \cdot b_{p} \cdot t_{c} \geq A_{a} \cdot f_{y d} \\
\text { "completa" } & \sum_{n=1}^{n_{\text {cs.p }}} Q_{R d} \geq 0.85 \cdot f_{c d} \cdot b_{p} \cdot t_{c} \wedge 0.85 \cdot f_{c d} \cdot b_{p} \cdot t_{c} \leq A_{a} \cdot f_{y d} \\
\text { "parcial" if } \sum_{n=1}^{n_{c s . p}} Q_{R d}<A_{a} \cdot f_{y d} \wedge \sum_{n=1}^{n_{c s . p}} Q_{R d}<0.85 \cdot f_{c d} \cdot b_{p} \cdot t_{c}
\end{array}
$$

Interação = "parcial" 
2.1.6 - Espessura da região comprimida da laje, ou para interação parcial, a espessura considerada efetiva

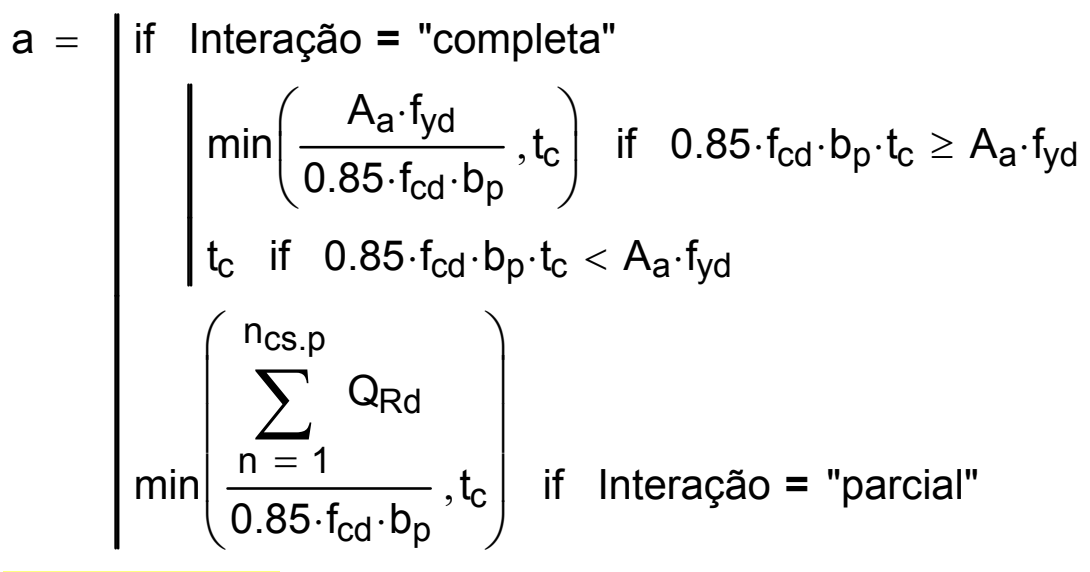

$\mathrm{a}=33.86 \cdot \mathrm{mm}$

2.1.7 - Força resistente de cálculo da espessura comprimida da laje de concreto

$\mathrm{C}_{\mathrm{cd}}=\mid \begin{aligned} & 0.85 \cdot \mathrm{f}_{\mathrm{cd}} \cdot \mathrm{b}_{\mathrm{p}} \cdot \mathrm{a} \text { if Interação = "completa" } \\ & \sum_{\mathrm{n}=1}^{\mathrm{n}_{\mathrm{cs} . \mathrm{p}}} \mathrm{Q}_{\mathrm{Rd}} \text { if Interação = "parcial" }\end{aligned}$

$\mathrm{C}_{\mathrm{cd}}=740 \cdot \mathrm{kN}$

2.1.8 - Força resistente de cálculo da região comprimida do perfil de aço

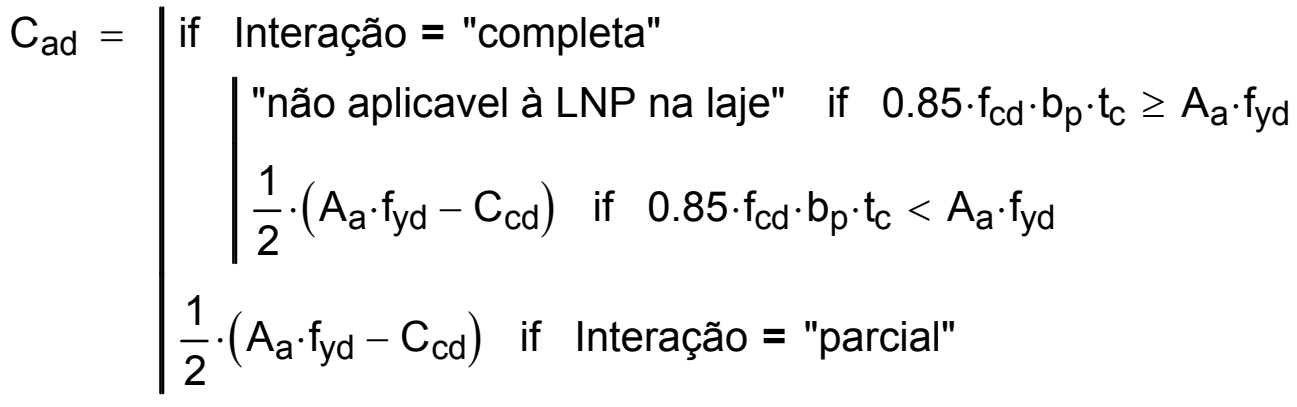

$\mathrm{C}_{\mathrm{ad}}=359.86 \cdot \mathrm{kN}$

2.1.9 - Força resistente de cálculo da região tracionada do perfil de aço

$T_{a d}=\mid \begin{aligned} & \text { if Interação = "completa" } \\ & \begin{array}{l}A_{a} \cdot f_{y d} \text { if } 0.85 \cdot f_{c d} \cdot b_{p} \cdot t_{c} \geq A_{a} \cdot f_{y d} \\ C_{c d}+C_{a d} \text { if } 0.85 \cdot f_{c d} \cdot b_{p} \cdot t_{c}<A_{a} \cdot f_{y d} \\ C_{c d}+C_{a d} \text { if Interação = "parcial" }\end{array}\end{aligned}$

$\mathrm{T}_{\mathrm{ad}}=1099.86 \cdot \mathrm{kN}$ 
2.1.10 - Elemento da viga mista em que a linha neutra plástica (LNP) corta para interação completa, ou para interação parcial, segunda LNP

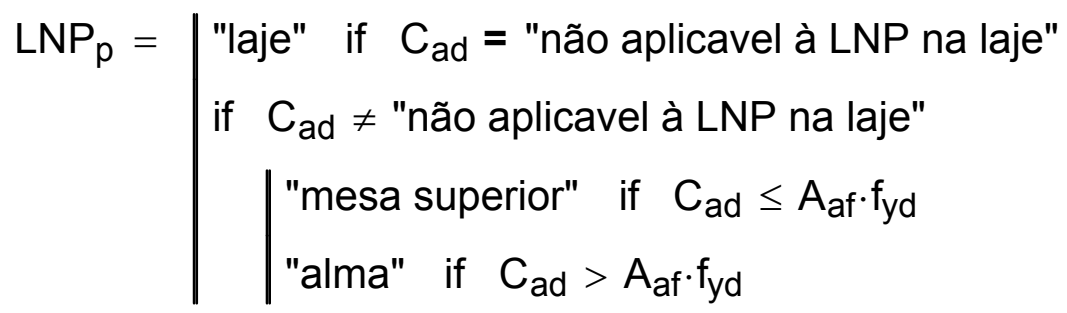

$\operatorname{LNP}_{\mathrm{p}}=$ "alma"

2.1.11 - Posição da LNP medida a partir do topo do perfil de aço

$$
\begin{aligned}
& y_{p}=\mid \begin{array}{l}
\frac{C_{a d}}{A_{a f} \cdot f_{y d}} \cdot t_{f} \text { if } L N P_{p}=\text { "mesa superior" } \\
t_{f}+h \cdot\left(\frac{C_{a d}-A_{a f} \cdot f_{y d}}{A_{a w} \cdot f_{y d}}\right) \text { if } L N P_{p}=\text { "alma" } \\
\text { "não aplicavel à LNP na laje" otherwise }
\end{array} \\
& y_{p}=37.74 \cdot m m
\end{aligned}
$$

2.1.12 - Distância do centróide da parte comprimida do perfil de aço até suć face superior

$$
y_{c}=\mid \begin{aligned}
& \frac{y_{p}}{2} \text { if } L N P_{p}=\text { "mesa superior" } \\
& \frac{\left(b_{f} \cdot t_{f}\right) \cdot \frac{t_{f}}{2}+\left[\left(y_{p}-t_{f}\right) \cdot t_{w}\right] \cdot\left(\frac{y_{p}-t_{f}}{2}+t_{f}\right)}{b_{f} \cdot t_{f}+\left(y_{p}-t_{f}\right) \cdot t_{w}} \text { if LNP } P_{p}=\text { "alma" } \\
& \text { "não aplicavel à LNP na laje" otherwise }
\end{aligned}
$$

$\mathrm{y}_{\mathrm{c}}=7.08 \cdot \mathrm{mm}$ 
2.1.13 - Distância do centróide da parte tracionada do perfil de aço até sua face inferior

$$
\begin{aligned}
& y_{t}=\left\{\begin{array}{l}
\frac{\left(b_{f} \cdot t_{f}\right) \cdot \frac{t_{f}}{2}+\left(h \cdot t_{w}\right) \cdot\left(\frac{h}{2}+t_{f}\right) \ldots}{+\left[b_{f} \cdot\left(t_{f}-y_{p}\right)\right] \cdot\left(\frac{t_{f}-y_{p}}{2}+h+t_{f}\right)} \\
\frac{b_{f} \cdot t_{f}+h \cdot t_{w}+b_{f} \cdot\left(t_{f}-y_{p}\right)}{\left(b_{f} \cdot t_{f}\right) \cdot \frac{t_{f}}{2}+\left[\left(d-t_{f}-y_{p}\right) \cdot t_{w}\right] \cdot\left(\frac{d-t_{f}-y_{p}}{2}+t_{f}\right)} \text { if LNP }=\text { if LNP } P_{p}=\text { "alma" } \\
\text { "não aplicavel à LNP na laje" otherwise superior" }
\end{array}\right. \\
& \mathrm{y}_{\mathrm{t}}=158.25 \cdot \mathrm{mm}
\end{aligned}
$$

\subsubsection{4 - Momento fletor resistente de cálculo positivo}

$$
M_{\text {Rd.p }}=\mid \begin{aligned}
& \text { if Interação = "completa" } \\
& \begin{array}{l}
\beta_{\mathrm{vm}} \cdot T_{\mathrm{ad}} \cdot\left(\mathrm{d}_{1}+\mathrm{h}_{\mathrm{F}}+\mathrm{t}_{\mathrm{c}}-\frac{\mathrm{a}}{2}\right) \\
\beta_{\mathrm{vm}} \cdot\left[\begin{array}{l}
\mathrm{C}_{\mathrm{ad}} \cdot\left(\mathrm{d}-\mathrm{y}_{\mathrm{t}}-\mathrm{y}_{\mathrm{c}}\right) \ldots \\
+\mathrm{C}_{\mathrm{cd}} \cdot\left(\frac{\mathrm{t}_{\mathrm{c}}}{2}+\mathrm{h}_{\mathrm{F}}+\mathrm{d}-\mathrm{y}_{\mathrm{t}}\right)
\end{array}\right] \text { if } 0.85 \cdot \mathrm{f}_{\mathrm{cd}} \cdot \mathrm{b}_{\mathrm{p}} \cdot \mathrm{t}_{\mathrm{c}} \geq \mathrm{A}_{\mathrm{a}} \cdot \mathrm{f}_{\mathrm{yd}}
\end{array} \\
& \beta_{\mathrm{vm}} \cdot\left[\begin{array}{l}
\mathrm{C}_{\mathrm{ad}} \cdot\left(\mathrm{d}-\mathrm{y}_{\mathrm{t} d}-\mathrm{y}_{\mathrm{c}}\right) \ldots \\
+\mathrm{C}_{\mathrm{cd}} \cdot\left(\mathrm{t}_{\mathrm{c}}-\frac{\mathrm{a}}{2}+\mathrm{t}_{\mathrm{c}}<\mathrm{h}_{\mathrm{a}}+\mathrm{d}-\mathrm{f}_{\mathrm{yd}}\right)
\end{array}\right] \text { if Interação = "parcial" }
\end{aligned}
$$

$\mathrm{M}_{\text {Rd.p }}=409.41 \cdot \mathrm{kN} \cdot \mathrm{m}$

\subsubsection{5 - Verificação da resistência ao momento fletor positivo}

Momento solicitante de cálculo:

$\mathrm{M}_{\mathrm{Sd} . \mathrm{p}}=297.4 \cdot \mathrm{kN} \cdot \mathrm{m}$

Momento resistente de cálculo:

$\frac{M_{\text {Sd.p }}}{M_{\text {Rd.p }}}=0.73$

$$
\mathrm{M}_{\mathrm{Rd} . \mathrm{p}}=409.41 \cdot \mathrm{kN} \cdot \mathrm{m}
$$

Verificação_MRd.p = "ok!" 
2.1.16 - Verificação do grau de interação da viga mista de alma cheia com mesas de áreas iguais

2.1.16.1 - Somatório das forças resistentes de cálculo individuais dos conectores de cisalhamento situados entre a seção do momento positivo máximo e a seção adjacente de momento nulo

$$
\sum_{n=1}^{n_{\text {cs.p }}} Q_{R d}=740 \cdot k N
$$

2.1.16.2 - Força de cisalhamento de cálculo entre o componente de aço e a laje

$$
F_{h d}=\min \left(A_{a} \cdot f_{y d}, 0.85 \cdot f_{c d} \cdot b_{p} \cdot t_{c}\right) \quad F_{h d}=1420.71 \cdot k N
$$

\subsubsection{3 - Grau de interação}

$$
\eta_{i}=\frac{\sum_{n=1}^{n_{\text {cs.p }}} Q_{R d}}{F_{h d}}
$$

$$
\eta_{\mathrm{i}}=0.52
$$

2.1.16.4 - Verificação do grau de interação

$$
\eta_{\text {i.min }}=\max \left[1-\frac{E}{578 \cdot f_{y}} \cdot\left(0.75-0.03 \cdot \frac{L_{e}}{m}\right), 0.4\right]
$$

$$
\begin{aligned}
& \text { Verificação_de_ } \eta_{i}=\mid \text { if Interação = "parcial" } \\
& \mid \begin{array}{l}
\text { "ok!" if } \eta_{i} \geq \eta_{i . m i n} \wedge L_{e} \leq 25 m \\
\text { "não ok!" otherwise }
\end{array} \\
& \text { if Interação = "completa" } \\
& \mid \begin{array}{l}
\text { "ok!" if } \quad \eta_{\mathrm{i}} \geq 1 \\
\text { "não ok!" otherwise }
\end{array}
\end{aligned}
$$

Verificação_de_ $\eta_{i}=$ "ok!" 
2.2 - Momento fletor resistente de cálculo em regiões de momentos negativos

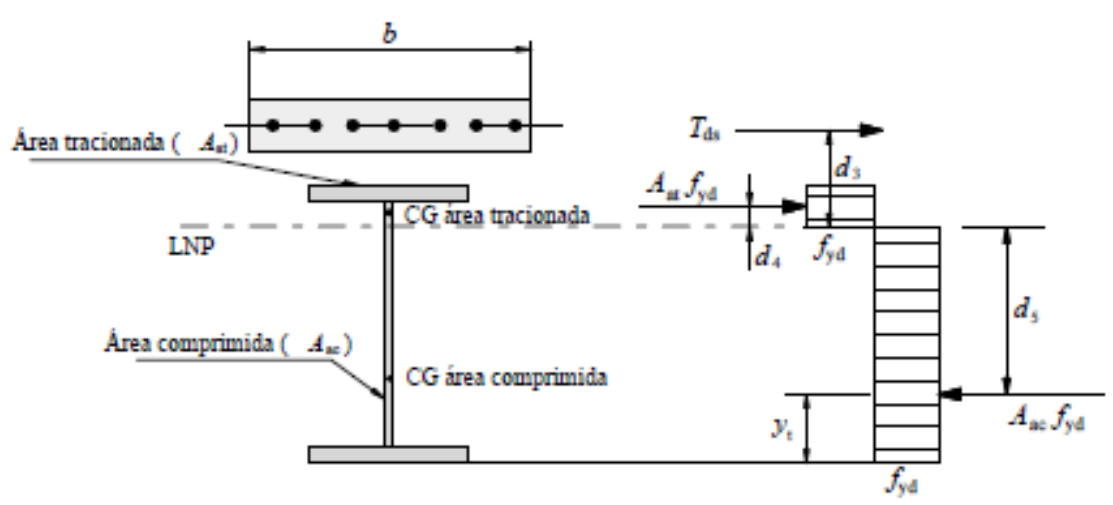

Figura 2.3 - Distribuição de tensões para momento fletor negativo (NBR 8800, 2008)

2.2.1 - Determinação da largura efetiva na região de momento negativo

$b_{e . n}=\mid \begin{aligned} & \min \left(\frac{1}{8} \cdot \frac{L+L_{1}}{4}, \frac{d_{v . e}}{2}\right) \text { if } T_{e}=\text { "INTERMEDIÁRIO" } \\ & \min \left(\frac{1}{8} \cdot \frac{L+L_{1}}{4}, d_{b}\right) \text { if } T_{e}=\text { "BALANÇO" }\end{aligned}$

$b_{e . n}=562.5 \cdot m m$

$b_{d . n}=\mid \begin{aligned} & \min \left(\frac{1}{8} \cdot \frac{L+L_{1}}{4}, \frac{d_{v . d}}{2}\right) \text { if } T_{d}=\text { "INTERMEDIÁRIO" } \\ & \min \left(\frac{1}{8} \cdot \frac{L+L_{1}}{4}, d_{b}\right) \text { if } T_{d}=\text { "BALANÇO" }\end{aligned}$

$b_{d . n}=562.5 \cdot m m$

$b_{n}=b_{e . n}+b_{d . n} \quad b_{n}=1125 \cdot m m$

2.2.2 - Força resistente de tração de cálculo nas barras de armadura longitudinal

$\mathrm{T}_{\mathrm{ds}}=\mathrm{A}_{\mathrm{s}} \cdot \mathrm{f}_{\mathrm{sd}}$

$\mathrm{T}_{\mathrm{ds}}=218.55 \cdot \mathrm{kN}$ 
2.2.3 - Força resistente de cálculo da região tracionada do perfil de aço $T_{a d}=\mid \begin{aligned} & \frac{1}{2} \cdot\left(A_{a} \cdot f_{y d}-A_{s l} \cdot f_{s d}\right) \text { if } A_{s l} \cdot f_{s d} \leq A_{a} \cdot f_{y d} \\ & \text { "taxa de armadura adotada maior do que o necessário" otherwise }\end{aligned}$ $\mathrm{T}_{\mathrm{ad}}=620.59 \cdot \mathrm{kN}$

2.2.4 - Força resistente de cálculo da região comprimida do perfil de aço $\mathrm{C}_{\mathrm{ad}}=\mid \begin{aligned} & \mathrm{T}_{\mathrm{ds}}+\mathrm{T}_{\mathrm{ad}} \text { if } \mathrm{A}_{\mathrm{sl}} \cdot \mathrm{f}_{\mathrm{sd}} \leq \mathrm{A}_{\mathrm{a}} \cdot \mathrm{f}_{\mathrm{yd}} \\ & \text { "taxa de armadura adotada maior do que o necessário" otherwise }\end{aligned}$ $\mathrm{C}_{\mathrm{ad}}=839.14 \cdot \mathrm{kN}$

2.2.5 - Elemento da viga mista em que a linha neutra plástica corta $\mathrm{LNP}_{\mathrm{n}}=\mid \begin{aligned} & \text { "mesa superior" if } \mathrm{T}_{\mathrm{ad}} \leq \mathrm{A}_{\mathrm{af}} \cdot \mathrm{f}_{\mathrm{yd}} \\ & \text { "alma" if } \mathrm{T}_{\mathrm{ad}}>\mathrm{A}_{\mathrm{af}} \cdot \mathrm{f}_{\mathrm{yd}}\end{aligned}$

$\mathrm{LNP}_{\mathrm{n}}=$ "alma"

2.2.6 - Posição da LNP medida a partir do topo do perfil de aço

$$
y_{n}=\mid \begin{aligned}
& \frac{T_{a d}}{A_{a f} \cdot f_{y d}} \cdot t_{f} \text { if } L N P_{n}=\text { "mesa superior" } \\
& t_{f}+h \cdot\left(\frac{T_{a d}-A_{a f} \cdot f_{y d}}{A_{a w} \cdot f_{y d}}\right) \text { if } L N P_{n}=\text { "alma" }
\end{aligned}
$$

$\mathrm{y}_{\mathrm{n}}=169.7 \cdot \mathrm{mm}$

2.2.7 - Distância do centro geométrico da armadura longitudinal à LNP $\mathrm{d}_{3}=\mathrm{t}_{\mathrm{c}}-\mathrm{c}_{\mathrm{nom}}-\frac{\phi}{2}+\mathrm{h}_{\mathrm{F}}+\mathrm{y}_{\mathrm{n}} \quad \mathrm{d}_{3}=285.7 \cdot \mathrm{mm}$ 
2.2.8 - Distância da força de tração, situada no centro geométrico da área tracionada à LNP

$$
d_{4}=\mid \begin{aligned}
& \frac{y_{n}}{2} \text { if } L N P_{n}=\text { "mesa superior" } \\
& \frac{\left(t_{f} \cdot b_{f}\right) \cdot\left(y_{n}-\frac{t_{f}}{2}\right)+\left[t_{w} \cdot\left(y_{n}-t_{f}\right)\right] \cdot\left(\frac{y_{n}-t_{f}}{2}\right)}{t_{f} \cdot b_{f}+t_{w} \cdot\left(y_{n}-t_{f}\right)} \text { if } L N P_{n}=\text { "alma" }
\end{aligned}
$$

$\mathrm{d}_{4}=122.01 \cdot \mathrm{mm}$

2.2.9 - Distância da força de compressão, situada no centro geométrico da área comprimida, à LNP

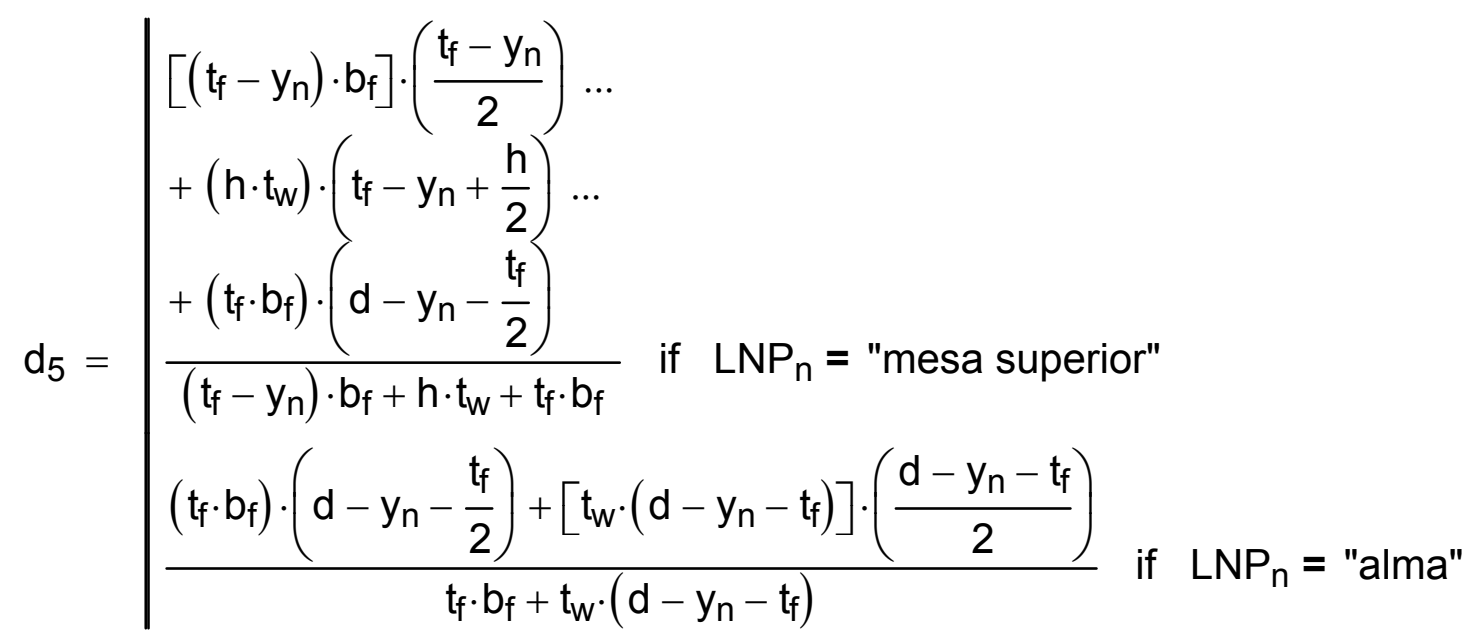

$\mathrm{d}_{5}=186.44 \cdot \mathrm{mm}$

2.2.10 - Área tracionada da seção do perfil de aço

$A_{a t}=\mid \begin{aligned} & b_{f} \cdot y_{n} \text { if } L N P_{n}=\text { "mesa superior" } \\ & t_{f} \cdot b_{f}+t_{w} \cdot\left(y_{n}-t_{f}\right) \text { if } L N P_{n}=\text { "alma" }\end{aligned}$

$A_{a t}=19.79 \cdot \mathrm{cm}^{2}$

2.2.11 - Área comprimida da seção do perfil de aço

$A_{a c}=\mid \begin{aligned} & \left(t_{f}-y_{n}\right) \cdot b_{f}+h \cdot t_{w}+t_{f} \cdot b_{f} \text { if } \quad L N P_{n}=\text { "mesa superior" } \\ & t_{f} \cdot b_{f}+t_{w} \cdot\left(d-y_{n}-t_{f}\right) \quad \text { if } \quad L N P_{n}=\text { "alma" }\end{aligned}$

$A_{a c}=26.76 \cdot \mathrm{cm}^{2}$ 


\subsubsection{2 - Momento fletor resistente de cálculo negativo}

$M_{R d . n}=T_{d s} \cdot d_{3}+A_{a t} \cdot f_{y d} \cdot d_{4}+A_{a c} \cdot f_{y d} \cdot d_{5}$

$M_{\text {Rd.n }}=294.61 \cdot \mathrm{kN} \cdot \mathrm{m}$

\subsubsection{3 - Verificação da resistência ao momento fletor negativo}

Momento solicitante de cálculo:

$\mathrm{M}_{\mathrm{Sd} . \mathrm{n}}=232.25 \cdot \mathrm{kN} \cdot \mathrm{m}$

Momento resistente de cálculo:

$M_{\text {Rd.n }}=294.61 \cdot \mathrm{kN} \cdot \mathrm{m}$

$$
\frac{M_{\text {Sd.n }}}{M_{\text {Rd.n }}}=0.79
$$

Verificação_MRd.n = "ok!"

\subsubsection{4 - Verificação da flambagem lateral com distorção da seção transvers}

\subsubsection{1 - Coeficiente Cbdist para vigas contínuas com carregamento no} comprimento L (Tabela O.1)

2.2.14.1.1 - Diagrama de momento fletor do vão analisado (1-6)

Diagrama_de_momento_fletor $=1$

2.2.14.1.2 - Momento máximo solicitante de cálculo, considerando tramo analisado como biapoiado

$$
M_{0}=\mid \begin{array}{|ccc|c|c|c|}
\frac{F_{d} \cdot L^{2}}{8} & \text { if } & \text { Diagrama_de_momento_fletor }=1 \\
\frac{F_{d} \cdot L^{2}}{8} \text { if } & \text { Diagrama_de_momento_fletor }=2 \\
\frac{F_{d} \cdot L^{2}}{8} \text { if } & \text { Diagrama_de_momento_fletor }=3 \\
\frac{F_{d} \cdot L^{2}}{8} \text { if } & \text { Diagrama_de_momento_fletor }=4 \\
\frac{P_{d} \cdot L}{4} \text { if } & \text { Diagrama_de_momento_fletor }=5 \\
\frac{P_{d} \cdot L}{4} \text { if } & \text { Diagrama_de_momento_fletor }=6
\end{array}
$$

$\mathrm{M}_{\mathrm{O}}=405.22 \cdot \mathrm{kN} \cdot \mathrm{m}$ 
2.2.14.1.3 - Determinação do coeficiente de entrada da tabela de valores de Cbdist $\psi=\frac{M_{S d . n}}{M_{0}}$ $\psi=0.57$

$\mathrm{C}_{\text {bdist }}=38.19 \quad($ Tabela O.1 da NBR 8800:2008)

2.2.14.3 - Parametro de esbeltez

$$
\begin{aligned}
& \lambda_{\text {dist }}=5 \cdot\left(1+\frac{t_{w} \cdot h_{0}}{4 \cdot b_{f} \cdot t_{f}}\right) \cdot\left[\left(\frac{f_{y}}{E \cdot C_{b d i s t}}\right)^{2} \cdot\left(\frac{h_{0}}{t_{w}}\right)^{3} \cdot\left(\frac{t_{f}}{b_{f}}\right)\right]^{0.25} \\
& \lambda_{\text {dist }}=0.71
\end{aligned}
$$

2.2.14.4 - Fator de redução para flambagem lateral com distorção da seção transversal

$$
\chi_{\text {dist }}=\mid \begin{aligned}
& 1 \text { if } \lambda_{\text {dist }}<0.4 \\
& 0.658^{\lambda_{\text {dist }}{ }^{2}} \text { if } 0.4 \leq \lambda_{\text {dist }} \leq 1.5 \\
& \frac{0.877}{\lambda_{\text {dist }}^{2}} \text { otherwise }
\end{aligned}
$$

$\chi_{\text {dist }}=0.81$

2.2.14.5 - Momento fletor resistente de cálculo para flambagem lateral com distorção da seção transversal

$$
M_{\text {dist.Rd.n }}=\chi_{\text {dist }} \cdot M_{\text {Rd.n }} \quad M_{\text {dist } . R d . n}=237.99 \cdot \mathrm{kN} \cdot \mathrm{m}
$$

2.2.14.6 - Verificação do momento fletor resistente de cálculo para flambagem lateral com distorção da seção transversal

Momento solicitante de cálculo:

$$
\mathrm{M}_{\mathrm{Sd} . \mathrm{n}}=232.25 \cdot \mathrm{kN} \cdot \mathrm{m}
$$

Momento resistente de cálculo:

$M_{\text {dist.Rd.n }}=237.99 \cdot \mathrm{kN} \cdot \mathrm{m}$

$$
\frac{M_{\text {Sd.n }}}{M_{\text {dist.Rd.n }}}=0.98
$$

Verificação_M dist.Rd.n = "ok!" 


\subsubsection{5 - Verificação da classificação da seção do perfil}

2.2.15.1 - Cálculo do dobro da parte comprimida da alma

$$
\begin{aligned}
& h_{p}=\mid \begin{array}{l}
2 \cdot h \quad \text { if } L N P_{n}=\text { "mesa superior" } \\
2 \cdot\left(d-y_{n}-t_{f}\right) \quad \text { if } \quad L N P_{n}=\text { "alma" }
\end{array} \\
& h_{p}=544.61 \cdot \mathrm{mm}
\end{aligned}
$$

2.2.15.2 - Índice de esbeltez e parâmetro de esbeltez limite da parte comprimida da alma para seções compactas

$$
\frac{h_{p}}{t_{w}}=86.45 \quad 3.76 \cdot \sqrt{\frac{E}{f_{y}}}=90.53
$$

$\underline{\text { 2.2.15.3 - Índice de esbeltez e parâmetro de esbeltez limite da mesa para seç̃̃es }}$ compactas
$\frac{b_{f}}{2 t_{f}}=7.5$
$0.38 \cdot \sqrt{\frac{E}{f_{y}}}=9.15$
$\frac{\frac{b_{f}}{2 t_{f}}}{0.38 \cdot \sqrt{\frac{E}{f_{y}}}}=0.82$

\subsubsection{4 - Verificação da classificação da seção do perfil}

Verificação_da_seção $=\mid \begin{aligned} & \text { "ok!" if } \frac{b_{f}}{2 t_{f}} \leq 0.38 \cdot \sqrt{\frac{E}{f_{y}}} \wedge \frac{h_{p}}{t_{w}} \leq 3.76 \cdot \sqrt{\frac{E}{f_{y}}} \\ & \text { "não aplicável às prescrições da NBR 8800" otherwise }\end{aligned}$

Verificação_da_seção = "ok!"

\subsubsection{6 - Verificação do número de conectores de cisalhamento}

Verificação_de_n $n_{\text {cs.n }}=\mid \begin{array}{ll}\text { "ok!" if } \sum_{n=1}^{n_{\text {cs.n }}} Q_{\text {Rd }} \geq T_{d s} \quad \text { (interação completa) } \\ \text { "não ok!" otherwise }\end{array}$

$$
\frac{\sum_{n=1}^{n_{c s . n}} Q_{R d}}{T_{d s}}=1.02
$$$$
\text { Verificação_de_n } \mathrm{n}_{\mathrm{cs} . \mathrm{n}}=\text { "ok!" }
$$ 
2.3 - Força cortante resistente de cálculo

2.3.1 - Determinação do coeficiente de flambagem

2.3.1.1 - Distância entre enrijecedores

$\mathrm{a}=\mathrm{L} \quad$ (Verificação sem enrijecedores)

2.3.1.2 - Coeficiente de flambagem

$\frac{a}{h}=20.74$

$$
\mathrm{K}_{\mathrm{v}}= \begin{cases}5 \text { if } \frac{\mathrm{a}}{\mathrm{h}}>3 & \mathrm{~K}_{\mathrm{v}=5} \\ 5 \text { if } \frac{\mathrm{a}}{\mathrm{h}}>\left(\frac{260}{\frac{\mathrm{h}}{\mathrm{t}_{\mathrm{w}}}}\right)^{2} & \\ {\left[5+\frac{5}{\left(\frac{\mathrm{a}}{\mathrm{h}}\right)^{2}}\right]} & \text { otherwise }\end{cases}
$$

2.3.2 - Parâmetro de esbeltez limite da correspondente a plastificação

$\lambda_{p}=1.10 \sqrt{\frac{K_{v} \cdot E}{f_{y}}} \quad \lambda_{p}=59.22$

2.3.3 - Parâmetro de esbeltez limite correspondente ao início do escoamenı

$\lambda_{r}=1.37 \sqrt{\frac{K_{v} \cdot E}{f_{y}}} \quad \lambda_{r}=73.76$

2.3.5 - Índice de esbeltez da alma

$\lambda=\frac{\mathrm{h}}{\mathrm{t}_{\mathrm{w}}}$

$\lambda=68.89$

2.3.6 - Força cortante relativo à plastificação da alma por cisalhamento

2.3.6.1 - Área efetiva de cisalhamento

$A_{w}=d \cdot t_{w}$

$A_{w}=28.35 \cdot \mathrm{cm}^{2}$

2.3.6.2 - Plastificação por força cortante

$\mathrm{V}_{\mathrm{pl}}=0.60 \cdot \mathrm{A}_{\mathrm{w}} \cdot \mathrm{f}_{\mathrm{y}}$

$\mathrm{V}_{\mathrm{pl}}=586.85 \cdot \mathrm{kN}$ 


\subsection{7 - Força cortante resistente de cálculo}

Situação $=$ " $\lambda . p<\lambda<\lambda . r "$

$\mathrm{V}_{\mathrm{Rk}}=\mid \begin{aligned} & \mathrm{V}_{\mathrm{pl}} \text { if } \lambda \leq \lambda_{\mathrm{p}} \\ & \mathrm{V}_{\mathrm{pl}} \cdot \frac{\lambda_{\mathrm{p}}}{\lambda} \text { if } \lambda_{\mathrm{p}}<\lambda \leq \lambda_{\mathrm{r}} \\ & 1.24 \cdot \mathrm{V}_{\mathrm{pl}} \cdot\left(\frac{\lambda_{\mathrm{p}}}{\lambda}\right)^{2} \text { if } \lambda>\lambda_{\mathrm{r}}\end{aligned}$

$\mathrm{V}_{\mathrm{Rd}}=\frac{\mathrm{V}_{\mathrm{Rk}}}{\gamma_{\mathrm{a} 1}} \quad \mathrm{~V}_{\mathrm{Rd}}=458.63 \cdot \mathrm{kN}$

\subsection{8 - Verificação da resistência à força cortante}

Esforço cortante solicitante de cálculo:........ $\mathrm{V}_{\mathrm{Sd}}=218 \cdot \mathrm{kN}$

Esforço cortante resistente de cálculo:......... $V_{\mathrm{Rd}}=458.63 \cdot \mathrm{kN}$

$\frac{\mathrm{V}_{\mathrm{Sd}}}{\mathrm{V}_{\mathrm{Rd}}}=0.475$

Verificação_V $V_{\mathrm{Rd}}=$ "ok!" 


\section{3 - Estados-limites de serviço (ELS)}

\section{1 - Controle dos deslocamentos excessivos}

\subsection{1 - Homogeneização teórica da seção mista na região de momento positivo aplicado a carregamentos de curta duração $\left(E_{c}\right)$}

\subsubsection{1 - Perfil de aço}

3.1.1.1.1 - Posição do centróide segundo a face superior da laje

$$
y^{\prime}{ }_{a}=\frac{d}{2}+h_{F}+t_{c} \quad y_{a}^{\prime}=36.5 \cdot c m
$$

\subsubsection{2 - Seção equivalente de concreto}

3.1.1.2.1 - Razão modular

$$
\alpha_{\mathrm{E}}=\frac{\mathrm{E}}{\mathrm{E}_{\mathrm{C}}} \quad \alpha_{\mathrm{E}}=9.4
$$

3.1.1.2.2 - Área equivalente de concreto
$A_{\text {e.c. } \alpha}=\frac{b_{p}}{\alpha_{E}} \cdot t_{c}$
$A_{\text {e.c. } \alpha}=124.53 \cdot \mathrm{cm}^{2}$

3.1.1.2.3 - Posição do centróide da seção de concreto equivalente segundo sua face superior

$$
y_{\text {e.c. } \alpha}^{\prime}=\frac{t_{c}}{2} \quad y_{\text {e.c. } \alpha}^{\prime}=3.25 \cdot \mathrm{cm}
$$

3.1.1.2.4 - Momento de inércia em relação ao eixo x passando pelo centróide da seção equivalente

$\mathrm{I}_{\text {e.c.x. } \alpha}=\frac{\frac{\mathrm{b}_{\mathrm{p}}}{\alpha_{\mathrm{E}}} \cdot \mathrm{t}_{\mathrm{c}}{ }^{3}}{12}$

$\mathrm{I}_{\text {e.c. } . \mathrm{\alpha} . \mathrm{\alpha}}=438.45 \cdot \mathrm{cm}^{4}$

\subsubsection{3 - Seção homogeneizada}

3.1.1.3.1 - Posição da linha neutra elástica (LNE) da seção homogeneizada Segundo a face superior da laje:

$$
y_{\text {p.s. } \alpha}=\frac{A_{\text {e.c. } \alpha} \cdot y_{\text {e.c. } \alpha}+A_{a} \cdot y_{a}^{\prime}}{A_{\text {e.c. } \alpha}+A_{a}} \quad y_{\text {p.s. } \alpha}=12.3 \cdot \mathrm{cm}
$$

Segundo a face inferior do perfil:

$$
y_{\text {p.i. } \alpha}=d+h_{F}+t_{c}-y_{\text {p.s. } \alpha} \quad y_{\text {p.i. } . \alpha}=46.7 \cdot \mathrm{cm}
$$


3.1.1.3.2 - Determinação da altura de concreto comprimido

$$
\begin{aligned}
& t_{c c . \alpha}=\mid \begin{array}{l}
t_{c c . \alpha} \leftarrow t_{c} \\
\text { while } t_{c c . \alpha}>y_{p . s . \alpha} \\
\mid \begin{array}{l}
t_{c c . \alpha} \leftarrow y_{p . s . \alpha} \\
A_{\text {e.c. } \alpha} \leftarrow b_{p} \cdot \frac{t_{c c . \alpha}}{\alpha_{E}} \\
y_{\text {e.c. } \alpha}^{\prime} \leftarrow \frac{t_{c c . \alpha}}{2} \\
y_{p . s . \alpha} \leftarrow \frac{A_{e . c . \alpha} \cdot y_{e . c . \alpha}^{\prime}+A_{a} \cdot y_{a}^{\prime}}{A_{e . c . \alpha}+A_{a}}
\end{array}
\end{array} \\
& \mathrm{t}_{\mathrm{cc} . \alpha}=6.5 \cdot \mathrm{cm}
\end{aligned}
$$

3.1.1.3.3 - Propriedades geométricas da seção homogeneizada desconsiderando a parcela de concreto tracionado $\left(\mathrm{t}_{\mathrm{cc} . \alpha}=6.5 \cdot \mathrm{cm}\right)$

Seção equivalente de concreto:

Área equivalente de concreto:

$A_{e . c . \alpha}=124.53 \cdot \mathrm{cm}^{2}$

Posição do centróide segundo a face

superior):

$y^{\prime}$ e.c. $\alpha=3.25 \cdot \mathrm{cm}$

Momento de inércia em relação ao eixo $x$ passando pelo centróide:

Ie.c.x. $=438.45 \cdot \mathrm{cm}^{4}$

Seção homogeneizada:

Área total:

$$
A_{\text {e.c. } \alpha}+A_{a}=171.07 \cdot \mathrm{cm}^{2}
$$

Posição da linha neutra elástica segundo a face superior):.. $y_{p . s . \alpha}=12.3 \cdot \mathrm{cm}$

Posição da linha neutra elástica segundo a face inferior):

$$
y_{p . i . \alpha}=46.7 \cdot \mathrm{cm}
$$

3.1.1.3.4 - Elemento da viga mista em que a LNE se encontra

$$
\mathrm{LNE}_{\alpha}=\mid \begin{aligned}
& \text { "laje" if } t_{c} \geq y_{\text {p.s. } \alpha} \\
& \text { "mesa superior" if } t_{c}+h_{F}<y_{\text {p.s. } \alpha} \leq t_{c}+h_{F}+t_{f} \\
& \text { "alma" otherwise }
\end{aligned}
$$

$\operatorname{LNE}_{\alpha}=$ "alma" 
3.1.1.3.5 - Momento de inércia em relação ao eixo $x$

$I_{\text {tr.p.x. } \alpha}=I_{\text {e.c.x. } \alpha}+I_{a x}+A_{\text {e.c. } \alpha} \cdot y^{\prime}{ }_{\text {e.c. } \alpha}{ }^{2}+A_{a} \cdot y^{\prime}{ }^{2}{ }^{2}-\left(A_{\text {e.c. } \alpha}+A_{a}\right) \cdot y_{\text {p.s. } \alpha}{ }^{2}$

$I_{\text {tr.p.x. }}=51564.9 \cdot \mathrm{cm}^{4}$

3.1.1.3.6 - Módulo de resistência elástico em relação ao eixo $x$

$$
\begin{array}{ll}
W_{\text {tr.p.x.s. } \alpha}=\frac{I_{\text {tr.p.x. } \alpha}}{y_{\text {p.s. } \alpha}} & W_{\text {tr.p.x.s. } \alpha}=4193.64 \cdot \mathrm{cm}^{3} \\
W_{\text {tr.p.x.i. } \alpha}=\frac{I_{\text {tr.p.x. } \alpha}}{y_{\text {p.i. } \alpha}} & W_{\text {tr.p.x.i. } \alpha}=1104.08 \cdot \mathrm{cm}^{3}
\end{array}
$$

3.1.1.3.7 - Módulo de resistência plástico em relação ao eixo x

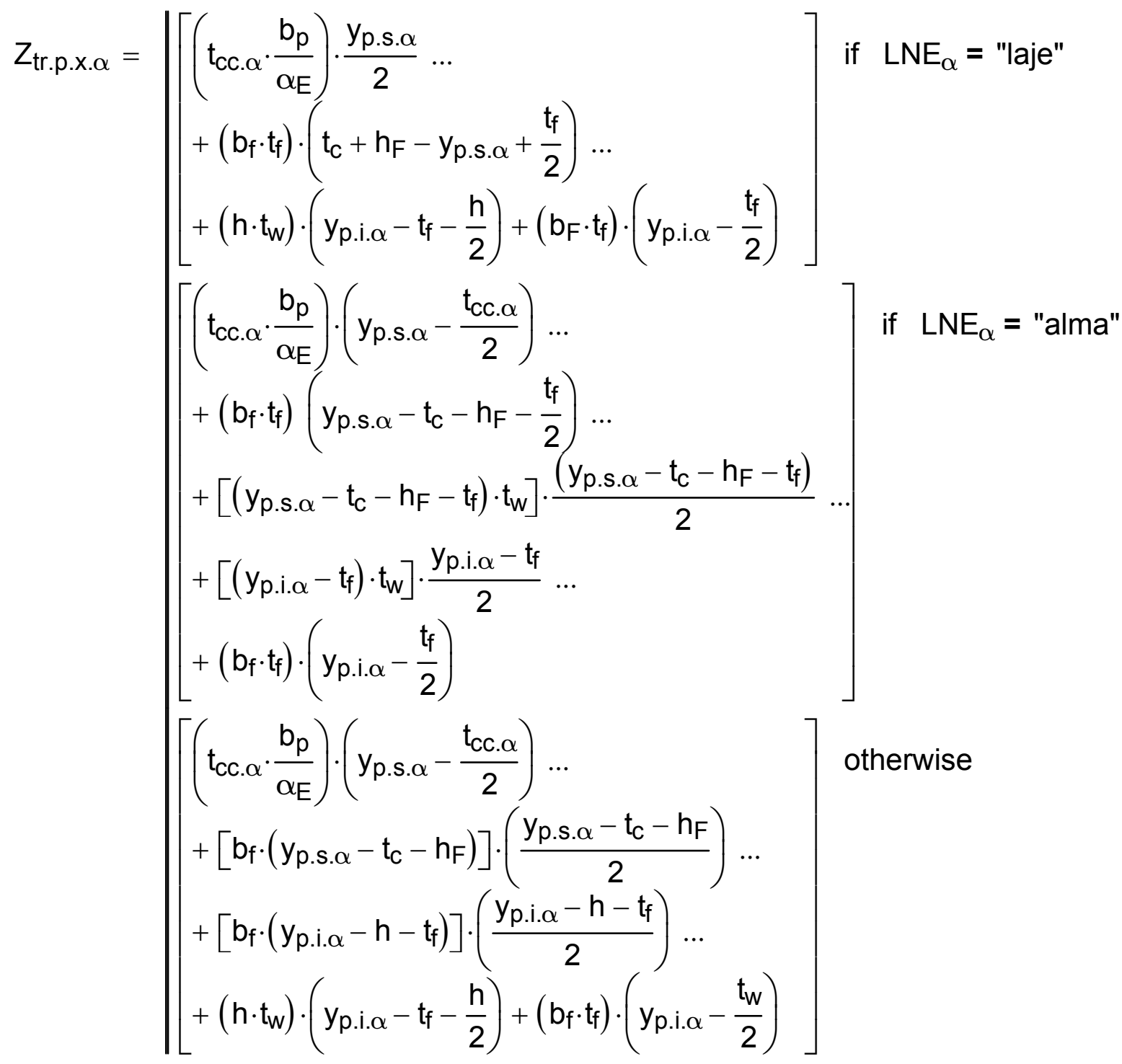

$$
\begin{aligned}
& Z_{\text {tr.p.x. } \alpha}=2216.56 \cdot \mathrm{cm}^{3}
\end{aligned}
$$


3.1.1.3.8 - Raio de giração em relação ao eixo x

$r_{\text {tr.p.x. } \alpha}=\sqrt{\frac{I_{\text {tr.p.x. } \alpha}}{A_{\text {e.c. } \alpha}+A_{a}}}$

$r_{\text {tr.p.x. } \alpha}=17.36 \cdot \mathrm{cm}$

\subsection{2 - Homogeneização teórica da seção mista na região de momento positivo aplicado a carregamentos de longa duração $\left(E_{c} / 3\right)$}

\subsubsection{1 - Perfil de aço}

Posição do centróide segundo a face superior da laje:

$y^{\prime}{ }_{a}=36.5 \cdot \mathrm{cm}$

\subsubsection{2 - Seção equivalente de concreto}

Razão modular:

$\alpha_{3 \alpha}=28.19$

Área equivalente de concreto:

$A_{e . c .3 \alpha}=41.51 \cdot \mathrm{cm}^{2}$

Posição do centróide segundo a face

superior da laje:

$y^{\prime}$ e.c. $3 \alpha=3.25 \cdot \mathrm{cm}$

Momento de inércia em relação ao eixo x passando pelo centróide:

$\mathrm{I}_{\text {e.c.x. } 3 \alpha}=146.15 \cdot \mathrm{cm}^{4}$

\section{$\underline{3.1 .2 .3 ~-~ S e c ̧ a ̃ o ~ h o m o g e n e i z a d a ~}$}

Área total:

$A_{e . c .3 \alpha}+A_{a}=88.05 \cdot \mathrm{cm}^{2}$

Posição da linha neutra elástica segundo a face superior da laje:

yp.s. $3 \alpha=20.83 \cdot \mathrm{cm}$

Posição da linha neutra elástica segundo a face inferior do perfil:

$\mathrm{y}_{\text {p.i. } 3 \alpha}=38.17 \cdot \mathrm{cm}$

Elemento da viga mista em que a LNE se encontra:

$\mathrm{LNE}_{3 \alpha}=$ "alma"

Momento de inércia em relação ao eixo x:

$I_{\text {tr.p.x. } 3 \alpha}=38073.72 \cdot \mathrm{cm}^{4}$

Módulo de resistência elástico em relação ao eixo x segundo a face superior da laje:.

$W_{\text {tr.p.x.s. } 3 \alpha}=1828.27 \cdot \mathrm{cm}^{3}$

Módulo de resistência elástico em relação ao eixo x segundo a face inferior do perfil:. $W_{\text {tr.p.x.i.3 }}=997.35 \cdot \mathrm{cm}^{3}$

Módulo de resistência plástico em relação ao eixo $\mathrm{x}$ :

$Z_{\text {tr.p.x. } 3 \alpha}=2018.88 \cdot \mathrm{cm}^{3}$

Raio de giração em relação ao eixo x:

$r_{\text {tr.p.x. } 3 \alpha}=20.79 \cdot \mathrm{cm}$ 


\subsection{3 - Homogeneização teórica da seção mista na região de momento positivo para o procedimento alternativo $\left(E_{c} / 2\right)$}

\subsubsection{1 - Perfil de aço}

Posição do centróide segundo a face superior da laje:

$$
y_{a}^{\prime}=36.5 \cdot \mathrm{cm}
$$

\subsubsection{2 - Seção equivalente de concreto}

Razão modular:

$$
\alpha_{2 \alpha}=18.79
$$

Área equivalente de concreto:

$$
\begin{aligned}
& A_{\text {e.c. } 2 \alpha}=62.27 \cdot \mathrm{cm}^{2} \\
& y_{\text {e.c. } 2 \alpha}^{\prime}=3.25 \cdot \mathrm{cm} \\
& \text { Ie.c.x. } 2 \alpha^{\prime}=219.23 \cdot \mathrm{cm}^{4}
\end{aligned}
$$

superior da laje:

\subsubsection{3 - Seção homogeneizada}

Área total:

$$
A_{e . c .2 \alpha}+A_{a}=108.81 \cdot \mathrm{cm}^{2}
$$

Posição da linha neutra elástica segundo a face superior da laje: $y_{p . s .2 \alpha}=17.47 \cdot \mathrm{cm}$

Posição da linha neutra elástica segundo a face inferior do perfil:

$$
\mathrm{y}_{\text {p.i. } 2 \alpha}=41.53 \cdot \mathrm{cm}
$$

Elemento da viga mista em que a LNE se encontra:

$$
\mathrm{LNE}_{2 \alpha}=\text { "alma" }
$$

Momento de inércia em relação ao eixo x: $I_{\text {tr.p.x. } 2 \alpha}=43334.79 \cdot \mathrm{cm}^{4}$

Módulo de resistência elástico em relação ao eixo $x$ segundo a face superior da laje:. $\quad W_{\text {tr.p.x.s. } 2 \alpha}=2480.16 \cdot \mathrm{cm}^{3}$

Módulo de resistência elástico em relação ao eixo $x$ segundo a face inferior do perfil:. $W_{\text {tr.p.x.i. } 2 \alpha}=1043.52 \cdot \mathrm{cm}^{3}$ Módulo de resistência plástico em relação ao eixo $\mathrm{x}$ :

$$
Z_{\text {tr.p.x. } 2 \alpha}=1916.67 \cdot \mathrm{cm}^{3}
$$

Raio de giração em relação ao eixo x:

$$
r_{\text {tr.p.x. } 2 \alpha}=19.96 \cdot \mathrm{cm}
$$


3.1.4 - Homogeneização efetiva da seção mista na região de momento positivo aplicado a carregamentos de curta duração $\left(E_{c}\right)$

3.1.4.1 - Momento de inércia efetivo em relação ao eixo $x$

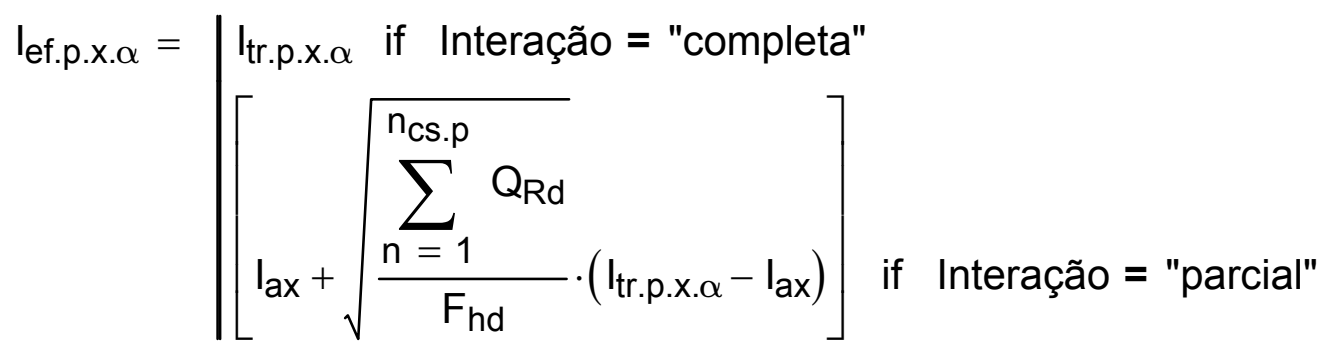

Ief.p.x. $=41019.21 \cdot \mathrm{cm}^{4}$

\subsubsection{2 - Módulo de resistência elástico em relação ao eixo x}

$W_{\text {ef.p.x.s. } \alpha}=W_{\text {tr.p.x.s. } \alpha}=4193.64 \cdot \mathrm{cm}^{3}$

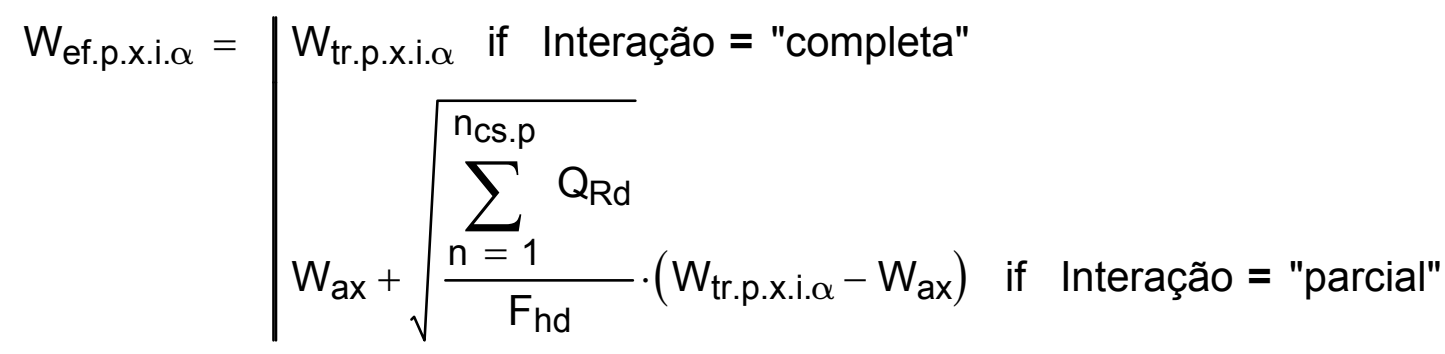

$W_{\text {ef.p.x.i. }}=965.9 \cdot \mathrm{cm}^{3}$

3.1.4.3 - Módulo de resistência plástico em relação ao eixo X

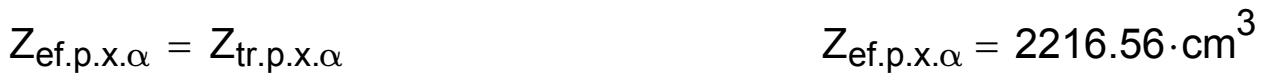

3.1.4.4 - Raio de giração em relação ao eixo x

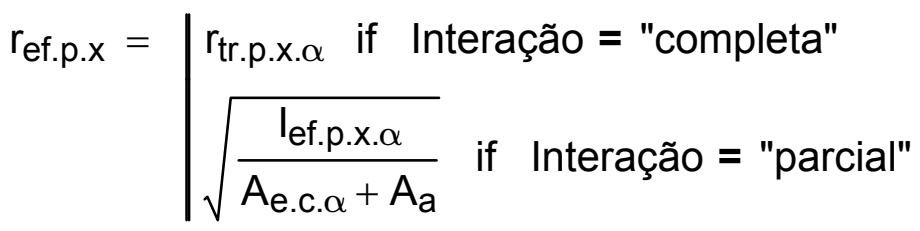

$$
\begin{aligned}
& r_{\text {ef.p.x }}=15.48 \cdot \mathrm{cm}
\end{aligned}
$$




\subsection{5 - Homogeneização efetiva da seção mista na região de momento positivo aplicado a carregamentos de longa duração $\left(E_{c} / 3\right)$}

Área total:

$$
A_{e . c .3 \alpha}+A_{a}=88.05 \cdot \mathrm{cm}^{2}
$$

Posição da linha neutra elástica segundo a face superior da laje:

$$
y_{p . s .3 \alpha}=20.83 \cdot \mathrm{cm}
$$

Posição da linha neutra elástica segundo a face inferior do perfil:

$$
y_{p . i .3 \alpha}=38.17 \cdot \mathrm{cm}
$$

Momento de inércia em relação ao eixo x:.

lef.p.x. $3 \alpha=31282.48 \cdot \mathrm{cm}^{4}$

Módulo de resistência elástico em relação ao eixo $\mathrm{x}$ segundo a face superior da laje:. $W_{\text {ef.p.x.s. } 3 \alpha}=1828.27 \cdot \mathrm{cm}^{3}$

Módulo de resistência elástico em relação ao eixo $x$ segundo a face inferior do perfil:. $W_{\text {ef.p.x.i. } 3 \alpha}=888.87 \cdot \mathrm{cm}^{3}$

Módulo de resistência plástico em relação ao eixo $\mathrm{x}$ : $Z_{\text {ef.p.x. } 3 \alpha}=2018.88 \cdot \mathrm{cm}^{3}$

Raio de giração em relação ao eixo x:....... $r_{\text {ef.p.x. } 3 \alpha}=18.85 \cdot \mathrm{cm}$

\subsection{6 - Homogeneização efetiva da seção mista na região de momento positivo aplicado ao procedimento alternativo $\left(E_{c} / 2\right)$}

Área total:

$$
A_{\text {e.c. } 2 \alpha}+A_{a}=108.81 \cdot \mathrm{cm}^{2}
$$

Posição da linha neutra elástica segundo a face superior da laje:

$y_{p . s .2 \alpha}=17.47 \cdot \mathrm{cm}$

Posição da linha neutra elástica segundo a face inferior do perfil:

$y_{p . i .2 \alpha}=41.53 \cdot \mathrm{cm}$

Momento de inércia em relação ao eixo x:. lef.p.x. $2 \alpha=35079.45 \cdot \mathrm{cm}^{4}$

Módulo de resistência elástico em relação ao eixo $\mathrm{x}$ segundo a face superior da laje:. $W_{\text {ef.p.x.s. } 2 \alpha}=2480.16 \cdot \mathrm{cm}^{3}$

Módulo de resistência elástico em relação ao eixo $\mathrm{x}$ segundo a face inferior do perfil:. $W_{\text {ef.p.x.i.2 } \alpha}=922.2 \cdot \mathrm{cm}^{3}$ Módulo de resistência plástico em relação ao eixo $\mathrm{x}$ : $Z_{\text {ef.p.x.2 }}=1916.67 \cdot \mathrm{cm}^{3}$

Raio de giração em relação ao eixo x:....... $\quad r_{\text {ef.p.x.2 } 2 \alpha}=17.96 \cdot \mathrm{cm}$ 


\subsection{7 - Homogeneização teórica da seção na região de momento negativo}

3.1.7.1 - Armadura longitudinal

3.1.7.1.1 - Posição do centróide da armadura longitudinal segundo a face superior da laje

$y^{\prime}{ }_{s l}=c_{n o m}+\frac{\phi}{2} \quad y^{\prime}{ }_{s l}=2.4 \cdot \mathrm{cm}$

3.1.7.1.3 - Momento de inércia das armaduras em relação ao eixo x passando pelo centróide

$\mathrm{I}_{\mathrm{sl} . \mathrm{x}}=\mathrm{n}_{\phi} \cdot \frac{\pi \cdot\left(\frac{\phi}{2}\right)^{4}}{4} \quad \quad \mathrm{I}_{\mathrm{sl} . \mathrm{x}}=0.2 \cdot \mathrm{cm}^{4}$

\subsubsection{2 - Perfil de aço}

3.1.7.2.1 - Posição do centróide segundo a face superior da laje

$$
y_{a}^{\prime}=\frac{d}{2}+h_{F}+t_{c} \quad y_{a}^{\prime}=36.5 \cdot c m
$$

3.1.7.3 - Seção homogeneizada (armadura longitudinal + perfil de aço)

\subsubsection{1 - Posição da linha neutra}

$$
\begin{array}{ll}
y_{n . s}=\frac{A_{s l} \cdot y_{s l}^{\prime}+A_{a} \cdot y_{a}^{\prime}}{A_{s l}+A_{a}} & y_{n . s}=33.18 \cdot c m \\
y_{n . i}=d+h_{F}+t_{c}-y_{n . s} & y_{n . i}=25.82 \cdot c m
\end{array}
$$

3.1.7.3.2 - Elemento da viga mista em que a LNE se encontra

$$
\text { LNE }=\mid \begin{aligned}
& \text { "mesa superior" if } t_{c}+h_{F}<y_{n . s} \leq t_{c}+h_{F}+t_{f} \\
& \text { "alma" if } y_{n . s}>t_{c}+h_{F}+t_{f}
\end{aligned}
$$

LNE = "alma"

3.1.7.3.3 - Momento de inércia em relação ao eixo $x$

$$
\begin{aligned}
& I_{\text {tr.n.x }}=I_{s l . x}+I_{a x}+A_{s l} \cdot y_{s}^{\prime}{ }^{2}+A_{a} \cdot y_{a}^{\prime}{ }^{2}-\left(A_{s l}+A_{a}\right) \cdot y_{n . s}{ }^{2} \\
& I_{\text {tr.n.x }}=18945.59 \cdot \mathrm{cm}^{4}
\end{aligned}
$$


3.1.7.3.4 - Módulo de resistência elástico em relação ao eixo x:

$$
\begin{array}{ll}
W_{\text {tr.n.x.s }}=\frac{I_{\text {tr.n.x }}}{y_{\text {n.s }}-c_{\text {nom }}-\frac{\phi}{2}} & W_{\text {tr.n.x.s }}=615.59 \cdot \mathrm{cm}^{3} \\
W_{\text {tr.n.x.i }}=\frac{I_{\text {tr.n.x }}}{y_{\text {n.i }}} & W_{\text {tr.n.x.i }}=733.65 \cdot \mathrm{cm}^{3}
\end{array}
$$

3.1.7.3.5 - Módulo de resistência plástico em relação ao eixo x

$$
\begin{aligned}
& \left.Z_{\text {tr.n.x }}=\mid\left[A_{s \mid} \cdot\left(y_{n . s}-c_{n o m}-\frac{\phi}{2}\right) \ldots\right] \quad\right] \text { if } L N E=\text { "alma" } \\
& +\left(b_{f} \cdot t_{f}\right) \cdot\left(y_{n \cdot s}-t_{c}-h_{F}-\frac{t_{f}}{2}\right) \ldots \\
& \left.\begin{array}{l}
+\left[\left(y_{n . s}-t_{c}-h_{F}-t_{f}\right) \cdot t_{w}\right] \cdot\left(\frac{y_{n . s}-t_{c}-h_{F}-t_{f}}{2}\right) \ldots \\
+\left[\left(y_{n . i}-t_{f}\right) \cdot t_{w}\right] \cdot\left(\frac{y_{n . i}-t_{f}}{2}\right)+\left(b_{f} \cdot t_{f}\right) \cdot\left(y_{n . i}-\frac{t_{f}}{2}\right)
\end{array}\right] \\
& {\left[A_{s l} \cdot\left(y_{n . s}-c_{n o m}-\frac{\phi}{2}\right) \ldots\right] \text { otherwise }} \\
& +\left[b_{f} \cdot\left(y_{n . s}-t_{c}-h_{F}\right)\right] \cdot\left(\frac{y_{n . s}-t_{c}-h_{F}}{2}\right) \ldots \\
& +\left[b_{f} \cdot\left(y_{n . i}-h-t_{f}\right)\right] \cdot\left(\frac{y_{n} \cdot i-h-t_{f}}{2}\right) \ldots \\
& {\left[+\left(h \cdot t_{w}\right) \cdot\left(y_{n . i}-t_{f}-\frac{h}{2}\right)+\left(b_{f} \cdot t_{f}\right) \cdot\left(y_{n . i}-\frac{t_{w}}{2}\right)\right]} \\
& Z_{\text {tr.n.x }}=882.64 \cdot \mathrm{cm}^{3}
\end{aligned}
$$

3.1.7.3.6 - Raio de giração em relação ao eixo x

$$
r_{\text {ef.n.x }}=\sqrt{\frac{I_{\text {tr.n.x }}}{A_{s l}+A_{a}}} \quad r_{\text {ef.n.x }}=19.17 \cdot \mathrm{cm}
$$




\subsection{8 - Fator de redução do momento fletor sobre os apoios} (EN 1994-1-1:2004)

3.1.8.1 - Fator de redução do momento fletor devido a fissuração do concreto 3.1.8.1.1 - Máxima tensão de tração no concreto

$$
\sigma_{\mathrm{ct}}=\frac{\mathrm{M}_{\mathrm{L} \text {.Srar.n. } \alpha}}{\frac{\mathrm{I}_{\text {tr.n.x }}}{\mathrm{y}_{\mathrm{n} . \mathrm{s}}}}+\frac{\mathrm{M}_{\mathrm{L} . \text { Srar.n. } 3 \alpha}}{\frac{\mathrm{I}_{\text {tr.n.x }}}{\mathrm{y}_{\mathrm{n} . \mathrm{s}}}} \quad \sigma_{\mathrm{ct}}=24.61 \cdot \frac{\mathrm{kN}}{\mathrm{cm}^{2}}
$$

3.1.8.1.2 - Fator de redução devido a fissuração do concreto Diagrama resultante dos carregamentos de curta duração:

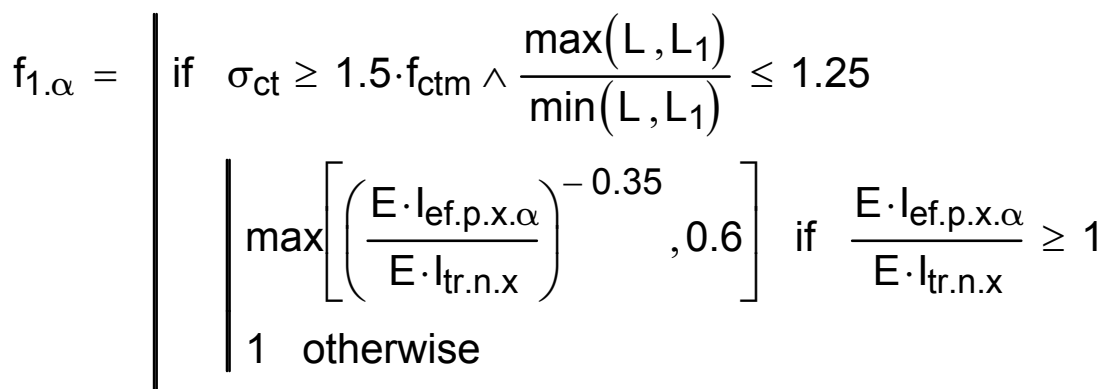

$$
\begin{aligned}
& \mid \begin{array}{l}
0.6 \text { if } \sigma_{\mathrm{ct}} \geq 1.5 \cdot \mathrm{f}_{\mathrm{ctm}} \wedge \frac{\max \left(\mathrm{L}, \mathrm{L}_{1}\right)}{\min \left(\mathrm{L}, \mathrm{L}_{1}\right)}>1.25 \\
1 \text { otherwise }
\end{array} \\
& f_{1 . \alpha}=0.76
\end{aligned}
$$

Diagrama resultante dos carregamentos de longa duração:

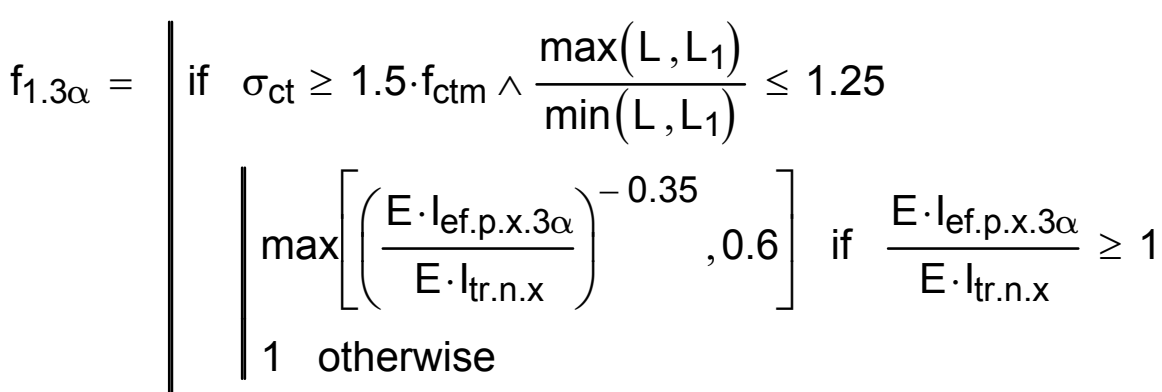

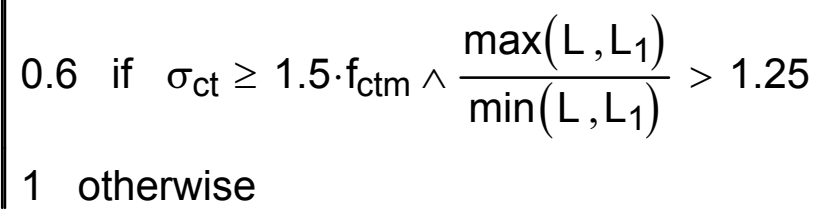

$f_{1.3 \alpha}=0.84$ 
Diagrama resultante dos carregamentos do procedimento alternativo:

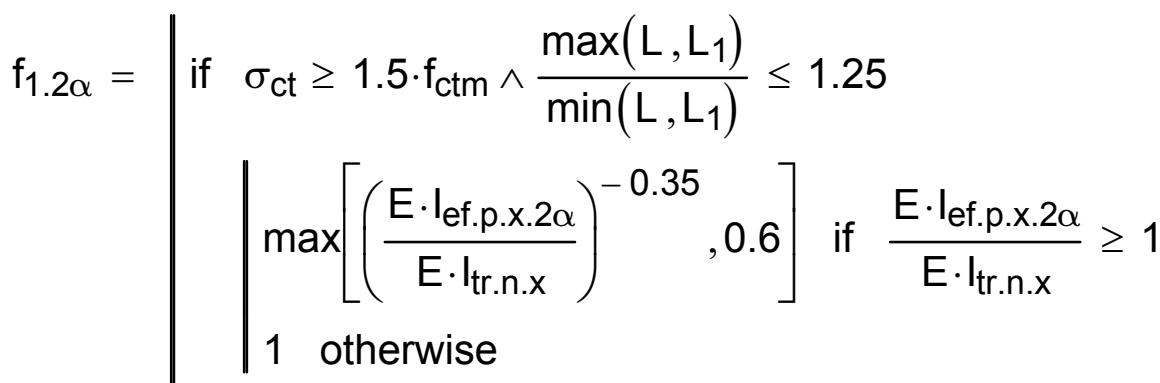

$$
\begin{aligned}
& \begin{array}{l}
0.6 \text { if } \sigma_{\mathrm{ct}} \geq 1.5 \cdot \mathrm{f}_{\mathrm{ctm}} \wedge \frac{\max \left(L, L_{1}\right)}{\min \left(L, L_{1}\right)}>1.25 \\
1 \text { otherwise }
\end{array} \\
& f_{1.2 \alpha}=0.81
\end{aligned}
$$

3.1.8.2 - Influência do escoamento do aço estrutural sobre os apoios:

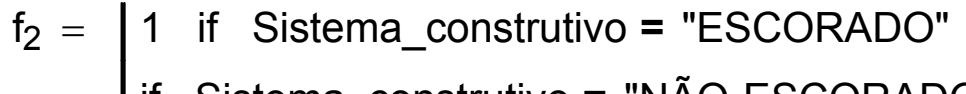

$$
\begin{aligned}
& \text { if Sistema_construtivo = "NÃO-ESCORADO" }
\end{aligned}
$$

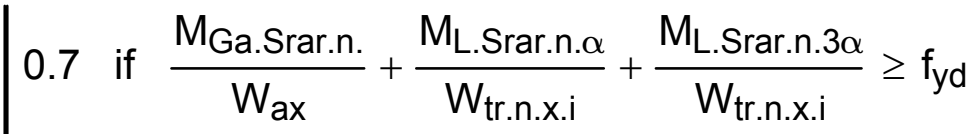

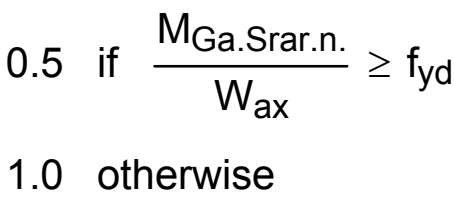

$$
\begin{aligned}
& f_{2}=1
\end{aligned}
$$

\subsubsection{3 - Fator de redução do momento fletor}

3.1.8.3.1 - Diagrama dos carregamentos de curta duração

$$
\mathrm{f}_{\text {red. } \alpha}=\mathrm{f}_{1 . \alpha} \cdot \mathrm{f}_{2} \quad \mathrm{f}_{\text {red. } \alpha}=0.76
$$

3.1.8.3.2 - Diagrama dos carregamentos de longa duração

$$
\begin{array}{ll}
f_{\text {red. } 3 \alpha}=f_{1.3 \alpha} \cdot f_{2} & f_{\text {red. } 3 \alpha}=0.84
\end{array}
$$

3.1.8.3.4 - Diagrama dos carregamentos do procedimento alternativo $f_{\text {red. } 2 \alpha}=f_{1.2 \alpha} \cdot f_{2}$

$$
\mathrm{f}_{\text {red.2 } 2 \alpha}=0.81
$$


3.1.9 - Flecha dos carregamentos de curta duração

$\delta_{\alpha}=3.1 \cdot \mathrm{mm} \quad($ Vão $=$ "EXTREMO" )

3.1.10 - Flecha dos carregamentos de longa duração

$\delta_{3 \alpha}=9.26 \cdot \mathrm{mm} \quad($ Vão $=$ "EXTREMO" )

\subsubsection{1 - Flecha final}

$$
\delta_{\text {final }}=\delta_{\alpha}+\delta_{3 \alpha} \quad \delta_{\text {final }}=12.36 \cdot \mathrm{mm}
$$

3.1.12 - Flecha calculada pelo procedimento alternativo $\delta_{2 \alpha}=11.94 \cdot \mathrm{mm} \quad$ (Vão = "EXTREMO" )

3.1.13 - Relação entre os procedimentos adotados $\frac{\delta_{2 \alpha}}{\delta_{\text {final }}}=0.97$

3.2 - Controle das fissuras no concreto

3.2.1 - Armadura mínima de tração sob deformações impostas 3.2.1.1 - Área efetiva da laje de concreto
$A_{c t}=b_{n} \cdot t_{c}$
$A_{c t}=731.25 \cdot \mathrm{cm}^{2}$

3.2.1.2 - Coeficiente de correção que considera o mecânismo de geração de tensões de tração

$\mathrm{k}=0.8$

3.2.1.3 - Coeficiente de redução da força normal na laje devido à fissuração inicial e ao deslizamento local da ligação entre a laje e o perfil de aço

$\mathrm{k}_{\mathrm{s}}=0.9$

3.2.1.4 - Coeficiente que considera o equilíbrio e a distribuição das tensões na laje de concreto imediatamente antes da ocorrência das fissuras

$\mathrm{k}_{\mathrm{c}}=1$ 
3.2.1.5 - Resistência média à tração efetiva do concreto no instante em que se formam as primeiras fissuras

$f_{\text {ct.ef }}=0.3 \frac{\mathrm{kN}}{\mathrm{cm}^{2}}$

3.2.1.6 - Máxima tensão de tração permitida na armadura, imediatamente após a ocorrência da fissuração

$\sigma_{\mathrm{st}}=\min \left[810 \cdot\left(\frac{\mathrm{w}_{\mathrm{k}}}{\mathrm{mm}}\right)^{0.5} \cdot \sqrt{\frac{\left(\frac{\mathrm{f}_{\mathrm{ck}}}{\mathrm{MPa}}\right)^{\frac{2}{3}}}{\left(\frac{\phi}{\mathrm{mm}}\right)^{2}}} \cdot \mathrm{MPa}, \mathrm{f}_{\mathrm{ys}}\right]$

$\sigma_{\mathrm{st}}=42.58 \cdot \frac{\mathrm{kN}}{\mathrm{cm}^{2}}$

3.2.1.7 - Armadura mínima de tração sob deformações impostas
$A_{\text {sl.di }}=\frac{k \cdot k_{c} \cdot k_{s} \cdot f_{c t . e f} \cdot A_{c t}}{\sigma_{\text {st }}}$
$A_{\text {sl.di }}=3.71 \cdot \mathrm{cm}^{2}$

$\underline{3.2 .1 .8 ~-~ A r m a d u r a ~ l o n g i t u d i n a l ~ a d o t a d a ~}$

$A_{S I}=5.03 \cdot \mathrm{cm}^{2}$

3.2.1.9 - Verificação da armadura mínima de tração sob deformações impostas

Verificação_de_Asl $=\mid \begin{array}{ll}\text { "ok!" if } & A_{\text {sl }} \geq A_{\text {sl.di }} \\ \text { "não ok!" } & \text { otherwise }\end{array}$

Verificação_de_Asl = "ok!" 


\subsection{2 - Armadura mínima de tração sob ações impostas}

\subsubsection{1 - Tensão de tração no centro geométrico da armadura}

$$
\sigma_{\mathrm{si}}=\frac{\mathrm{M}_{\mathrm{L} . \text { Sfre.n }}}{\mathrm{W}_{\text {tr.n.x.s }}} \quad \sigma_{\mathrm{si}}=147.29 \cdot \mathrm{MPa}
$$

\subsubsection{2 - Espaçamento das barras da armadura}

$$
\mathrm{S}=\frac{\mathrm{b}_{\mathrm{n}}}{\mathrm{n}_{\phi}} \quad \mathrm{S}=112.5 \cdot \mathrm{mm}
$$

3.2.2.2.1 - Espaçamento máximo das barras da armadura

$$
S_{\max }=\mid \begin{aligned}
& 150 \mathrm{~mm} \text { if } \sigma_{\mathrm{si}} \leq 280 \mathrm{MPa} \\
& 100 \mathrm{~mm} \text { if } 280 \mathrm{MPa}<\sigma_{\mathrm{si}} \leq 320 \mathrm{MPa} \\
& 50 \mathrm{~mm} \text { if } 320 \mathrm{MPa}<\sigma_{\mathrm{si}} \leq 360 \mathrm{MPa} \\
& 0 \mathrm{~mm} \text { otherwise }
\end{aligned}
$$

$\mathrm{S}_{\max }=150 \cdot \mathrm{mm}$

3.2.2.2.2 - Verificação do espaçamento máximo das barras da armadura

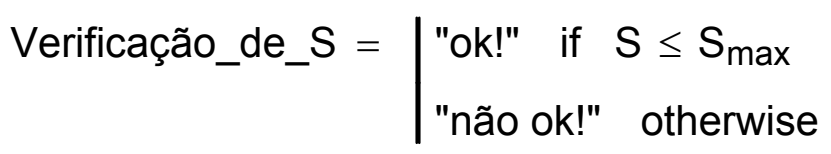

Verificação_de_S = "ok!"

3.2.2.2.3 - Espaçamento adotado das barras da armadura

$$
\mathrm{S}_{\mathrm{ad}}=115 \mathrm{~mm}
$$

\subsubsection{3 - Diâmetro das barras longitudinais da armadura}

$\phi=8 \cdot \mathrm{mm}$

3.2.2.3.1 - Diâmetro máximo das barras da armadura

$$
\phi_{\max }=\mid \begin{aligned}
& 16 \mathrm{~mm} \text { if } \sigma_{\mathrm{si}} \leq 280 \mathrm{MPa} \\
& 12.5 \mathrm{~mm} \text { if } 280 \mathrm{MPa}<\sigma_{\mathrm{si}} \leq 320 \mathrm{MPa} \\
& 10 \mathrm{~mm} \text { if } 320 \mathrm{MPa}<\sigma_{\mathrm{si}} \leq 360 \mathrm{MPa} \\
& 8 \mathrm{~mm} \text { if } 360 \mathrm{MPa}<\sigma_{\mathrm{si}} \leq 400 \mathrm{MPa}
\end{aligned}
$$

$\phi_{\max }=16 \cdot \mathrm{mm}$ 
3.2.2.3.2 - Verificação do diâmetro das barras longitudinais da armadura

Verificação_do_ $\phi=\mid \begin{aligned} & \text { "ok!" if } \phi \leq \phi_{\max } \\ & \text { "não ok!" otherwise }\end{aligned}$

Verificação_do_ф = "ok!"

3.3 - Área mínima da armadura longitudinal dentro da largura efetiva da lajı de concreto (NBR 6118:2003)

3.3.1 - Área da armadura longitudinal

$A_{s l}=5.03 \cdot \mathrm{cm}^{2}$

3.3.2 - Área mínima da armadura longitudinal
$A_{s l . m i n}=b_{n} \cdot t_{c} \cdot \rho_{s}$
$\mathrm{A}_{\mathrm{sl} \text {.min }}=1.1 \cdot \mathrm{cm}^{2}$

3.3.3 - Verificação da área mínima de armadura longitudinal

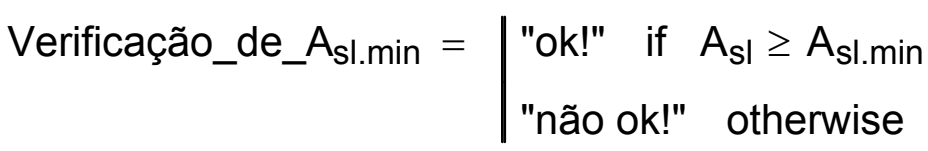

Verificação_de_Asl.min = "ok!" 


\section{4 - Verificação da análise elástica dos deslocamentos}

4.1 - Máxima tensão de tração no perfil de aço

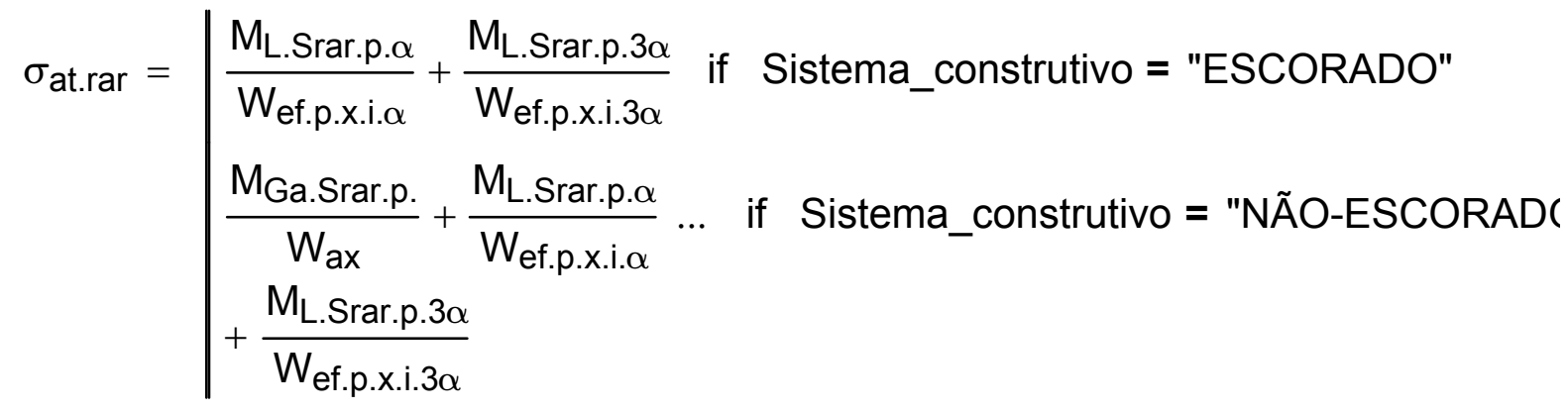

$$
\begin{aligned}
& \sigma_{\text {at.rar }}=30.65 \cdot \frac{\mathrm{kN}}{\mathrm{cm}^{2}}
\end{aligned}
$$

4.1.1 - Verificação da tensão máxima de tração no perfil de aço

Verificação_de_$\sigma_{\text {at.rar }}=\mid \begin{aligned} & \text { "ok!" if } \sigma_{\text {at.rar }}<f_{y d} \\ & \text { "A análise elástica não é aplicável" otherwise }\end{aligned}$

Verificação_de_ $\sigma_{\text {at.rar }}=$ "ok!"

4.2 - Máxima tensão de compressão no perfil de aço

As considerações adotadas sobre a análise elástica no item 3.1.8.2 permitem que a seção de aço sobre os apoios plastifique sem a necessidade de trocar a bitola.

\section{3 - Máxima tensão de tração na armadura}

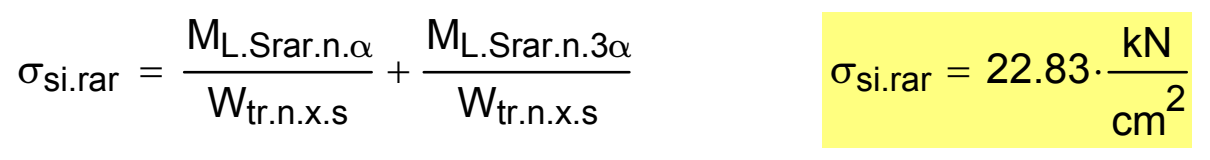

\subsection{1 - Verificação da tensão máxima de tração na armadura}

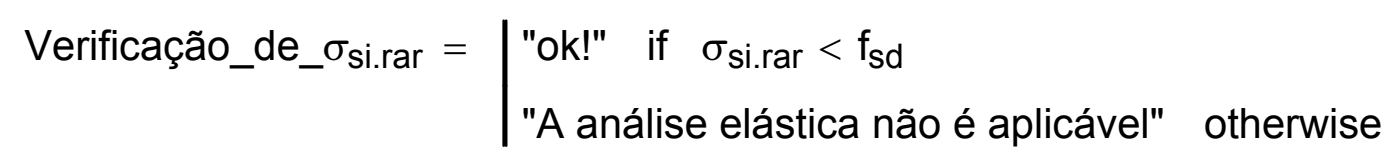

Verificação_de_ $\sigma_{\text {si.rar }}=$ "ok!" 
5 - Verificação do modelo não-fissurado para análise dos esforços no ELU (EN 1994-1-1:2004)

5.1 - Máxima tensão de tração no concreto - combinação característica (EN 1990:2002)

$$
\sigma_{\text {ct.car }}=\frac{0.7 \cdot M_{\text {Scar.n }}}{\frac{I_{\text {tr.n.x }}}{y_{\text {n.s }}}} \quad \sigma_{\text {ct.car }}=29.29 \cdot \frac{\mathrm{kN}}{\mathrm{cm}^{2}}
$$

\section{2 - Verificação dos modelos de análise não-fissurados}

\begin{tabular}{l|l} 
Verificação_de_$\sigma_{\text {ct.car }}=$ & $\begin{array}{l}\text { "ok!" if } \quad \sigma_{\text {ct.car }} \leq 2 \cdot f_{\text {ctm }} \\
\text { "analisar aplicando o modelo fissurado!" }\end{array}$
\end{tabular}

Verificação_de_ $\sigma_{\text {ct.car }}=$ "analisar aplicando o modelo fissurado!"

6 - Disposições para lajes de concreto com fôrma de aço incorporada e conectores de cisalhamento

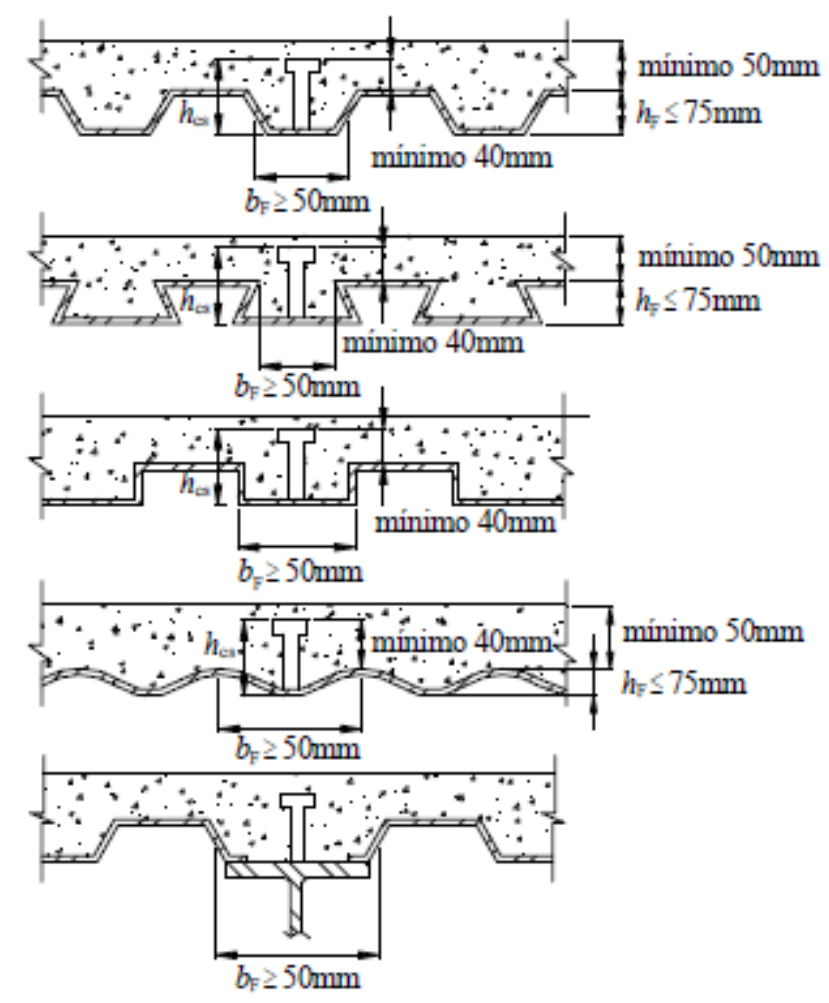

Figura 6.1 - Lajes de concreto com fôrma de aço incorporada (NBR 8800:2008)

6.1 - Verficação da altura das nervuras da fôrma de aço incorporada

\begin{tabular}{l|l} 
Verificação_de_h $h_{F}=\mid \begin{array}{l}\text { "ok!" if } h_{F} \leq 75 \mathrm{~mm} \\
\text { "não aplicável às prescrições da NBR 8800" otherwise }\end{array}$
\end{tabular}

Verificação_de_h $h_{F}=$ "ok!" 
6.2 - Verificação da largura média da mísula ou da nervura situada sobre o perfil de aço

\begin{tabular}{l|l} 
Verificação_de__b & "ok!" if $\quad b_{F} \geq 50 \mathrm{~mm}$ \\
"não aplicável às prescrições da NBR 8800" otherwise
\end{tabular}

Verificação_de_b $b_{F}=$ "ok!"

6.3 - Verificação da projeção dos conectores acima do topo da fôrma

Verificação_projeção $=\mid \begin{aligned} & \text { "ok!" if } h_{C S}-h_{F} \geq 40 m m \\ & \text { "não aplicável às prescrições da NBR 8800" otherwise }\end{aligned}$

Verificação_projeção = "ok!"

6.4 - Verificação do cobrimento de concreto acima do topo da fôrma de aço

\begin{tabular}{l||l} 
Verificação_de_t $t_{c}=$ & "ok!" if $t_{c} \geq 50 \mathrm{~mm}$ \\
"não aplicável às prescrições da NBR 8800" otherwise
\end{tabular}

Verificação_de_t ${ }_{c}=$ "ok!"

6.5 - Verificação do cobrimento $\left(c_{c s}\right)$ de concreto acima do topo do pino com cabeça

\begin{tabular}{l|l} 
Verificação_c $c_{c s}=\mid \begin{array}{l}\text { "ok!" if } t_{c}+h_{F}-h_{c s} \geq 10 m m \\
\text { "não aplicável às prescrições da NBR 8800" otherwise }\end{array}$
\end{tabular}

Verificação_c ${ }_{\mathrm{cs}}=$ "ok!"

6.6 - Verificação do comprimento final $\left(h_{c s}\right)$ do pino com cabeça

Verificação_de_h $h_{c s}=\mid \begin{aligned} & \text { "ok!" if } h_{c s} \geq 4 \cdot d_{C S} \\ & \text { "não aplicável às prescrições da NBR 8800" otherwise }\end{aligned}$

Verificação_de_h $\mathrm{h}_{\mathrm{cs}}=$ "ok!"

6.7 - Verificação do diâmetro (dcs) do pino com cabeça fora da posição correspondente à alma do perfil de aço

Verificação_de_d $d_{c s}=\mid \begin{aligned} & \text { "ok!" if } d_{C S} \leq 2.5 \cdot t_{f} \\ & \text { "posicionamento sobre a alma do perfil" otherwise }\end{aligned}$

Verificação_de_d 
7 - Análise do $C_{b}$ conforme item 5.4.2.4 da NBR 8800:2008

7.1 - Esforços solicitantes ao longo do vão analisado

7.1.1 - Maior momento fletor solicitante de cálculo que comprime a mesa livre nas extremidades do comprimento destravado

$M_{0}=-\psi \cdot M_{0}$

$\mathrm{M}_{0}=-232.25 \cdot \mathrm{kN} \cdot \mathrm{m}$

7.1.2 - Momento fletor solicitante de cálculo na outra extremidade do comprimento destravado

$M_{1}=\mid \begin{aligned} & 0 \text { if Diagrama_de_momento_fletor }=1 \\ & -0.5 \cdot \psi \cdot \mathrm{M}_{\mathrm{O}} \text { if Diagrama_de_momento_fletor }=2 \\ & -0.75 \cdot \psi \cdot \mathrm{M}_{\mathrm{O}} \text { if Diagrama_de_momento_fletor }=3 \\ & -\psi \cdot \mathrm{M}_{\mathrm{O}} \text { if Diagrama_de_momento_fletor }=4 \\ & 0 \text { if Diagrama_de_momento_fletor }=5 \\ & -\psi \cdot \mathrm{M}_{\mathrm{O}} \text { if Diagrama_de_momento_fletor }=6\end{aligned}$

$\mathrm{M}_{1}=0 \cdot \mathrm{kN} \cdot \mathrm{m}$

7.1.3 - Momento fletor solicitante de cálculo na seção central do comprimento destravado

$\mathrm{M}_{2}=\mathrm{M}_{\mathrm{o}}+\frac{\mathrm{M}_{0}+\mathrm{M}_{1}}{2} \quad \mathrm{M}_{2}=289.09 \cdot \mathrm{kN} \cdot \mathrm{m}$

7.2 - Fator de modificação para diagrama de momento fletor não-uniforme

$\mathrm{C}_{\mathrm{b}}=3-\frac{2}{3} \cdot \frac{\mathrm{M}_{1}}{\mathrm{M}_{0}}-\frac{8}{3} \cdot \frac{\mathrm{M}_{2}}{\left(\mathrm{M}_{0}+\mathrm{M}_{1}\right)} \quad \mathrm{C}_{\mathrm{b}}=6.32$

7.3 - Coeficiente $\beta_{1}$

$\beta_{1}=\frac{\left(f_{y}-f_{r}\right) \cdot W_{a x}}{E \cdot J} \quad \beta_{1}=9.51 \frac{1}{m}$

7.4 - Classificação da seção quanto a ocorrencia de flambagem local

7.4.1 - Parâmetro de esbeltez correspondente à plastificação

$\lambda_{p}=1.76 \cdot \sqrt{\frac{E}{f_{y}}} \quad \lambda_{p}=42.38$ 
7.4.2 - Parâmetro de esbeltez correspondente ao início do escoamento

$\lambda_{r}=\frac{1.38 \cdot \sqrt{l_{a y} \cdot J}}{r_{a y} \cdot J \cdot \beta_{1}} \cdot \sqrt{1+\sqrt{1+\frac{27 \cdot C_{w} \cdot \beta_{1}^{2}}{l_{a y}}}}=123.3$

7.4.3 - Índice de esbeltez

$\lambda=\frac{\mathrm{L}_{\mathrm{b}}}{\mathrm{r}_{\mathrm{ay}}}=403.71$

7.4.4 - Momento resistente de cálculo para flambagem lateral distorcional

Momento de proporcionalidade:

$M_{r}=W_{a x} \cdot f_{y}=209.61 \cdot k N \cdot m$

Momento de plastificação:

$M_{p l}=Z_{a x} \cdot f_{y}=248.74 \cdot k N \cdot m$

Momento fletor de flambagem elástica:

$\mathrm{M}_{\mathrm{cr}}=\frac{\mathrm{C}_{\mathrm{b}} \cdot \pi^{2} \cdot \mathrm{E} \cdot \mathrm{l}_{\mathrm{ay}}}{\mathrm{L}_{\mathrm{b}}^{2}} \cdot \sqrt{\frac{\mathrm{C}_{\mathrm{w}}}{\mathrm{lay}_{\mathrm{ay}}} \cdot\left(1+0.039 \cdot \frac{\mathrm{J} \cdot \mathrm{L}_{\mathrm{b}}^{2}}{\mathrm{C}_{\mathrm{w}}}\right)}=139.87 \cdot \mathrm{kN} \cdot \mathrm{m}$

$M_{\text {Rd.Cb }}=\mid \begin{aligned} & \frac{M_{p l}}{\gamma_{a 1}} \text { if } \lambda \leq \lambda_{p} \\ & \min \left[\frac{C_{b}}{\gamma_{a 1}} \cdot\left[M_{p l}-\left(M_{p l}-M_{r}\right) \cdot \frac{\lambda-\lambda_{p}}{\lambda_{r}-\lambda_{p}}\right], \frac{M_{p l}}{\gamma_{a 1}}\right] \text { if } \lambda_{p}<\lambda \leq \lambda_{r} \\ & \min \left(\frac{M_{c r}}{\gamma_{a 1}}, \frac{M_{p l}}{\gamma_{a 1}}\right) \text { if } \lambda>\lambda_{r}\end{aligned}$

$M_{R d . C b}=127.15 \cdot k N \cdot m \quad$ Situação $=" \lambda>\lambda . r "$

7.5 - Relação entre os momentos resistentes encontrados pelos dois procedimentos

$$
\frac{M_{\text {Rd.Cb }}}{M_{\text {dist.Rd.n }}}=0.53
$$




\section{VERIFICAÇÃO DOS DESLOCAMENTOS}

1 - Deslocamentos antes da cura do concreto

1.1 - Flecha crítica ( Vão = "EXTREMO" )

$\delta_{\mathrm{Ga}}=36.04 \cdot \mathrm{mm}$

2 - Deslocamentos após a cura do concreto

2.1 - Deslocamentos sem efeitos de longa duração das ações variáveis $\delta_{\alpha}=3.1 \cdot \mathrm{mm}$

2.2 - Deslocamentos com efeitos de longa duração das ações permanentes e quase permanentes

$\delta_{3 \alpha}=9.26 \cdot \mathrm{mm}$

2.3 - Deslocamentos calculados pelo procedimento alternativo (item 1.4.4.3) - Vão = "EXTREMO"

$\delta_{2 \alpha}=11.94 \cdot \mathrm{mm}$

3 - Sobreposição dos deslocamentos

3.1 - Flecha total

$\delta_{\text {tot }}=\delta_{\mathrm{Ga}}+\delta_{\alpha}+\delta_{3 \alpha} \quad \delta_{\text {tot }}=48.4 \cdot \mathrm{mm}$

3.3 - Deslocamento limite para vigas de piso

$\delta_{\lim }=\frac{\mathrm{L}}{350}$

$\delta_{\lim }=25.71 \cdot \mathrm{mm}$

3.4 - Verificação da flecha total

$\frac{\delta_{\text {tot }}}{\delta_{\lim }}=1.88 \quad$ Verificação_de_ $\delta_{\text {tot }}=$ "não ok!"

3.5 - Aplicando uma contraflecha com valor dos deslocamentos das ações permanentes antes da cura
$\delta_{0}=\delta_{\mathrm{Ga}}$
$\delta_{0}=36.04 \cdot \mathrm{mm}$

3.5.1 - Deslocamento máximo atingido pela viga mista

$\delta_{\max }=\delta_{\mathrm{Ga}}+\delta_{\alpha}+\delta_{3 \alpha}-\delta_{0}$

$\delta_{\max }=12.36 \cdot \mathrm{mm}$ 
3.4 - Verificação das flechas máxima atingida pela viga mista
$\frac{\delta_{\max }}{\delta_{\lim }}=0.48$
Verificação_de_ $\delta_{\max }=$ "ok!" 


\section{APÊNDICE C \\ CÁLCULO DE UM PILAR ISOLADO SOB SOLICITAÇÕES COMBINADAS SEGUNDO AS PRESCRIÇÕES DA ABNT NBR $8800: 2008$}




\section{APÊNDICE C: Cálculo de um pilar isolado sob solicitações combinadas segundo as prescrições da NBR 8800:2008}

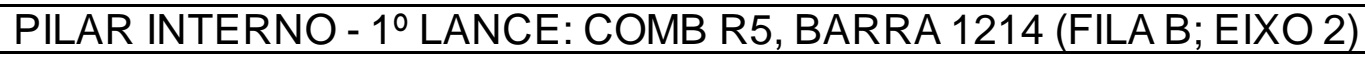

\section{1 - Dados de entrada}

1.1 - Propriedades goemétricas do perfil de aço ( Bitola = "PS $750 \times 431 "$ )

Altura total:

Largura da mesa:

Espessura da mesa:

Altura da alma:

Espessura da alma:

Área bruta:

Mom. de Inércia $X$ :

Mom. de Inércia Y:

Mom. de Inércia Torção:

Raio de Giração X:

Raio de Giração Y:

Const. de Empenamento

Módulo elástico $X$ :

Módulo elástico $Y$ :

Módulo plástico X:

Módulo plástico Y:

Coord. X Centro de Torção:

Coord. Y Centro de Torção:

$$
\mathrm{d}=750 \cdot \mathrm{mm}
$$

$$
b_{f}=450 \cdot \mathrm{mm}
$$$$
\mathrm{t}_{\mathrm{f}}=44.5 \cdot \mathrm{mm}
$$$$
\mathrm{h}=661 \cdot \mathrm{mm}
$$$$
\mathrm{t}_{\mathrm{w}}=22.4 \cdot \mathrm{mm}
$$$$
A_{a}=548.56 \cdot \mathrm{cm}^{2}
$$$$
\mathrm{l}_{\mathrm{ax}}=552923.55 \cdot \mathrm{cm}^{4}
$$$$
I_{\text {ay }}=67646.29 \cdot \mathrm{cm}^{4}
$$

$\mathrm{J}=2891.28 \cdot \mathrm{cm}^{4}$

$r_{a x}=31.75 \cdot c m$

$r_{a y}=11 \cdot 1 \cdot \mathrm{cm}$

$C_{w}=84174006.48 \cdot \mathrm{cm}^{6}$

$\mathrm{W}_{\mathrm{ax}}=14744.63 \cdot \mathrm{cm}^{3}$

$W_{\text {ay }}=3006.5 \cdot \mathrm{cm}^{3}$

$\mathrm{Z}_{\mathrm{ax}}=16574.4 \cdot \mathrm{cm}^{3}$

$Z_{a y}=4588.54 \cdot \mathrm{cm}^{3}$

$x_{0}=0 \mathrm{~cm}$

$y_{0}=0 \mathrm{~cm}$ 


\section{2 - Propriedades mecânicas do aço}

Tensão de escoamento:

$$
\begin{array}{r}
f_{y}=34.5 \frac{\mathrm{kN}}{\mathrm{cm}^{2}} \\
f_{u}=45 \frac{\mathrm{kN}}{\mathrm{cm}^{2}}
\end{array}
$$

Tensões residuais:

$$
\sigma_{r}=0.3 \cdot f_{y}=10.35 \cdot \frac{\mathrm{kN}}{\mathrm{cm}^{2}}
$$

Módulo de Elasticidade Longitudinal:

$$
\begin{aligned}
& E=20000 \frac{\mathrm{kN}}{\mathrm{cm}^{2}} \\
& G=7700 \frac{\mathrm{kN}}{\mathrm{cm}^{2}}
\end{aligned}
$$

\section{3 - Sistema estrutural}

Comprimento da barra:

$$
\mathrm{L}=3500 \mathrm{~mm}
$$

Comprimento destravado da barra para flexão no eixo $x$ :

$$
L_{x}=3500 m m
$$

Comprimento destravado da barra para flexão no eixo y:

$$
\mathrm{L}_{\mathrm{y}}=3500 \mathrm{~mm}
$$

Comprimento destravado da barra para torção no eixo z:

$$
L_{z}=3500 m m \quad L_{b}=L_{z}
$$

Coeificiente de flambagem por flexão no eixo $x$

$$
\mathrm{K}_{\mathrm{X}}=1
$$

Coeificiente de flambagem por flexão no eixo y:......

$$
\mathrm{K}_{\mathrm{y}}=1
$$

Coeificiente de flambagem por flexão no eixo $z$ :

$$
\mathrm{K}_{\mathrm{z}}=1
$$

Distância entre enrijecedores:

$$
a=3500 \mathrm{~mm}
$$

\section{4 - Coeficiente de ponderação e fator de redução}

\subsection{1 - Coeficiente de ponderação das ações (combinações normais)}

Açoes permanentes diretas agrupadas:....

$$
\gamma_{g 1}=1.4
$$

Demais ações variáveis, icluindo as decorrentes do uso e ocupação: 
1.4.2 - Fatores de combinação $\left(\psi_{0}\right)$ e redução $\left(\psi_{1}\right.$ e $\left.\psi_{2}\right)$ para as ações variáveis

Pressão dinâmica do vento nas estruturas em geral:

$$
\begin{array}{lll}
\psi_{0_{1}}=0.6 & \psi_{1_{1}}=0.3 & \psi_{2_{1}}=0 \\
\psi_{0_{2}}=0.7 & \psi_{1_{2}}=0.6 & \psi_{2_{2}}=0.4
\end{array}
$$

Locais em que há predominância de elevadas concentrações de pessoas:

\subsection{3 - Coeficientes de ponderação das resistências (combinações normais)}

Escoamento do aço estrutural:

$\gamma_{\mathrm{a} 1}=1.10$

Ruptura do aço estrutural:

$$
\gamma_{\mathrm{a} 2}=1.35
$$

\section{5 - Solicitações de cálculo}

\subsection{1 - Compressão}

\subsubsection{1 - Coeficientes B2 (Anexo D - NBR 8800/2008)}

Carga gravitacional total de projeto atuante no andar considerado:

$$
\Sigma \mathrm{N}_{\mathrm{Sd}}=29848.59 \mathrm{kN}
$$

Força cortante total de projeto no andar considerado:

$$
\Sigma \mathrm{H}_{\mathrm{Sd}}=1055.96 \mathrm{kN}
$$

Coeficiente de ajuste para o sistema estrutural adotado:.

$$
R_{S}=1
$$

Deslocamento interpavimento resultante da análise linear ( $1^{\mathrm{a}}$ ordem):

$$
\Delta_{\mathrm{h}}=4.35 \mathrm{~mm}
$$

Altura do pavimento :

$$
h_{\text {pvto }}=3.5 \mathrm{~m}
$$

$$
\mathrm{B}_{2}=\frac{1}{1-\frac{1}{\mathrm{R}_{\mathrm{S}}} \cdot \frac{\Delta_{\mathrm{h}}}{\mathrm{h}_{\text {pvto }}} \cdot \frac{\Sigma \mathrm{N}_{\mathrm{Sd}}}{\Sigma \mathrm{H}_{\mathrm{Sd}}}}
$$

\subsubsection{2 - Análise da estrutura impedida de deslocar-se lateralmente (estrutura nt)}

$$
\mathrm{N}_{\mathrm{nt}}=8393.08 \mathrm{kN}
$$

\subsubsection{3 - Análise da estrutura deslocável (estrutura lt)}

$$
\mathrm{N}_{\mathrm{lt}}=3640.50 \mathrm{kN}
$$

\subsubsection{4 - Superposição dos esforço normal amplificado}

$$
\mathrm{N}_{\mathrm{Sd}}=\mathrm{N}_{\mathrm{nt}}+\mathrm{B}_{2} \cdot \mathrm{N}_{\mathrm{lt}} \quad \mathrm{N}_{\mathrm{Sd}}=12166.13 \cdot \mathrm{kN}
$$




\subsection{2 - Flexão}

1.5.2.1 - Coeficientes $\mathrm{B}_{1}$ (Anexo D - NBR 8800:2008)

Força axial que provoca flambagem

elástica por flexão em x (ver item 2.2.1):..... $\quad \mathrm{N}_{\mathrm{e}}=0.8 \cdot \mathrm{N}_{\mathrm{ex}}=712768.87 \cdot \mathrm{kN}$

Força axial de compressão solicitante de cálculo na barra considerada, em análise de primeira ordem:

$$
\mathrm{N}_{\mathrm{Sd} 1}=\mathrm{N}_{\mathrm{nt}}+\mathrm{N}_{\mathrm{lt}}=12033.58 \cdot \mathrm{kN}
$$

Menor momento fletor na direção $\mathrm{x}$ da estrutura nt, nas extremidades apoiadas da barra:.

Maior momento fletor na direção $\mathrm{x}$ da estrutura nt, nas extremidades apoiadas da barra:

Coeficiente $\mathrm{C}_{\mathrm{m}}$ :

$$
M_{1}=-8.28 \mathrm{kN} \cdot \mathrm{m}
$$

$$
C_{m}=0.6-0.4 \cdot\left(-\frac{M_{1}}{M_{2}}\right) \quad C_{m}=0.63
$$

$B_{1}=\mid \begin{aligned} & \frac{C_{m}}{1-\frac{N_{S d 1}}{N_{e}}} \text { if } \frac{C_{m}}{1-\frac{N_{S d 1}}{N_{e}}} \geq 1 \\ & 1 \text { otherwise }\end{aligned}$

$$
\begin{array}{ll}
\frac{\mathrm{C}_{\mathrm{m}}}{1-\frac{\mathrm{N}_{\mathrm{Sd} 1}}{\mathrm{~N}_{\mathrm{e}}}}=0.64 & \mathrm{~B}_{1}=1
\end{array}
$$

1.5.2.2 - Análise da estrutura impedida de deslocar-se lateralmente (estrutura nt)

$$
\mathrm{M}_{\mathrm{ntx}}=-8.28 \mathrm{kN} \cdot \mathrm{m} \quad \mathrm{M}_{\mathrm{nty}}=-2.25 \mathrm{kN} \cdot \mathrm{m}
$$

\subsubsection{3 - Análise da estrutura deslocável (estrutura It)}

$M_{\mathrm{ltx}}=-763.05 \mathrm{kN} \cdot \mathrm{m}$

$$
\mathrm{M}_{\text {lty }}=6.38 \mathrm{kN} \cdot \mathrm{m}
$$

1.5.2.4 - Superposição dos esforço de flexão amplificado

$$
\begin{array}{ll}
M_{\text {Sd.x }}=B_{1} \cdot M_{\text {ntx }}+B_{2} \cdot M_{\text {ltx }} & M_{\text {Sd.y }}=B_{1} \cdot M_{\text {nty }}+B_{2} \cdot M_{\text {lty }} \\
M_{\text {Sd.x }}=\left|M_{\text {Sd.x }}\right|=799.11 \cdot \mathrm{kN} \cdot \mathrm{m} & M_{\text {Sd.y }}=\left|M_{\text {Sd.y }}\right|=4.36 \cdot \mathrm{kN} \cdot \mathrm{m}
\end{array}
$$


1.5.3 - Cortante na direção $x$

$\mathrm{V}_{\mathrm{Sd} . \mathrm{x}}=88.41 \mathrm{kN} \quad(\mathrm{C} 1)$

1.5.4 - Cortante na direção y

$\mathrm{V}_{\text {Sd.y }}=235.92 \mathrm{kN} \quad(\mathrm{C} 2)$

2 - Estados-limites últimos (ELU) - compressão

2.1 - Flambagem Local (Anexo F - NBR 8800:2008)

2.1.1 - Elementos comprimidos AL - Mesa

Tabela F.1 (NBR 8800:2008): Grupo $_{A L}=5$

2.1.1.1 - Índice de esbeltez da mesa

$\lambda=\frac{b_{f}}{2 \cdot t_{f}}$

$$
\lambda=5.06
$$

2.1.1.2 - Parâmetro de esbeltez limite da mesa para flambagem local

$\lambda_{\lim }=k_{1} \cdot \sqrt{\frac{E \cdot k_{c}}{f_{y}}}$

$$
\lambda_{\lim }=13.22
$$

Sendo: $k_{1}=0.64$

$$
\mathrm{k}_{\mathrm{c}}=0.74
$$


2.1.1.3 - Fator de redução devido a flambagem local da mesa

$$
Q_{s}=\mid \begin{aligned}
& 1.0 \text { if } \lambda \leq \lambda_{\lim } \\
& k_{2}-k_{3} \lambda \cdot \sqrt{\frac{f_{y}}{k_{c} \cdot E}} \text { if } k_{1} \cdot \sqrt{\frac{E}{\left(\frac{f_{y}}{k_{c}}\right)}}<\lambda \leq k_{5} \sqrt{\frac{E}{\left(\frac{f_{y}}{k_{c}}\right)}} \\
& \frac{k_{4} E \cdot k_{c}}{f_{y} \cdot(\lambda)^{2}} \text { if } \lambda>k_{5} \sqrt{\frac{E}{\left(\frac{f_{y}}{k_{c}}\right)}}
\end{aligned}
$$

$\mathrm{Q}_{\mathrm{S}}=1$

Sendo: $\mathrm{k}_{1}=0.64$

$$
\begin{aligned}
& k_{2}=1.42 \\
& k_{3}=0.65 \\
& k_{4}=0.9 \\
& k_{5}=1.17
\end{aligned}
$$

\subsection{2 - Elementos comprimidos AA - Alma}

Tabela F.1 (NBR 8800:2008):

$$
\text { Grupo }_{A A}=2
$$

2.1.1.1 - Índice de esbeltez da alma

$$
\lambda=\frac{\mathrm{h}}{\mathrm{t}_{\mathrm{w}}} \quad \lambda=29.51
$$

2.1.1.2 - Parâmetro de esbeltez limite da alma para flambagem local

$$
\lambda_{\lim }=k_{6} \cdot \sqrt{\frac{E}{f_{y}}}
$$

$$
\lambda_{\lim }=35.87
$$

Sendo: $\mathrm{k}_{6}=1.49$

\subsubsection{3 - Fator de redução devido a flambagem local da alma}

2.1.1.3.1 - Tensão máxima na seção:

$\sigma=\mathrm{f}_{\mathrm{y}} \quad$ (a favor da segurança) 
2.1.1.3.2 - Largura efetiva do elemento AA

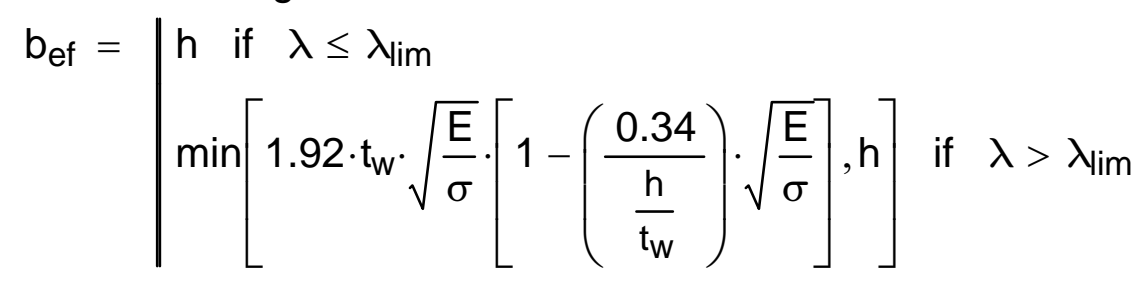

$b_{\text {ef }}=66.1 \cdot \mathrm{cm}$

2.1.1.3.3 - Área efetiva do elemento AA

$A_{e f}=\mid \begin{aligned} & A_{a} \text { if } \lambda \leq \lambda_{\text {lim }} \\ & A_{a}-\left(h-b_{e f}\right) \cdot t_{w} \text { if } \lambda>\lambda_{\text {lim }}\end{aligned}$

$A_{\text {ef }}=548.56 \cdot \mathrm{cm}^{2}$

2.1.1.3.4 - Fator de redução devido a flambagem local da alma

$\mathrm{Q}_{\mathrm{a}}=\frac{\mathrm{A}_{\mathrm{ef}}}{\mathrm{A}_{\mathrm{a}}} \quad \mathrm{Q}_{\mathrm{a}}=1$

\subsection{3 - Parâmetro de flambagem local para a seção}
$\mathrm{Q}=\mathrm{Q}_{\mathrm{a}} \cdot \mathrm{Q}_{\mathrm{s}}$
$\mathrm{Q}=1$

2.2 - Flambagem elástica da barra (Anexo E - NBR 8800:2008)

\subsection{1 - Flambagem por flexão em $x$}

$$
\mathrm{N}_{\mathrm{ex}}=\frac{\pi^{2} \cdot \mathrm{E} \cdot \mathrm{l}_{\mathrm{ax}}}{\left(\mathrm{K}_{\mathrm{x}} \cdot \mathrm{L}_{\mathrm{x}}\right)^{2}} \quad \mathrm{~N}_{\mathrm{ex}}=890.96 \times 10^{3} \cdot \mathrm{kN}
$$

\subsection{2 -Flambagem por flexão em y}

$\mathrm{N}_{\mathrm{ey}}=\frac{\pi^{2} \cdot \mathrm{E} \cdot \mathrm{I}_{\mathrm{ay}}}{\left(\mathrm{K}_{\mathrm{y}} \cdot \mathrm{L}_{\mathrm{y}}\right)^{2}}$

$\mathrm{N}_{\text {ey }}=109 \times 10^{3} \cdot \mathrm{kN}$

\subsection{3 -Flambagem por torção}

$$
\begin{array}{ll}
r_{\mathrm{o}}=\sqrt{\mathrm{r}_{\mathrm{ax}}{ }^{2}+\mathrm{r}_{\mathrm{ay}}{ }^{2}+\mathrm{x}_{\mathrm{o}}{ }^{2}+\mathrm{y}_{\mathrm{o}}{ }^{2}} & \mathrm{r}_{\mathrm{o}}=33.63 \cdot \mathrm{cm} \\
\mathrm{N}_{\mathrm{ez}}=\frac{1}{\mathrm{r}_{\mathrm{o}}{ }^{2}} \cdot\left[\left[\frac{\pi^{2} \cdot \mathrm{E} \cdot \mathrm{C}_{\mathrm{w}}}{\left(\mathrm{K}_{\mathrm{z}} \cdot \mathrm{L}_{\mathrm{z}}\right)^{2}}\right]+\mathrm{G} \cdot \mathrm{J}\right] & \mathrm{N}_{\mathrm{ez}}=139.58 \times 10^{3} \cdot \mathrm{kN}
\end{array}
$$


2.3 - Normal resistente de cálculo

2.3.1 - Força axial de flambagem elástica

$\mathrm{N}_{\mathrm{e}}=\min \left(\mathrm{N}_{\mathrm{ex}}, \mathrm{N}_{\mathrm{ey}}, \mathrm{N}_{\mathrm{ez}}\right) \quad \mathrm{N}_{\mathrm{e}}=109 \times 10^{3} \cdot \mathrm{kN}$

Situação = "Flambagem por flexão em Y"

2.3.2 - Índice de esbeltes reduzido

$\lambda_{0}=\sqrt{\mathrm{Q} \cdot \frac{\mathrm{A}_{\mathrm{a}} \cdot \mathrm{f}_{\mathrm{y}}}{\mathrm{N}_{\mathrm{e}}}}$

$\lambda_{0}=0.42$

2.3.3 - Fator de redução $\chi$

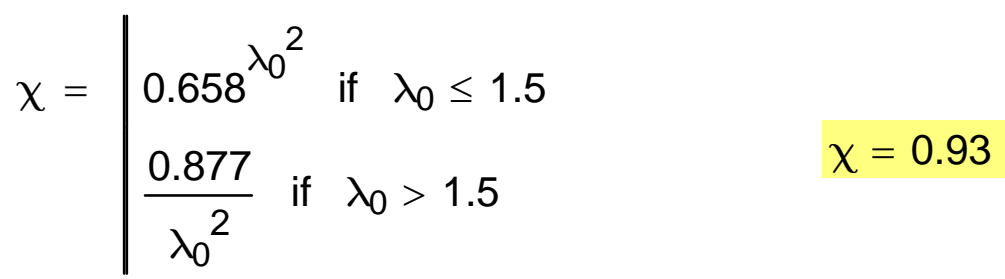

2.3.4 -Normal resistente de cálculo

$$
N_{R d}=\frac{\left(\chi \cdot Q \cdot A_{a} \cdot f_{y}\right)}{\gamma_{a 1}}
$$$$
\mathrm{N}_{\mathrm{Rd}}=16 \times 10^{3} \cdot \mathrm{kN}
$$

2.3.5 - Verificação da resistência a compressão

$\frac{N_{S d}}{N_{R d}}=0.76$

Verificação_NSd = "ok!"

3 - ELU - flexão em torno do eixo $x$

3.1 - Flambagem local alma - FLA

3.1.1 - Índice de esbeltez da alma

$$
\lambda=\frac{\mathrm{h}}{\mathrm{t}_{\mathrm{w}}}
$$

$$
\lambda=29.51
$$

3.1.2 - Parâmetro de esbeltez limite para seções compactas

$$
\lambda_{p}=3.76 \cdot \sqrt{\frac{E}{f_{y}}} \quad \lambda_{p}=90.53
$$


3.1.3 - Parâmetro de esbeltez limite para seções semicompactas

$$
\lambda_{r}=5.70 \cdot \sqrt{\frac{E}{f_{y}}}
$$$$
\lambda_{r}=137.24
$$

3.2.4 - Momento de proporcionalidade

$\mathrm{M}_{\mathrm{r}}=\mathrm{W}_{\mathrm{ax}} \cdot \mathrm{f}_{\mathrm{y}}=5086.9 \cdot \mathrm{kN} \cdot \mathrm{m}$

3.2.5 - Momento de plastificação

$\mathrm{M}_{\mathrm{pl}}=\mathrm{Z}_{\mathrm{ax}} \cdot \mathrm{f}_{\mathrm{y}}=5718.17 \cdot \mathrm{kN} \cdot \mathrm{m}$

3.2.7 - Momento resistente de cálculo para flambagem local da alma

$$
M_{\text {Rd.a }}=\mid \begin{aligned}
& \frac{M_{p l}}{\gamma_{a 1}} \text { if } \lambda \leq \lambda_{p} \\
& \frac{1}{\gamma_{a 1}} \cdot\left[M_{p l}-\left(M_{p l}-M_{r}\right) \cdot \frac{\lambda-\lambda_{p}}{\lambda_{r}-\lambda_{p}}\right] \text { if } \lambda_{p}<\lambda \leq \lambda_{r} \\
& \text { "'Viga esbelta!" if } \lambda>\lambda_{r}
\end{aligned}
$$

$M_{\text {Rd.a }}=5198.33 \cdot k N \cdot m \quad$ Situação $=" \lambda<\lambda p "$

3.2 - Flambagem local da mesa - FLM

3.2.1 - Índice de esbeltez da mesa

$$
\lambda=\frac{b_{f}}{2 \cdot t_{f}} \quad \lambda=5.06
$$

3.2.2 - Parâmetro de esbeltez limite para seções compactas

$$
\lambda_{p}=0.38 \sqrt{\frac{E}{f_{y}}}
$$$$
\lambda_{p}=9.15
$$

3.2.3 - Parâmetro de esbeltez limite para seções semicompactas

$$
\lambda_{r}=k_{1} \cdot \sqrt{\frac{E}{\frac{f_{y}-\sigma_{r}}{k_{c}}}}
$$$$
\lambda_{r}=23.46
$$

Onde: $\mathrm{k}_{1}=0.95$ (perfil = "soldado" )

$$
\mathrm{k}_{\mathrm{c}}=0.736
$$


3.2.4 - Momento de proporcionalidade

$M_{r}=W_{a x} \cdot\left(f_{y}-\sigma_{r}\right)=3560.83 \cdot k N \cdot m$

3.2.5 - Momento de plastificação

$\mathrm{M}_{\mathrm{pl}}=\mathrm{Z}_{\mathrm{ax}} \cdot \mathrm{f}_{\mathrm{y}}=5718.17 \cdot \mathrm{kN} \cdot \mathrm{m}$

3.2.6 - Momento fletor de flambagem elástica

$\mathrm{M}_{\mathrm{cr}}=\frac{\mathrm{k}_{2} \cdot \mathrm{E} \cdot \mathrm{k}_{\mathrm{c}} \cdot \mathrm{W}_{\mathrm{ax}}}{\lambda^{2}}=76444.21 \cdot \mathrm{kN} \cdot \mathrm{m}$

Onde: $\mathrm{k}_{2}=0.9$ (perfil = "soldado" $)$

$$
\mathrm{k}_{\mathrm{c}}=0.736
$$

3.2.7 - Momento resistente de cálculo para flambagem local da mesa

$$
M_{R d . m}=\mid \begin{aligned}
& \frac{M_{p l}}{\gamma_{a 1}} \text { if } \lambda \leq \lambda_{p} \\
& \frac{1}{\gamma_{a 1}} \cdot\left[M_{p l}-\left(M_{p l}-M_{r}\right) \cdot \frac{\lambda-\lambda_{p}}{\lambda_{r}-\lambda_{p}}\right] \text { if } \lambda_{p}<\lambda \leq \lambda_{r} \\
& \frac{M_{c r}}{\gamma_{a 1}} \text { if } \lambda>\lambda_{r}
\end{aligned}
$$

Situação $=" \lambda<\lambda p "$

$M_{\mathrm{Rd} . \mathrm{m}}=5198.33 \cdot \mathrm{kN} \cdot \mathrm{m}$

3.3 - Flambagem lateral com torção - FLT

3.3.1 - Índice de esbeltez da barra

$$
\lambda=\frac{L_{b}}{r_{\text {ay }}} \quad \lambda=31.52
$$

3.3.2 - Parâmetro de esbeltez limite para barras curtas

$$
\lambda_{p}=1.76 \sqrt{\frac{E}{f_{y}}}
$$$$
\lambda_{p}=42.38
$$ 
3.3.3 - Parâmetro de esbeltez limite para barras intermediárias

$$
\begin{array}{ll}
\beta_{1}=\frac{\left(f_{y}-\sigma_{r}\right) W_{a x}}{E \cdot J} & \beta_{1}=0.62 \frac{1}{m} \\
\lambda_{r}=\frac{1.38 \sqrt{l_{\text {ay }} \cdot J}}{r_{\text {ay }} \cdot J \cdot \beta_{1}} \cdot \sqrt{1+\sqrt{1+\frac{27 \cdot \mathrm{C}_{\mathrm{W}} \cdot \beta_{1}^{2}}{l_{\text {ay }}}}} & \lambda_{\mathrm{r}}=154.59
\end{array}
$$

\subsection{4 - Momento de proporcionalidade}

$M_{r}=W_{a x} \cdot\left(f_{y}-\sigma_{r}\right)=3560.83 \cdot k N \cdot m$

\subsection{5 - Momento de plastificação}

$\mathrm{M}_{\mathrm{pl}}=\mathrm{Z}_{\mathrm{ax}} \cdot \mathrm{f}_{\mathrm{y}}=5718.17 \cdot \mathrm{kN} \cdot \mathrm{m}$

3.3.7 - Momento resistente de cálculo para flambagem lateral com torção $\mathrm{C}_{\mathrm{b}}=1$ Adotado conservadoramente $\mathrm{C}_{\mathrm{b}}=1$ igual a 1,0 .

$$
M_{R d . f l t}=\mid \begin{aligned}
& \frac{M_{p l}}{\gamma_{a 1}} \text { if } \lambda<\lambda_{p} \\
& \frac{C_{b}}{\gamma_{a 1}} \cdot\left[M_{p l}-\left(M_{p l}-M_{r}\right) \cdot \frac{\lambda-\lambda_{p}}{\lambda_{r}-\lambda_{p}}\right] \text { if } \lambda_{p}<\lambda \leq \lambda_{r} \\
& \frac{\pi^{2} C_{b} \cdot E \cdot l_{a y}}{\gamma_{a 1} \cdot\left(L_{b}\right)^{2}} \cdot \sqrt{\frac{C_{w}}{l_{a y}} \cdot\left[1+0.039 \cdot \frac{\mathrm{J} \cdot\left(L_{b}\right)^{2}}{C_{w}}\right]} \text { if } \lambda>\lambda_{r}
\end{aligned}
$$

$$
M_{R d . f l t}=\mid \begin{aligned}
& M_{R d . f l t} \text { if } \quad M_{R d . f l t} \leq \frac{M_{p l}}{\gamma_{a 1}} \\
& \frac{M_{p l}}{\gamma_{a 1}} \text { otherwise }
\end{aligned}
$$

$M_{\text {Rd.flt }}=5198.33 \cdot \mathrm{kN} \cdot \mathrm{m}$ 
3.4 - Momento resistente de cálculo

3.4.1 - Momento resistente de cálculo para flambagem local da alma

$\mathrm{M}_{\mathrm{Rd} . \mathrm{a}}=5198.33 \cdot \mathrm{kN} \cdot \mathrm{m}$

3.4.2 - Momento resistente cálculo para flambagem local da mesa

$M_{\text {Rd. } m}=5198.33 \cdot \mathrm{kN} \cdot \mathrm{m}$

3.4.3 - Momento resistente cálculo para flambagem lateral como torção

$M_{\text {Rd.flt }}=5198.33 \cdot \mathrm{kN} \cdot \mathrm{m}$

3.4.4 - Momento limite para validade da análise elástica

$\mathrm{M}_{\lim }=1.50 \cdot \mathrm{W}_{\mathrm{ax}} \cdot \frac{\mathrm{f}_{\mathrm{y}}}{\gamma_{\mathrm{a} 1}}=6936.68 \cdot \mathrm{kN} \cdot \mathrm{m}$

3.4.5 - Momento resistente de cálculo

$M_{\text {Rd.x }}=\min \left(M_{\text {Rd.a }}, M_{\text {Rd.m }}, M_{\text {Rd.flt }}, M_{\text {lim }}\right)$

$\mathrm{M}_{\mathrm{Rd} . \mathrm{x}}=5198.33 \cdot \mathrm{kN} \cdot \mathrm{m}$

3.5 - Momento solicitante de cálculo

$\mathrm{M}_{\mathrm{Sd} \cdot \mathrm{x}}=799.11 \cdot \mathrm{kN} \cdot \mathrm{m}$

3.6 - Verificação da resistência ao momento fletor

Momento solicitante de cálculo:

$\mathrm{MSd} . \mathrm{x}=799.11 \cdot \mathrm{kN} \cdot \mathrm{m}$

Momento resistente de cálculo:

$\mathrm{M}_{\mathrm{Rd} . \mathrm{x}}=5198.33 \cdot \mathrm{kN} \cdot \mathrm{m}$

$\frac{M_{\text {Sd.x }}}{M_{\text {Rd.x }}}=0.15$

Verificação_M ${ }_{S d . x}=$ "ok!" 
4 - ELU - flexão em torno do eixo y

4.1 Flambagem local alma - FLA

Perfis I e H fletidos no eixo de menor inércia (eixo Y, neste caso) não estão sujeitos ao Estado Limite Último de Flambagem Local da Alma.

4.2 - Flambagem local da mesa - FLM

4.2.1 - Índice de esbeltez da mesa

$$
\lambda=\frac{b_{f}}{2 \cdot t_{f}} \quad \lambda=5.06
$$

4.2.2 - Parâmetro de esbeltez limite para seções compactas

$$
\lambda_{p}=0.38 \sqrt{\frac{E}{f_{y}}}
$$$$
\lambda_{p}=9.15
$$

4.2.3 - Parâmetro de esbeltez limite para seções semicompactas

$$
\lambda_{r}=k_{1} \cdot \sqrt{\frac{E}{\frac{f_{y}-\sigma_{r}}{k_{c}}}} \quad \begin{aligned}
& \text { Onde: } k_{1}=0.95 \\
& k_{c}=0.74
\end{aligned} \quad \lambda_{r}=23.46
$$

4.2.4 - Momento de proporcionalidade

$\mathrm{M}_{\mathrm{r}}=\mathrm{W}_{\mathrm{ay}} \cdot\left(\mathrm{f}_{\mathrm{y}}-\sigma_{\mathrm{r}}\right)=726.07 \cdot \mathrm{kN} \cdot \mathrm{m}$

\subsection{5 - Momento de plastificação}

$\mathrm{M}_{\mathrm{pl}}=\mathrm{Z}_{\mathrm{ay}} \cdot \mathrm{f}_{\mathrm{y}}=1583.05 \cdot \mathrm{kN} \cdot \mathrm{m}$

4.2.6 - Momento fletor de flambagem elástica

$\mathrm{M}_{\mathrm{cr}}=\frac{\mathrm{k}_{2} \cdot \mathrm{E} \cdot \mathrm{k}_{\mathrm{c}} \cdot \mathrm{W}_{\mathrm{ay}}}{\lambda^{2}}=15587.35 \cdot \mathrm{kN} \cdot \mathrm{m}$

Onde: $\mathrm{k}_{2}=0.9$ (perfil = "soldado" $)$

$$
\mathrm{k}_{\mathrm{c}}=0.736
$$


4.2.7 - Momento resistente de cálculo para flambagem local da mesa

$$
M_{R d . m}=\mid \begin{aligned}
& \frac{M_{p l}}{\gamma_{a 1}} \text { if } \lambda \leq \lambda_{p} \\
& \frac{M_{p l}-\left(M_{p l}-M_{r}\right)}{\gamma_{a 1}} \cdot \frac{\lambda-\lambda_{p}}{\lambda_{r}-\lambda_{p}} \text { if } \lambda_{p}<\lambda \leq \lambda_{r} \\
& \frac{M_{c r}}{\gamma_{a 1}} \text { if } \lambda>\lambda_{r}
\end{aligned}
$$

Situação $=" \lambda<\lambda p "$

$\mathrm{M}_{\mathrm{Rd} . \mathrm{m}}=1439.13 \cdot \mathrm{kN} \cdot \mathrm{m}$

\subsection{Flambagem lateral com torção - FLT}

Perfis I, H e U fletidos no eixo de menor inércia (eixo Y, neste caso) não estão sujeitos ao Estado Limite Último de Flambagem Lateral com Torção.

\section{4 - Momento Resistente de Cálculo}

\subsection{2 - Momento resistente cálculo para flambagem local da mesa}

$\mathrm{M}_{\mathrm{Rd} . \mathrm{m}}=1439.13 \cdot \mathrm{kN} \cdot \mathrm{m}$

\subsection{3 - Momento limite para validade da análise elástica}

$$
M_{\text {lim }}=1.50 \cdot W_{\text {ay }} \cdot \frac{f_{y}}{\gamma_{a 1}}=1414.42 \cdot \mathrm{kN} \cdot \mathrm{m}
$$

\subsection{4 - Momento resistente de cálculo}

$$
M_{\text {Rd.y }}=\min \left(M_{\text {Rd.m }}, M_{\text {lim }}\right)=1414.42 \cdot \mathrm{kN} \cdot \mathrm{m}
$$

\section{5 - Momento solicitante de cálculo}

$\mathrm{M}_{\text {Sd.y }}=4.36 \cdot \mathrm{kN} \cdot \mathrm{m}$

\section{6 - Verificação da resistência ao momento fletor}

Momento solicitante de cálculo:

$$
\mathrm{M}_{\mathrm{Sd} . \mathrm{y}}=4.36 \cdot \mathrm{kN} \cdot \mathrm{m}
$$

Momento resistente de cálculo:

$$
M_{R d . y}=1414.42 \cdot k N \cdot m
$$

$$
\frac{M_{\text {Sd.y }}}{M_{\text {Rd.y }}}=0
$$


5 - ELU - flexo-compressão

5.1 - Verificação da compressão
$\frac{\mathrm{N}_{\mathrm{Sd}}}{\mathrm{N}_{\mathrm{Rd}}}=0.76$
Verificação_N $N_{S d}=$ "ok!"

\section{2 - Verificação momento fletor}
$\frac{M_{\text {Sd.x }}}{M_{\text {Rd.x }}}=0.15$
Verificação_M ${ }_{S d . x}=$ "ok!"
$\frac{M_{\text {Sd.y }}}{M_{\text {Rd.y }}}=0$
Verificação_MSd.y = "ok!"

\section{3 - Equação de interação}

Interação $=\mid \begin{aligned} & \frac{N_{S d}}{N_{R d}}+\frac{8}{9} \cdot\left(\frac{M_{S d . x}}{M_{R d . x}}+\frac{M_{\text {Sd.y }}}{M_{\text {Rd.y }}}\right) \text { if } \frac{N_{S d}}{N_{R d}} \geq 0.2 \\ & \frac{N_{S d}}{2 \cdot N_{R d}}+\left(\frac{M_{S d . x}}{M_{R d . x}}+\frac{M_{S d . y}}{M_{R d . y}}\right) \text { otherwise }\end{aligned}$

$\frac{N_{\text {Sd }}}{N_{\text {Rd }}}+\frac{8}{9} \cdot\left(\frac{M_{\text {Sd.x }}}{M_{\text {Rd.x }}}+\frac{M_{\text {Sd.y }}}{M_{\text {Rd.y }}}\right)=0.9$

$\frac{N_{S d}}{2 \cdot N_{R d}}+\left(\frac{M_{S d . x}}{M_{R d} \cdot x}+\frac{M_{S d . y}}{M_{R d . y}}\right)=0.54$

Interação $=0.9$

Verificação_Interação = "ok!" 
6 - ELU - cortante na direção y

6.1 - Coeficiente de flambagem

6.1.1 - Distância entre enrijecedores

$\mathrm{a}=3500 \cdot \mathrm{mm} \quad$ (Verificação sem enrijecedores)

\subsection{2 - Coeficiente de flambagem}

$K_{v}=\left\{\begin{array}{l}5 \text { if } \frac{a}{h}>3 \\ 5 \text { if } \frac{a}{h}>\left(\frac{260}{\frac{h}{t_{w}}}\right)^{2} \\ {\left[5+\frac{5}{\left(\frac{a}{h}\right)^{2}}\right] \text { otherwise }}\end{array}\right.$

$\frac{\mathrm{a}}{\mathrm{h}}=5.3$

$\mathrm{K}_{\mathrm{v}}=5$

6.2 - Parâmetro de esbeltez limite da alma

$$
\lambda_{p}=1.10 \sqrt{\frac{K_{v} \cdot E}{f_{y}}} \quad \lambda_{p}=59.22
$$

6.3 - Parâmetro de esbeltez limite da alma

$$
\begin{array}{ll}
\lambda_{\mathrm{r}}=1.37 \sqrt{\frac{\mathrm{K}_{\mathrm{v}} \cdot \mathrm{E}}{\mathrm{f}_{\mathrm{y}}}} \quad \lambda_{\mathrm{r}}=73.76
\end{array}
$$

6.4 - Índice de esbeltez da alma

$$
\lambda=\frac{\mathrm{h}}{\mathrm{t}_{\mathrm{w}}}
$$

$$
\lambda=29.51
$$


6.5 - Força cortante referente à plastificação da alma por cisalhamento 6.5.1 - Área efetiva de cisalhamento
$A_{w}=d \cdot t_{w}$
$A_{w}=168 \cdot \mathrm{cm}^{2}$

6.5.2 - Plastificação por força cortante

$\mathrm{V}_{\mathrm{pl}}=0.60 \cdot \mathrm{A}_{\mathrm{w}} \cdot \mathrm{f}_{\mathrm{y}} \quad \mathrm{V}_{\mathrm{pl}}=3477.6 \cdot \mathrm{kN}$

6.6 - Força cortante resistente de cálculo

Situação $=" \lambda<\lambda p "$

$V_{R k . y}=\mid \begin{aligned} & V_{p l} \text { if } \lambda \leq \lambda_{p} \\ & V_{p l} \cdot \frac{\lambda_{p}}{\lambda} \text { if } \lambda_{p}<\lambda \leq \lambda_{r} \\ & 1.24 \cdot V_{p l} \cdot\left(\frac{\lambda_{p}}{\lambda}\right)^{2} \text { if } \lambda>\lambda_{r}\end{aligned}$

$\mathrm{V}_{\mathrm{Rd} . \mathrm{y}}=\frac{\mathrm{V}_{\mathrm{Rk} . \mathrm{y}}}{\gamma_{\mathrm{a} 1}} \quad \mathrm{~V}_{\mathrm{Rd} . \mathrm{y}}=3161.45 \cdot \mathrm{kN}$

6.7 - Verificação da resistência à força cortante

Esforço cortante solicitante de cálculo:........ $\mathrm{V}_{\mathrm{Sd} . \mathrm{y}}=235.92 \cdot \mathrm{kN}$

Esforço cortante resistente de cálculo:......... $\vee_{\mathrm{Rd} . \mathrm{y}}=3161.45 \cdot \mathrm{kN}$

$\frac{V_{\text {Sd.y }}}{V_{\text {Rd.y }}}=0.075 \quad$ Verificação_ $V_{R d . y}=$ "ok!" 
7 - ELU - cortante na direção $x$

7.1 - Coeficiente de flambagem

$\mathrm{K}_{\mathrm{v}}=1.2$

7.2 - Parâmetro de esbeltez limite da mesa

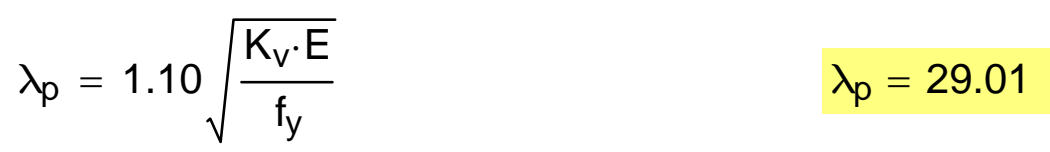

7.3 - Parâmetro de esbeltez limite da mesa

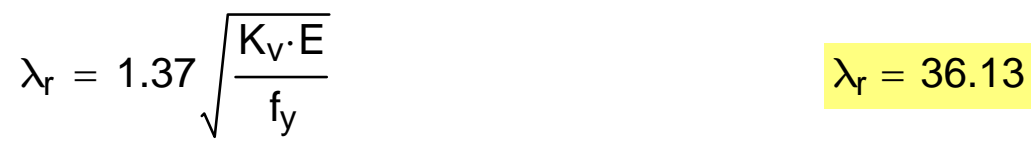

7.4 - Índice de esbeltez da mesa

$$
\lambda=\frac{b_{f}}{2 \cdot t_{f}} \quad \lambda=5.06
$$

7.5 - Força cortante referente à plastificação da alma por cisalhamento 7.5.1 - Área efetiva de cisalhamento

$$
A_{w}=2 \cdot b_{f} \cdot t_{f} \quad A_{w}=400.5 \cdot \mathrm{cm}^{2}
$$

\subsection{2 - Plastificação por força cortante}

$\mathrm{V}_{\mathrm{pl}}=0.60 \cdot \mathrm{A}_{\mathrm{w}} \cdot \mathrm{f}_{\mathrm{y}}$

$$
\mathrm{V}_{\mathrm{pl}}=8290.35 \cdot \mathrm{kN}
$$

7.6 - Força cortante resistente de cálculo

$$
\begin{aligned}
& \text { Situação }=" \lambda<\lambda p " \\
& V_{\text {Rk.x }}=\mid \begin{array}{ll}
V_{p l} \text { if } \lambda \leq \lambda_{p} & \\
V_{p l} \cdot \frac{\lambda_{p}}{\lambda} \text { if } \lambda_{p}<\lambda \leq \lambda_{r} & V_{R k . x}=8290.35 \cdot k N \\
1.24 \cdot V_{p l} \cdot\left(\frac{\lambda_{p}}{\lambda}\right)^{2} \text { if } \lambda>\lambda_{r} & \\
V_{\text {Rd.x }}=\frac{V_{R k . x}}{\gamma_{a 1}} & V_{R d . x}=7536.68 \cdot \mathrm{kN}
\end{array}
\end{aligned}
$$


7.7 - Verificação da resistência à força cortante

Esforço cortante solicitante de cálculo:........ $\quad V_{\text {Sd.x }}=88.41 \cdot \mathrm{kN}$

Esforço cortante resistente de cálculo:......... $\vee_{\mathrm{Rd} . \mathrm{x}}=7536.68 \cdot \mathrm{kN}$

$\frac{V_{\text {Sd.x }}}{V_{\text {Rd.x }}}=0.012 \quad$ Verificação_ $V_{R d . x}=$ "ok!"

8 - Estado-limite de serviço (ELS) - compressão

8.1 - Índice de esbeltez do eixo $x$

$\lambda_{\mathrm{x}}=\frac{\mathrm{K}_{\mathrm{x}} \cdot \mathrm{L}_{\mathrm{x}}}{\mathrm{r}_{\mathrm{ax}}} \quad \lambda_{\mathrm{x}}=11.02$

8.2 - Índice de esbeltez do eixo y

$\lambda_{y}=\frac{K_{y} \cdot L_{y}}{r_{a y}} \quad \lambda_{y}=31.52$

8.3 - Índice de esbeltez limite

$\lambda_{\lim }=200$

8.4 - Verificação do índice de esbeltez

8.4.1 - Índice de esbeltez do eixo $x$

$\frac{\lambda_{x}}{\lambda_{\lim }}=0.06$

Verificação_ $\lambda_{x}=$ "ok!"

8.4.2 - Índice de esbeltez do eixo y

$\frac{\lambda_{\mathrm{y}}}{\lambda_{\lim }}=0.16$

Verificação_ $\lambda_{y}=$ "ok!" 
